\title{
PERFORMANCE OF ZINC ANODES FOR CATHODIC PROTECTION OF REINFORCED CONCRETE BRIDGES
}

\author{
Final Report
}

SPR 364

\author{
by \\ Bernard S. Covino, Jr., Stephen D. Cramer, Sophie J. Bullard, \\ Gordon R. Holcomb, James H. Russell, and W. Keith Collins \\ Albany Research Center \\ U.S. Department of Energy \\ Albany OR 97321 \\ H. Martin Laylor, Research Group \\ Curtis B. Cryer, Bridge Engineering Section \\ Oregon Department of Transportation \\ Salem OR 97301-5192
}

for

Oregon Department of Transportation, Research Group 200 Hawthorne Avenue, S.E., Suite B-240, Salem OR 97301-5192

and

Federal Highway Administration

400 Seventh Street, S.W., Washington DC 20590

March 2002 

Technical Report Documentation Page

\begin{tabular}{|c|c|c|}
\hline $\begin{array}{l}\text { 1. Report No. } \\
\text { FHWA-OR-RD-02-10 }\end{array}$ & 2. Government Accession No. & 3. Recipient's Catalog No. \\
\hline \multicolumn{2}{|l|}{ 4. Title and Subtitle } & 5. Report Date \\
\hline \multicolumn{2}{|c|}{$\begin{array}{l}\text { PERFORMANCE OF ZINC ANODES FOR CATHODIC PROTECTION OF REINFORCED } \\
\text { CONCRETE BRIDGES }\end{array}$} & 6. Performing Organization Code \\
\hline \multicolumn{3}{|c|}{$\begin{array}{l}\text { Bernard S. Covino, Jr., Stephen D. Cramer, Sophie J. Bullard, } \\
\text { Gordon R. Holcomb, James H. Russell, and W. Keith Collins } \\
\text { Albany Research Center, U.S. Department of Energy, Albany OR } 97321\end{array}$} \\
\hline \multicolumn{2}{|l|}{ 9. Performing Organization Name and Address } & 10. Work Unit No. (TRAIS) \\
\hline \multicolumn{2}{|l|}{$\begin{array}{l}\text { Oregon Department of Transportation } \\
\text { Research Group } \\
200 \text { Hawthorne Ave. SE, Suite B-240 } \\
\text { Salem, OR 97301-5192 }\end{array}$} & \\
\hline \multicolumn{2}{|l|}{ 12. Sponsoring Agency Name and Address } & 13. Type of Report and Period Covered \\
\hline \multirow{2}{*}{$\begin{array}{l}\text { Oregon Department of Transportation } \\
\text { Research Group } \\
200 \text { Hawthorne Ave. SE, Suite B-240 } \\
\text { Salem, OR 97301-5192 }\end{array}$} & \multirow{2}{*}{$\begin{array}{l}\text { and Federal Highway Administration } \\
\text { 400 Seventh Street SW } \\
\text { Washington, DC } 20590\end{array}$} & Final Report \\
\hline & & 14. Sponsoring Agency Code \\
\hline
\end{tabular}

15. Supplementary Notes

16. Abstract

Operation of thermal spray zinc $(\mathrm{Zn})$ anodes for cathodic protection $(\mathrm{CP})$ of reinforced concrete structures was investigated in laboratory and field studies conducted by the Albany Research Center (ARC) in collaboration with the Oregon Department of Transportation. The purposes of the research presented in this report were: evaluate the need for preheating concrete to improve the adhesion of the anode; estimate the service life of thermal spray $\mathrm{Zn} \mathrm{CP}$ anodes; determine the optimum thickness for $\mathrm{Zn} \mathrm{CP}$ anodes; characterize the anode-concrete interfacial chemistry; and correlate field and laboratory results.

Laboratory studies involved accelerated electrochemical aging of thermal sprayed $\mathrm{Zn}$ anodes on concrete slabs, some of which were periodically wetted while others were unwetted. Concrete used in the slabs contained either 1.2 or $3 \mathrm{~kg} \mathrm{NaCl} / \mathrm{m} 3(2 \mathrm{or} 5 \mathrm{lbs} \mathrm{NaCl} / \mathrm{yd} 3)$ as part of the concrete mix design. The $\mathrm{Zn}$ anodes were applied to the slabs using the twin wire arc-spray technique. Half of the slabs were preheated to $120-160 \mathrm{oC}(250-320 \mathrm{oF})$ to improve the initial $\mathrm{Zn}$ anode bond strength and the other half were not. Accelerated aging was done at a current density of $0.032 \mathrm{~A} / \mathrm{m} 2(3 \mathrm{~mA} / \mathrm{ft} 2), 15$ times that used on Oregon DOT Coastal bridges, i.e, . $0.0022 \mathrm{~A} / \mathrm{m} 2(0.2 \mathrm{~mA} / \mathrm{ft} 2)$

Cores from the Cape Creek Bridge (OR), the Richmond San Rafael Bridge (CA), and the East Camino Underpass (CA) were used to study the anode-concrete interfacial chemistry, to relate the chemistry to electrochemical age at the time of sampling, and to compare the chemistry of the field anodes to the chemistry of anodes from the laboratory studies. Cores from a CALTRANS study of a silane sealant used prior to the application of the $\mathrm{Zn}$ anodes and cores with galvanized rebar from the Longbird Bridge (Bermuda) were also studied.

Aged laboratory and field anodes were characterized by measuring some or all of the following parameters: thickness, bond strength, anode-concrete interfacial chemistry, bulk chemistry, anode resistance, circuit resistance, electrochemical age, and air and water permeability.

Models are presented for the operation of periodically-wetted and unwetted thermal spray $\mathrm{Zn}$ anodes from the initial energizing of the anode to the end of its service life. The models were developed in terms of bond strength, circuit resistance, anode-concrete interfacial chemistry, electrochemical age, and anode condition.

The most significant results of the research are: (1) preheating concrete surfaces prior to coating with $\mathrm{Zn}$ is unnecessary; (2) anodes generally fail due to loss of bond strength rather than Zn consumption; (3) Unwetted anodes fail more quickly than periodically-wetted anodes; (4) $0.47-0.60 \mathrm{~mm}$ (12-15 mil) anode thickness is adequate for most Oregon DOT coastal impressed current CP (ICCP) installations; (5) based on bond strength, thermal spray Zn ICCP anode service life is approximately 27 years at $0.0022 \mathrm{~A} / \mathrm{m} 2(0.2 \mathrm{~mA} / \mathrm{ft} 2)$; (6) anode reaction products alter the anode-concrete interface by rejecting $\mathrm{Ca}$ from the cement paste, by replacing it with $\mathrm{Zn}$, and by the accumulation of a $\mathrm{Zn}$ mineral layer that includes chloride and sulfur compounds; (7) CP system circuit resistance provides an effective means for monitoring the condition of $\mathrm{Zn}$ ICCP anodes as they age.

\section{Key Words}

Zinc, anode, thermal spray, twin-wire arc spray, rebar, reinforcing bar, reinforced concrete bridges, concrete, cathodic protection, impressed current cathodic protection, sacrificial anode cathodic protection, circuit resistance, electrochemical age, bond strength, zinc minerals, chloride, salt, service life, life cycle cost, scanning electron microscopy, $\mathrm{pH}$

\section{Distribution Statement}

Available from NTIS

Oregon Department of Transportation

(http://www.odot.state.or.us/tddresearch)

\begin{tabular}{|l|l|l|l|}
\hline $\begin{array}{l}\text { 19. Security Classification (of this report) } \\
\text { Unclassified }\end{array}$ & $\begin{array}{c}\text { 20. Security Classification (of this page) } \\
\text { Unclassified }\end{array}$ & $\begin{array}{c}21 . \text { No. of Pages } \\
150+\text { appendices }\end{array}$ & 22. Price \\
\hline
\end{tabular}

Technical Report Form DOT F 1700.7 (8-72)

Reproduction of completed page authorized

(7) Printed on recycled paper 


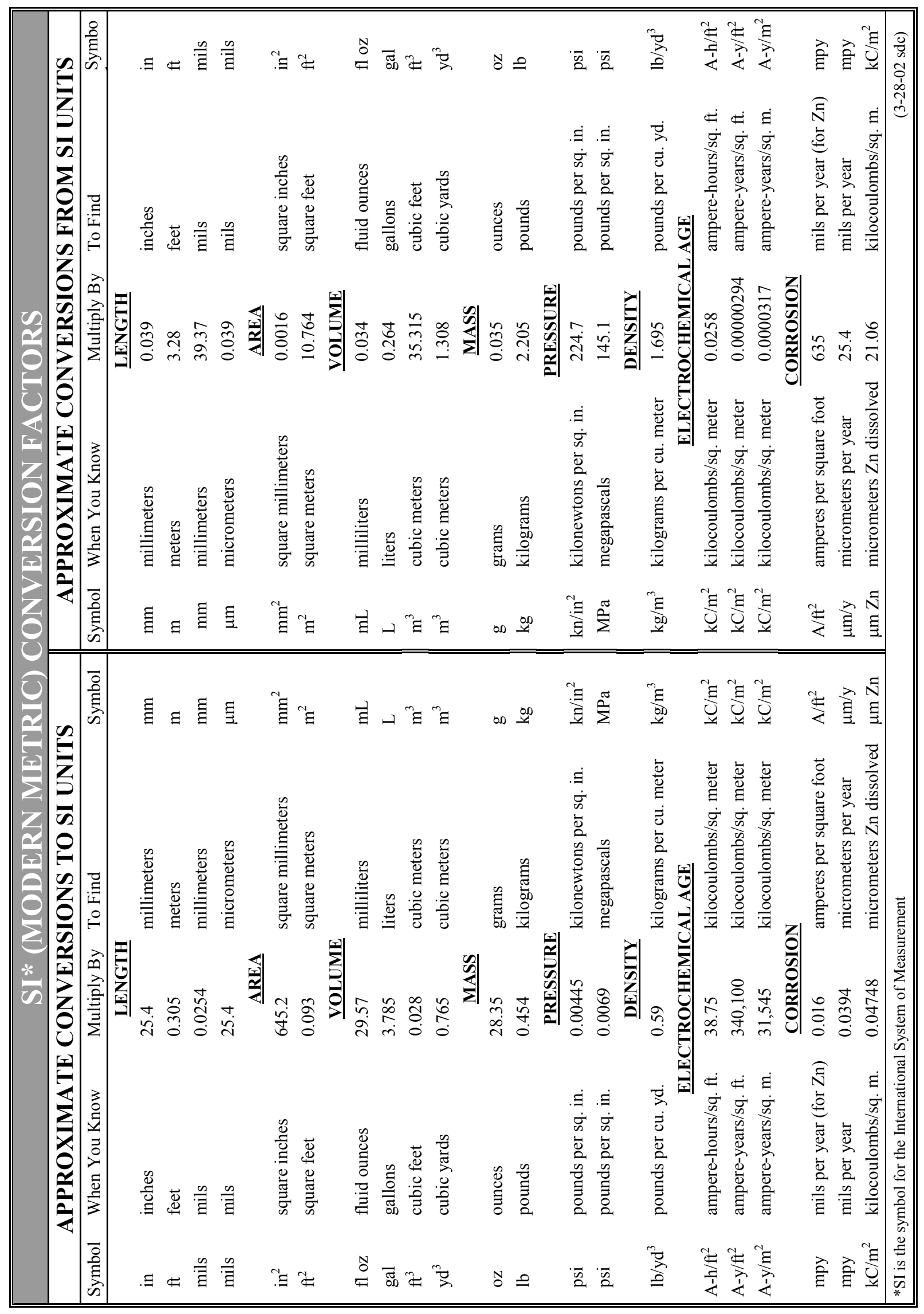




\section{ACKNOWLEDGMENTS}

The authors wish to thank the following Albany Research Center, U. S. Department of Energy, employees for their valued contributions to the research: Neal Duttlinger for conducting the bond strength measurements, Dale Govier for x-ray diffraction analyses, Darrell Hoskins for crosssectioning the concrete slabs, Al Hunt, Joan Williams and Henrietta White for preparing the anode cross-sections for electron microscopy, and Rick Wilson for estimates of Zn splat cooling rates.

We thank Frank Rogers, Thermion Metallizing Systems, for helpful discussions of the thermal spray process and for assistance in adapting thermal spray equipment. We thank Rob Reis, Rick Carter, John Hemiup, and Doug Parks, California Department of Transportation (CALTRANS), for providing access to thermal sprayed $\mathrm{Zn}$ anodes on the Richmond-San Rafael Bridge, for the opportunity to study these anodes and collect small samples, and for the historical record of anode performance data. We thank Alan Stoneman, International Lead and Zinc Research Organization (ILZRO) for galvanized rebar samples from the Longbird Bridge, Bermuda, and associated performance data. We thank Steve Yeomans, Australian Defence Force Academy (Canberra AU), Jack Tinnea, John S. Tinnea \& Associates, and Jack Bennett, JE Bennett Consulting, for valued discussions of $\mathrm{Zn}$ anodes in reinforced concrete and zinc-concrete interactions. We thank John Milius, formerly with Platt Brothers and now with Ingersoll Rand, for timely and knowledgeable assistance with materials for thermal sprayed anodes. We thank Fred Andrews-Phaedonos, VicRoads in Melbourne, AU and Ike Solomon, Solomon Engineering in Melbourne, AU for discussions of thermal sprayed $\mathrm{Zn}$ anode applications in Australia. We thank Andrew Brickman, Materials Laboratory Manager, Civil Engineering Department, Oregon State University, for collaborating on the measurement of concrete surface temperature while thermal spraying zinc.

We thank Galen McGill, Oregon Department of Transportation (Oregon DOT), for his help in starting this project. We also thank the Oregon DOT technical advisory committee for their direction and review of this work.

We gratefully acknowledge financial support from the U.S. Department of Energy, Oregon Department of Transportation, and the Federal Highway Administration (through the State Research and Planning Program). 


\section{DISCLAIMER}

This document is disseminated under the sponsorship of the Oregon Department of Transportation and the U.S. Department of Transportation in the interest of information exchange. The State of Oregon and the U.S. Government assumes no liability of its contents or use thereof.

The contents of this report reflect the views of the author(s) who are solely responsible for the facts and accuracy of the material presented. The contents do not necessarily reflect the official views of the Oregon Department of Transportation or the U.S. Department of Transportation.

The State of Oregon and the U.S. Government do not endorse products or manufacturers.

Trademarks or manufacturer's names appear herein only because they are considered essential to the object of this document.

This report does not constitute a standard, specification, or regulation. 


\section{PERFORMANCE OF METALLIZED ZINC ANODES FOR CATHODIC PROTECTION OF REINFORCED CONCRETE BRIDGES}

\section{TABLE OF CONTENTS}

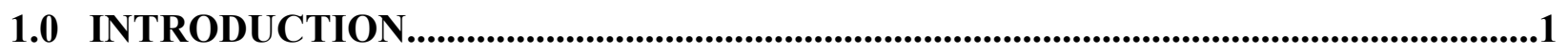

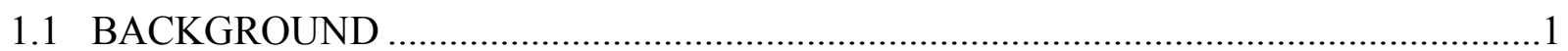

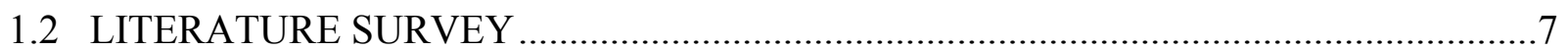

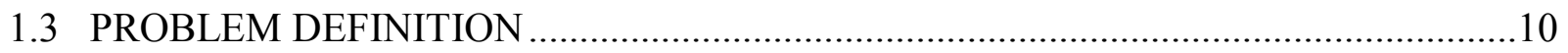

1.4 CHEMICAL AND ELECTROCHEMICAL REACTIONS DURING CP .....................10

2.0 EXPERIMENTAL PROCEDURES ….................................................................................13

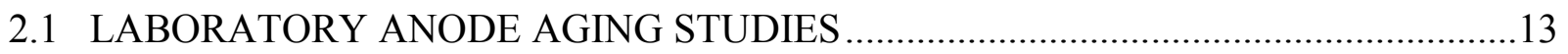

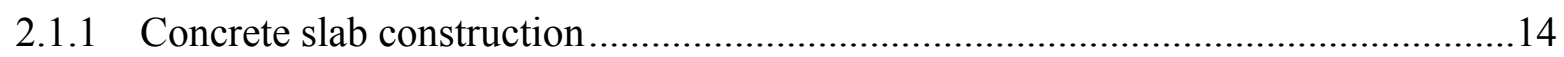

2.1.2 Concrete surface preparation ............................................................................... 15

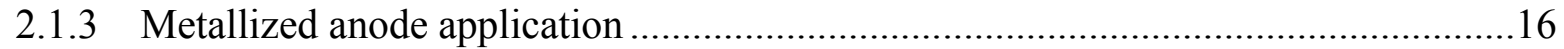

2.1.4 Anode electrochemical aging ........................................................................19

2.2 FIELD ANODE AGING STUDIES ...................................................................22

2.2.1 Cape Creek Bridge (OR) ..............................................................................22

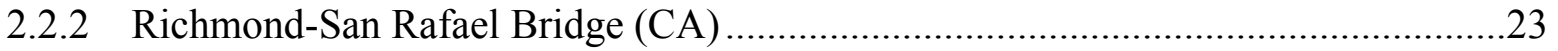

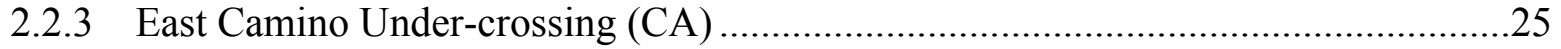

2.2.4 CALTRANS laboratory silane study ..........................................................26

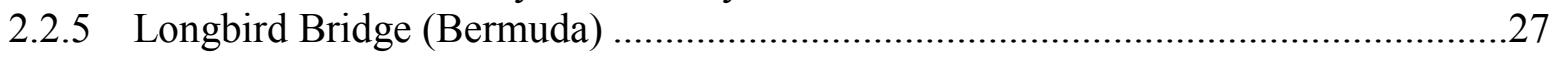

3.0 ANODE CHARACTERIZATION TECHNIQUES .............................................29

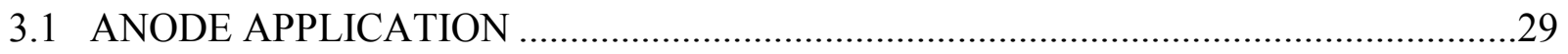

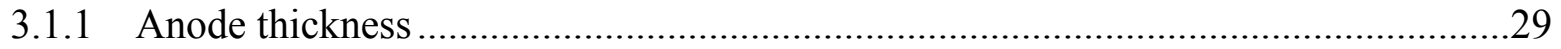

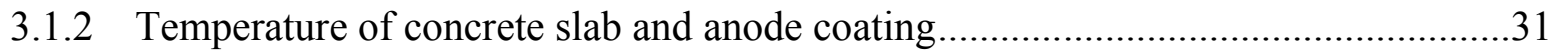

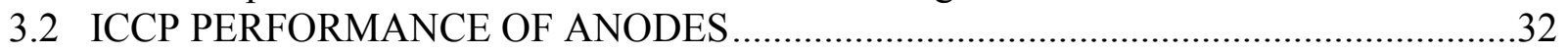

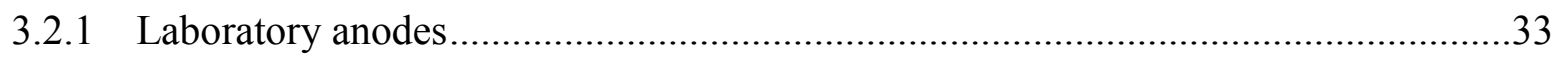

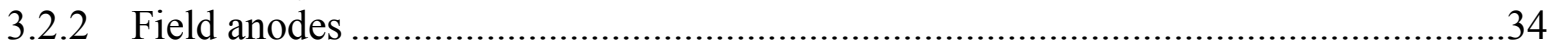

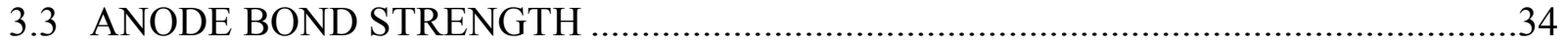

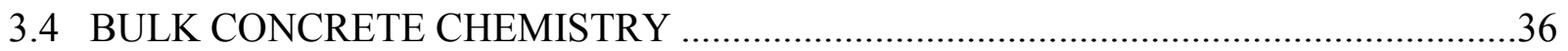

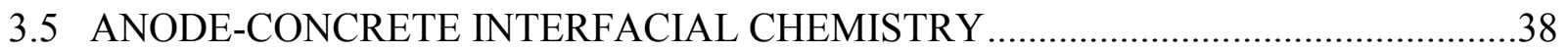

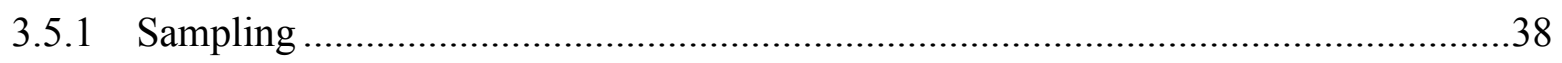

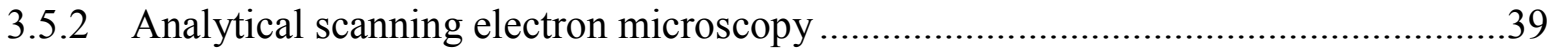

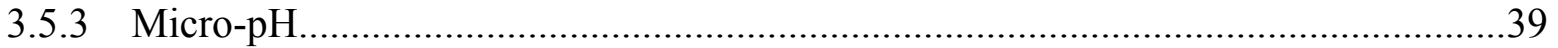

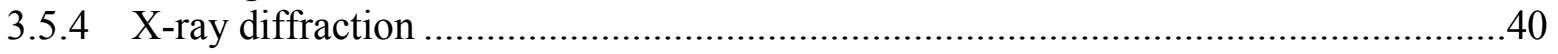

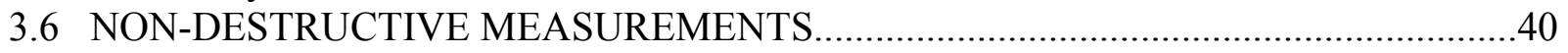

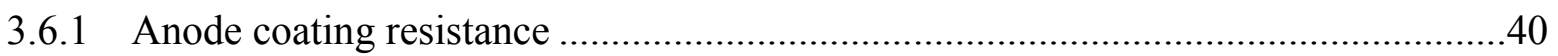

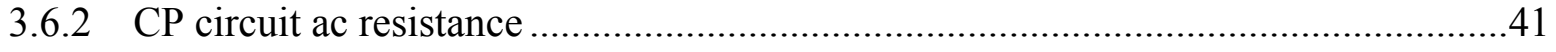

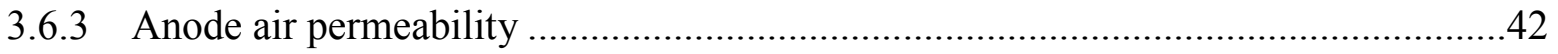




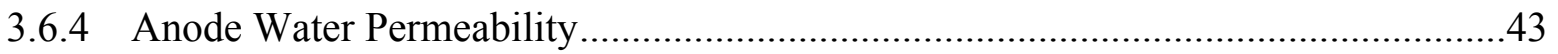

4.0 LABORATORY ANODE AGING STUDIES -- RESULTS.........................................45

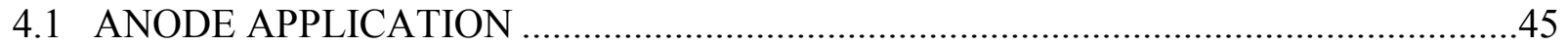

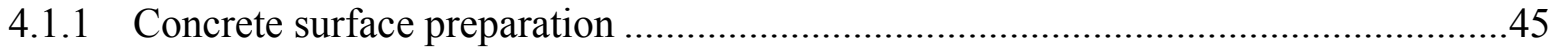

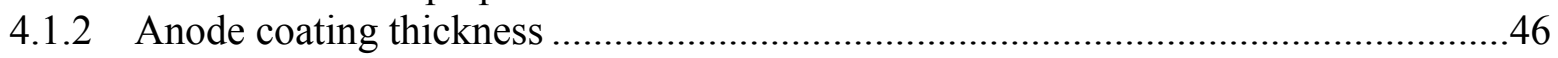

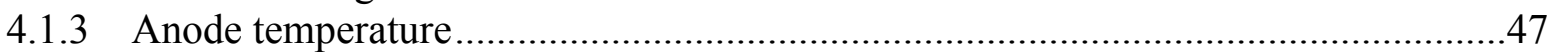

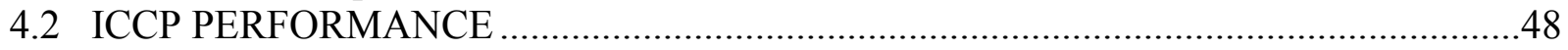

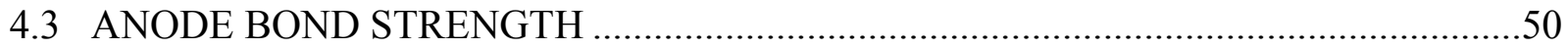

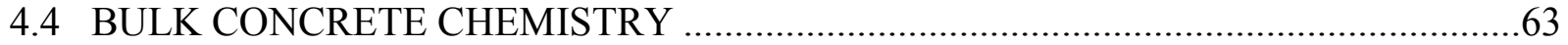

4.5 ANODE-CONCRETE INTERFACIAL CHEMISTRY …...............................................63

4.5.1 Analytical scanning electron microscopy ………..................................................63

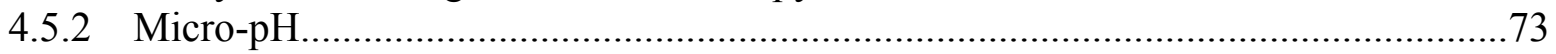

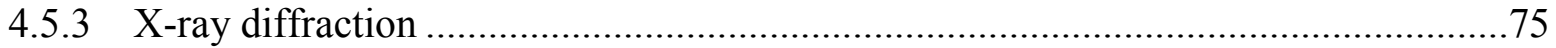

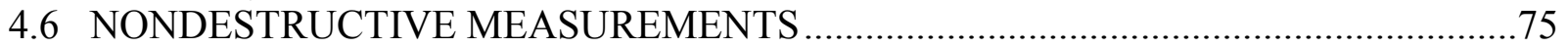

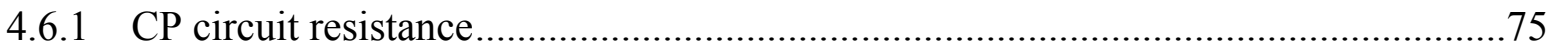

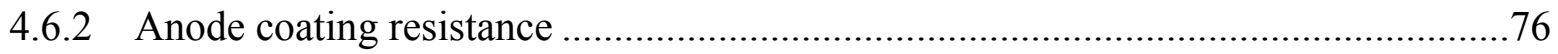

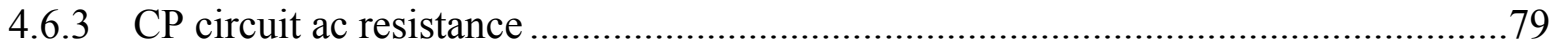

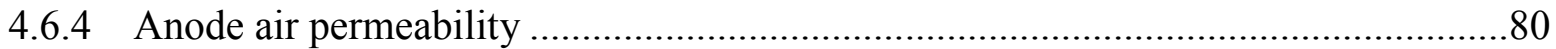

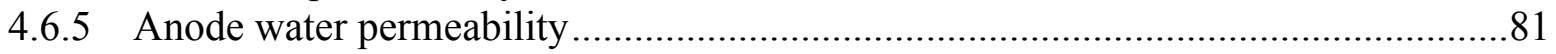

5.0 FIELD AGING STUDIES -- RESULTS.............................................................................83

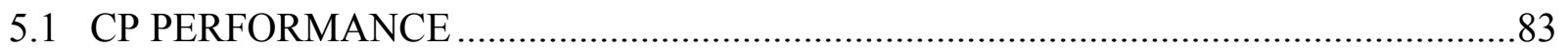

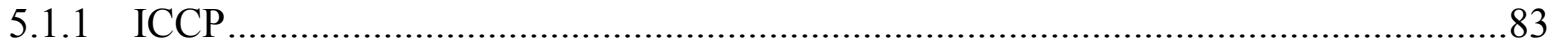

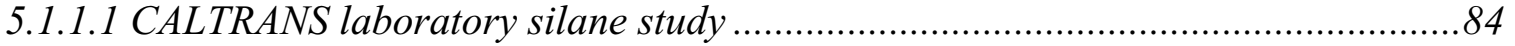

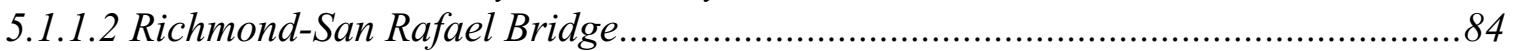

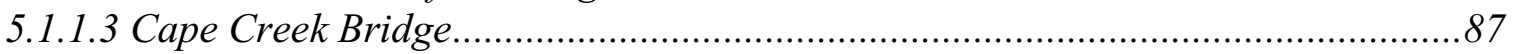

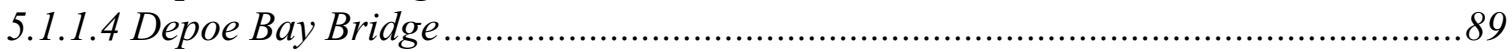

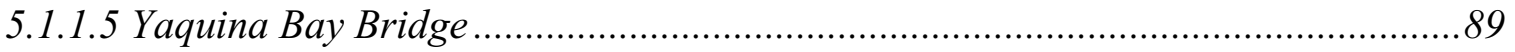

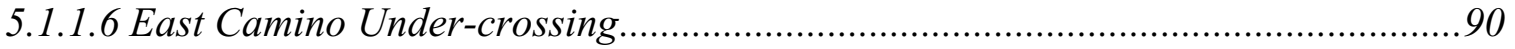

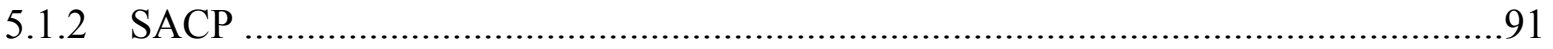

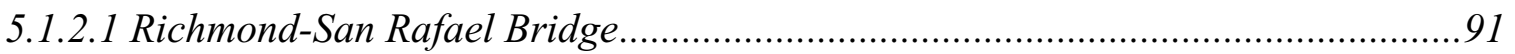

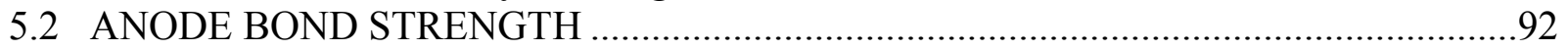

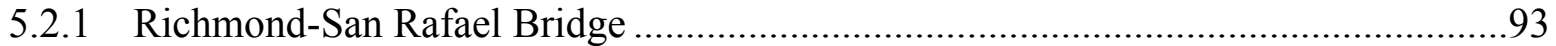

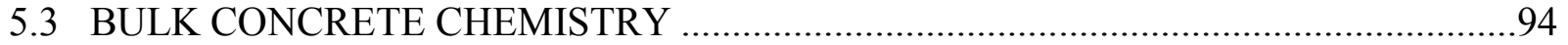

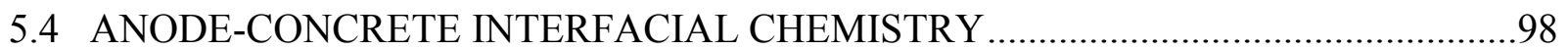

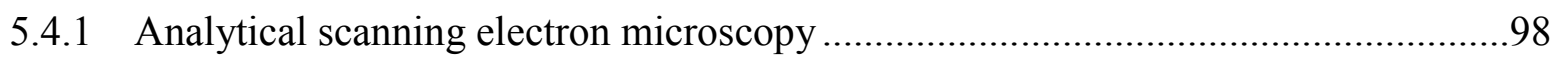

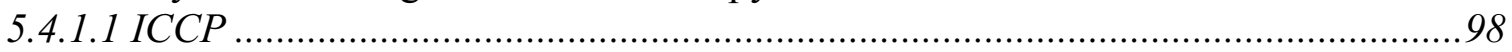

5.4.1.2 SACP

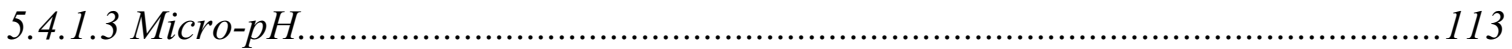

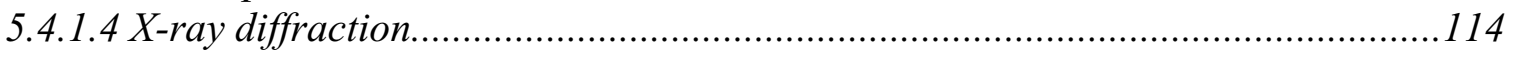

6.0 MODELING ZINC ANODE OPERATION ............................................................115

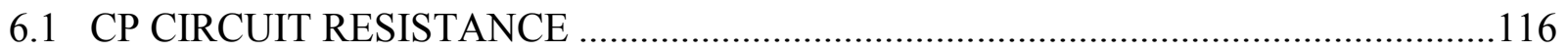

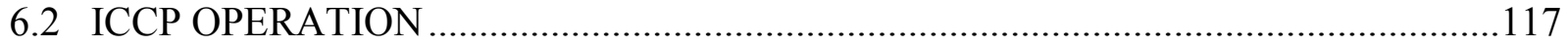




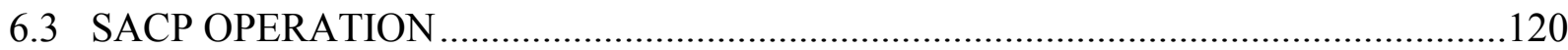

7.0 ZINC ANODE PERFORMANCE.............................................................................123

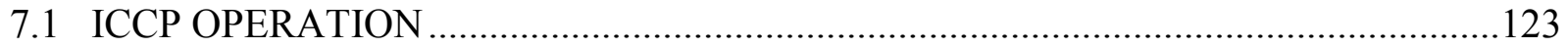

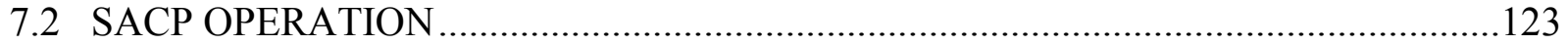

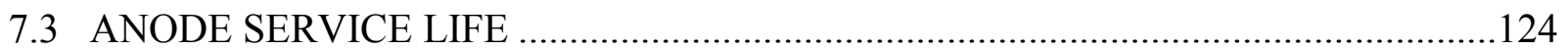

7.4 COMPARISON WITH OTHER CONDUCTIVE COATING ANODES ....................124

8.0 CONCLUSIONS AND RECOMMENDATIONS...............................................127

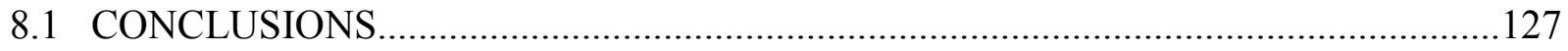

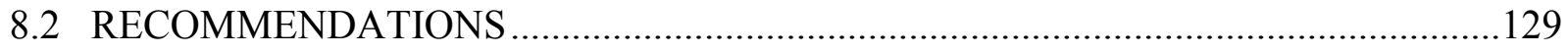

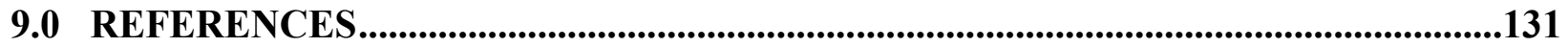

\section{APPENDICES}

\section{APPENDIX A: TABULATED LABORATORY BOND STRENGTH MEASUREMENTS \\ APPENDIX B: TABULATED INITIAL FIELD BOND STRENGTH AND COATING THICKNESS MEASUREMENTS \\ APPENDIX C: POWDER SAMPLING TECHNIQUES \\ APPENDIX D: CHLORIDE ANALYSIS OF CONCRETE POWDER SAMPLES \\ APPENDIX E: COST OF THERMAL-SPRAY ZN ANODE IMPRESSED CURRENT \\ CATHODIC PROTECTION SYSTEMS FOR COASTAL OREGON BRIDGES}

E.1 Impressed Current Cathodic Protection Projects

E. 2 Project Costs

E.3 Project Economic Evaluation

\section{LIST OF TABLES}

Table 1.1: Oregon DOT conductive coating anode CP projects.

Table 2.1: Timeline for laboratory experiments

Table 2.2: Concrete mix design for laboratory slabs per cubic yard of concrete.................................................15

Table 2.3: Twin-wire arc-spray application parameters, spray rates, and deposition efficiencies. (Rogers 2000)

Table 2.4: Laboratory concrete slabs examined.

Table 2.5: Core samples taken from bridges and some laboratory slabs ...................................................................23

Table 3.1: TS Zn coating thickness on a steel calibration panel with a target thickness of $0.38 \mathrm{~mm}$ (15 mils) and mean thickness of $0.39 \mathrm{~mm}$ (15.5 mils).

Table 3.2: Ceramic porosity standards for air permeability measurements..........................................................43

Table 4.1: Voltage decay parameters for TS $\mathrm{Zn}$ anodes on periodically-wetted concrete slabs (based on Figure 4.6).

Table 4.2: Pull strength of concrete in bare test slabs ........................................................................................................51

Table 4.3: Bond strength of naturally-aged TS $\mathrm{Zn}$ anodes on periodically-wetted concrete slabs........................52 
Table 4.4: Model parameters for bond strength of TS $\mathrm{Zn}$ anodes on preheated and unheated concrete slabs in periodically-wetted and un-wetted experiments.....................................................................................56

Table 4.5: Equivalent values of model parameters in Equations 4-1 and 4-2 .....................................................60

Table 4.6: Nominal composition of cement paste (Bullard 1997a)................................................................63

Table 4.7: Reaction zone thickness for TS anodes on periodically-wetted slabs ...............................................69

Table 4.8: TS Zn anode-concrete interfacial chemistry ..................................................................................71

Table 4.9: Metal ionic radii and radii ratios with respect to oxygen, for octahedral $(\mathrm{CN}=6)$ coordination (Shannon 1976)

Table 4.10: Molecular volumes of metals and compounds associated with anode-concrete interfacial

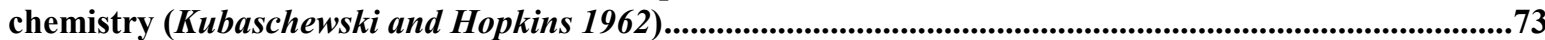

Table 4.11: Description of periodically-wetted laboratory samples analyzed ........................................................74

Table 5.1: TS Zn anodes on the Richmond-San Rafael Bridge (Carello, et al. 1989)............................................85

Table 5.2: Performance of TS Zn anodes on zones 11 and 15 of the Cape Creek Bridge .....................................88

Table 5.3: Average initial bond strength of TS Zn anodes on selected bridges...............................................92

Table 5.4: Bond strength of TS Zn anodes on the Richmond-San Rafael Bridge...............................................94

Table 5.5: Concrete mix design for selected bridges....................................................................................95

Table 5.6: Description of field samples analyzed .....................................................................................95

Table 7.1 Comparison of thermal-sprayed $\mathrm{Zn}$ anode with other conductive coating anodes ...........................125

Table E-1: Total cost and cost breakdown for CP projects on Oregon coast bridges ....................................E-4

\section{LIST OF FIGURES}

Figure 1.1: Concrete spalling from deck underside at the Big Creek Bridge prior to restoration................................2

Figure 1.2: Cape Creek Bridge built in 1932 and located on the Oregon coast south of Cape Perpetua....................... 3

Figure 1.3: Cape Creek Bridge showing morning fog that aids the deposition of salt on the bridge surface as a

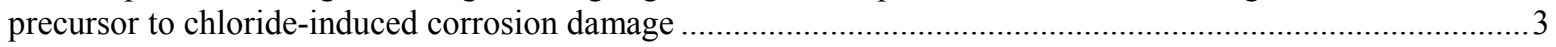

Figure 1.4: Yaquina Bay Bridge built in 1936 and located on the Oregon coast at Newport ..................................

Figure 1.5: South approach of the Yaquina Bay Bridge .......................................................................

Figure 1.6: Depoe Bay Bridge built in 1927, widened in 1940, and located on the Oregon coast at Depoe Bay.........5

Figure 1.7: Cape Perpetua Half-Viaduct built in 1931 on the central Oregon coast.....................................................5

Figure 1.8: Big Creek Bridge built in 1931 and located on the Oregon coast south of Cape Perpetua .......................6

Figure 2.1: Design of the laboratory concrete slabs with embedded steel mesh cathode ....................................14

Figure 2.2: Thermal spraying Zn on a bridge substructure using the twin-wire arc-spray process ......................... 16

Figure 2.3: General view of twin-wire arc-spray equipment showing wire spools, the wire-feed drive, and the

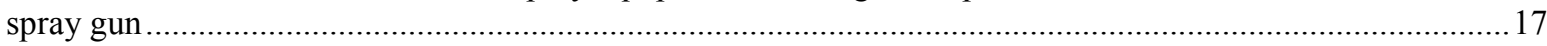

Figure 2.4: Oregon DOT robotic $\mathrm{x}-\mathrm{y}$ traversing system used to apply TS Zn anode to concrete slabs .................... 17

Figure 2.5: Schematic representation of thermal spraying showing the splat (droplet) impact and coating formation processes..

Figure 2.6: Multiple concrete slabs undergoing accelerated electrochemical aging in a controlled humidity enclosure: (a) overall view; (b) close-up of concrete slabs ............................................................20

Figure 2.7: Flowchart showing the concrete slab treatments used in the first electrochemical aging experiment.......21

Figure 2.8: Flowchart showing the concrete slab treatments used in the second electrochemical aging experiment.

Figure 2.9: Richmond-San Rafael Bridge (CA) built in 1956 spans the northern San Francisco Bay .....................24

Figure 2.10: South column of pier 4, Richmond-San Rafael Bridge (CA), showing two of the four ICCP Zn anode bands (zones) and the SACP Zn anode zone on the barrel at the column base.................................24

Figure 2.11: East Camino Under-crossing (CA) built in 1964 and located east of Placerville, CA .........................25

Figure 2.12: East Camino Under-crossing (CA) showing soffit areas that were thermal sprayed with $\mathrm{Zn}$...............26 
Figure 2.13: Experimental design for the CALTRANS laboratory silane study

Figure 3.1: SEM photomicrograph of cross-section showing unaged TS Zn anode microstructure and anodeconcrete interface for anode on concrete.

Figure 3.2: View of thermocouples attached to concrete slab for surface temperature measurements.....................

Figure 3.3: Twin-wire arc-spray equipment prior to applying TS Zn anode to concrete slab for surface temperature measurements.

Figure 3.4: Schematic wiring diagram for TS Zn anodes in electrochemical aging study showing series connections between slabs and power source, $\mathrm{V}$ and I measurement locations, and the computer ..................33

Figure 3.5: Schematic of data measurement instrumentation and telemetry equipment used by Oregon DOT for

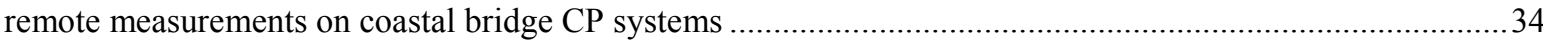

Figure 3.6: Instron universal tensile tester used to measure the bond strength of TS Zn anodes on a concrete

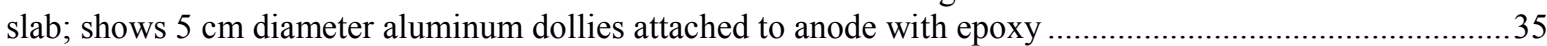

Figure 3.7: Close up of aluminum dollies used for bond strength measurements: one dolly attached and one pulled off......

Figure 3.8: Proceq portable tester used to measure the bond strength of the TS Zn anode on concrete....................36

Figure 3.9: Concrete powder samples are taken from a concrete bridge beam using the Oregon DOT sampling equipment. Powder samples are analyzed to determine the salt concentration in the concrete as a function of depth in the beam.

Figure 3.10: The hollow anchor drill bit, depth spacers, and vacuum filter assembly used in taking powder samples from concrete.

Figure 3.11: Portable gasoline-powered core drill for taking concrete core samples ........................................38

Figure 3.12: Oregon DOT resistance probe for measurement of anode coating resistivity ..................................41

Figure 3.13: Portable surface air permeability instrument in use ...............................................................42

Figure 3.14: Close-up of measuring head for surface air permeability instrument showing the flexible rubber gasket that forms a vacuum seal between the measuring head and concrete surface .......................................42

Figure 3.15: Schematic drawing of apparatus used to measure the TS Zn anode permeability to water...................44

Figure 4.1: Multiple SEM photomicrographs of cross sections from uncoated slabs. (a) as cast, back scattered electron (BSE); (b) as cast, secondary electron (SE); (c) sandblasted, BSE; (d) sandblasted and preheated, BSE.

Figure 4.2: Location of measurements on 56 concrete slabs showing average and standard deviation values of TS Zn coating thickness from eddy current measurements.

Figure 4.3: TS Zn coating surface temperature versus time for two thermocouples under the coating on the concrete slab.

Figure 4.4: TS Zn anode circuit resistance versus electrochemical age for both periodically-wetted and unwetted concrete slabs.

Figure 4.5: CP system voltage rise due to drying of the anode-concrete interface versus drying time for selected electrochemical ages .

Figure 4.6: CP system voltage decay due to wetting of the anode-concrete interface versus elapsed time after wetting for selected electrochemical ages....

Figure 4.7a: Bond strength of the TS Zn anode on periodically-wetted, preheated concrete slabs versus electrochemical age

Figure 4.7b: Bond strength of the TS Zn anode on periodically-wetted, unheated concrete slabs versus electrochemical age.

Figure 4.8a: Bond strength of the TS Zn anode on un-wetted, preheated concrete slabs versus electrochemical

Figure 4.8b: Bond strength of the TS $\mathrm{Zn}$ anode on un-wetted, unheated concrete slabs versus electrochemical age

Figure 4.9: Model bond strength curve for electrochemically-aged TS Zn anodes on concrete slabs.......................56

Figure 4.10: Effect of curing time on the compressive strength of five ASTM concretes......................................58

Figure 4.11: SEM photomicrograph showing cracking of periodically-wetted cement paste at the TS Zn anodeconcrete interface following $747 \mathrm{kC} / \mathrm{m}^{2}$ aging, the equivalent of 11.0 years at $0.0022 \mathrm{~A} / \mathrm{m}^{2}$. 
Figure 4.12: Delaminated TS Zn anode on periodically-wetted concrete slab following $\sim 1800 \mathrm{kC} / \mathrm{m}^{2}$ aging......

Figure 4.13: Pullout of concrete as a result of bond strength tests for bare concrete (left) and TS Zn coated concrete (right)......

Figure 4.14: Back-scattered electron SEM photomicrograph of a cross-section of TS Zn anode on periodicallywetted concrete electrochemically aged for $640 \mathrm{kC} / \mathrm{m}^{2}$, the equivalent of 9.4 years at $0.0022 \mathrm{~A} / \mathrm{m}^{2}$; shows reaction zones......

Figure 4.15: X-ray maps of elemental distributions at the Zn-concrete interface in Figure 4.14: (a) Zn; (b) O; (c) $\mathrm{Si}$; (d) $\mathrm{Ca}$

Figure 4.16: X-ray maps of elemental distributions at the Zn-concrete interface in Figure 4.14: (a) $\mathrm{Cl}$; (b) $\mathrm{S}$..........66

Figure 4.17: Cross-section of TS Zn anode on periodically-wetted concrete electrochemically aged for 1080 $\mathrm{kC} / \mathrm{m}^{2}$, the equivalent of 15.9 years at $0.0022 \mathrm{~A} / \mathrm{m}^{2}$ : (a) back-scattered electron SEM photomicrograph; and x-ray maps, (b) $\mathrm{Zn}$, (c) $\mathrm{Ca}$, (d) $\mathrm{Cl}$.

Figure 4.18: WDS concentration profiles for $\mathrm{Zn}, \mathrm{O}$, and $\mathrm{Ca}$ at the TS $\mathrm{Zn}$ anode-concrete interface in Figure 4.14...68

Figure 4.19: WDS concentration profiles of $\mathrm{Zn}, \mathrm{Cl}$ and $\mathrm{S}$ at the TS $\mathrm{Zn}$ anode-concrete interface in Figure $4.14 \ldots . . .68$

Figure 4.20: $\mathrm{Cl}$ concentration profiles as a function of TS $\mathrm{Zn}$ anode electrochemical age in years at $0.0022 \mathrm{~A} / \mathrm{m}^{2}$ for periodically-wetted concrete slabs.

Figure 4.21: $\mathrm{S}$ profiles as a function of TS $\mathrm{Zn}$ anode electrochemical age in years at $0.0022 \mathrm{~A} / \mathrm{m}^{2}$ for periodically-wetted concrete slabs

Figure 4.22: $\mathrm{Zn}$ profiles as a function of TS $\mathrm{Zn}$ anode electrochemical age in years at $0.0022 \mathrm{~A} / \mathrm{m}^{2}$ for periodically-wetted concrete slabs .....

Figure 4.23: $\mathrm{pH}$ versus electrochemical age for $\mathrm{TS} \mathrm{Zn}$ anode-concrete and steel-concrete interfaces for periodically-wetted concrete slabs

Figure 4.24: Relationship between CP system circuit resistance and TS Zn anode bond (adhesion) strength for

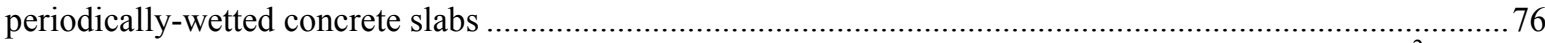

Figure 4.25: Surface resistance of TS $\mathrm{Zn}$ anode as a function of electrochemical age in years at $0.0022 \mathrm{~A} / \mathrm{m}^{2}$ for periodically-wetted concrete slabs ....

Figure 4.26: Apparent TS Zn anode thickness as a function of electrochemical age in years at $0.0022 \mathrm{~A} / \mathrm{m}^{2} \ldots \ldots \ldots . .78$

Figure 4.27: Volume average AC resistivity of material between the TS Zn anode and the steel as a function of electrochemical age in years at $0.0022 \mathrm{~A} / \mathrm{m}^{2}$; average includes zinc minerals at anode, altered and unaltered concrete, and corrosion film on steel.

Figure 4.28: Surface air permeability determined using ceramic disc porosity standards as a function of maximum pore diameter and percent pore volume (porosity).

Figure 4.29: Surface air permeability vacuum pressure for TS $\mathrm{Zn}$ anodes on periodically-wetted concrete slabs as a function of airflow rate through the instrument ....

Figure 4.30: Permeability of water through TS Zn anode on periodically-wetted concrete slabs as a function of electrochemical age

Figure 5.1: Circuit resistance as a function of electrochemical age for slabs from CALTRANS laboratory silane experiment; measurements on each slab were for the same time period.

Figure 5.2: ICCP system voltage for the TS Zn bands (zones) on the south column, pier 4 of the Richmond-San Rafael Bridge (CA).

Figure 5.3: Circuit resistance as a function of time for TS Zn anode bands (zones) 1 and 4 on the south column, pier 4 of the Richmond-San Rafael Bridge .

Figure 5.4: Circuit resistance as a function of electrochemical age for TS Zn anode bands (zones) 1 and 4 on the south column, pier 4 of the Richmond-San Rafael Bridge...

Figure 5.5: Current density and monthly precipitation as a function of time for TS Zn anode band (zones) 4 on the south column, pier 4 of the Richmond-San Rafael Bridge......

Figure 5.6: Circuit resistance as a function of TS Zn electrochemical age for ICCP zones 11 and 15 on the Cape Creek Bridge; measurements on each zone were for the same time period. ..........................................8

Figure 5.7: Circuit resistance as a function of electrochemical age for ICCP zones 13 (TS Zn anode) and 14 (TS Ti anode) on the Depoe Bay Bridge; measurements on each zone were for the same time period.

Figure 5.8: Circuit resistance as a function of TS Zn electrochemical age for humectant-treated ICCP zones 11 and 13 and control ICCP zones 10 and 14 on the Yaquina Bay Bridge; measurements on each zone were for the same time period. 
Figure 5.9: Circuit resistance as a function of TS Zn electrochemical age for the soffit and deck of the East Camino Under-crossing; measurements on each zone were for the same time period.

Figure 5.10: Current density and monthly precipitation as a function of time for TS Zn SACP anode on the barrel at the base of the south column, pier 4 of the Richmond-San Rafael Bridge.

Figure 5.11: Bond strength of the TS Zn anodes on the south column, pier 4 of the Richmond-San Rafael Bridge as a function of height above the sea level, after $\sim 10$ years service.

Figure 5.12: Chloride concentration profiles for TS Zn anodes on the south column, pier 4 of the Richmond-San Rafael Bridge, after $\sim 10$ years service.

Figure 5.13: Chloride concentration profiles for original concrete in beam A1 of the Rocky Point Viaduct after 40 years service on the Oregon coast.

Figure 5.14: Chloride concentration profiles for patch concrete in beam A1 of the Rocky Point Viaduct after 40 years service on the Oregon coast.

Figure 5.15: BSE photomicrograph and x-ray maps of TS Zn anode-concrete interface of Richmond-San Rafael Bridge, band 1 after aging $\sim 1200 \mathrm{kC} / \mathrm{m}^{2}$ service or $\sim 10$ years service: (a) BSE photomicrograph; (b) $\mathrm{Zn}$; (c) $\mathrm{Ca}$; (d) $\mathrm{Cl}$......

Figure 5.16: WDS line scan for $\mathrm{Zn}, \mathrm{O}, \mathrm{Ca}$, and $\mathrm{Cl}$ across the TS $\mathrm{Zn}$ anode-concrete interface for the RichmondSan Rafael Bridge, band 1 after aging $\sim 1200 \mathrm{kC} / \mathrm{m}^{2}$ or $\sim 10$ years service.

Figure 5.17: WDS line scan for $\mathrm{Zn}, \mathrm{O}, \mathrm{Ca}$, and $\mathrm{Cl}$ across the TS $\mathrm{Zn}$ anode-concrete interface for the RichmondSan Rafael Bridge, band 2 after aging $\sim 950 \mathrm{kC} / \mathrm{m}^{2}$ or $\sim 10$ years service.

Figure 5.18: BSE photomicrograph and x-ray maps of TS $\mathrm{Zn}$ anode-concrete interface for concrete slab treated with silane but not sandblasted, then aged $\sim 700 \mathrm{kC} / \mathrm{m}^{2}$ : (a) BSE photomicrograph; (b) $\mathrm{Zn}$; (c) Si; (d) $\mathrm{Cl}$..... 101

Figure 5.19: WDS line scan for $\mathrm{Zn}, \mathrm{O}, \mathrm{Ca}$, and $\mathrm{Si}$ across the TS Zn anode-concrete interface for concrete slab treated with silane but not sandblasted, then aged $\sim 700 \mathrm{kC} / \mathrm{m}^{2}$

Figure 5.20: WDS line scan for $\mathrm{Zn}, \mathrm{O}, \mathrm{Ca}, \mathrm{Si}$, and $\mathrm{Cl}$ across the TS $\mathrm{Zn}$ anode-concrete interface for concrete slab treated with silane and sandblasted, then aged $\sim 600 \mathrm{kC} / \mathrm{m}^{2}$.

Figure 5.21: Effect of sandblasting on the WDS line scan for $\mathrm{Zn}$ across the TS $\mathrm{Zn}$ anode-concrete interface for concrete slabs treated with silane.

Figure 5.22: WDS line scan for $\mathrm{Zn}, \mathrm{O}, \mathrm{Ca}, \mathrm{Si}$, and $\mathrm{Cl}$ across the TS $\mathrm{Zn}$ anode-concrete interface for the soffit of East Camino Under-crossing aged $\sim 330 \mathrm{kC} / \mathrm{m}^{2}$.

Figure 5.23: WDS line scan for $\mathrm{Zn}, \mathrm{O}, \mathrm{Ca}$, and $\mathrm{Si}$, across the TS $\mathrm{Zn}$ anode-concrete interface for original concrete on the Cape Creek Bridge after about 3.7 years in ICCP service at $0.0022 \mathrm{~A} / \mathrm{m}^{2}$.

Figure 5.24: WDS line scan for $\mathrm{Zn}, \mathrm{O}, \mathrm{Ca}$, and $\mathrm{Si}$, across the TS $\mathrm{Zn}$ anode-concrete interface for patch concrete on the Cape Creek Bridge after about 3.7 years in ICCP service at $0.0022 \mathrm{~A} / \mathrm{m}^{2}$.

Figure 5.25: SEM photomicrograph of TS Zn anode-concrete interface for the Richmond-San Rafael Bridge SACP zone on the barrel of the south column aged $\sim 700 \mathrm{kC} / \mathrm{m}^{2}$ or $\sim 10$ years service...

Figure 5.26: BSE photomicrograph and x-ray maps of TS Zn anode-concrete interface for the Richmond-San Rafael Bridge SACP zone on the barrel of the south column aged $\sim 700 \mathrm{kC} / \mathrm{m}^{2}$ or $\sim 10$ years service: (a) BSE photomicrograph; (b) Zn; (c) Ca; (d) Cl..

Figure 5.27: WDS line scan for $\mathrm{Zn}, \mathrm{O}, \mathrm{Ca}$, and $\mathrm{Cl}$ across the TS $\mathrm{Zn}$ anode-concrete interface for the RichmondSan Rafael Bridge SACP zone on the barrel of the south column aged $\sim 700 \mathrm{kC} / \mathrm{m}^{2}$ or $\sim 10$ years service.... 108

Figure 5.28: WDS line scan for $\mathrm{Zn}, \mathrm{O}, \mathrm{Ca}$, and $\mathrm{Cl}$ across another area of the TS $\mathrm{Zn}$ anode-concrete interface for the Richmond-San Rafael Bridge SACP zone on the barrel of the south column aged $\sim 700 \mathrm{kC} / \mathrm{m}^{2}$ or $\sim 10$ years service.

Figure 5.29: WDS line scan for Zn, O, Ca, and Si across the TS Zn anode-concrete interface for a SACP zone on the Cape Creek Bridge after aging about 3.7 years.

Figure 5.30: SEM photomicrograph of galvanized rebar-concrete interface from the abutment of the Longbird Bridge after 46 years service.

Figure 5.31: SEM photomicrograph of galvanized rebar-concrete interface from the sidewalk of the Longbird Bridge after 46 years service.

Figure 5.32: WDS line scan for $\mathrm{Zn}, \mathrm{Fe}, \mathrm{O}, \mathrm{Ca}$, and $\mathrm{Si}$ across the galvanized rebar-concrete interface for rebar from the sidewalk of the Longbird Bridge after 46 years service.

Figure 5.33: WDS line scan for $\mathrm{Zn}, \mathrm{O}, \mathrm{Ca}$, and $\mathrm{Si}$ across a second location on the galvanized rebar-concrete interface for rebar from the sidewalk of the Longbird Bridge after 46 years service. 
Figure 5.34: WDS line scan for $\mathrm{Zn}, \mathrm{Fe}, \mathrm{O}$, and $\mathrm{Ca}$ across the galvanized rebar-concrete interface for rebar from the abutment of the Longbird Bridge after 46 years service.

Figure 5.35: $\mathrm{pH}$ as a function of height above sea level for the TS Zn anode ICCP bands (zones) on the Richmond-San Rafael Bridge after $\sim 10$ years service.

Figure 6.1: Equivalent circuit for ICCP between TS Zn anode and rebar. A Randles-circuit approximates the response of the anode-concrete and rebar-concrete interfaces.

Figure E.1: Terminal plate connection prior to thermal spraying with $\mathrm{Zn}$ 


\subsection{INTRODUCTION}

\subsection{BACKGROUND}

Oregon's coastal highway includes over 120 bridges, most of which are reinforced concrete structures over $15 \mathrm{~m}$ (50 ft) in length (Smith, Norman and Dykman 1989). Twelve of the bridges are historic reinforced concrete bridges designed and built by respected Oregon bridge engineer Conde B. McCullough in the 1920s and 1930s. These twelve bridges are listed on the National Register of Historic Places (Smith, Norman and Dykman 1989). They are essential links in the coastal transportation corridor and evoke a lasting image, for visitors and residents alike, of the grace and beauty of the rugged Oregon coastline.

The presence of steel reinforcement (rebar) in these historic 70 year old bridges and other reinforced concrete bridges on the Oregon coast makes them susceptible to structural damage from chloride-induced corrosion of the rebar. Steel reinforcement is naturally passive in uncontaminated concrete where $\mathrm{pH}$ values are typically 12-13. However, environmental constituents such as salt $(\mathrm{NaCl})$ and carbon dioxide $\left(\mathrm{CO}_{2}\right)$ can contaminate the concrete, breaking down the passive film and reducing the concrete $\mathrm{pH}$, thereby initiating corrosion of the rebar (Broomfield 1997). This leads to cracking of the concrete as a result of the expansive forces produced by the corrosion product (Allan 1995), delamination of the cover concrete, and ultimately mechanical deterioration of the structure. In coastal areas and areas using de-icing salts, salt contamination is primarily responsible for the deterioration of steel-reinforced concrete bridges. Figure 1.1 shows rebar in the substructure of the Big Creek Bridge (OR) exposed by spalling of the concrete cover as a consequence of chloride-induced corrosion damage. It illustrates the need for technology to halt or reduce deterioration of existing bridges caused by rebar corrosion and to extend bridge service life.

Chloride-induced corrosion damage, typically found on many older coastal bridges, results in high maintenance costs, reduced load carrying capacity, and the need for early replacement of the bridge. Along the Oregon coast, the decision to replace or to preserve older bridges involves not only issues of public funds and public safety, but historic considerations as well. The 1987 replacement of the Alsea Bay Bridge in Waldport, OR cost approximately \$45 million and resulted in public protest of the loss of a landmark bridge designed by Conde B. McCullough. Faced with a need to preserve deteriorating historic coastal bridges, the Oregon DOT selected a thermal-sprayed (TS) zinc (Zn) anode cathodic protection (CP) system that provides protection to the bridge while retaining its historic appearance (Carello, Parks and Apostolos 1989). 


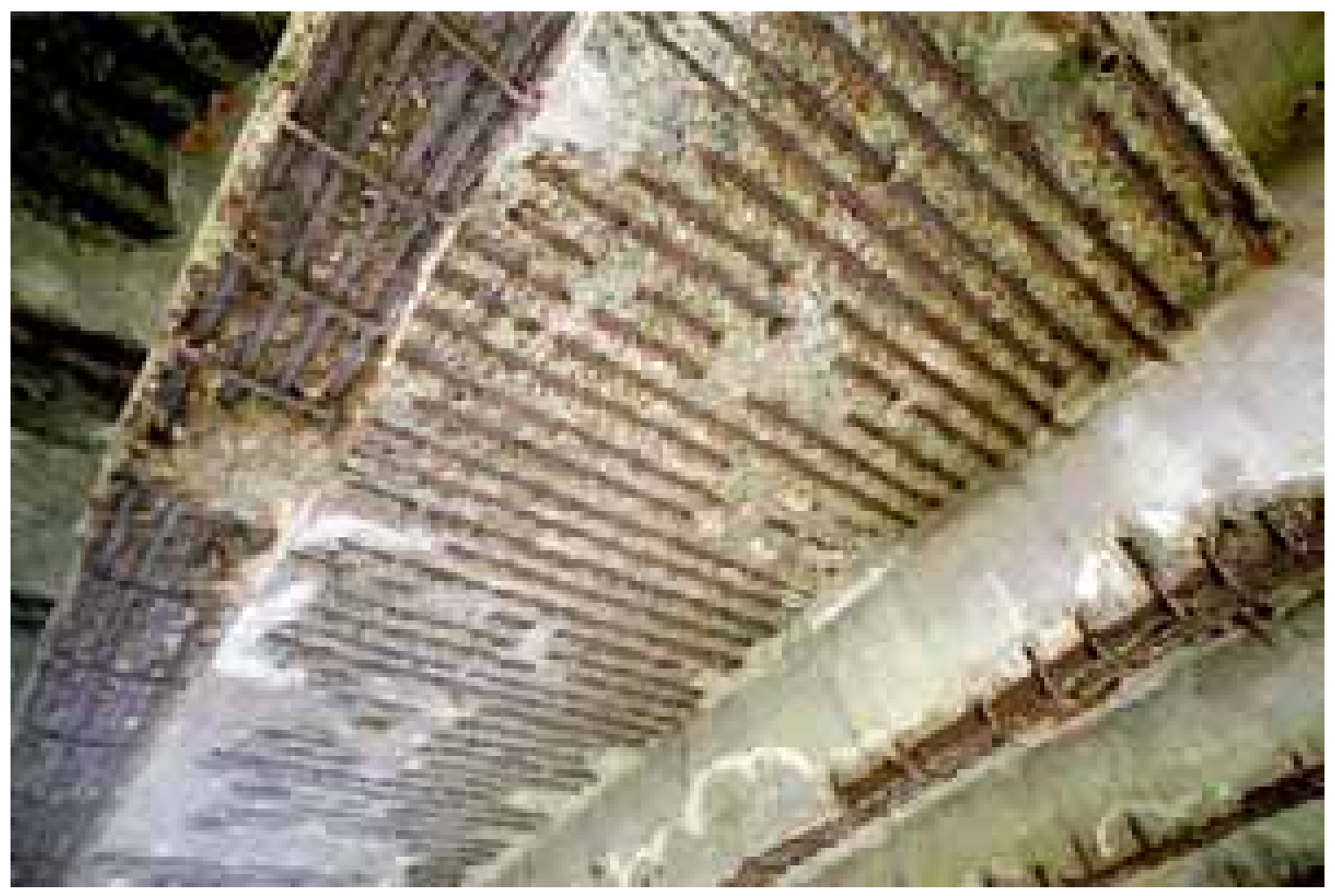

Figure 1.1: Concrete spalling from deck underside at the Big Creek Bridge prior to restoration

The first Oregon Department of Transportation (DOT) impressed current CP (ICCP) system using thermal-sprayed $\mathrm{Zn}$ anodes was installed in 1990 to protect the Cape Creek Bridge, Figures 1.2 and 1.3. The next TS Zn anode system was installed on the Yaquina Bay Bridge arches, Figure 1.4, followed later by the south approach, Figure 1.5. The Depoe Bridge TS Zn anode project, Figure 1.6, also included one CP zone using cobalt-catalyzed thermal-sprayed titanium as the anode. The Cape Perpetua Viaduct was used for a demonstration of TS Zn and TS Aluminum-12Zinc-0.2In (AlZnIn) anodes and a Zn-hydrogel anode in a sacrificial anode CP (SACP) systems, Figure 1.7. Installation of TS $\mathrm{Zn}$ anodes for the Big Creek Bridge ICCP system was completed in 1998, Figure 1.8. Projects are currently underway at Rocky Creek (Ben Jones) Bridge and the Rogue River (Patterson) Bridge. 


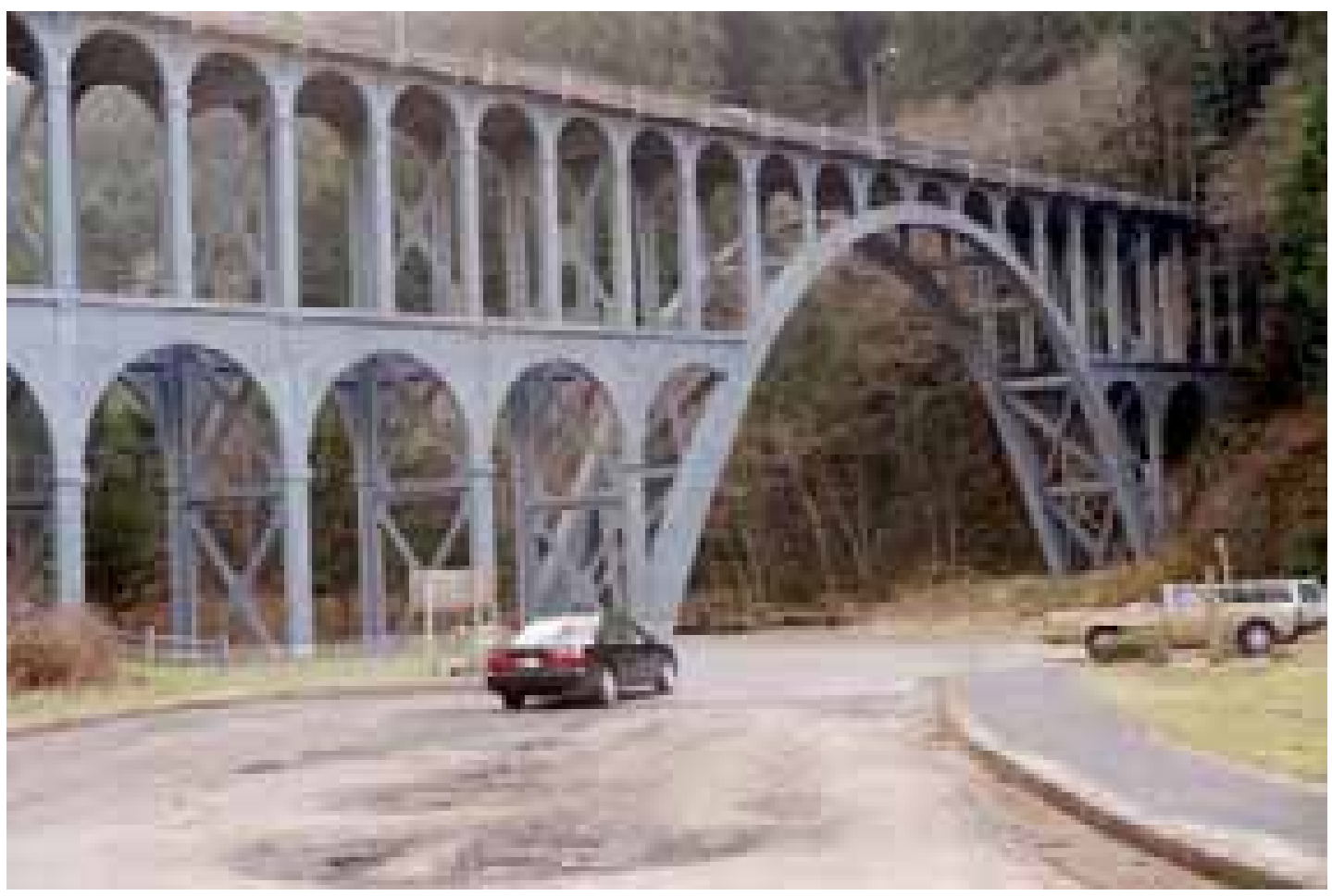

Figure 1.2: Cape Creek Bridge built in 1932 and located on the Oregon coast south of Cape Perpetua

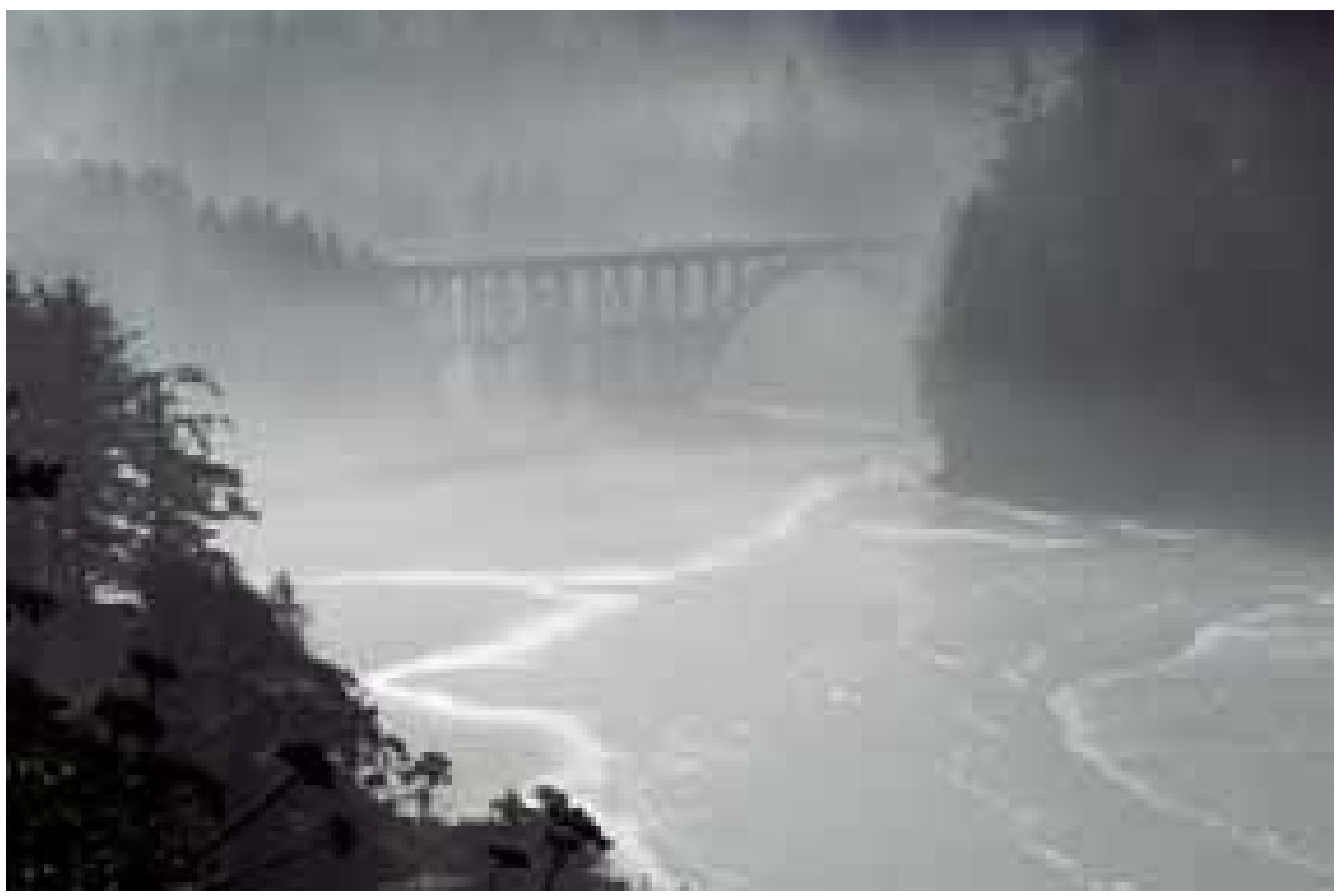

Figure 1.3: Cape Creek Bridge showing morning fog that aids the deposition of salt on the bridge surface as a precursor to chloride-induced corrosion damage 

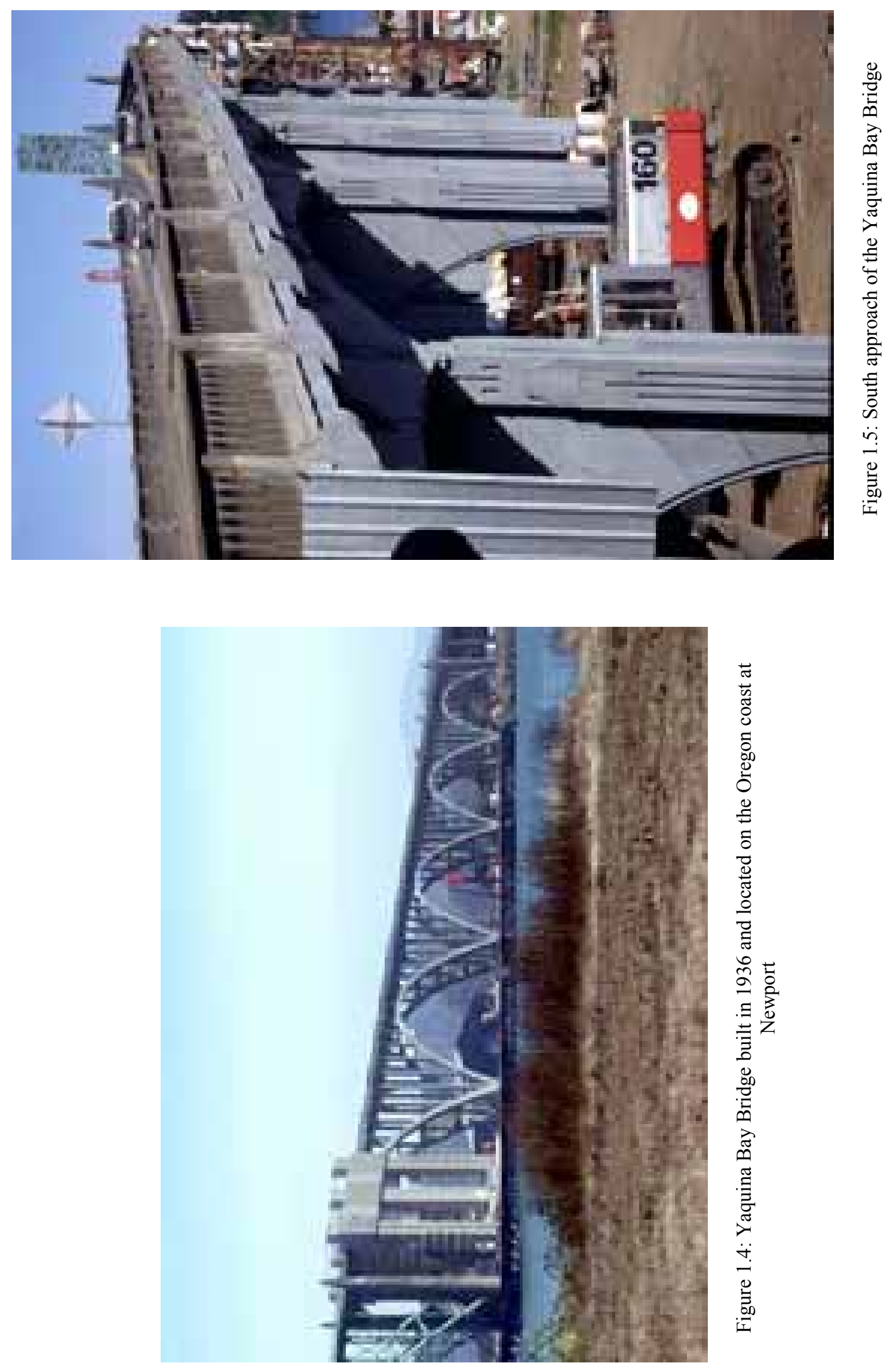


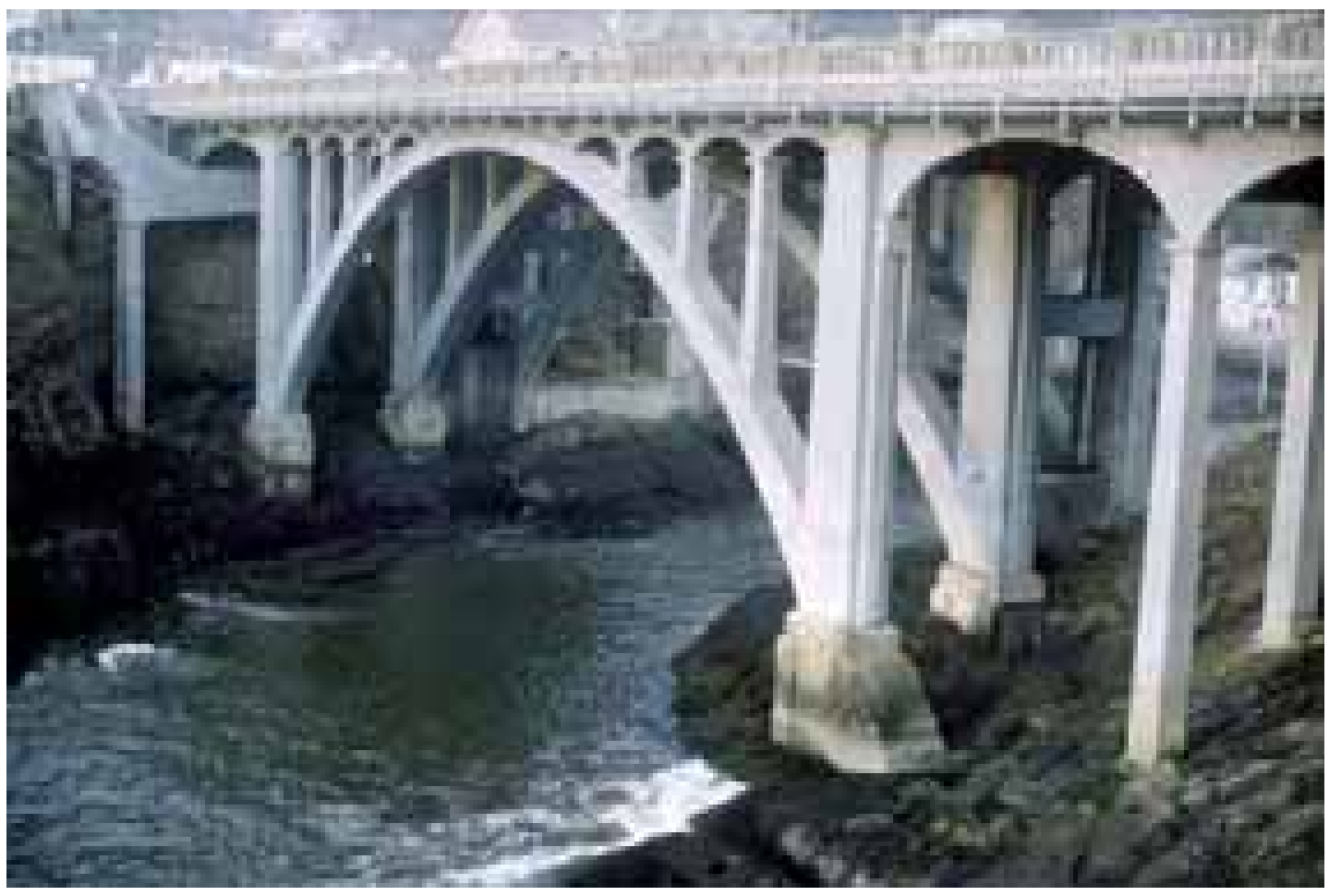

Figure 1.6: Depoe Bay Bridge built in 1927, widened in 1940, and located on the Oregon coast at Depoe Bay

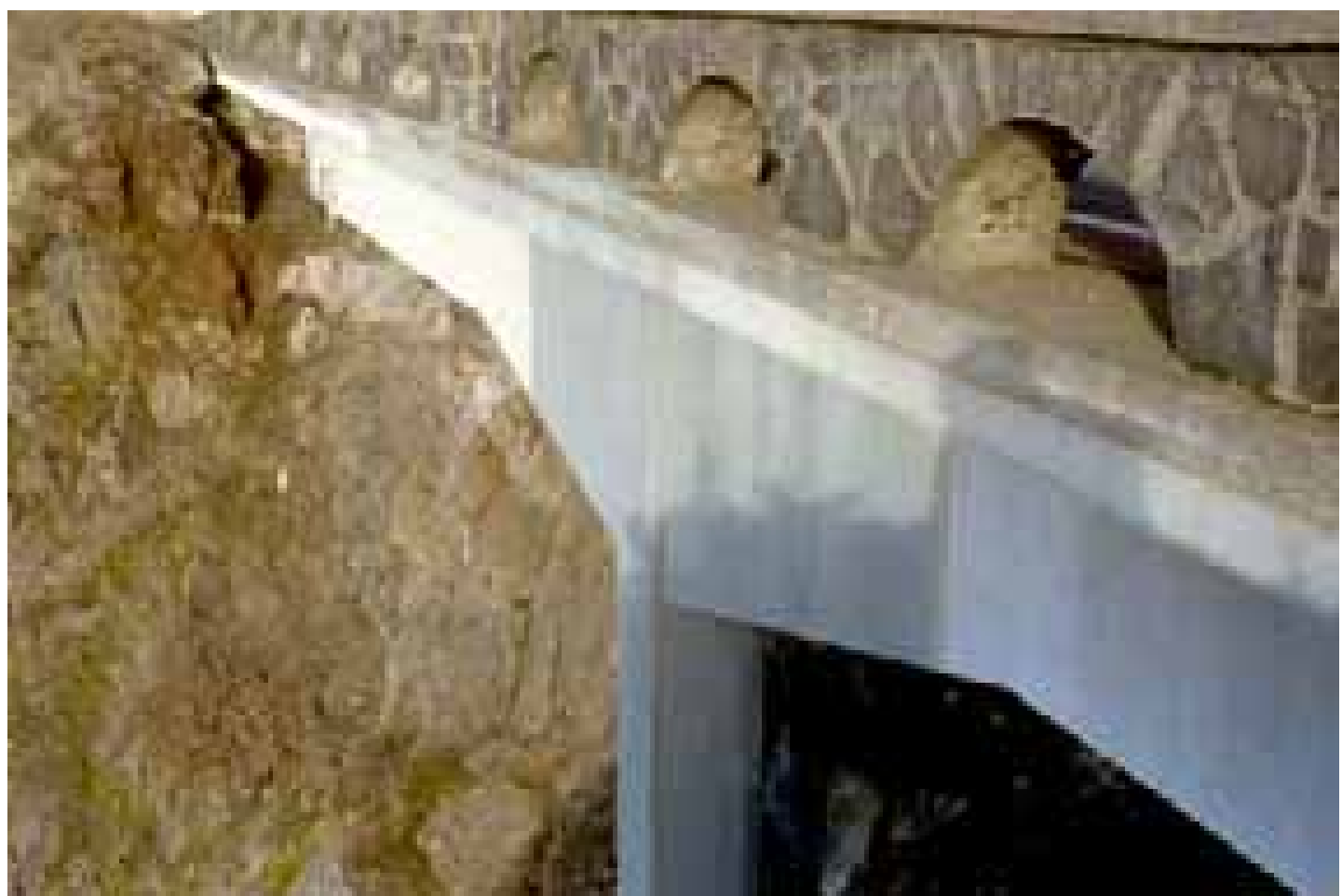

Figure 1.7: Cape Perpetua Half-Viaduct built in 1931 on the central Oregon coast 


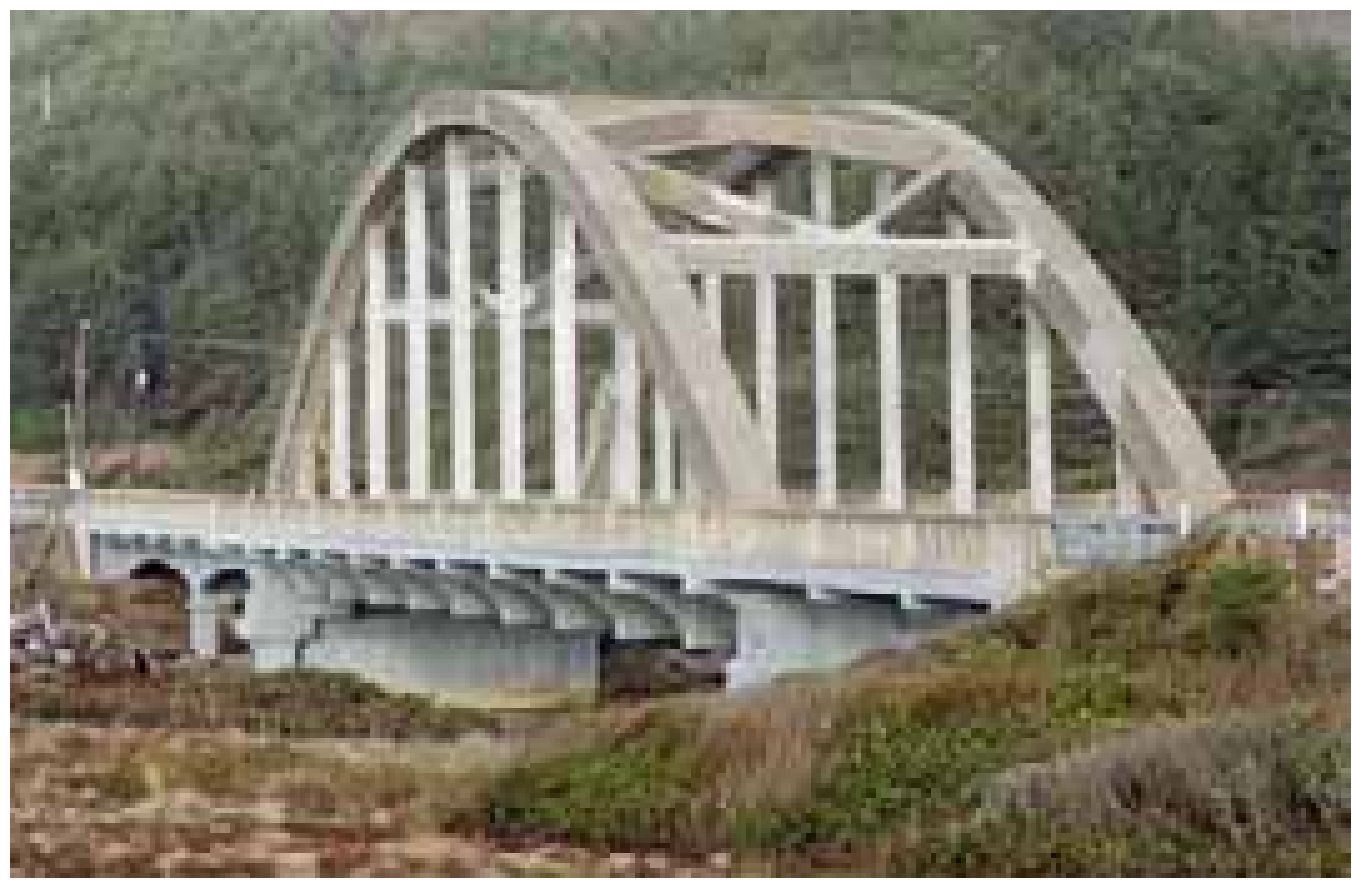

Figure 1.8: Big Creek Bridge built in 1931 and located on the Oregon coast south of Cape Perpetua

Table 1.1 lists all of the conductive coating anode CP systems, including thermal-spray $\mathrm{Zn}$ anode CP systems, in progress or completed by Oregon DOT, the year energized, the anode area, and the thickness of the anode.

Table 1.1: Oregon DOT conductive coating anode CP projects

\begin{tabular}{|c|c|c|c|c|c|}
\hline Bridge & Figure no. & $\begin{array}{c}\text { Year } \\
\text { energized }\end{array}$ & $\begin{array}{c}\text { Area, } \\
\mathbf{m}^{2}\left(\mathrm{ft}^{2}\right)\end{array}$ & $\begin{array}{c}\text { Anode } \\
\text { material }\end{array}$ & $\begin{array}{l}\text { Thickness, } \\
\text { mm (mils) }\end{array}$ \\
\hline Cape Creek Bridge & $1.2,1.3$ & 1991 & $9,530(102,500)$ & TS Zn & $0.51(20)$ \\
\hline Yaquina Bay Bridge - arches & 1.4 & 1994 & $18,170(195,500)$ & TS Zn & $0.57(22.6)$ \\
\hline Depoe Bay Bridge & 1.6 & 1995 & $5,940 \quad(63,960)$ & $\mathrm{TS} \mathrm{Zn}$ & $0.55(21.7)$ \\
\hline Yaquina Bay Bridge - south approach & 1.5 & 1997 & $6,041 \quad(65,000)$ & TS Zn & $0.51(20)$ \\
\hline Cape Perpetua Viaduct & 1.7 & 1997 & $(607)$ & TS Zn & $0.50(19.7)$ \\
\hline Big Creek Bridge & $1.1,1.8$ & 1998 & $1,865 \quad(20,026)$ & TS Zn & $0.38(15)$ \\
\hline Rocky Creek (Ben Jones) Bridge & & 2001 & $3,700 \quad(40,000)$ & TS Zn & $0.38(15)$ \\
\hline Cummins Creek & & 2001 & $1,865 \quad(20,000)$ & TS Zn & $0.38(15)$ \\
\hline Rogue River (Patterson) Bridge & & 2003 & $33,000(350,000)$ & TS Zn & $0.38(15)$ \\
\hline Yaquina Bay Bridge - north approach & & 1986 & $(6910)$ & C paint & $0.50(20) \mathrm{dft}$ \\
\hline Depoe Bay Bridge & & 1995 & $(3015)$ & TS Ti & $0.10(4)$ \\
\hline Cape Perpetua Viaduct & & 1997 & $(610)$ & TS AlZnIn & $0.40(15.8)$ \\
\hline Cape Perpetua Viaduct & & 1997 & $(610)$ & $\begin{array}{c}\mathrm{Zn} \\
\text { hydrogel }\end{array}$ & $0.25(10)$ \\
\hline \multicolumn{3}{|c|}{ TOTAL installed area } & \multicolumn{3}{|l|}{$81,206 \quad(873,780)$} \\
\hline
\end{tabular}


Between 1990 and the present, Oregon DOT-sponsored research has improved the procedures used to install and operate thermal-sprayed $\mathrm{Zn}$ anode $\mathrm{CP}$ systems. This research was driven by the need to evaluate and improve procedures used on the first two projects, Cape Creek Bridge and the Yaquina Bay Bridge arches, and to develop a better understanding of the long-term performance of this relatively new technology. One of the early considerations was to evaluate the need for preheating the concrete surface prior to applying the thermal-sprayed Zn anode so as to assure good long-term bond strength of the anode to the concrete. The preheating was known to improve the initial anode bond strength, but at a substantial cost premium. The question initially addressed by this research was whether preheating had a long-term benefit that would extend anode service life. Other research addressing chemical modification of the anodes (humectants) and alternative anode materials followed this initial effort. This report addresses the following issues of interest to Oregon DOT regarding thermal-sprayed Zn anode CP systems:

- Effect of preheating on long-term anode bond strength

- Effect of anode-concrete interfacial chemistry on anode performance

- Effect of moisture on anode performance

- Factors affecting anode service life

- Effect of electrochemical aging on anode service life

- Methods for characterizing anode condition in service.

\subsection{LITERATURE SURVEY}

Steel in concrete can exhibit passivity over a range of potentials of +175 to $-590 \mathrm{mV}$ vs the saturated calomel electrode (SCE). Steel passivity is dependent on oxygen availability, and moisture and chloride content of the concrete. Increasing chloride content results in more negative potentials (Weale 1992). The two main mechanisms responsible for disruption of the protective passive film on rebar in concrete is neutralization of the concrete by dissolved $\mathrm{CO}_{2}$ to form a less basic environment for the rebar and the presence of chlorides (Weale 1992).

In the United States, the most important agent responsible for deterioration of reinforced concrete structures, such as bridges, parking structures, and light standards, is salt, both road salt and marine salt, that can penetrate the concrete. Specifically, it is the chloride ion $(\mathrm{Cl})$ in the salt that is the damaging agent. In coastal environments, as well as in areas where road salts are used, $\mathrm{Cl}$ ions penetrate the concrete and accumulate at the rebar-concrete interface. Rebar, which is normally passive in the high $\mathrm{pH}$ concrete environment, loses passivity and begins to corrode when a threshold level of chloride is exceeded (West and Hime 1985). The iron corrosion products occupy a larger volume than the rebar consumed. This leads to a static pressure buildup at the rebar-concrete interface and tensile stresses that crack the concrete (Allan 1995), cause delamination of the concrete and more direct exposure of the rebar to the environment, and lead to further corrosion damage.

Cathodic protection is the most commonly used remediation technology available for existing reinforced concrete structures, other than short-term "chip and patch" maintenance work. In fact, $\mathrm{CP}$ is the only approach that has been proven to control corrosion in high chloride environments (Mudd, et al. 1988). Cathodic protection combined with concrete restoration, especially when 
using thermal-sprayed anodes for a more uniform distribution of current to the rebar, can minimize structural effects of existing chloride-induced corrosion damage and prevent future corrosion damage if properly maintained.

Thermal sprayed Zn anodes are increasingly being used in SACP and ICCP systems designed to extend the service lives of bridges. Thermal spray technology has improved, particularly with respect to metal spray rates, spray efficiencies, and operator mobility. Anode application costs have decreased and contractors are more experienced with their application. The Federal Highway Administration (FHWA) (Jackson 1997) states that CP is now more affordable than ever. In recent years, the cost of rehabilitating and protecting bridges with $\mathrm{CP}$ has fallen by as much as one-half and there are more than 500 bridges in North America with installed CP systems. Zn coatings have been thermal-sprayed on a number of reinforced concrete bridges as large-area consumable anodes (Apostolos, Parks and Carello 1987; Powers, Sagues and Murase 1992; Cramer, et al. 2002a).

Early applications of thermal-sprayed $\mathrm{Zn}$ anodes required the concrete surface be kept at $21^{\circ} \mathrm{C}$ $\left(70^{\circ} \mathrm{F}\right)$ or higher to keep it dry and the use of supplemental heating immediately prior to $\mathrm{Zn}$ application to bring the concrete surface temperature to about $120^{\circ} \mathrm{C}\left(250^{\circ} \mathrm{F}\right)$ to achieve a good bond between the anode and concrete (Brousseau, Arnott and Dallaire 1993). Research at that time (Brousseau, Arnott and Baldock 1994a; Brousseau, et al. 1994b) had shown that a high initial bond strength was achieved by low moisture levels on the concrete, high concrete surface temperatures, a minimum of exposed aggregate, and the absence of surface contamination. Brousseau proposed that the highest possible initial bond strength should be obtained because there is loss of coating adhesion during the subsequent cathodic protection process (Brousseau, Arnott and Baldock 1994a).

As further background for the present project, it is instructive to understand that the corrosion of rebar is the result of a natural battery where the rebar is consumed by the flow of current between anodic and cathodic sites on the rebar. In reinforced concrete bridges, the cathodic sites are typically formed by the reduction of dissolved oxygen to form hydroxyl ions. If an equal amount of current is applied to the rebar from an external power source (ICCP) or galvanic couple (SACP) so that the current flows in the opposite direction from the naturally-occurring corrosion reaction, then the corrosion stops (Apostolos, Parks and Carello 1987). This is the basis for cathodic protection. CP was first used to reduce the corrosion of copper-sheathed hulls on British Navy ships by Sir Humphrey Davy in 1824 (Uhlig 1977). CP is regularly used today in hot water heaters, automobiles, pipelines, bridges, and for partially and fully immersed marine structures (ships, pipelines and drilling platforms).

Cathodic protection was first applied to above-ground reinforced concrete structures in 1957 as part of an experimental program investigating ways to repair highway bridge decks suffering severe chloride-induced corrosion damage resulting from the application of de-icing salts (Stratfull 1959). Anodes for these applications consisted of embeddable wires, strips or mesh with a limited ability to distribute current uniformly to the rebar. Slotted anode systems generally consisted of platinized wire strands or carbon fibers embedded in grooves cut in cementitious grouts (Wyatt 1989). The anodes typically operated at high current densities and produced a correspondingly high acidity at the anode-concrete interface. Chlorine evolution at inert anodes was possible at relatively low concentrations of $\mathrm{Cl}$ ions (Shreir and Hayfield 1986). 
Later advancements in anode technology included conductive paint anodes. It was not until the $1980 \mathrm{~s}$ that thermal-sprayed metal anodes were developed. These anodes provide a more uniform current distribution to the rebar while conforming to the shape of the structure. For $\mathrm{Zn}$ anodes, the Concrete Society predicted (Concrete Society 1989) a service life of 10 years for a 200 micron (8 mils) thick coating at a current density of $0.007 \mathrm{~A} / \mathrm{m}^{2}$, a consumption rate of 808 $\mathrm{Ah} / \mathrm{kg}$, and an efficiency factor of 2 (Weale 1992).

An inevitable consequence of $\mathrm{CP}$ of reinforced concrete structures is acidification, or reduced alkalinity, of the cement paste adjacent to the anode (Weale 1992). Accelerated and long-term testing of CP systems has confirmed the production of anode reaction products that contribute to acidification of the anode-concrete interface and local modification of the cement paste (Schell, Manning and Clear 1984; Mussinelli, Tettamanti and Pedeferri 1987). Accelerated testing of mesh anodes in concrete has resulted in rapid failure of the concrete due to acidification (Bennett and Martin 1987). The $\mathrm{pH}$ at the anode-concrete interface of an embedded activated Ti mesh anode fell to $\mathrm{pH} 10$ within 40 days at $0.1 \mathrm{~A} / \mathrm{m}^{2}$, to $\mathrm{pH} 8.7$ at $1 \mathrm{~A} / \mathrm{m}^{2}$, and $\mathrm{pH} 6$ at $2 \mathrm{~A} / \mathrm{m}^{2}$ (Weale 1992).

Another effect of CP is the redistribution of chlorides in the concrete between the rebar (cathode) and the anode. While measured chloride profiles have indicated that little chloride migration occurred at low current densities of $0.01 \mathrm{~A} / \mathrm{m}^{2}$, migration away from the rebar and general chloride depletion in its vicinity were observed at $0.05 \mathrm{~A} / \mathrm{m}^{2}$, and even more so at $0.222 \mathrm{~A} / \mathrm{m}^{2}$ (Polland and Page 1988). Chloride migration was also noted during application of CP to concrete specimens using an activated Ti mesh anode at current densities in the range of 0.1 to 2 $\mathrm{A} / \mathrm{m}^{2}$ (Mussinelli, Tettramanti and Pedeferri 1987) with chloride depletion within $10 \mathrm{~mm}$ of the rebar and chloride accumulation within $10 \mathrm{~mm}$ of the anode. Similar results have been obtained in accelerated testing using thermal-sprayed $\mathrm{Zn}$ anodes on concrete exposed 40 years to a marine environment (Cramer, et al. 2000) and by modeling $\mathrm{Cl}$ transport in concrete in the presence of the potential gradient produced by CP (Cramer, et al. 2000; Cramer, et al. 2002a). Total chloride concentration was reduced at the rebar and increased at the anode, with salt emerging from the concrete and crusting on the surface of the thermal-sprayed zinc anode.

During CP with a thermal-sprayed $\mathrm{Zn}$ anode, a white corrosion product was observed to develop at the interface between the $\mathrm{Zn}$ and cement paste (Weale 1992). With formation of the white corrosion product, the $\mathrm{Zn}$ coating became increasingly less adherent, leaving a layer of corrosion product adhering to the cement paste (Weale 1992). Zn migration was enhanced by $\mathrm{CP}$, and $\mathrm{Zn}$ ions accumulated in the cement paste adjacent to the cathode (Weale 1992). The $\mathrm{Zn}$ to concrete adhesive bond improved initially with the formation of $\mathrm{Zn}$ hydroxides but decreased in time when the thickness of the corrosion product layer exceeded a critical value (Weale 1992). Values of the $\mathrm{pH}$ in the corrosion product were in the range $\mathrm{pH} 8$ to 10 (Weale 1992). X-ray diffraction (XRD) showed the $\mathrm{Zn}$ corrosion product was a microcrystalline complex form of zinc hydroxide, or white rust (Weale 1992). Other minerals found in the corrosion product included: $\mathrm{Zn}$ hydroxychloride or $\mathrm{ZnCl}_{2} \cdot 4 \mathrm{Zn}(\mathrm{OH})_{2}$ [an alternative formula is $\left.\mathrm{Zn}_{5}(\mathrm{OH})_{8} \mathrm{Cl}_{2}\right)$ ] and simonkolleite, $\mathrm{Zn}_{5}(\mathrm{OH})_{8} \mathrm{Cl}_{2} \cdot \mathrm{H}_{2} \mathrm{O}$.

Several studies have used high current densities over short periods in an effort to simulate longterm CP operating results (Apostolos 1984; Mussinelli, Tettamanti and Pedeferri 1987; Kramer 1989). A study of rebar bond loss in concrete due to applied current indicated that cumulative 
current density or total electrical charge per unit area was the critical factor in determining the bond strength (Vrable 1977).

\subsection{PROBLEM DEFINITION}

The cost of applying thermal-sprayed $\mathrm{Zn}$ anodes varies from bridge to bridge (Holcomb and Cryer 1998). In Oregon, part of the cost is related to difficult access at the projects; part is related to stringent Oregon DOT surface preparation and bond strength requirements resulting from the premise that high initial bond strength would yield anodes that remain bonded to the concrete for a long time. To assure success in complying with these specifications, extensive training is given to the contractors, anode applicators, and inspectors. Training, strict environmental controls, and stringent surface preparation requirements increased the cost of applying the $\mathrm{Zn}$ anode. Preheating the surface to achieve high initial bond strength alone contributed about $16 \%$ to the cost of anode application in early anode installations.

$\mathrm{Zn}$ minerals form at the anode-concrete interface as the anode protects the rebar. This mineral layer can affect the anode adhesion to the concrete and, hence, the long-term ability of the anode to adhere to a bridge. The effort to get high initial bond strength may be of little benefit if a relatively thin layer of zinc minerals then degrades the bond. The mineral layer also contains minerals that are electrically insulating in nature and, therefore, could affect the current carrying capacity of the anode. Furthermore, TS Zn anodes for CP systems are a relatively new technology and the factors that affect service life have not been identified nor has the long-term performance of the anodes been demonstrated.

The initial purpose of the research was twofold. The first was to understand whether the benefits of high initial anode bond strength were realized throughout the service life of the TS Zn anode. The second was to understand the anode bonding mechanism to provide a basis for estimating the effects of electrochemical aging on anode service life. The results of the research would allow the impact of initial bond strength on anode service life to be quantified and the investment in high initial bond strength to be evaluated. As the research progressed, additional issues related to the newness of the technology and the need to understand long-term anode performance became apparent. Principle among these were the effect of chemistry of the anodeconcrete interface on long-term performance of the anode, ways to determine the condition of the anode while in service, and ways to predict future performance of the anode.

\subsection{CHEMICAL AND ELECTROCHEMICAL REACTIONS DURING CP}

Corrosion of rebar in concrete is usually initiated by the action of chloride ions disrupting the normal passive film that forms on iron at alkaline $\mathrm{pH}$ values, typically 12-13 (Broomfield 1997). The oxidation reaction of the steel involves the formation of ferrous ions according to reaction $1-1$.

$$
\mathrm{Fe} \rightarrow \mathrm{Fe}^{2+}+2 \mathrm{e}^{-}
$$


ICCP and SACP are often used to slow or stop reaction 1.1. This is achieved by supplying electrons to the structure to be protected, i.e., causing the reverse of reaction 1.1 to occur. An applied potential (ICCP) or a more electronegative metal coupled to the structure (SACP) forces electrons from a sacrificial anode (the $\mathrm{Zn}$ coating) through the circuit to the rebar, while a concurrent net flow of positive charge flows through the electrolyte (the concrete) to the rebar.

At the alkaline conditions existing in uncontaminated concrete, $\mathrm{Zn}$ dissolves to form bizincate ions (Pourbaix 1966; Zhang 1996). However, at CP conditions the anode-concrete interface becomes increasingly less alkaline (i.e., acidified) and the anode reaction is that given by reaction $1-2$.

$$
\mathrm{Zn} \rightarrow \mathrm{Zn}^{2+}+2 \mathrm{e}^{-}
$$

Zinc hydroxide precipitates at the anode-concrete interface as in reaction 1.3 to form what is referred to generically referred to in this report as the "Zn oxide layer."

$$
\mathrm{Zn}^{2+}+2 \mathrm{H}_{2} \mathrm{O} \rightarrow \mathrm{Zn}(\mathrm{OH})_{2}+2 \mathrm{H}^{+}
$$

It is apparent from this reaction that the interface $\mathrm{pH}$ will decrease as CP continues. Under drying conditions zinc hydroxide may convert to zinc oxide by a dehydration reaction as in reaction 1.4 .

$$
\mathrm{Zn}(\mathrm{OH})_{2} \rightarrow \mathrm{ZnO}+\mathrm{H}_{2} \mathrm{O}
$$

Secondary mineralization reactions may occur as the zinc hydroxide, reaction 1-3, or zinc oxide, reaction 1-4, combines with other constituents of the environment such as chloride, sulfate or carbonate ions, or minerals in the cement paste to form more complex minerals. As time progresses, the more stable of these minerals will predominate over the less stable minerals in the "Zn oxide layer."

At the cathode, which under $\mathrm{CP}$ is the rebar, the usual reaction is the reduction of oxygen to the hydroxyl ion, reaction 1-5.

$$
\mathrm{O}_{2}+2 \mathrm{H}_{2} \mathrm{O}+4 \mathrm{e}^{-} \rightarrow 4 \mathrm{OH}^{-}
$$

Thus, the rebar environment becomes more alkaline with time and the conditions that again favor passivation of the steel are established. A further benefit of $\mathrm{CP}$ is that $\mathrm{Cl}$ ions are transported away from the rebar under the influence of the CP potential gradient (Cramer, et al. 2000). The current density requirements to achieve protection in CP systems are usually determined empirically, and a typical range (Fontana and Greene 1978) for rebar in concrete is 0.0011 to $0.0054 \mathrm{~A} / \mathrm{m}^{2}\left(0.1\right.$ to $\left.0.5 \mathrm{~mA} / \mathrm{ft}^{2}\right)$. Typically, polarization or depolarization measurements are made to verify that the steel is in fact protected (Baeckmann, Schwenk and Prinz 1997). 
Bulk anode service lives can be calculated using equation 1-6, a form a Faraday's law, where $t$ is the anode life (y), $I_{a}$ is the anode current output (A), $W$ is the weight of the anode $(\mathrm{kg}), f$ is a utilization factor (value between 0 and 1), $e$ is an efficiency factor related to the amount of selfcorrosion of the anode (value between 0 and 1 ), and $C_{r}$ is the consumption rate (kg/A-y).

$$
t=W * f * e /\left(I_{a} * C_{r}\right)
$$

Included in consumption rate, $C_{r}$, in equation 1.6 is the Faraday constant $(96,500$ Coulombs/equivalent). Equation 1.6 can be modified to compute the amount of zinc consumed at any point in the life of the anode, e.g., either $W$ or $f$ or the product $W^{*} f$ can be computed when the time to disbondment is known. 


\subsection{EXPERIMENTAL PROCEDURES}

\subsection{LABORATORY ANODE AGING STUDIES}

Two laboratory experiments were conducted on thermal-sprayed zinc (TS Zn) anodes as part of this study. The purpose of the first experiment was to determine, for periodically wetted TS Zn anodes (Covino, et al. 1996a; Covino, et al. 1996b; Bullard, et al. 1997b; Holcomb, et al. 1996; Covino, et al. 1995; Covino, et al. 1997a):

- the relationship between $\mathrm{Zn}$ oxide layer thickness and the zinc-to-concrete bond strength,

- the effect of original zinc-to-concrete bond strength on the long-term bond strength,

- the initial $\mathrm{Zn}$ bond mechanism and the bond mechanism after $\mathrm{Zn}$ reaction product growth at the zinc-concrete interface,

- the chemical composition of the $\mathrm{Zn}$ reaction product at the zinc-concrete interface, and

- the effect of preheating on long-term bond strength of TS Zn anodes to concrete.

The purpose of the second experiment was to verify the results from the first experiment for short electrochemical ages, and to determine the effect not wetting the anode would have on TS $\mathrm{Zn}$ anode performance (Bullard, et al. 1997a).

Concrete slabs were cast so as to physically, mechanically, and electrochemically approximate a section of bridge substructure in a typical arc-sprayed $\mathrm{Zn}$ anode $\mathrm{CP}$ installation. The concrete mix design included two levels of dissolved chloride to simulate marine exposed concrete. A steel mesh was embedded in the slab to simulate the rebar and to act as the cathode. After curing, the slab surfaces were sand blasted and surface prepared following Oregon DOT specifications.

Immediately prior to arc-spraying with $\mathrm{Zn}$, the top surface of half the slabs was preheated to between $120-160^{\circ} \mathrm{C}\left(250-320^{\circ} \mathrm{F}\right)$. The top surface of the remaining slabs was not preheated before spraying with $\mathrm{Zn}$. The thermal-sprayed $\mathrm{Zn}$ anodes were then electrochemically aged at an accelerated rate using a current density (based on the nominal concrete surface area) of 0.032 $\mathrm{A} / \mathrm{m}^{2}\left(3 \mathrm{~mA} / \mathrm{ft}^{2}\right)$. This is approximately 15 times the current density used by Oregon DOT to protect its coastal bridges. Slabs were periodically removed from the experiment to measure the bond strength of the $\mathrm{Zn}$ coating and to determine the chemistry of the zinc-concrete and steelconcrete interfaces.

Conditions within the slabs differed from those expected to exist within coastal bridges in two important ways. The chloride was uniformly distributed throughout the laboratory slabs, obtained by dissolving sodium chloride in the mix water prior to forming the concrete, rather than diffused into the concrete from the outer surface, which would have resulted in a typical Fickian distribution of chloride. The salt distribution obtained by mixing may also put chloride 
in locations not readily accessible by diffusion, i.e., isolated pores and blind channels. Secondly, the impressed current density was higher in the laboratory experiment than the approximately $0.0022 \mathrm{~A} / \mathrm{m}^{2}\left(0.2 \mathrm{~mA} / \mathrm{ft}^{2}\right)$ used on the Oregon DOT bridges (Covino, et al. 1995). This can have the effect of altering transport processes relative to electrochemical and chemical process, so as to give results that vary, at least in fine detail, from those being approximated by the experiment. For example, effects from the accumulation of $\mathrm{Zn}$ minerals at the anode-concrete interface and acidification of this interface may be less apparent at the longer times associated with cathodically protected bridges. Because of these potential differences, a considerable effort was made to compare results from laboratory experiments to the performance of field $\mathrm{Zn}$ anode $\mathrm{CP}$ systems to help validate the larger details of the laboratory results.

\subsubsection{Concrete slab construction}

Concrete slabs for both experiments, measuring $0.23 \mathrm{~m} \mathrm{x} 0.33 \mathrm{~m} \times 0.05 \mathrm{~m}$ ( 9 in $\times 13$ in $\times 2$ in), were cast with No. 16 expanded steel mesh covering the full dimensions of the form bottom. Steel mesh was used in place of rebar because of its smaller size to provide uniform current density distribution to all areas of the $\mathrm{Zn}$ anode. Steel wire was welded to the mesh and extended above the top surface of the form to provide an electrical connection to the mesh. A thin layer of concrete was spread in the bottom of the form prior to placing the mesh to ensure that there were no voids behind the mesh. The cover concrete over the steel mesh was $3.2 \mathrm{~cm}$ (1.25 in) thick. A schematic of the slab construction is shown in Figure 2.1. The dates for construction, curing, thermal spraying, adhesion testing, and electrochemical aging of the slabs for both experiments are given in Table 2.1.

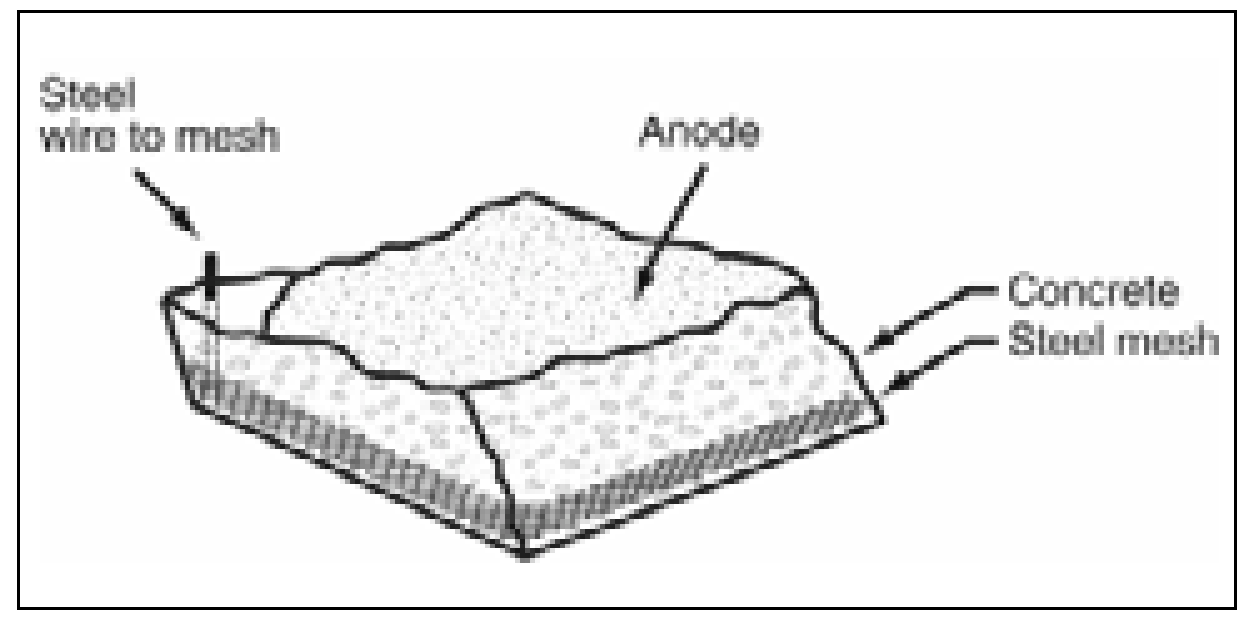

Figure 2.1: Design of the laboratory concrete slabs with embedded steel mesh cathode 
Table 2.1: Timeline for laboratory experiments

\begin{tabular}{l|l|l}
\hline Fabrication Steps & First Experiment & Second Experiment \\
\hline Concrete Slabs Cast & July 20-22, 1994 & September 7-11, 1995 \\
\hline Concrete Slabs Wet Cured & July 23-August 14, 1994 & September 12-October 12, 1995 \\
\hline Thermal spray Zn Applied to Slabs & September 26-27, 1994 & March 14, 1996 \\
\hline Slabs delivered to ARC & October 1, 1994 & Not available \\
\hline Adhesion Testing of Anode & November 15, 1994 & June 11, 1996 \\
\hline Aging Experiment Started & January 9, 1995 & June 24, 1996 \\
\hline Aging Experiment Completed & April 30, 1996 & October 19, 1996 \\
\hline
\end{tabular}

The concrete mix was intended to approximate that used in Oregon DOT's older coastal bridges. It is shown in Table 2.2 and has been published elsewhere (Bullard, et al. 1997a). The resulting water-cement $(\mathrm{w} / \mathrm{c})$ ratio of 0.48 is similar to that of Oregon DOT older coastal bridges. The coarse aggregate size was $4.75 \mathrm{~mm}(0.20 \mathrm{in})$ to $6.4 \mathrm{~mm}(0.25 \mathrm{in})$, and is smaller than aggregate typically used in bridge construction. This change in aggregate size was necessary to obtain a more uniform current distribution in the slab between the $\mathrm{Zn}$ anode and the steel mesh cathode than would have been possible with larger aggregate. Sodium chloride was added to the concrete mix to approximate marine exposed concrete. On a per cubic meter of concrete basis, the salt concentration in a majority of the slabs was $3 \mathrm{~kg} \mathrm{NaCl} / \mathrm{m}^{3}\left(5 \mathrm{lb} \mathrm{NaCl} / \mathrm{yd}^{3}\right)$; a few contained 1.2 $\mathrm{kg} \mathrm{NaCl} / \mathrm{m}^{3}\left(2 \mathrm{lbNaCl} / \mathrm{yd}^{3}\right)$ to test the effect of chloride concentration on the corrosion chemistry at the zinc-concrete interface.

Table 2.2: Concrete mix design for laboratory slabs per cubic yard of concrete.

\begin{tabular}{|c|c|c|}
\hline Component & Weight, kg & Weight, lb. \\
\hline Cement & 259 & 570 \\
\hline Coarse aggregate $^{1}$ & 704 & 1550 \\
\hline Sand $^{1}$ & 738 & 1624 \\
\hline Water & 125 & 275 \\
\hline
\end{tabular}

\subsubsection{Concrete surface preparation}

Following Oregon DOT specifications, the slabs were cured three to four weeks in a moist room, then air dried for one week, Table 2.1. Prior to applying the Zn coating, the tops of the slabs were sandblasted to remove the weak cement paste or laitance layer on the surface, expose a small amount of aggregate, and give the surface a medium sandpaper texture. Half of the slabs 
were preheated to between $120-160^{\circ} \mathrm{C}\left(250-320^{\circ} \mathrm{F}\right)$ with an oxy-acetylene torch immediately prior to thermal-spraying; half were not preheated before spraying. An optical pyrometer was used to measure surface temperatures during preheating of the concrete slabs for the first and the second experiments.

\subsubsection{Metallized anode application}

The twin-wire arc-spray process was used to apply the $\mathrm{Zn}$ anodes to the concrete surface (Covino, et al. 1995). In this process, an arc is created that melts two $\mathrm{Zn}$ wires that are brought into close proximity with each other. The molten $\mathrm{Zn}$ is then atomized into droplets by a jet of compressed gas and propelled to the concrete surface. There the droplets coalesce, penetrate into surface roughness, and then freeze into a solid layer of Zn composed of many small "splats" of $\mathrm{Zn}$. The resulting coating is held in place on the concrete surface by a mechanical bond. Compressed air is typically used to atomize the molten $\mathrm{Zn}$ droplets and propel them to the surface. Figure 2.2 shows twin-wire arc-spray equipment being used to apply an anode to a bridge on the Oregon coast.

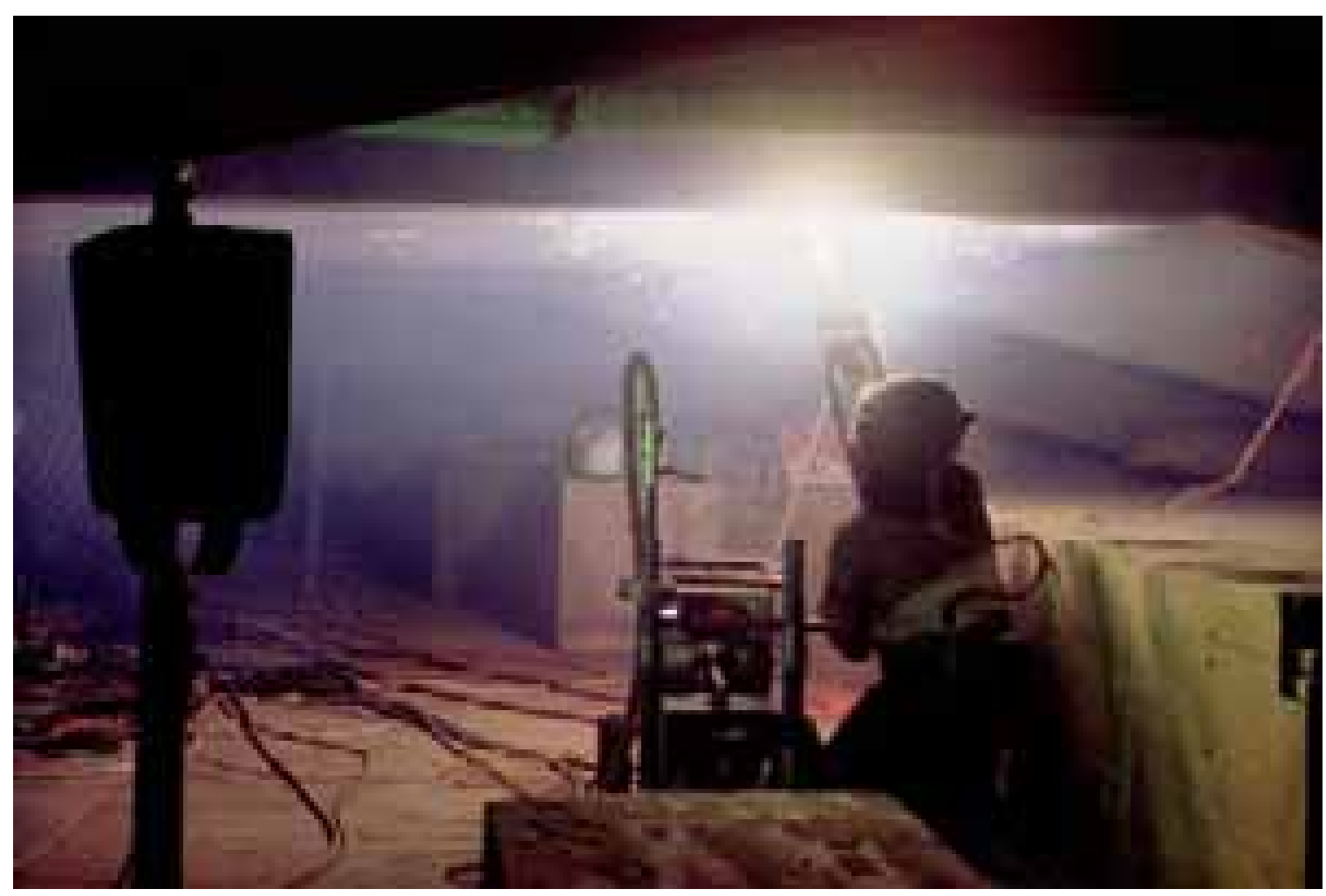

Figure 2.2: Thermal spraying $\mathrm{Zn}$ on a bridge substructure using the twin-wire arc-spray process

The twin-wire arc-spray equipment is shown in Figure 2.3 and includes the wire feed system and spray gun or nozzle. The spray parameters were: $265 \mathrm{~A}$ (DC); $25 \mathrm{~V}$ (DC); air pressure, 0.65 $\mathrm{MPa}$ (105 psi); spray distance, 150 - $230 \mathrm{~mm}$ (6 - 9 in); spray angle, normal to surface; $\mathrm{Zn}$ wire 
diameter, $4.8 \mathrm{~mm}$ (3/16-in); spray rate, $14.5 \mathrm{~kg}$ zinc/hr (32 lbs zinc/hr). A custom designed and constructed programmable X-Y traversing system, Figure 2.4, was used to control the movement of the spray head to obtain a uniform $\mathrm{Zn}$ anode coating thickness on the concrete slabs. The zinc anode typically was $0.5 \mathrm{~mm}(0.020 \mathrm{in})$ thick for the laboratory studies.

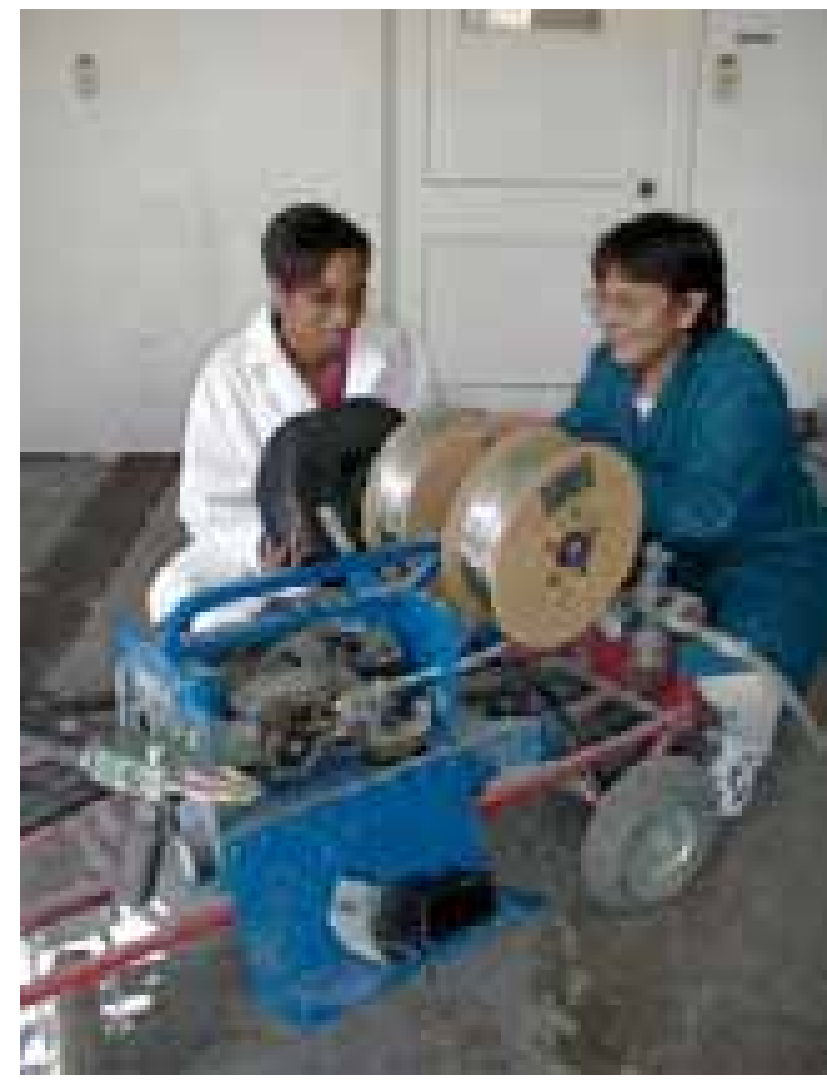

Figure 2.3: General view of twin-wire arc-spray equipment showing wire spools, the wire-feed drive, and the spray gun

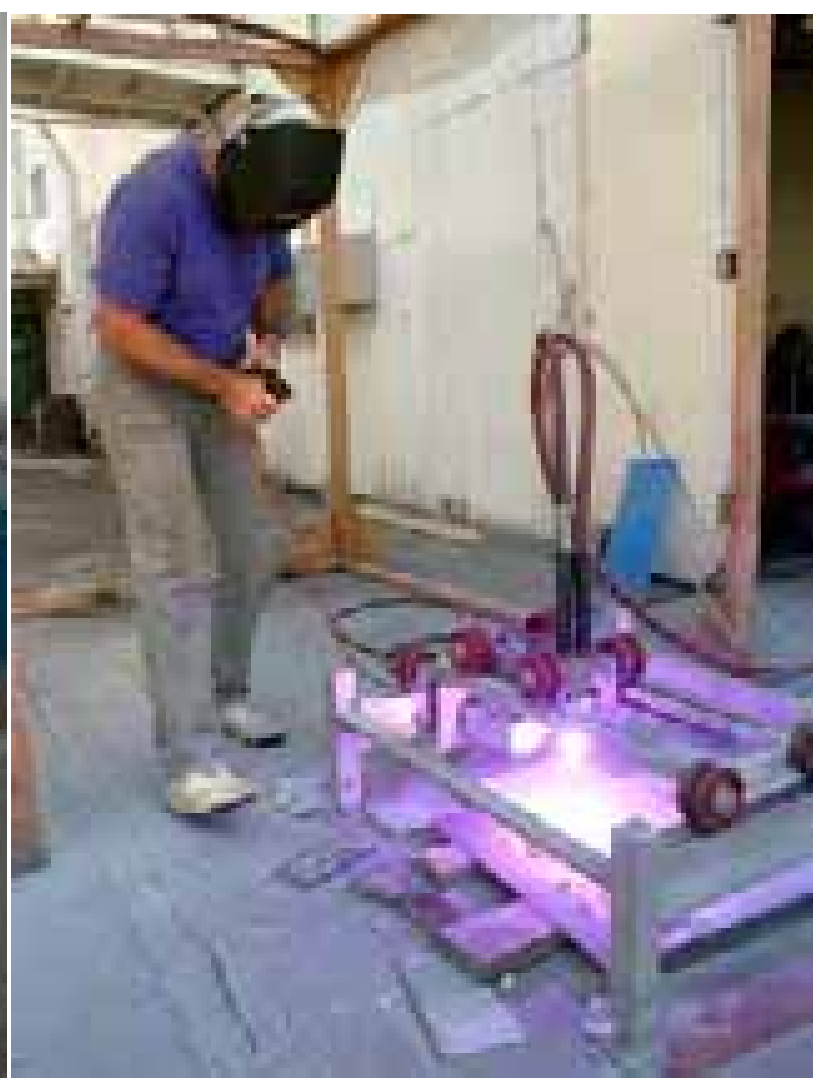

Figure 2.4: Oregon DOT robotic x-y traversing system used to apply TS $\mathrm{Zn}$ anode to concrete slabs

Typical parameters for arc-spraying $\mathrm{Zn}$ and their effect on deposition rate and efficiency are listed in Table 2.3 (Rogers 2000). The table shows the effect of wire size and current on deposition rate and efficiency. Note that deposition efficiency for the smaller wire size decreases with increasing current due to proportionally larger over-spray losses. Deposition efficiency increased for the larger diameter wire. 
Table 2.3: Twin-wire arc-spray application parameters, spray rates, and deposition efficiencies. (Rogers 2000)

\begin{tabular}{|c|c|c|c|c|c|c|c|c|c|c|c|c|}
\hline \multirow[t]{2}{*}{ Wire type } & \multirow{2}{*}{$\begin{array}{l}\text { Wire } \\
\text { size } \\
\text { inch }\end{array}$} & \multirow[t]{2}{*}{$\begin{array}{c}\text { DC } \\
\text { amps }\end{array}$} & \multirow[t]{2}{*}{$\begin{array}{c}\text { DC } \\
\text { volts }\end{array}$} & \multicolumn{2}{|c|}{$\begin{array}{l}\text { Spray } \\
\text { rate }\end{array}$} & \multirow{2}{*}{$\begin{array}{c}\text { Deposition } \\
\text { Efficiency } \\
\%\end{array}$} & \multicolumn{2}{|c|}{$\begin{array}{l}\text { Deposition } \\
\text { rate }\end{array}$} & \multicolumn{2}{|c|}{ Wire density } & \multicolumn{2}{|c|}{$\begin{array}{c}\text { Deposition volume } \\
\text { Rate }\end{array}$} \\
\hline & & & & $\mathrm{lb} / \mathrm{hr}$ & $\mathrm{kg} / \mathrm{hr}$ & & $\mathbf{l b} / \mathbf{h r}$ & $\mathrm{kg} / \mathrm{hr}$ & $\mathrm{lb} / \mathbf{i n}^{3}$ & $\mathrm{~g} / \mathrm{cm}^{3}$ & $\mathrm{in}^{3} / \mathrm{hr}$ & $\mathrm{cm}^{3} / \mathrm{hr}$ \\
\hline Zinc & $1 / 8$ & 250 & 27 & 57.2 & 25.9 & $58.0 \%$ & 33.2 & 15.0 & 0.25 & 7.14 & 132.7 & 2180 \\
\hline Zinc & $1 / 8$ & 350 & 27 & 83.0 & 37.6 & $58.0 \%$ & 48.1 & 21.8 & 0.25 & 7.14 & 192.6 & 3160 \\
\hline Zinc & $1 / 8$ & 400 & 27 & 91.0 & 41.2 & $58.0 \%$ & 52.8 & 23.9 & 0.25 & 7.14 & 211.1 & 3460 \\
\hline Zinc & $1 / 8$ & 450 & 27 & 102.0 & 46.2 & $53.6 \%$ & 54.7 & 24.8 & 0.25 & 7.14 & 218.7 & 3590 \\
\hline Zinc & $1 / 8$ & 600 & 27 & 129.0 & 58.4 & $50.0 \%$ & 64.5 & 29.2 & 0.25 & 7.14 & 258.0 & 4230 \\
\hline Zinc & $3 / 16$ & 250 & 27 & 84.7 & 38.4 & $61.8 \%$ & 52.3 & 23.7 & 0.25 & 7.14 & 209.4 & 3430 \\
\hline Zinc & $3 / 16$ & 350 & 27 & 113.0 & 51.2 & $64.8 \%$ & 73.2 & 33.2 & 0.25 & 7.14 & 292.9 & 4800 \\
\hline Zinc & $3 / 16$ & 400 & 27 & 124.0 & 56.2 & $64.0 \%$ & 79.4 & 36.0 & 0.25 & 7.14 & 317.4 & 5200 \\
\hline Zinc & $3 / 16$ & 450 & 27 & 135.1 & 61.2 & $67.4 \%$ & 91.1 & 41.2 & 0.25 & 7.14 & 364.2 & 5970 \\
\hline Zinc & $3 / 16$ & 600 & 27 & 166.0 & 75.2 & $68.0 \%$ & 112.9 & 51.1 & 0.25 & 7.14 & 451.5 & 7400 \\
\hline
\end{tabular}

The "splat" impact and coating formation processes are shown schematically in more detail in Figure 2.5. Molten metal droplets are propelled to the concrete surface using a compressed gas. The molten droplets impact the surface forming a splat that solidifies relatively quickly. Subsequent metal droplets form splats on top of splats, thus building up the coating thickness. If the metal is easily oxidized, then the metal droplets form an oxide skin that is incorporated into the coating. This does not happen for Zn but has been reported for arc-sprayed Ti (Cramer, et al. 1998; Cramer, et al. 1999 ). Most metals also leave scattered voids between splats during the thermal spray process. 


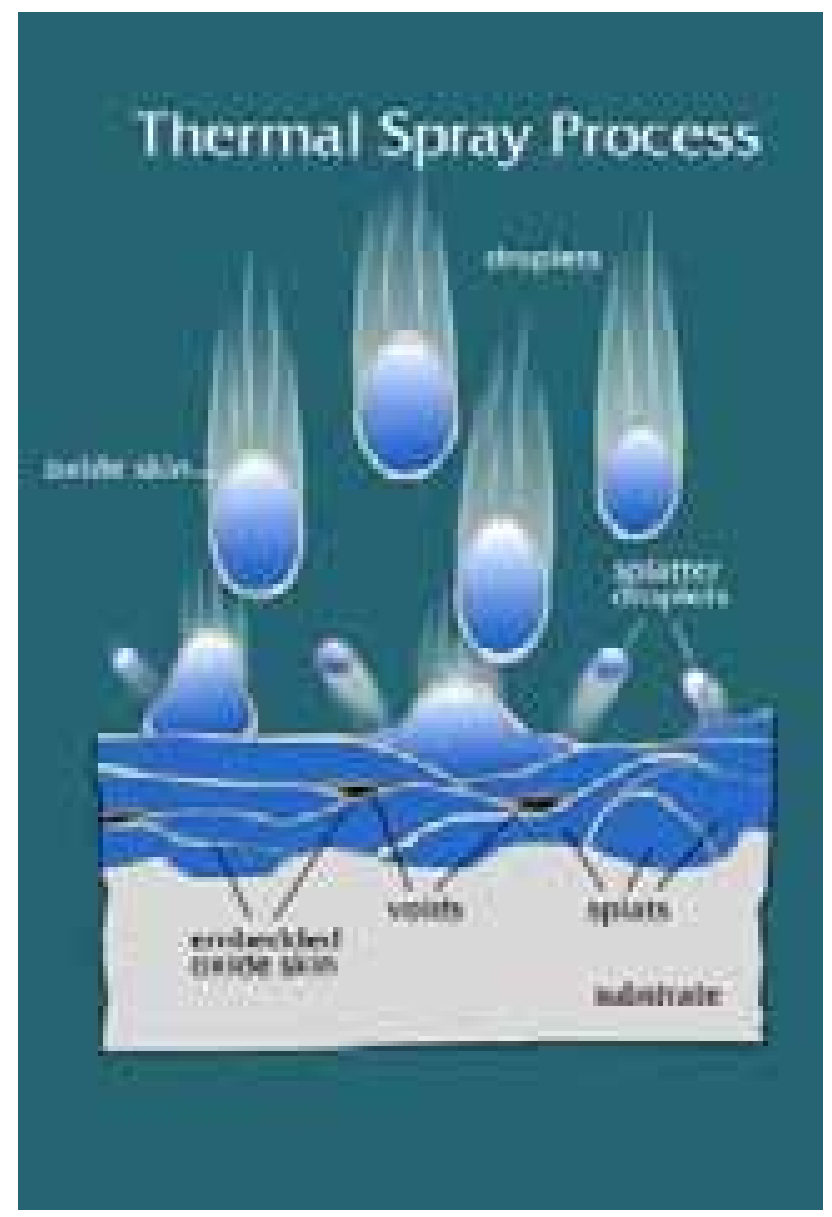

Figure 2.5: Schematic representation of thermal spraying showing the splat (droplet) impact and coating formation processes

\subsubsection{Anode electrochemical aging}

Electrochemical aging of the slabs was conducted in a constant temperature-constant humidity enclosure to keep the slabs from drying out. The temperature was about $24^{\circ} \mathrm{C}\left(75^{\circ} \mathrm{F}\right)$ and the relative humidity varied from 80 to $85 \%$. For purposes of electrochemical aging, the slabs were divided into several groups. Slabs in each group were wired in series, with $\mathrm{Zn}$ as the anode and the steel mesh as the cathode. Figure 2.6 shows concrete slabs being aged in the controlled environment enclosure. Slabs were polarized at a current density of $0.032 \mathrm{~A} / \mathrm{m}^{2}\left(3 \mathrm{~mA} / \mathrm{ft}^{2}\right)$ using constant current power supplies. Total voltage across each group of slabs, the impressed current, and the laboratory temperature were recorded hourly on a data acquisition system to provide long-term performance data for the zinc/concrete/steel electrochemical (CP) system. Figures 2.7 and 2.8 are flow charts that represent the organization of the first and second experiments, respectively. Slab numbers are shown in the boxes. Note that slabs with two different concentrations of $\mathrm{NaCl}$ in the concrete were studied in the first experiment while only one concentration was studied in the second experiment. Table 2.4 shows basically the same information and gives the total number of slabs tested for each configuration and test duration. 

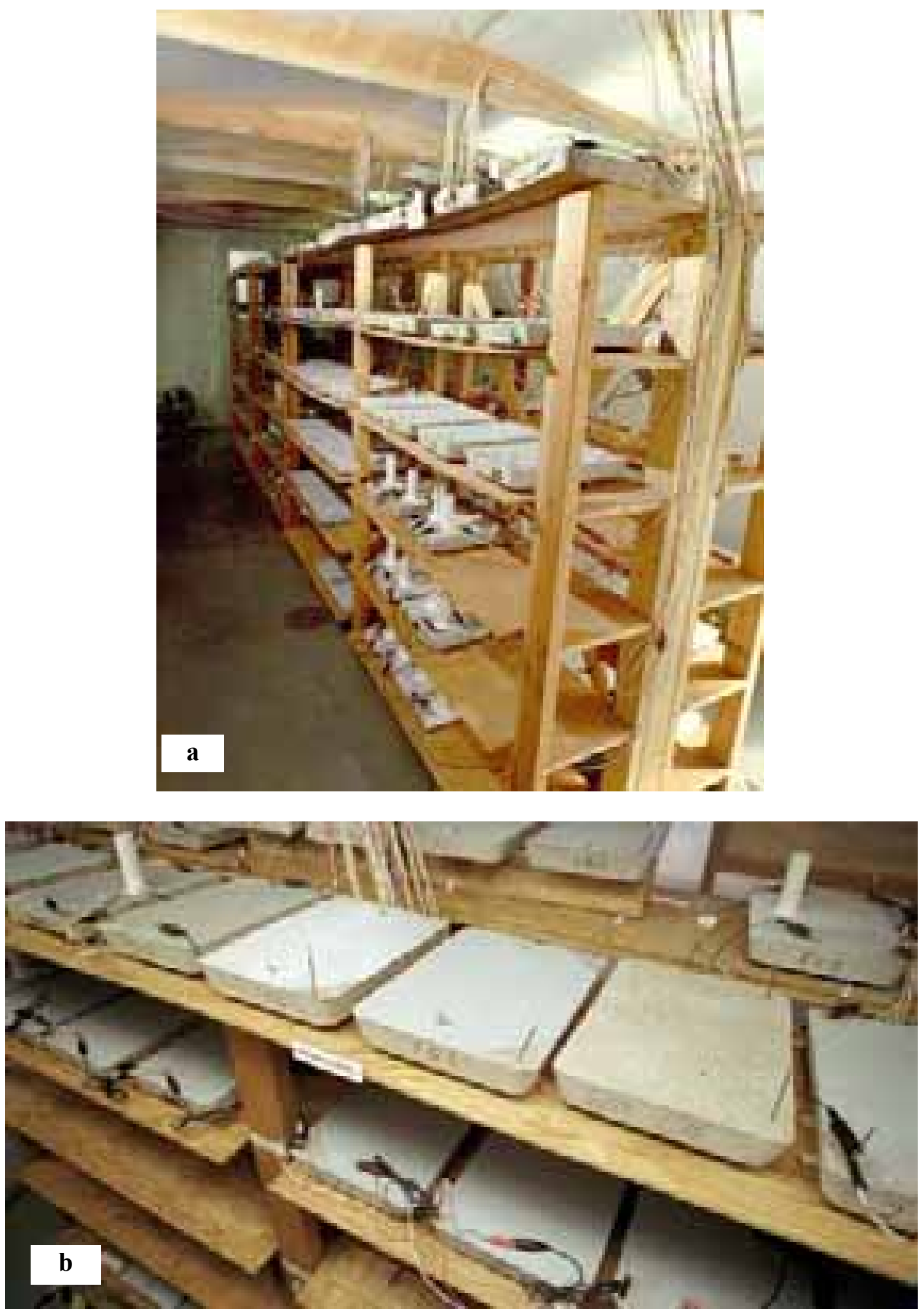

Figure 2.6: Multiple concrete slabs undergoing accelerated electrochemical aging in a controlled humidity enclosure: (a) overall view; (b) close-up of concrete slabs 


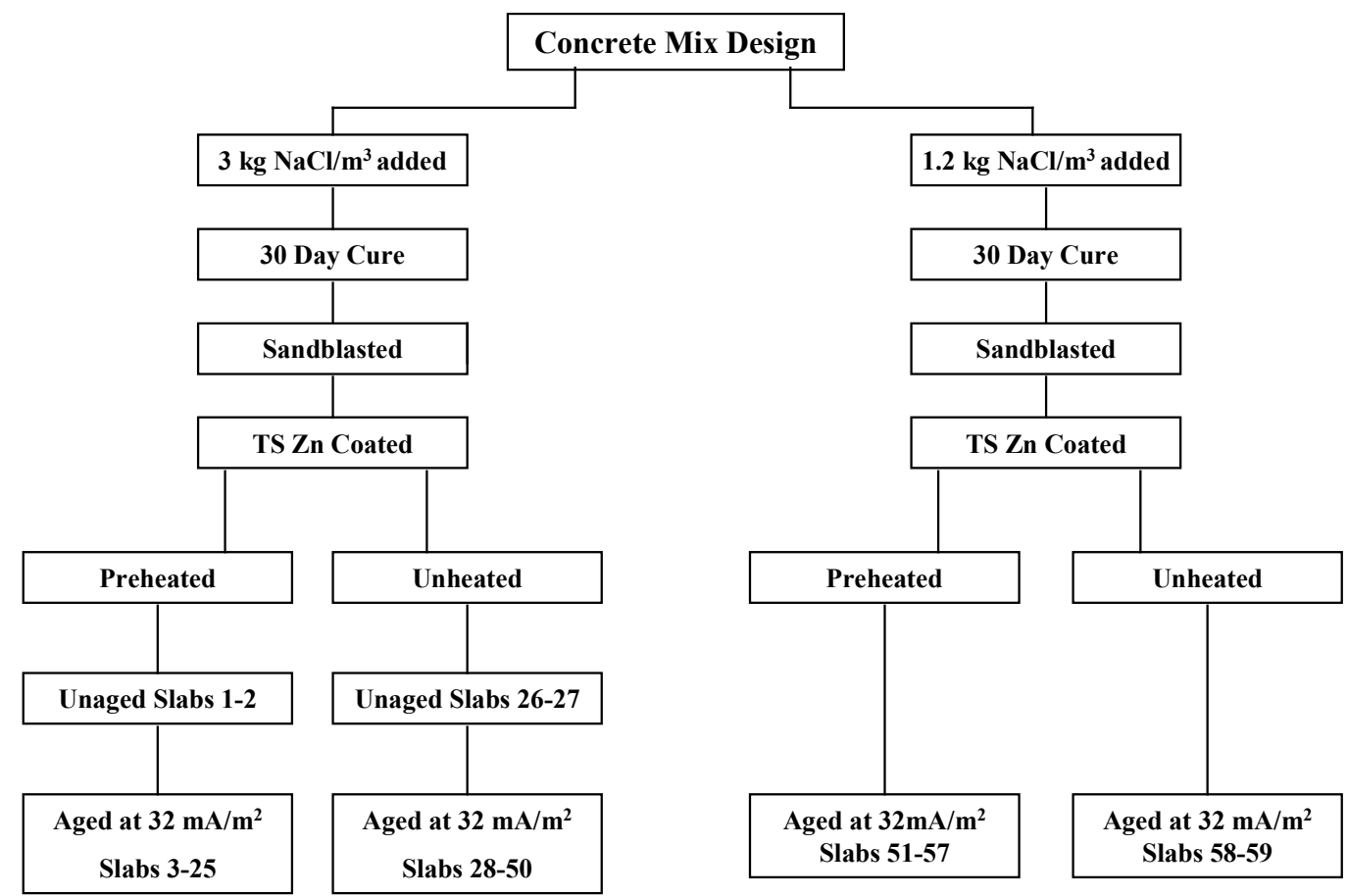

Figure 2.7: Flowchart showing the concrete slab treatments used in the first electrochemical aging experiment

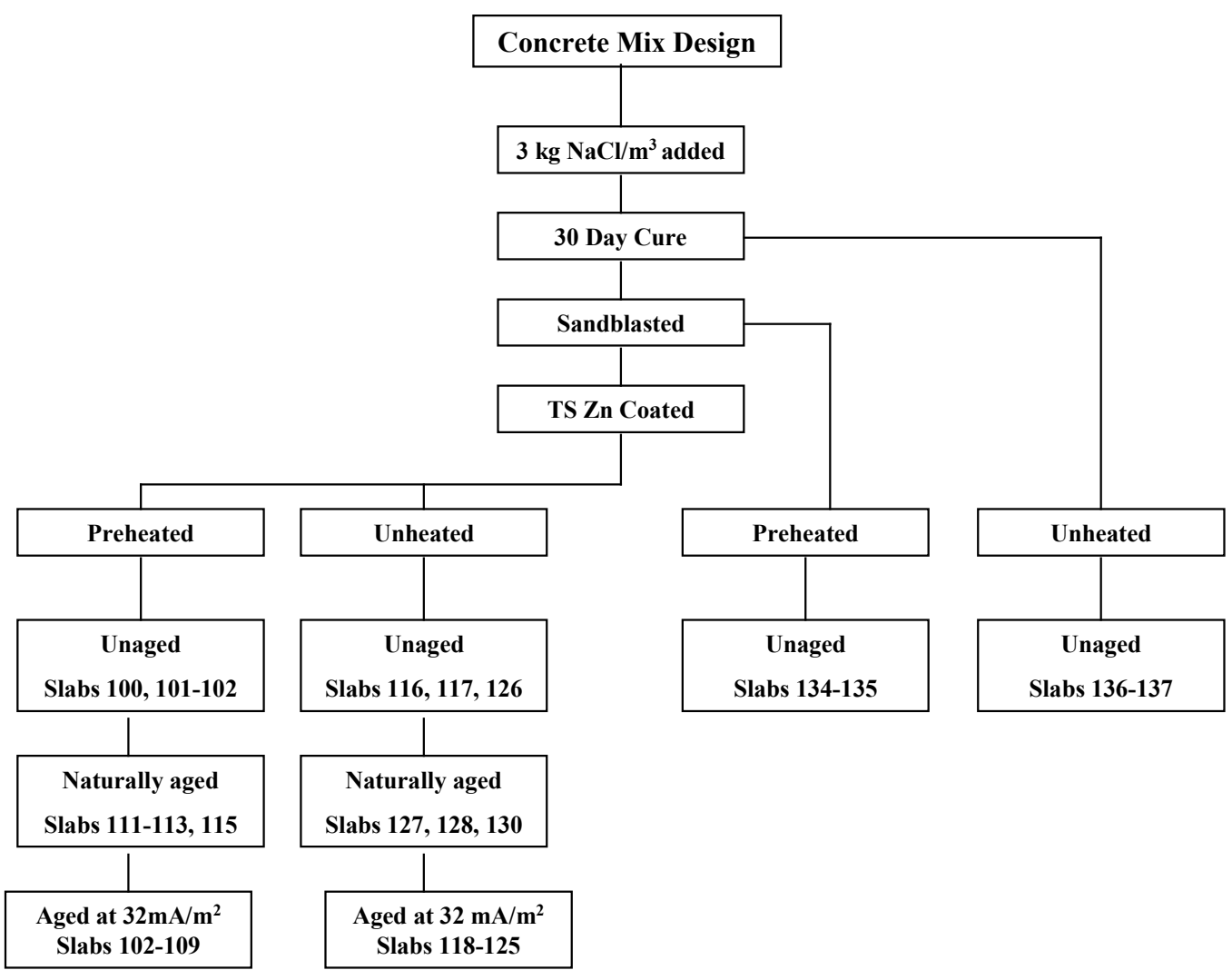

Figure 2.8: Flowchart showing the concrete slab treatments used in the second electrochemical aging experiment 
Table 2.4: Laboratory concrete slabs examined

\begin{tabular}{|c|c|c|c|c|c|c|c|}
\hline \multicolumn{3}{|c|}{ Surface Treatment } & \multirow{2}{*}{$\begin{array}{l}\mathrm{NaCl}, \\
\mathrm{kg} / \mathrm{m}^{3}\end{array}$} & \multicolumn{2}{|c|}{ Number of slabs } & \multirow{2}{*}{ Aging } & \multirow{2}{*}{$\begin{array}{c}\text { Duration of } \\
\text { Test, years }\end{array}$} \\
\hline Sandblasted & Preheated & Zn Coated & & Expt 1 & Expt 2 & & \\
\hline No & No & No & 3 & 0 & 2 & Unaged & 0 \\
\hline Yes & No & No & 3 & 0 & 2 & Unaged & 0 \\
\hline Yes & No & Yes & 3 & 2 & 3 & Unaged & 0 \\
\hline Yes & Yes & No & 3 & 0 & 2 & Unaged & 0 \\
\hline Yes & Yes & Yes & 3 & 2 & 3 & Unaged & 0 \\
\hline Yes & No & Yes & 3 & 0 & 3 & Natural & $0-1$ \\
\hline Yes & Yes & Yes & 3 & 0 & 4 & Natural & $0-1$ \\
\hline Yes & No & Yes & 3 & 22 & 7 & Accelerated & $0-1.3$ \\
\hline Yes & No & Yes & 1.2 & 2 & 0 & Accelerated & $0-1.3$ \\
\hline Yes & Yes & Yes & 3 & 22 & 7 & Accelerated & $0-1.3$ \\
\hline Yes & Yes & Yes & 1.2 & 7 & 0 & Accelerated & $0-1.3$ \\
\hline
\end{tabular}

\subsection{FIELD ANODE AGING STUDIES}

Core samples from bridges with TS Zn anodes, from bridges with galvanized rebar, and from laboratory slabs from a CALTRANS study were analyzed using the Analytical Scanning Electron Microscope (ASEM). The types, number, and chronological age of those samples (anodes or rebar) are listed in Table 2.5. Most of these cores were taken to compare the $\mathrm{Zn}$ concrete interfacial chemistry from a non-accelerated bridge anode sample to those from the accelerated laboratory experiments. The galvanized rebar from the Longbird Bridge were taken to determine how effective the galvanized rebar was after a half century of use. The CALTRANS silane samples were analyzed to determine if exterior coatings on the concrete surface can reduce the chloride-induced corrosion damage of rebar.

Bridge CP zone monitoring data was also evaluated for evidence of trends related to electrochemical aging. The data included zone potentials and current densities, anode bond strength, and anode-concrete interfacial $\mathrm{pH}$ and mineral constituents.

\subsubsection{Cape Creek Bridge (OR)}

The Cape Creek Bridge is located on the Oregon coast south of Cape Perpetua, Figures 1.2 and 1.3. Oregon DOT extensively repaired the bridge in 1991 and then installed thermal sprayed $\mathrm{Zn}$ anodes on the surface for a multi-zone ICCP system. Some ICCP zones were converted to SACP zones following installation because of shorts between the anode and rebar. The CP system was energized in January 1992. Six $5 \mathrm{~cm}$ (2 in) diameter core samples were taken from the bridge in October 1995 representing both ICCP and SACP zones with $\mathrm{Zn}$ on both original concrete and patch concrete. Table 2.5 lists the six samples. Small sections of the cores were cut and mounted in epoxy for microanalysis. 
Table 2.5: Core samples taken from bridges and some laboratory slabs

\begin{tabular}{c|c|c|c}
\hline Location & Description & \# Samples & $\begin{array}{c}\text { Time since CP } \\
\text { installation, y }\end{array}$ \\
\hline Cape Creek Bridge (OR) & ICCP, original & 3 & 3.7 \\
\hline “ & ICCP, patch & 1 & 3.7 \\
\hline “ & SACP, original & 1 & 3.7 \\
\hline Richmond-San Rafael Bridge (CA) & SACP, patch & 1 & 3.7 \\
\hline “ & Band 1, Core 1 & 1 & 12 \\
\hline “ & Band 1, Core 2 & 1 & 12 \\
\hline East Camino Under-crossing (CA) & Band 2, Core 1 & 1 & 12 \\
\hline CALTRANS laboratory silane study & ICCP Soffit & 1 & 12 \\
\hline Longbird Bridge (Bermuda) & Slabs & 4 & 4.9 \\
\hline “ & abutment & 1 & 46 \\
\hline
\end{tabular}

\subsubsection{Richmond-San Rafael Bridge (CA)}

The Richmond-San Rafael Bridge, Figure 2.9, is a major bridge in the northern half of San Francisco Bay on Route 17. The south column of pier 4, Figure 2.10, was thermal sprayed with $\mathrm{Zn}$ in 4 bands (zones) on May 1983. The barrel at the base of the column (on which the upper two researchers are standing) was also thermal sprayed with zinc. The $\mathrm{Zn}$ in each zone was applied by flame spraying to a thickness of approximately $0.22 \mathrm{~mm}(9 \mathrm{mils})$ using an oxyacetylene flame. [However, coatings cross-sections examined by SEM and shown in this report suggest the actual coating thickness was greater, perhaps $0.37-0.49 \mathrm{~mm}(15-20 \mathrm{mils})$.] Initial bond strength of the $\mathrm{Zn}$ to concrete ranged from 1.0-3.4 MPa (150-500 psi) with an average value for 14 measurements of $1.93 \mathrm{MPa}$ (280 psi) (Carello, Parks and Apostolos 1989).

Each band is $1.2 \mathrm{~m}(4 \mathrm{ft})$ in vertical height, surrounds the column, and is separated from the one above and below it by a $15.2 \mathrm{~cm}$ (6 in) gap. The anode on the barrel was operated galvanically. Bands 1 through 4, on the column, were operated as ICCP anodes. The low edge of band 1 is within $3 \mathrm{~m}(10 \mathrm{ft})$ of the water surface and fully exposed to the action of waves and precipitation. Band 4 is higher on the column, partially sheltered from precipitation by the roadbed immediately above it, while fully exposed to the drying effects of the wind. The CP systems were operated and the driving (or operating) voltage and system current for each anode was monitored by CALTRANS continuously for 12 years from 1983 through 1994. In May 1997, bond strength tests were performed on anode bands 1 through 4 on the north and east faces of the south column. Powder samples and $5 \mathrm{~cm}$ ( 2 in) diameter core samples were taken from bands 1 , 2 , and 3 on the north face of the south column and from the footer, Table 2.5. To date, the Richmond-San Rafael thermal-sprayed Zn anodes are the longest operating TS Zn anodes anywhere. 

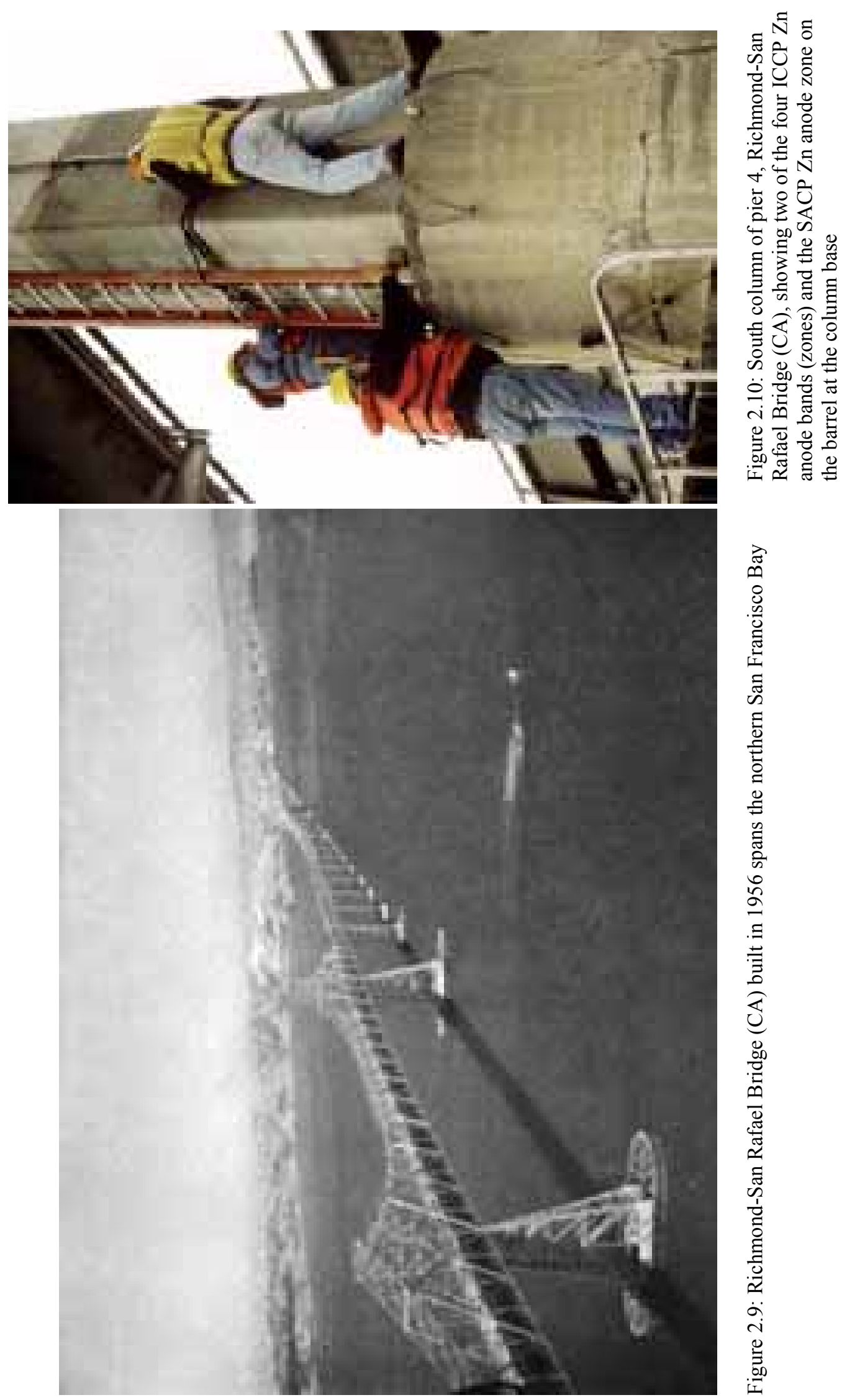


\subsubsection{East Camino Under-crossing (CA)}

The East Camino Under-crossing, part of the California State Highway system, includes the first steel-reinforced concrete bridge deck to be protected with a metallized $\mathrm{Zn}$ anode ICCP system (Carello and Parks 1992). Shown in Figure 2.11, it is located on State Route 50, $10 \mathrm{~km}$ (6 mi) east of Placerville, CA, in the west hills of the Sierra Nevada Mountains at an elevation of $1 \mathrm{~km}$ $(3300 \mathrm{ft})$. It is a $27 \mathrm{~m}(89 \mathrm{ft})$ long, 3 span, reinforced concrete, T-beam structure and was built in 1964. The total deck surface area is approximately $669 \mathrm{~m}^{2}\left(7200 \mathrm{ft}^{2}\right)$. Deicing salts were applied to the bridge deck during winter. Average annual precipitation at a site $3.2 \mathrm{~km}$ ( 2 miles) west of the structure is $102 \mathrm{~cm}$ (40 in).

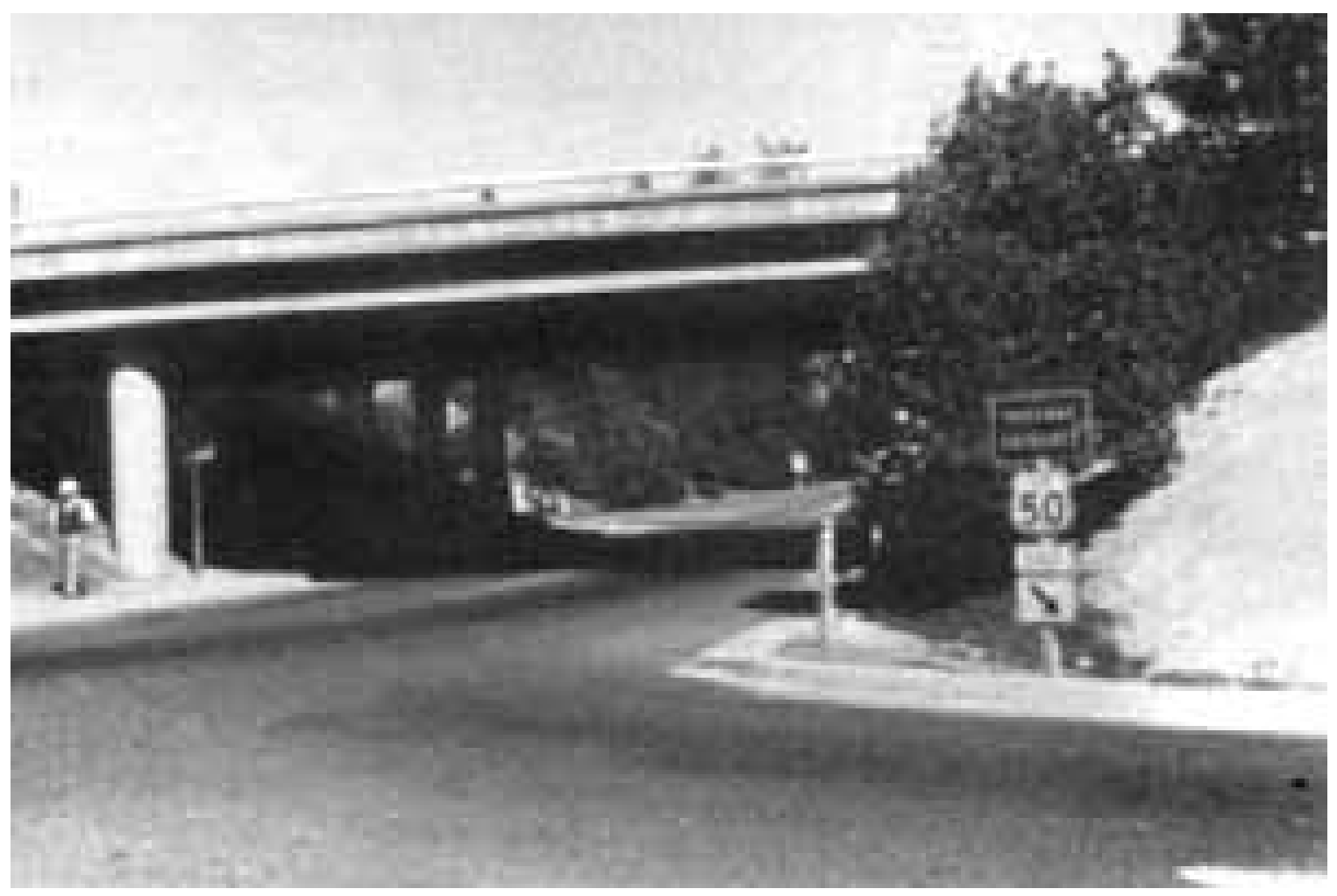

Figure 2.11: East Camino Under-crossing (CA) built in 1964 and located east of Placerville, CA

Both the top (deck) and bottom (soffit) surfaces were coated with thermal sprayed Zn, Figure 2.12. The concrete surfaces were sandblasted with 20-grit copper slag prior to spraying. Metallizing of the soffit was performed with a flame-spray (oxygen/acetylene) spray gun. An average of $0.6 \mathrm{~mm}$ ( $0.023 \mathrm{in}) \mathrm{Zn}$ was applied to the soffit. The system was energized in November 1985. 


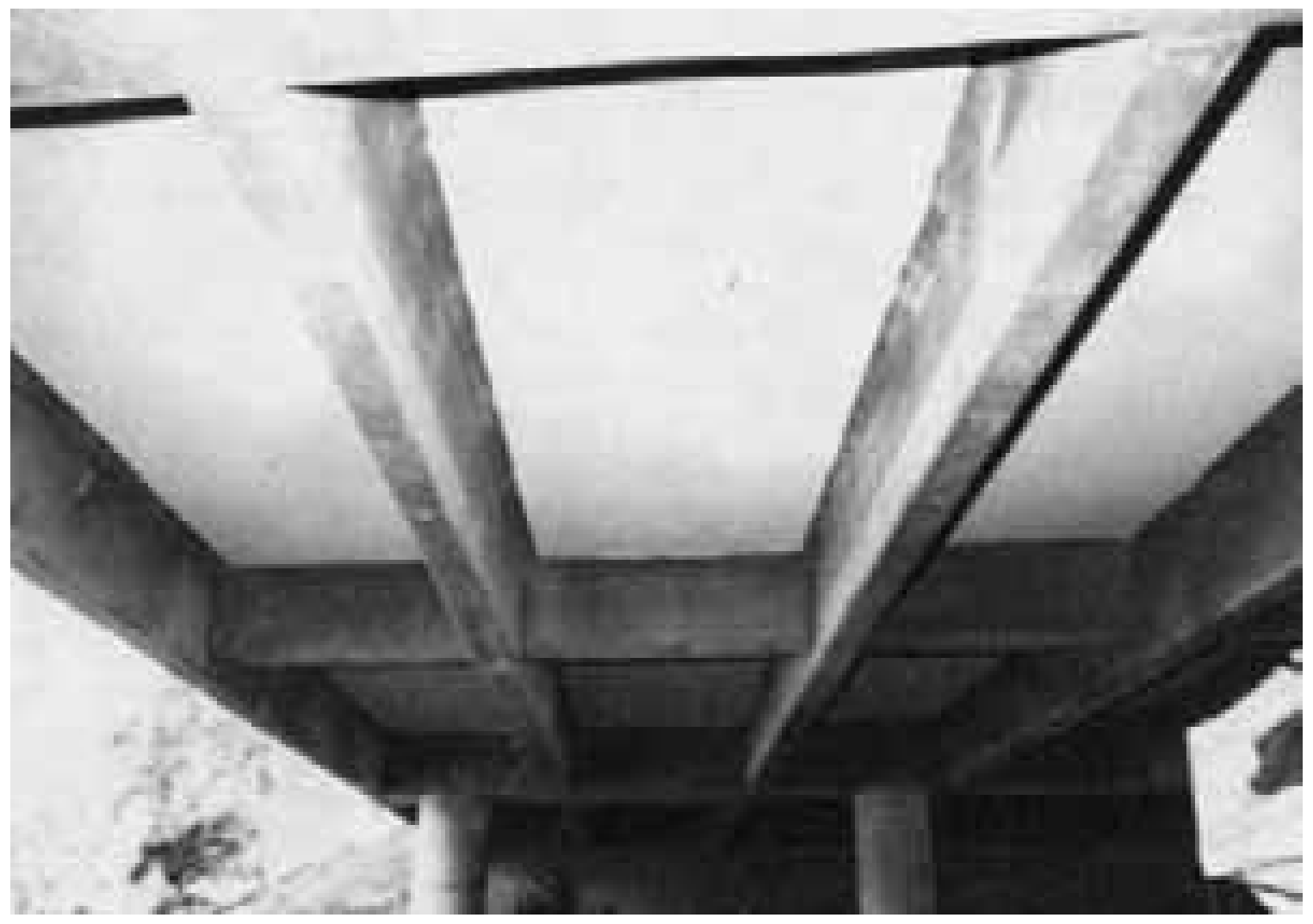

Figure 2.12: East Camino Under-crossing (CA) showing soffit areas that were thermal sprayed with $\mathrm{Zn}$

The sample for this study was taken from the soffit in Bay I in November 1995, 10 years after energizing. Bay I is a sheltered area of the bridge not directly wetted by precipitation or splashing on a regular basis. The driving voltage was 26 to $40 \mathrm{~V}$ and resulted in an average current density of $0.0046 \mathrm{~A} / \mathrm{m}^{2}\left(0.43 \mathrm{~mA} / \mathrm{ft}^{2}\right)$ (based on the area of steel rebar). CP currents were higher during the wet winter months and lower during the dry summer months. CALTRANS determined that the presence of adequate moisture was necessary for the continued delivery of CP current. Small sections of the samples were cut and mounted in epoxy for microanalysis.

\subsubsection{CALTRANS laboratory silane study}

CALTRANS conducted a study to determine if the prior application of a silane penetrant sealant to a concrete surface affected the ability of a metallized $\mathrm{Zn}$ anode $\mathrm{CP}$ system to deliver current to steel rebar in the concrete (Parks 1990). The study began in 1986 and used concrete test slabs with a $0.40 \mathrm{w} / \mathrm{c}$ ratio and $9 \mathrm{~kg} / \mathrm{m}^{3}\left(15 \mathrm{lbs} / \mathrm{yd}^{3}\right)$ chloride. The slabs were $5.7 \mathrm{~cm} \times 11.4 \mathrm{~cm} \times 38$ $\mathrm{cm}$ (2.25 in $x 4.5$ in $\times 15$ in) size and had No. 5 steel rebar embedded to act as the cathode. Prior to embedding the rebar, it was machined to 0.5 in diameter, cleaned, and then partially coated with epoxy to expose only $0.009 \mathrm{~m}^{2}\left(14 \mathrm{in}^{2}\right)$ of steel per slab. A flowchart of the experiment organization is shown in Figure 2.13. After sandblasting the as-cast surface, four of five slabs were coated with the silane penetrant on the face to receive the $\mathrm{Zn}$ anode. After the sealant cured, the silane-sealed surfaces of two of the four coated slabs were lightly sandblasted. 


\section{CALTRANS SILANE STUDY}

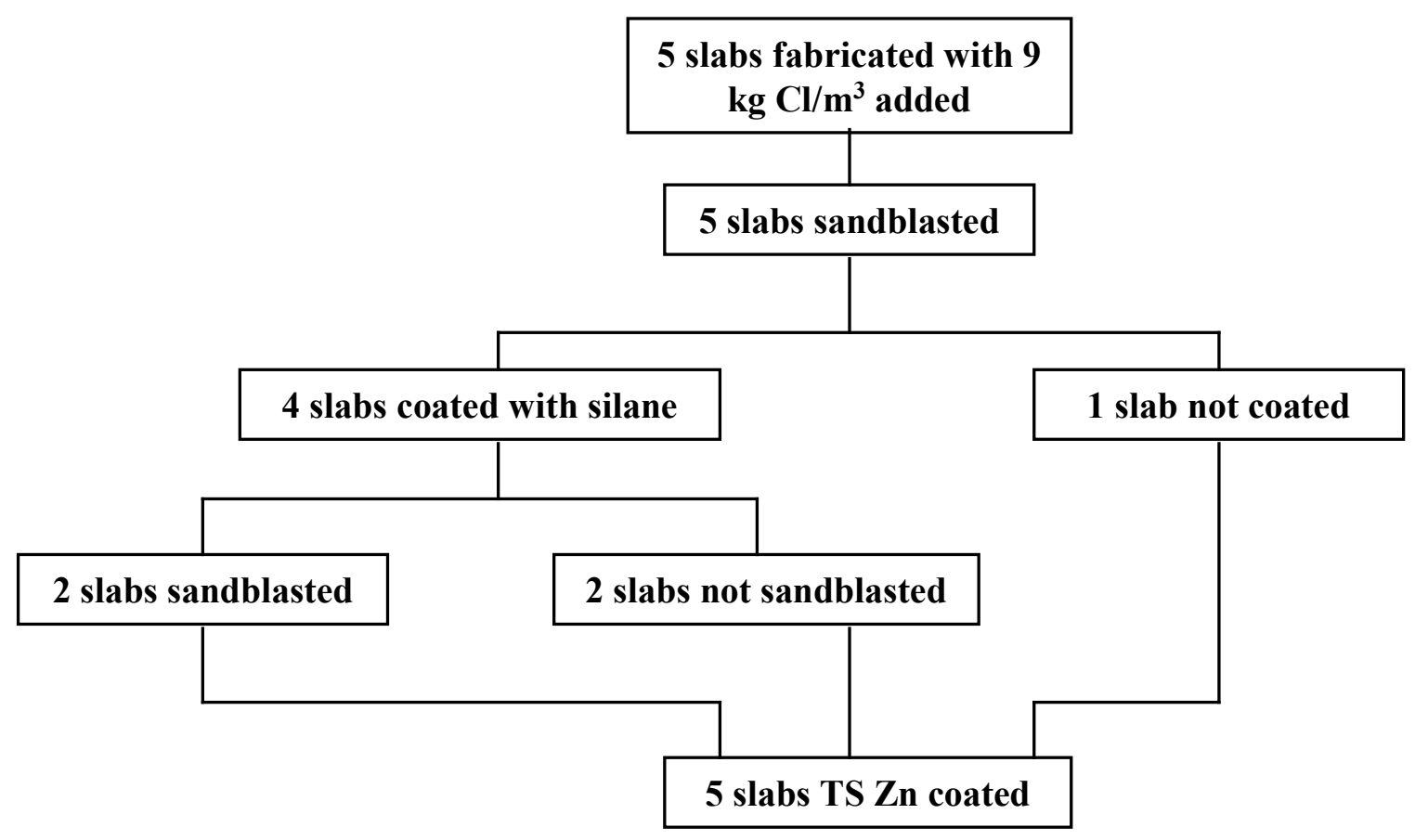

Figure 2.13: Experimental design for the CALTRANS laboratory silane study

Approximately $0.3 \mathrm{~mm}$ (12 mils) metallized $\mathrm{Zn}$ coating was then applied to the treated face of the four slabs and the untreated face of the fifth slab. The slabs were partially submerged in a salt solution, equivalent to the $15 \mathrm{lb} \mathrm{Cl} / \mathrm{yd}^{3}$ in the concrete, and the ICCP system energized. Current was applied for a total of $4.9 \mathrm{y}(43,000 \mathrm{~h})$ during which time the current densities ranged from 0.0036 to $2.7 \mathrm{~A} / \mathrm{m}^{2}$ (0.33 to $\left.248 \mathrm{~mA} / \mathrm{ft}^{2}\right)$.

After $0.64 \mathrm{y}(5,600 \mathrm{~h})$ of ICCP, CALTRANS determined that the silane penetrant sealant reduced the ability of the metallized $\mathrm{Zn}$ anode to deliver current to the rebar. Higher driving voltages were required for those slabs treated with the silane sealant. Light sandblasting was observed to have reduced the voltage requirement for the silane-treated slabs. ICCP application was continued on the partially submerged slabs for $4.9 \mathrm{y}(43,000 \mathrm{~h})$ when the $\mathrm{Zn}$ samples used by ARC, Table 2.5, were taken from the slabs.

\subsubsection{Longbird Bridge (Bermuda)}

The Longbird Bridge, Figure 2.14, is located in Bermuda. It was constructed in 1948 and is a single span with a concrete deck approximately $5.5 \mathrm{~m}(18 \mathrm{ft})$ long by $6.1 \mathrm{~m}(20 \mathrm{ft})$ wide. The concrete deck is $25 \mathrm{~cm}$ (10 inch) thick and contains No. 6 round galvanized rebar; the adjacent sidewalk contains smaller diameter round galvanized rebar. The bridge was the subject of a study in 1976 after 28 years service (ILZRO 1978). Chloride analyses at that time showed a high 
of $7.4 \mathrm{~kg} / \mathrm{m}^{3}\left(12.3 \mathrm{lb} / \mathrm{yd}^{3}\right)$ to a low of $3.8 \mathrm{~kg} / \mathrm{m}^{3}\left(6.4 \mathrm{lb} / \mathrm{yd}^{3}\right)$ at distances of $10.2-10.8 \mathrm{~cm}(4-4.25$ inch) from the top surface of the deck.

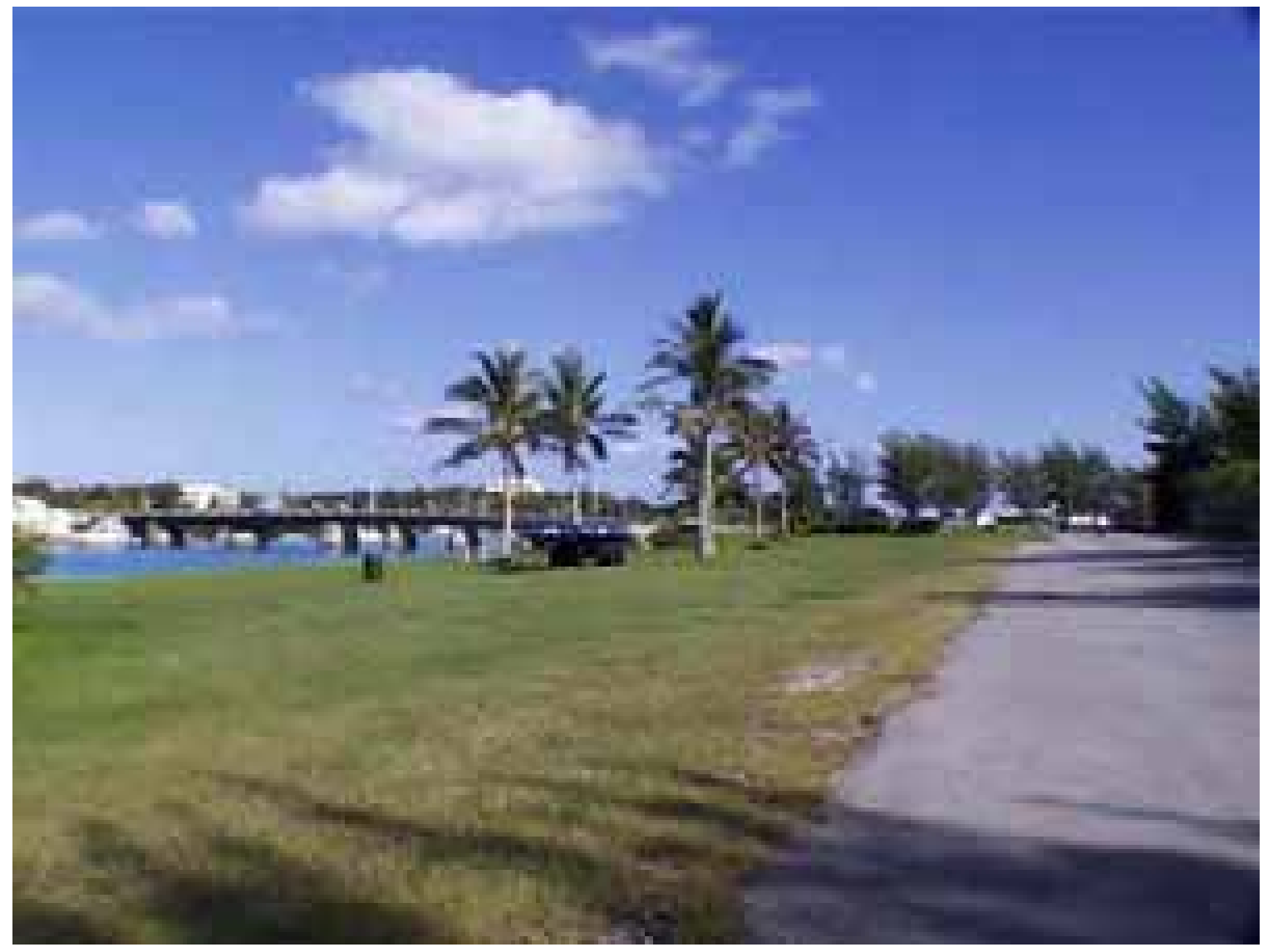

Figure 2.14: Longbird Bridge built in 1948 in Bermuda

Further analyses showed that the $\mathrm{Zn}$ coating on the steel consisted of an $\eta$ (eta) layer of pure $\mathrm{Zn}$, covering a thick layer of $\zeta$ (zeta)-intermetallic crystals ( 5.8 to 6.2 weight $\% \mathrm{Fe}$ ), followed by a $\delta$ (delta)-intermetallic layer (7-12 weight \% Fe) and then the steel (ILZRO 1978; Yeomans 1993). There was no evidence of the $\Gamma$ (gamma)-intermetallic layer $(21-28$ weight $\% \mathrm{Fe}$ ) between the steel and the $\delta$-layer. At 28 years service, the average remaining coating thickness was $0.23 \mathrm{~mm}$ (9.1 mil). There was no evidence of reaction between the $\mathrm{Zn}$ and the concrete; nor was there any evidence of cracking of the concrete due to the buildup of minerals form $\mathrm{Zn}$ corrosion products.

Core samples for the present study, Table 2.5, were taken from the Longbird Bridge in September 1994 after 46 years service. These samples came from the sidewalk and from the abutment several feet above the sea level. 


\subsection{ANODE CHARACTERIZATION TECHNIQUES}

Characterization of thermal spray $\mathrm{Zn}$ anodes on bridges and on laboratory concrete slabs generally involved measurement of anode thickness, anode bond strength to the concrete, anodeconcrete interfacial chemistry, and post mortem assessment of anode performance, including anode service life estimates. While most of these characterization techniques are destructive, some nondestructive techniques, such as CP system circuit resistance, anode AC resistance, anode air permeability, and anode water permeability, were developed for this study.

\subsection{ANODE APPLICATION}

Some parameters of TS Zn anode application, such as anode thickness and minimum initial bond strength, are specified by the structure owner. Additionally, training and certification are required for thermal spray applicators on Oregon DOT projects.

\subsubsection{Anode thickness}

Anode thickness is important to its installation and operation. An anode that is too thin may not have the desired service life. An anode that is too thick may not only waste material but may delaminate prematurely due to internal thermal stresses within the coating.

The method most often used to measure coating thickness at field spray projects involves a piece of duct tape and a micrometer. The duct tape is placed within the thermal spray application area and is coated along with the concrete while the $\mathrm{Zn}$ anode is being applied. The $\mathrm{Zn}$-coated tape is then removed from the concrete, the $\mathrm{Zn}$ coating removed from the tape, and its thickness measured directly using a micrometer. On early projects, the small bare area where the duct tape stuck was often left uncoated.

An alternative technique that was used on the Yaquina Bay Bridge and on all of the laboratory slabs is the eddy current technique. This technique, which was able to measure $\mathrm{Zn}$ anode thickness on concrete surfaces, was used to measure twelve separate locations on each slab. These values were then averaged to give the $\mathrm{Zn}$ anode thickness.

Laboratory slab anode thickness was also determined indirectly using a magnetic thickness probe and steel coupon. This approach was possible because the thermal spray $\mathrm{Zn}$ anode was applied with a robotic $x-y$ traversing system that produced coatings of fairly uniform thickness. The robotic system was programmed to spray a sandblasted steel surface for a specific number of $\mathrm{x}-$ and y-traverses at a given deposition rate. The TS Zn coating thickness was then measured with the thickness gauge. This procedure was repeated for different spray conditions until the desired coating thickness was achieved. This established the conditions for spraying the concrete slabs. As an example of the variation in anode thickness on slabs sprayed by the robotic system, Table 3.1 shows the average coating thickness on several steel panels as a function of position on the 
panel. The target thickness for the steel panels was $0.38 \mathrm{~mm}(15 \mathrm{mils})$ and the average thickness was $0.39 \mathrm{~mm}$ (15.5 mils).

Table 3.1: TS Zn coating thickness on a steel calibration panel with a target thickness of $0.38 \mathrm{~mm}$ (15 mils) and mean thickness of $0.39 \mathrm{~mm}(15.5 \mathrm{mils})$

\begin{tabular}{c|c|c|c}
\hline \multirow{2}{*}{$\begin{array}{c}\text { Distance from } \\
\text { top of panel, }\end{array}$} & \multicolumn{3}{|c}{ Measured, mm (mils) } \\
\cline { 2 - 4 } cm (in) & Left Side & Center & Right Side \\
\hline $1.3(0.5)$ & $0.381(15.0)$ & $0.427(16.8)$ & $0.363(14.3)$ \\
\hline $3.8(1.5)$ & $0.391(15.4)$ & $0.371(14.6)$ & $0.368(14.5)$ \\
\hline $6.3(2.5)$ & $0.391(15.4)$ & $0.396(15.6)$ & $0.379(14.9)$ \\
\hline $8.8(3.5)$ & $0.389(15.3)$ & $0.381(15.0)$ & $0.396(15.6)$ \\
\hline $11.3(4.5)$ & $0.391(15.4)$ & $0.404(15.9)$ & $0.409(16.1)$ \\
\hline $13.8(5.5)$ & $0.427(16.8)$ & $0.422(16.6)$ & $0.384(15.1)$ \\
\hline
\end{tabular}

The scanning electron microscope is another way to measure coating thickness. Figure 3.1 shows a SEM photomicrograph of a cross-section of unaged TS Zn anode on concrete. Because this is a destructive and time intensive method, the SEM was not used to measure coating thickness. It is, however, an excellent technique for characterizing coating consumption and correlating it with electrochemical age.

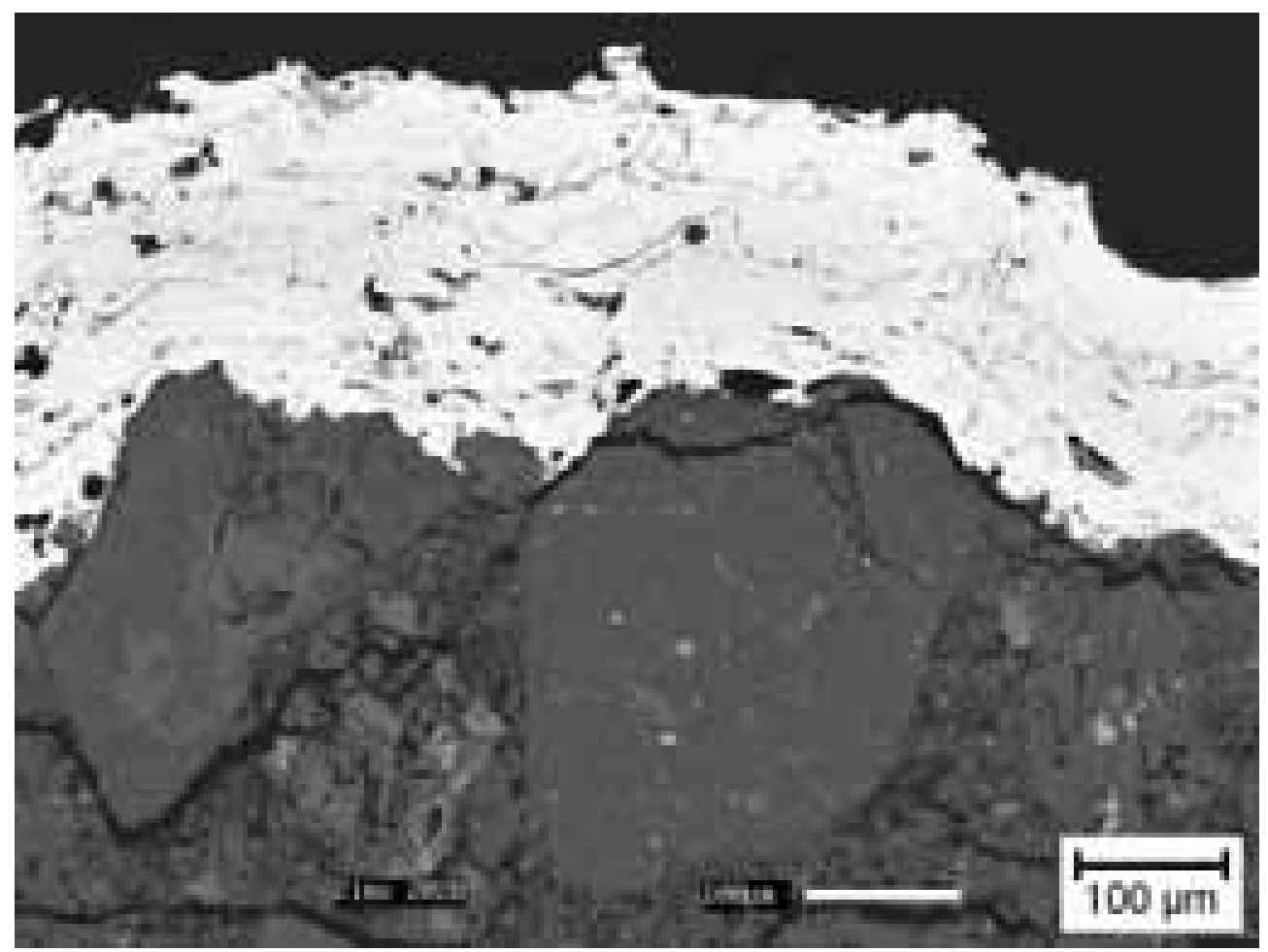

Figure 3.1: SEM photomicrograph of cross-section showing unaged TS Zn anode microstructure and anode-concrete interface for anode on concrete 


\subsubsection{Temperature of concrete slab and anode coating}

An experiment was conducted to measure the temperature of the $\mathrm{Zn}$ thermal spray surface at the time of spraying. The purpose was to determine how the heat contained in the spray of molten $\mathrm{Zn}$ droplets, which melt at approximately $420^{\circ} \mathrm{C}\left(788^{\circ} \mathrm{F}\right)$, would affect the concrete surface temperature. The concrete surface temperature was measured with Type $\mathrm{K}$ (chromel-alumel) thermocouples $(0.33 \mathrm{~mm}$ diameter wire) epoxy coated to prevent electrical shorts by the thermalsprayed $\mathrm{Zn}$. Two thermocouples were attached to a concrete slab as shown in Figure 3.2 and secured with duct tape. They were positioned about halfway across the slab width and one-third in from the ends.

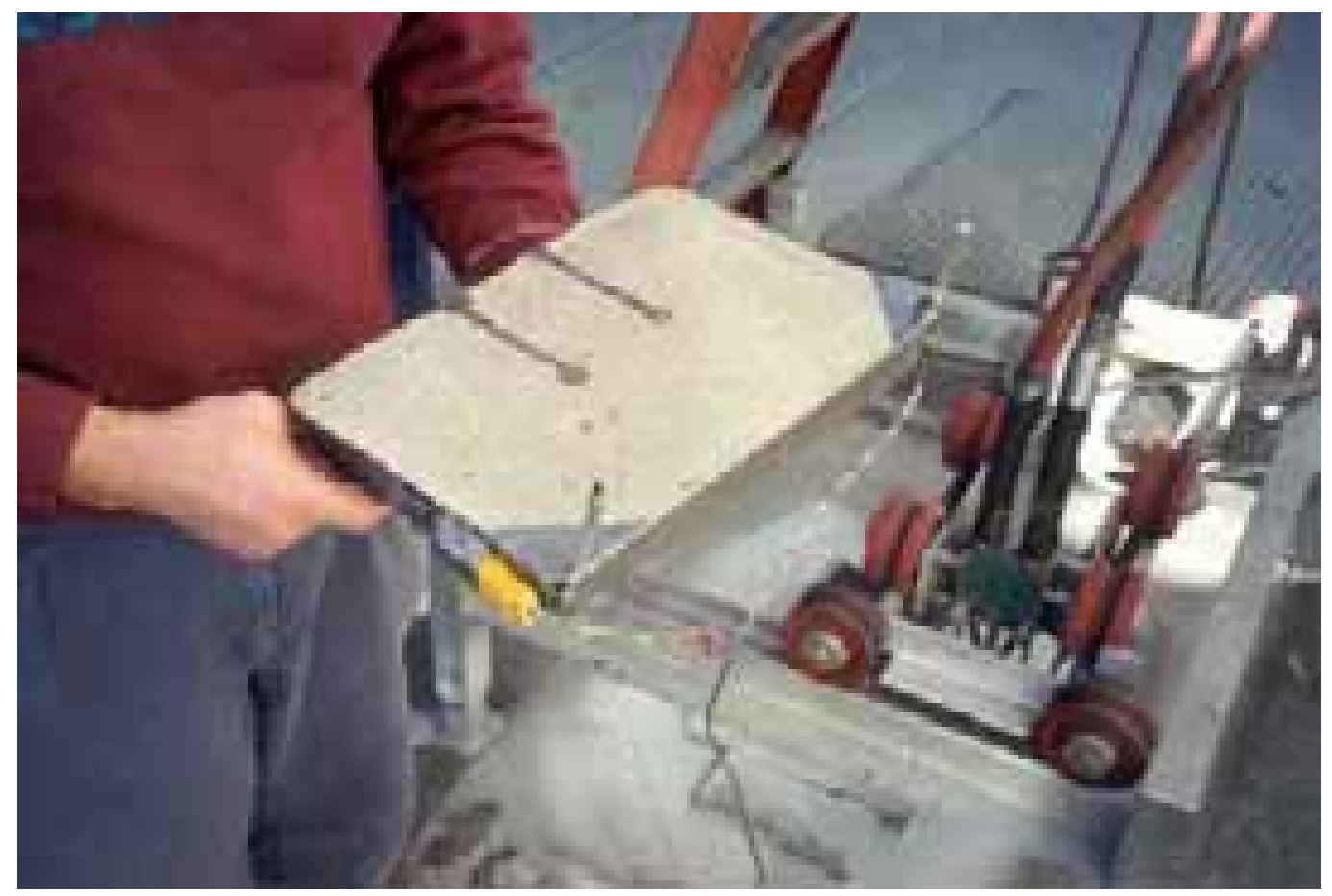

Figure 3.2: View of thermocouples attached to concrete slab for surface temperature measurements

The thermocouple tips were exposed and touching the concrete surface. Individually shielded twisted wire pairs were connected to the thermocouples rather than thermocouple extensiongrade wire. The use of the twisted wire pair reduced the error, as determined by the "Standard Method for Calibration of Thermocouples By Comparison Techniques" (ASTM 1996), in temperature readings. The measured error was used to correct the final temperature readings. A Validyne model UPC-607 was used for thermocouple sensor signal conditioning and for analogto-digital conversion. This unit features 14-bit conversion and a sampling rate of 5,000 readings per second. After the thermocouples were connected to the data acquisition system, the slabs were positioned within the robotic $x-y$ traverse thermal spray unit, Figure 2.4, and sprayed with $0.38 \mathrm{~mm}$ (15 mils) of Zn, Figure 3.3. Temperature response of the concrete surface was recorded as a function of time. 
The temperature of the anode surface during accelerated electrochemical aging was measured with respect to ambient air temperature. To do this measurement, one type $\mathrm{K}$ thermocouple was attached to the anode surface with duct tape and another was positioned nearby to measure the ambient air temperature. Measurements were manually recorded daily using a multimeter and a zero point correction module.

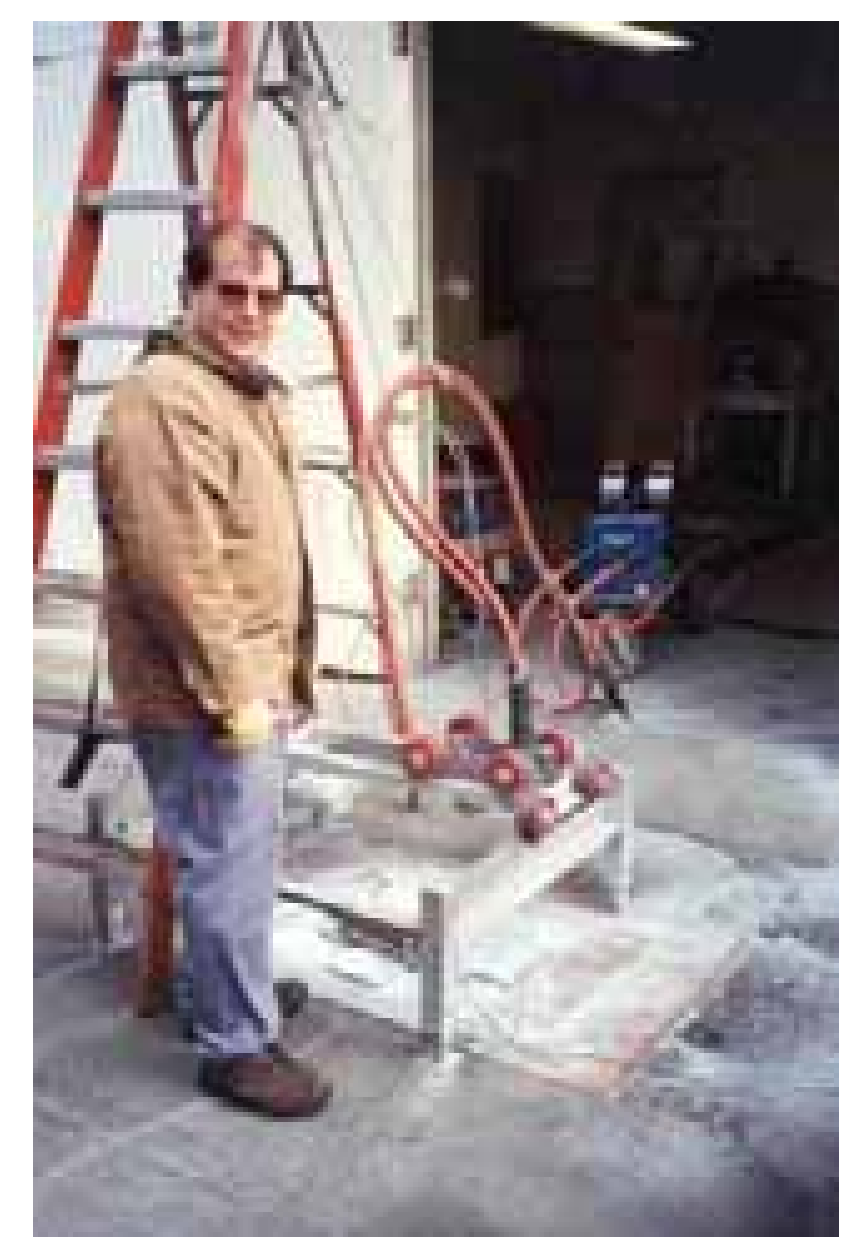

Figure 3.3: Twin-wire arc-spray equipment prior to applying TS Zn anode to concrete slab for surface temperature measurements

\subsection{ICCP PERFORMANCE OF ANODES}

The performance of ICCP anodes was not determined using typical anode parameters, such as consumption rate (the rate in pounds of anode consumed per ampere of current per year) or efficiency (a comparison of the actual anode mass consumed to the theoretical mass required). Nor was rebar depolarization used, i.e., the $100 \mathrm{mV}$ depolarization criteria (NACE International 1996). Anode ICCP performance was quantified instead by the CP circuit resistance (CR) and the anode electrochemical age (EA). 
Anode electrochemical age at time $t$ is defined as the cumulative charge passed across the anode per unit area over the life of the anode and is given by equation 3-1.

$$
\mathbf{E A}(\mathbf{t})=\int \mathbf{J}(\mathbf{t}) \mathrm{dt} \quad\left(\text { coulombs } / \mathbf{m}^{2}\right)
$$

Where $\mathrm{J}(\mathrm{t})$ is the CP current density $\left(\mathrm{A} / \mathrm{m}^{2}\right)$ and $\mathrm{t}$, the time in seconds. The product $\mathrm{J}(\mathrm{t}) * \mathrm{dt}$ is integrated from the beginning of the experiment to time $t$.

$\mathrm{CP}$ circuit resistance at time $\mathrm{t}$ is simply the quotient of the voltage, $\mathrm{V}(\mathrm{t})$ (volts), between the steel cathode and the $\mathrm{Zn}$ anode and the CP current density, J, as in equation 3-2.

$$
\operatorname{CR}(t)=V(t) / J(t) \quad\left(o h m s-m^{2}\right)
$$

It is a dc (direct current) measurement. While interfacial polarization effects contribute to CR, the changes that occur in CR with time are expected to be largely related to resistive elements in the CP system and these elements would be the same whether measured by dc or ac (alternating current) techniques [see Section 6.1 CP Circuit Resistance].

\subsubsection{Laboratory anodes}

Figure 3.4 shows a schematic of the wiring diagram of one of the series of approximately 20 slabs that were used in the experiments. Current (I) flowing through each series and the total voltage (V) across each series were recorded by computer data acquisition. A series (1-20 slabs) and an average per slab circuit resistance, see equation 3.2 above, was calculated from the data. Laboratory anodes were evaluated on the basis of their response to wetting/drying cycles and by the change in average slab circuit resistance with electrochemical age.

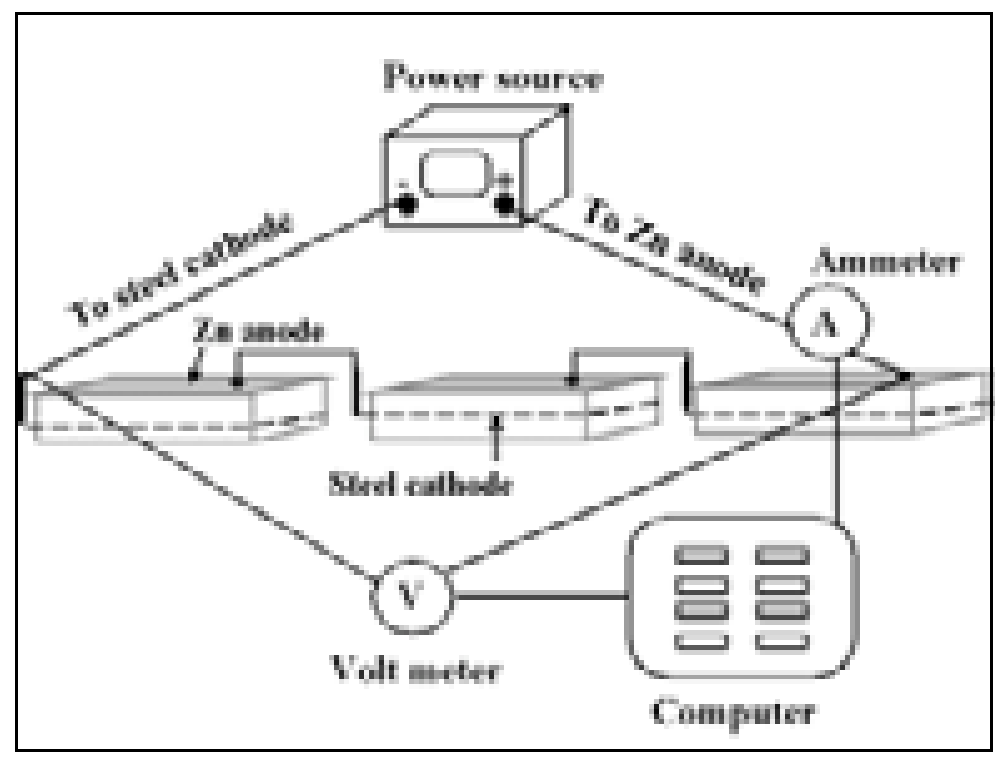

Figure 3.4: Schematic wiring diagram for TS Zn anodes in electrochemical aging study showing series connections between slabs and power source, $\mathrm{V}$ and I measurement locations, and the computer 


\subsubsection{Field anodes}

Performance data for field anodes was recorded using telemetry and instrumentation similar to that shown in Figure 3.5. Field anodes were evaluated in the same way as laboratory anodes. The field data were compared to that from the laboratory anodes to determine if similar electrochemical aging effects and trends were present.

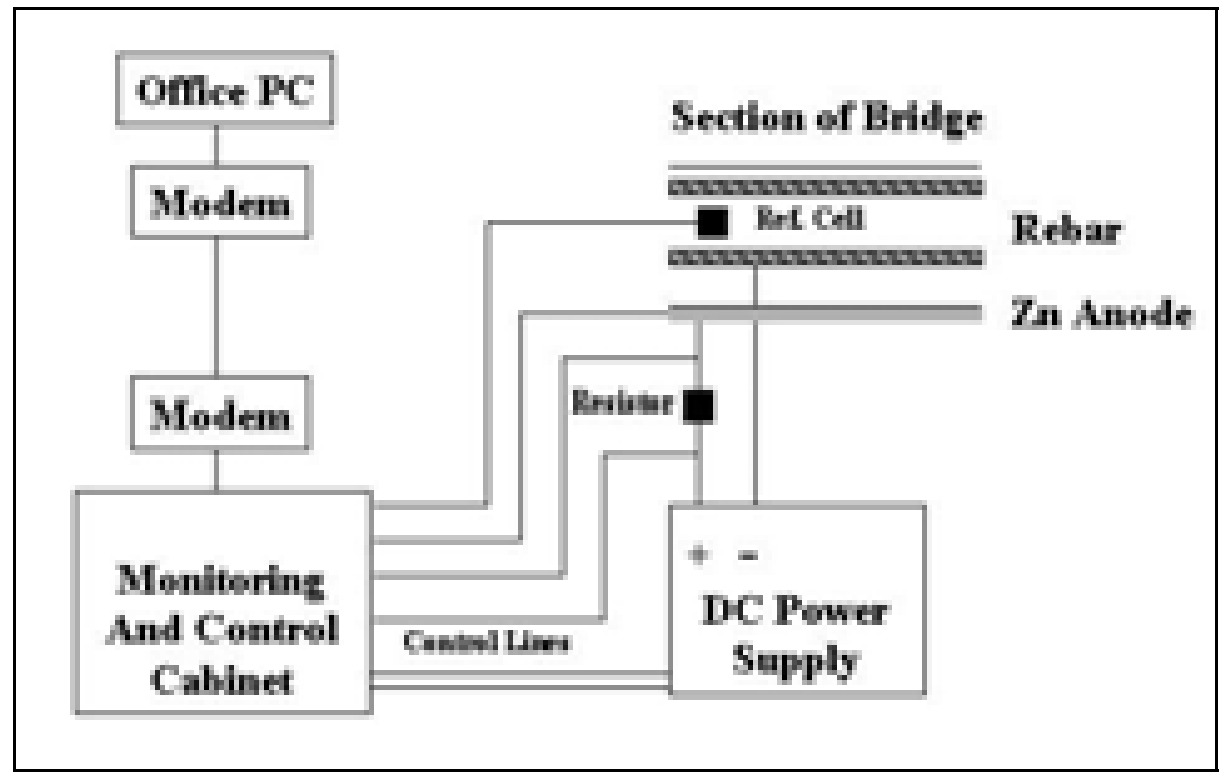

Figure 3.5: Schematic of data measurement instrumentation and telemetry equipment used by Oregon DOT for remote measurements on coastal bridge CP systems

\subsection{ANODE BOND STRENGTH}

Pairs of slabs, preheated and unheated, were removed from the electrochemical aging experiment at regular time intervals. The slabs were equilibrated with dry air for one day, and prepared for bond strength measurements by attaching aluminum dollies to the $\mathrm{Zn}$ coating at six predetermined locations using epoxy. The aluminum dollies, $50 \mathrm{~mm}$ (1.9 in) diameter, were identical to those used with portable adhesion testers on Oregon bridges. A high viscosity, high strength, short cure time ( $300 \mathrm{~s}$ ) epoxy was used to eliminate failures at the epoxy-dolly interface and to prevent epoxy penetration through the coating to the concrete. $\mathrm{Zn}$ bond strength measurements were made using a universal testing machine, Figure 3.6 (Bullard, et al. 1997a; Covino, et al. 1995; Covino, et al. 1997a). In preliminary measurements, pre-scoring of the $\mathrm{Zn}$ coating around the dollies did not improve reproducibility of the bond strength measurements and was not used. 


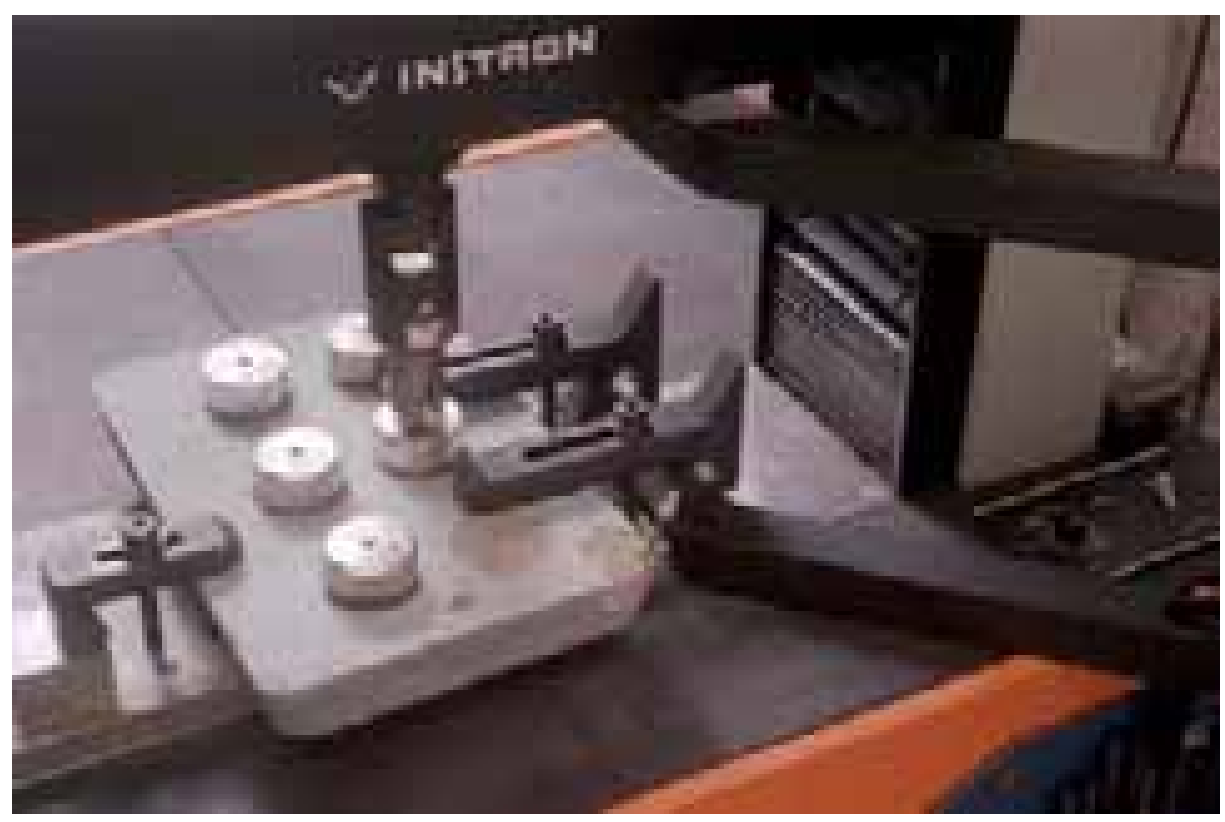

Figure 3.6: Instron universal tensile tester used to measure the bond strength of TS Zn anodes on a concrete slab; shows $5 \mathrm{~cm}$ diameter aluminum dollies attached to anode with epoxy

Initial $\mathrm{Zn}$ bond strengths were determined by measurements on unaged slabs from the group of preheated and unheated slabs. The numbers of slabs used to determine the initial bond strengths are shown in Table 2.4. All subsequent bond strength measurements were made on one slab for each electrochemical age/slab condition. Figure 3.7 shows the before and after view of a bond strength test for a TS Zn anode on concrete. The tensile or cohesive strength of cured, uncoated concrete also was measured in an identical manner by attaching the aluminum dollies to the lightly sandblasted concrete surface.

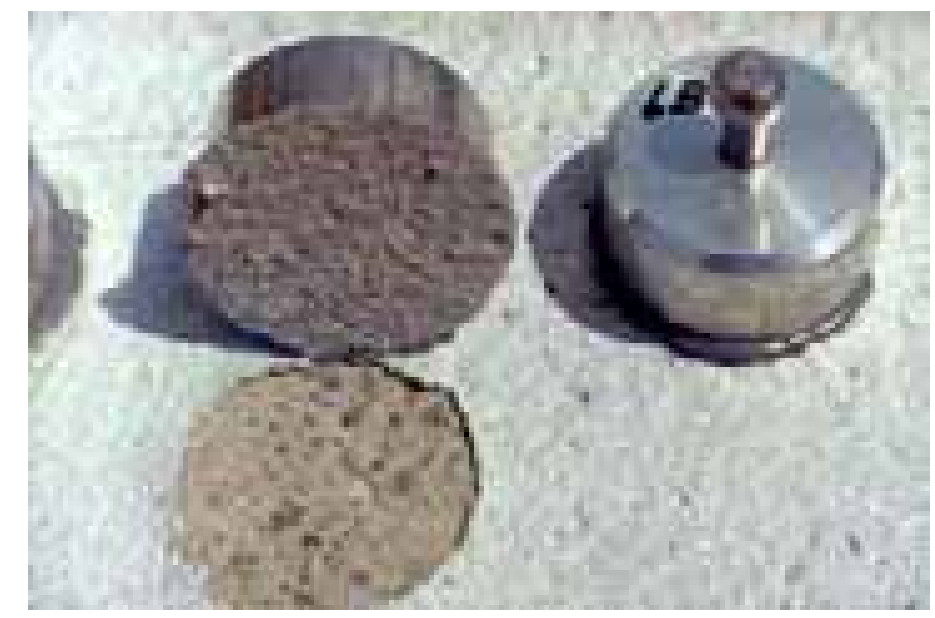

Figure 3.7: Close up of aluminum dollies used for bond strength measurements: one dolly attached and one pulled off 
Bond strength measurements on field anodes used the same dollies and adhesive as used in the laboratory but were made using a Proceq Adhesion Tester, Figure 3.8.

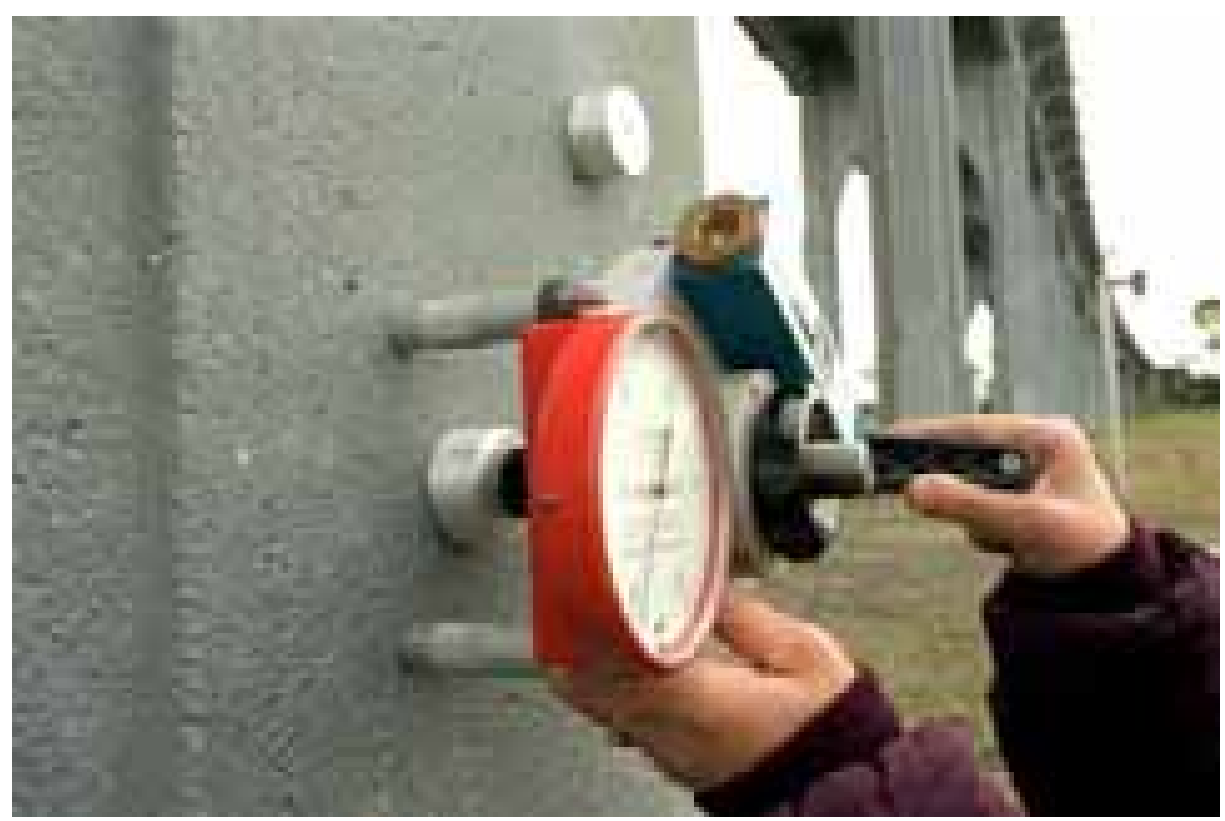

Figure 3.8: Proceq portable tester used to measure the bond strength of the TS Zn anode on concrete

\subsection{BULK CONCRETE CHEMISTRY}

The $\mathrm{Cl}$ and $\mathrm{Ca}$ content of field structures such as the Rocky Point Viaduct, Brush Creek Bridge, and Yaquina Bay Bridge was determined using the Oregon DOT powder sampling procedure being used in Figure 3.9 on a Rocky Point Viaduct beam. Details of the powder sampling procedure are given in APPENDIX C and elsewhere (Cramer, et al. 2000). A closer view of some of the powder sampling equipment discussed there is given in Figure 3.10. The analytical procedures used to determine total and water-soluble chlorides in the powdered cement are presented in detail in APPENDIX D.

Another technique used to collect samples to evaluate bulk chemistry of the bridge concrete and anode-concrete interfacial chemistry involves coring the bridges. This was done using a gaspowered portable drill with a $5 \mathrm{~cm}$ ( 2 in) diameter hollow diamond coring bit and cooling water. Figure 3.11 shows this apparatus in use on the Yaquina Bay Bridge. Slices cut from these cores with a diamond saw were examined for anode-concrete interfacial chemistry. 


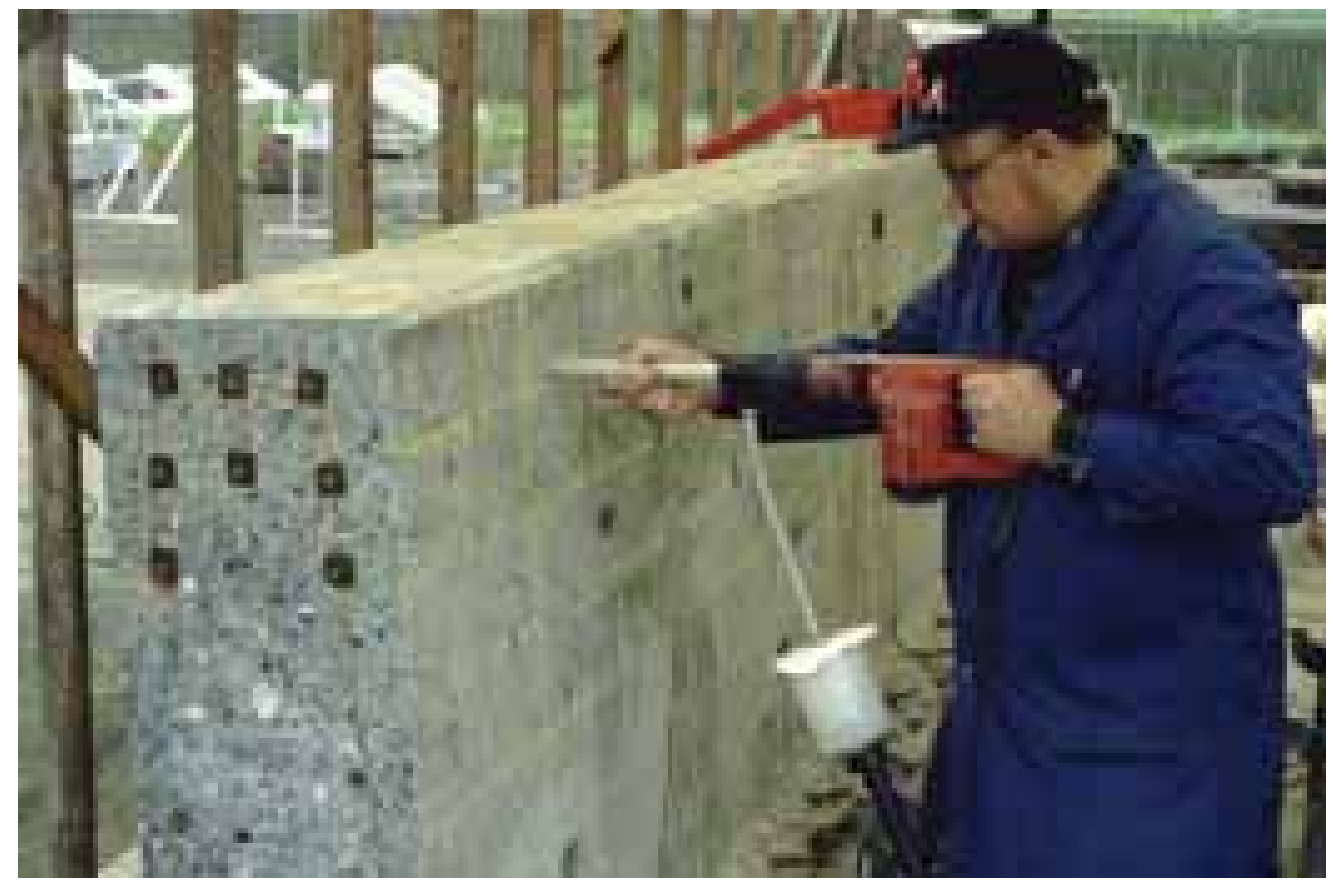

Figure 3.9: Concrete powder samples are taken from a concrete bridge beam using the Oregon DOT sampling equipment. Powder samples are analyzed to determine the salt concentration in the concrete as a function of depth in the beam.

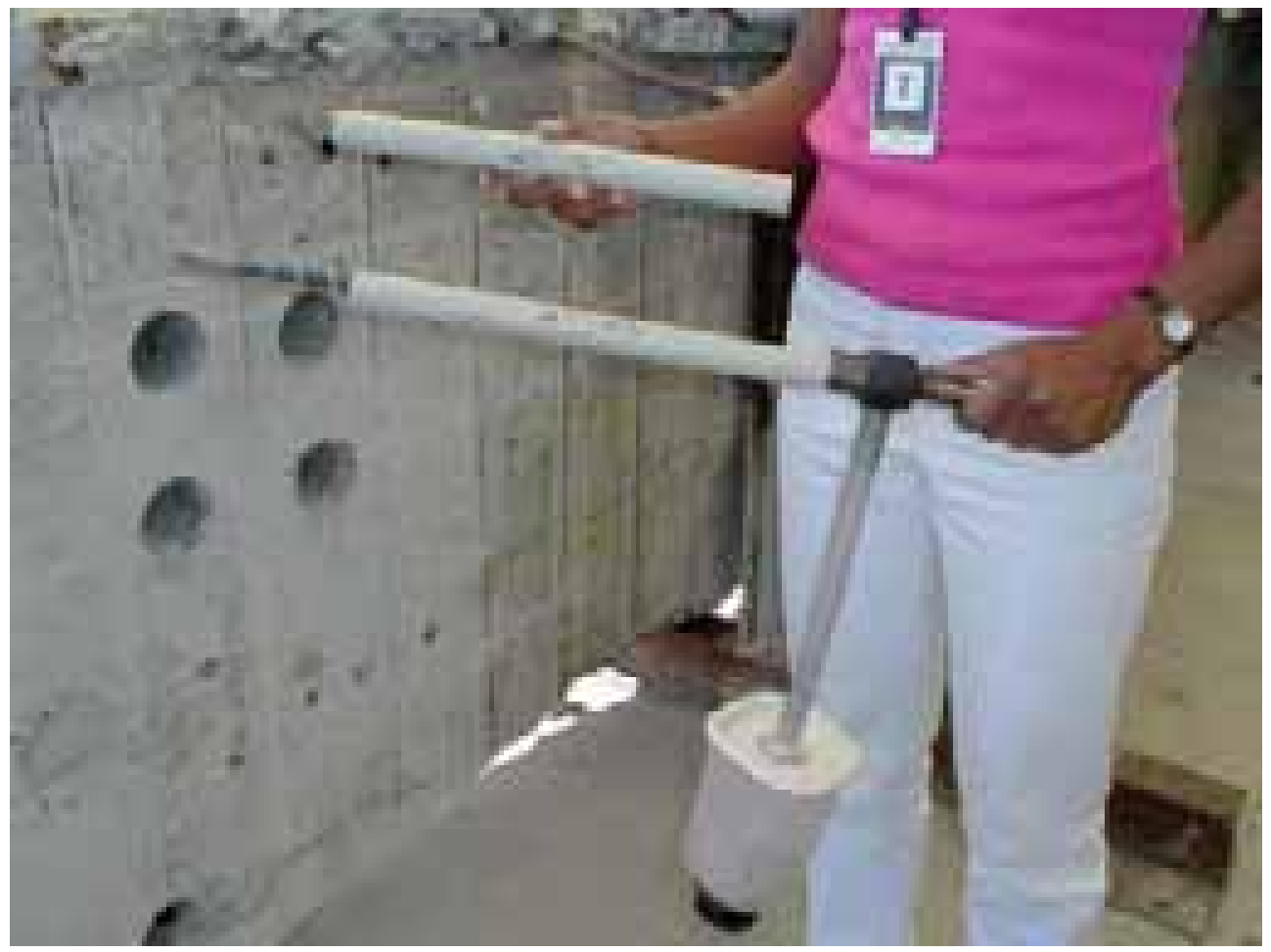

Figure 3.10: The hollow anchor drill bit, depth spacers, and vacuum filter assembly used in taking powder samples from concrete 


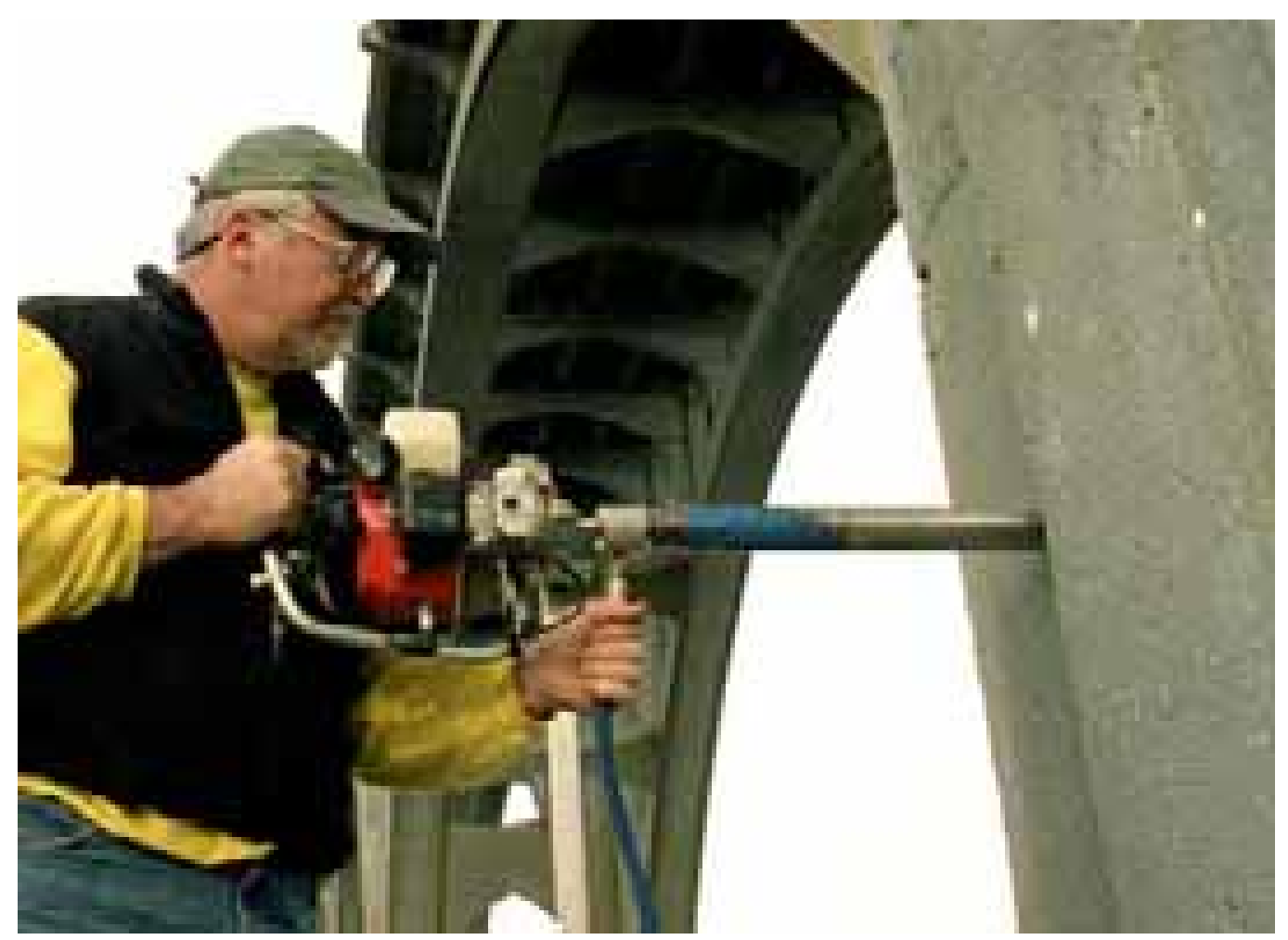

Figure 3.11: Portable gasoline-powered core drill for taking concrete core samples

\subsection{ANODE-CONCRETE INTERFACIAL CHEMISTRY}

Anode-concrete cross-sections were cut from slabs or bridge core samples. They were cut with a water-cooled diamond blade and dried overnight in a $38^{\circ} \mathrm{C}\left(100^{\circ} \mathrm{F}\right)$ oven. In order to keep the concrete from crumbling during grinding and polishing, the samples were embedded in ring forms with epoxy, infiltrated with the epoxy under vacuum, and then cured overnight in a pressure tank. The sample cross-sections were then polished to a $1 \mu \mathrm{m}$ diamond finish.

Anodes and anode-concrete interfaces were evaluated using an analytical scanning electron microscope (ASEM). Polished cross-sections, and in some cases, samples chipped from slabs and bridge anodes were examined to determine physical, chemical, and mineralogical characteristics of the zinc-concrete interface and changes associated with the effects of aging on bond strength, operation of the CP system, and water permeability of the anode. The ASEM included energy-dispersive spectroscopy (EDS) and wavelength dispersive spectroscopy (WDS).

\subsubsection{Sampling}

Cross-sectioned samples were taken from the laboratory slabs at a slice cut from the slab between two of the three rows of dollies used for bond strength measurements, Figure 3.6. This ensured that the sample was not near the end of a slab where edge effects could occur. 
Core samples were taken from pre-determined locations on the bridges. The decision for core location was based on CP zone, types of concrete, and orientation to the ocean.

\subsubsection{Analytical scanning electron microscopy}

Anode coatings were analyzed with an ASEM and an electron microprobe (EMP) to determine the local composition and physical structure of the coatings. Images, point analyses, line scans, and x-ray maps of the aged anode-concrete interface were obtained. The results were used to establish the relationship between local chemistry, structure, and properties of the anodeconcrete interface. Cross-sectioned samples were carbon coated prior to imaging to increase electrical conductivity. Chemical analyses were performed using a WDS x-ray analyzer with 4 crystals, and an EDS x-ray analyzer with atmospheric thin window for low atomic number elements. The results were $\mathrm{ZAF}$ corrected $(\mathrm{Z}$ atomic number, $\mathrm{A}=\mathrm{x}$-ray absorption, and $\mathrm{F}$ fluorescence) and converted into atomic percent. Zinc, $\mathrm{Cl}, \mathrm{S}, \mathrm{Ca}$, and $\mathrm{O}$ were analyzed by WDS with accuracies of $0.1,0.1,0.1,0.1$ and 2 weight $\%$ absolute. Aluminum, Fe, K, Na, and Si were analyzed by EDS, with accuracies of about 2 weight $\%$ absolute. Pure element standards were used with the following exceptions: $\mathrm{Ca}-\mathrm{CaCO}_{3}, \mathrm{Cl}-\mathrm{NaCl}$, and $\mathrm{S}-\mathrm{FeS}_{2}$. Carbon was not analyzed because the samples were carbon coated. The $\mathrm{NaK}_{\alpha}$ and $\mathrm{ZnL}_{\alpha}$ lines overlapped causing errors in the $\mathrm{Na}$ values for high $\mathrm{Zn}$ regions. ASEM results are reported as concentrations in atomic percent (at pct) so that simple ratios provide evidence of the mineral species that may be present.

Images of the coatings were obtained with a LEO Stereoscan S440 scanning electron microscope using secondary (SE) and back-scattered (BSE) electrons. Secondary electron images yield primarily topographical detail. Backscattered electron images are sensitive to average atomic number of the analysis volume and accentuate composition differences. Since voids and cracks are one extreme in the spectrum of atomic number, i.e., $\sim 0$, the BSE images show these features in stark detail.

\subsubsection{Micro-pH}

$\mathrm{pH}$ values at the anode-concrete interface were measured using an Accumet Model $925 \mathrm{pH}$ meter with automatic temperature compensation and a Microelectrodes micro-combination $\mathrm{pH}$ electrode that required as little as $0.1 \mathrm{~mL}$ of solution for a measurement. Samples for analysis were obtained from the laboratory aging experiment and from field anodes (using the core samples). Calibration was done using a two-point method and $\mathrm{pH} 7$ and 10 standard solutions. Measured $\mathrm{pH}$ values agreed well with standards from $\mathrm{pH} 4$ to 10 . Measured values above 10 were lower than those of standards. For example, using the $\mathrm{pH} 12$ standard, the measured value was 11.5.

To measure the $\mathrm{pH}$ of the anode-concrete interface, a piece of $\mathrm{Zn}$ anode was carefully separated from the concrete substrate using a thin blade. A drop of high-purity water was then applied to the exposed $\mathrm{Zn}$ anode surface and mixed, using a thin glass rod, with any cementitious material remaining attached to the $\mathrm{Zn}$ surface. The $\mathrm{pH}$ of the resulting solution was measured after roughly a 5-minute equilibration period. This $\mathrm{pH}$ value was defined as the $\mathrm{pH}$ on the anode side of the interface, to distinguish it from the $\mathrm{pH}$ on the concrete side of the interface. 
The $\mathrm{pH}$ of the concrete at the interface was measured using powder scrapings carefully removed from the concrete interfacial surface exposed when the anode was separated from the concrete. These scrapings were placed in a small polyethylene cup, a drop of high-purity water was added to the scrapings to form a slurry. The $\mathrm{pH}$ of the slurry was measured after a 5-minute equilibration period. This $\mathrm{pH}$ value was defined as the $\mathrm{pH}$ on the concrete side of the interface. The sample being analyzed to determine the $\mathrm{pH}$ on the concrete side of the interface contains less of the interfacial cementitious material and more unaltered concrete.

Powder scrapings were also removed from sample cross-sections at locations well removed from the $\mathrm{Zn}$ anode to give the $\mathrm{pH}$ for bulk concrete, i.e., concrete unaltered by reactions at the anodeconcrete interface. Again, a drop of water was added to the powder to form a slurry. The $\mathrm{pH}$ of the slurry was measured after a 5-minute equilibration period.

\subsubsection{X-ray diffraction}

Samples of $\mathrm{Zn}$ anode material and reaction products formed at the anode-concrete interface were analyzed by XRD to identify crystalline phases. Phase and lattice parameter analysis was performed using a Philips APD 3720 diffractometer system. The instrument was equipped with an automated goniometer, $\mathrm{Cu} \mathrm{X}$-ray tube, variable divergence slit, focusing graphite monochromator and scintillation counter.

\subsection{NON-DESTRUCTIVE MEASUREMENTS}

\subsubsection{Anode coating resistance}

The dc (direct current) resistance of thermal-sprayed $\mathrm{Zn}$ anode coatings was measured as a function of electrochemical age. No surface preparation was required for these measurements. The probe used to make this measurement was built by the Oregon DOT (McGill, et al. 1999) and is shown in use on the Yaquina Bay Bridge in Newport, OR, Figure 3.12. The probe measured only the resistance of the TS anode, since the underlying concrete was orders of magnitude more resistive when dry. Resistance measurements were made on laboratory slabs before electrochemical aging and at the conclusion of the aging experiment. By knowing the anode coating thickness, the resistance can be converted into coating resistivity values. 


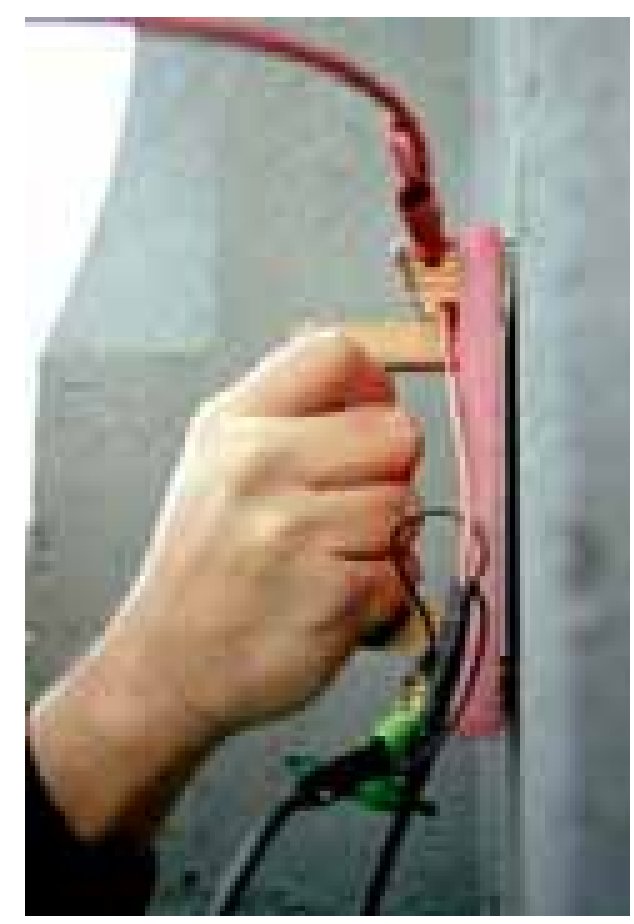

Figure 3.12: Oregon DOT resistance probe for measurement of anode coating resistivity

The probe allowed for a 4-point resistance measurement that eliminated the contact resistance common to 2-point measurements. The current source, which was connected to the outer row of pins of the probe, was typically set to $1.0 \mathrm{~A}_{\mathrm{dc}}$. The voltage measurement was made using a high impedance electrometer by connections to the inner pins. The probe provided accurate results requiring no corrections when the sample being measured was the same width as the probe. Anodes having a width greater than the probe introduce correctible errors as a result of additional current pathways (McGill, et al. 1999). The effect of these additional pathways is a reduction of the measured resistance. Anode widths more than twice the probe width, such as would be encountered with bridge CP zones, lead to a measured resistance about $60 \%$ of the true resistance.

\subsubsection{CP circuit ac resistance}

The ac circuit resistance of the aged thermal-sprayed anodes was measured in the laboratory between the $\mathrm{Zn}$ anode and the steel mesh cathode. Measurements were made at the beginning of the electrochemical aging experiment and others during and after the experiment was completed. Some measurements were made as soon as the slabs were removed from the elevated humidity enclosure and then several days later after the slabs had equilibrated with ambient indoor conditions. A conductivity bridge was used to make the measurements at $50-60 \mathrm{~Hz}$. AC resistance was converted to an effective resistivity using the surface area of the anode and the thickness of concrete between the anode and the steel mesh cathode. 


\subsubsection{Anode air permeability}

The permeability of the TS Zn anode to the ingress of air can be determined by a surface air permeability measurement. The instrument is based on the principle that flow of air through a surface will be higher for a surface with a higher permeability. Operation of the instrument required a vacuum of about $640 \mathrm{~mm}(25 \mathrm{in}) \mathrm{Hg}$. Air flow was measured by a mass flowmeter. The instrumentation was available as a self-contained portable unit. Its operation is described in the "Showcase Workshop on Concrete Durability" (U.S. FHWA-SHRP 1995) and in SHRP-S329, "Condition Evaluation of Concrete Bridges Relative to Reinforcement Corrosion - Volume 7: Method for Field Measurement of Concrete Permeability" (Whiting and Cady 1993). The instrument is shown in Figure 3.13 in use on a thermal-sprayed $\mathrm{Zn}$ anode $\mathrm{CP}$ zone on the Yaquina Bay Bridge. Figure 3.14 gives a closer view of the instrument showing the flexible rubber gasket used to form a vacuum seal between the measuring head and the bridge surface.

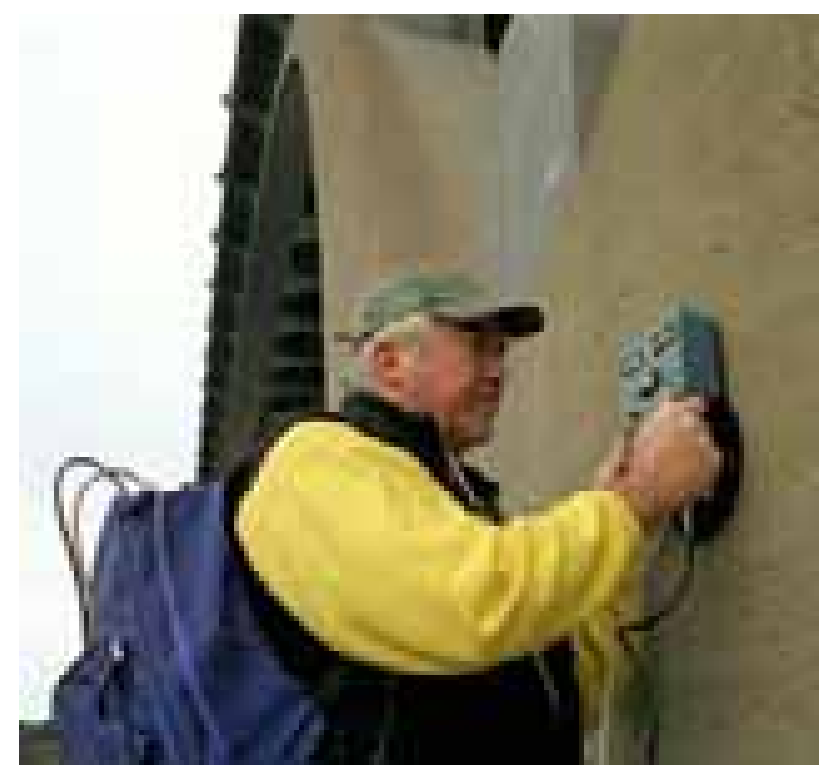

Figure 3.13: Portable surface air permeability instrument in use

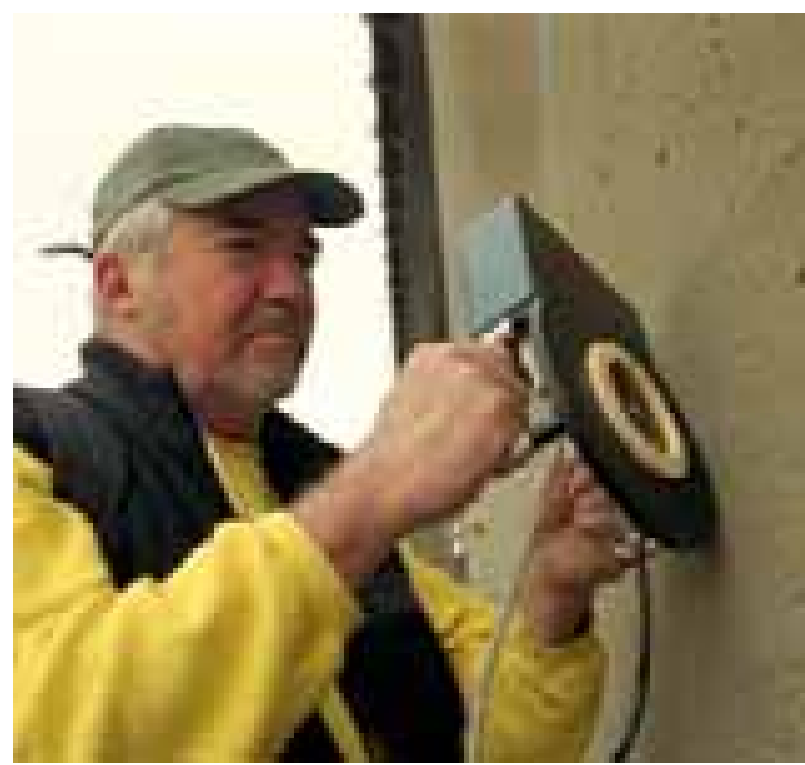

Figure 3.14: Close-up of measuring head for surface air permeability instrument showing the flexible rubber gasket that forms a vacuum seal between the measuring head and concrete surface 
A series of calibration experiments were conducted with ceramic porosity standards, Table 3.2, to help understand the results obtained from the instrument. A special adapter was machined to hold the $5 \mathrm{~cm}$ ( 2 in) diameter ceramic discs to the measuring head. The discs were obtained from Coors Ceramics Company. The maximum pore diameter and permeability were determined by Coors using "Standard Test Method for Maximum Pore Diameter and Permeability of Rigid Porous Filters for Laboratory Use" (ASTM 1999). Independent measurements of mean pore diameter and porosity for some of the disks were made using mercury porosimetry, Table 3.2. The was significant difference between the two sets of measurements. Air flow rate and absolute pressure at the flow meter were measured for the discs in Table 3.2. The same measurement technique was also used to measure the permeability of $\mathrm{Zn}$ anodes on laboratory slabs in experiments 1 and 2.

Table 3.2: Ceramic porosity standards for air permeability measurements

\begin{tabular}{|c|c|c|c|c|c|}
\hline \multirow[t]{2}{*}{$\begin{array}{l}\text { Coors } \\
\text { Designation }\end{array}$} & \multicolumn{3}{|c|}{$\begin{array}{c}\text { Data provided by Coors using ASTM E128 } \\
\text { (ASTM 1999) }\end{array}$} & \multicolumn{2}{|c|}{$\begin{array}{l}\text { Independently measured data } \\
\text { using mercury porosimetry } \\
\text { (Holcomb 1996) }\end{array}$} \\
\hline & $\begin{array}{l}\text { Maximum pore } \\
\text { diameter, } \mu \mathbf{m}\end{array}$ & $\begin{array}{l}\text { Apparent } \\
\text { porosity, \% }\end{array}$ & $\begin{array}{l}\text { Permeability, } \\
\text { mDarcy }\end{array}$ & $\begin{array}{l}\text { Mean pore } \\
\text { diameter, } \mu \mathrm{m}\end{array}$ & $\begin{array}{l}\text { Porosity } \\
\text { \% }\end{array}$ \\
\hline $\mathrm{Al}_{2} \mathrm{O}_{3}$ & 0.10 & 0 & 0 & & \\
\hline AP-998-C & 0.13 & 19.6 & 0.3 & 0.32 & 25 \\
\hline $\mathrm{P}-1 / 2 \mathrm{~B}-\mathrm{C}$ & 0.15 & 38.5 & 0.15 & 0.15 & 39 \\
\hline P-1-C & 0.6 & 33 & 2.7 & & \\
\hline P-3-C & 2.2 & 45.4 & 40 & & \\
\hline P-6-C & 6 & 36.5 & 80 & 1.66 & 36 \\
\hline P-12-C & 10.5 & 39 & 300 & $3.86^{1}$ & 44 \\
\hline P-40-C & 40 & 37.6 & 3280 & $20.1^{2}$ & 34 \\
\hline
\end{tabular}

\subsubsection{Anode Water Permeability}

The rate of water permeation through aged $\mathrm{Zn}$ anodes and into the concrete was measured on small areas, $0.0096 \mathrm{~m}^{2}\left(14.9 \mathrm{in}^{2}\right)$, of the TS $\mathrm{Zn}$ anodes. The apparatus is shown schematically in Figure 3.15. Water under constant pressure was applied to the surface using a $100 \mathrm{ml}$ buret attached to an inverted glass funnel sealed to the $\mathrm{Zn}$ surface by a silicone adhesive. Water flow through the zinc-concrete interface was measured as a function of time for up to 14 days. The water permeation rate was computed from the initial slope of the curves, representing the rate unaffected by back pressure from accumulated water in the concrete. 


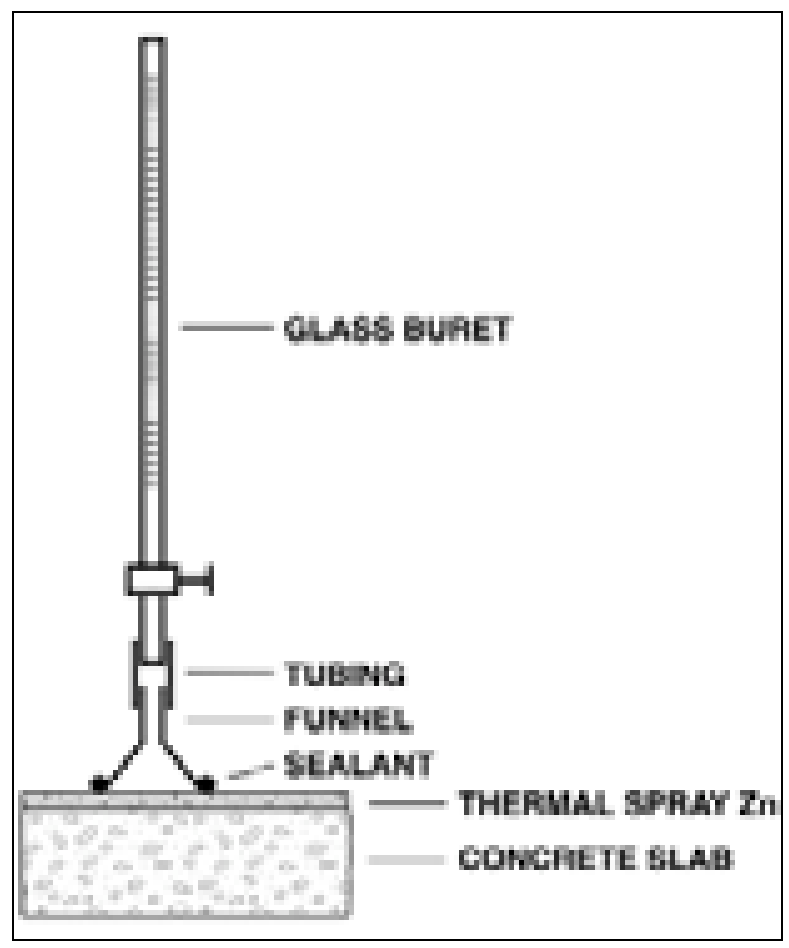

Figure 3.15: Schematic drawing of apparatus used to measure the TS $\mathrm{Zn}$ anode permeability to water 


\subsection{LABORATORY ANODE AGING STUDIES -- RESULTS}

\subsection{ANODE APPLICATION}

\subsubsection{Concrete surface preparation}

$\mathrm{X}$-ray diffraction analysis of the top surface of as-cast, non-sandblasted concrete showed the laitance layer on the surface contained calcite $\left(\mathrm{CaCO}_{3}\right)$ as a primary phase with quartz $\left(\mathrm{SiO}_{2}\right)$ and albite $\left(\mathrm{NaAlSi}_{3} \mathrm{O}_{8}\right)$ as secondary phases. Optical microscope examination of polished crosssections showed this surface to be a shallow translucent layer containing only very fine cementitious material.

The sandblasted, unheated concrete surface contained quartz as a primary phase with albite as a secondary phase, vaterite (an unstable form of calcite) as a minor phase, and a trace of calcite. Optical microscopy showed that the shallow translucent layer had been largely removed by sandblasting. The sandblasted, preheated concrete surface contained roughly equal amounts of quartz and albite as primary phases, with traces of calcite and vaterite.

Scanning electron photomicrographs of the concrete surface are shown in Figure 4.1. Figures 4.1(a) and 4.1(b) are back-scattered electron (BSE) and secondary electron (SE) images, respectively, of the as-cast, non-sandblasted surface. Figure 4.1(c) is a BSE image of the sandblasted, unheated surface and Figure 4.1(d) is a BSE image of the sandblasted, preheated surface. All are at the same magnification. The thin laitance layer of fine cementitious material present on the surface of the as-cast slab is clearly visible in Figures 4.1(a) and 4.1(b); aggregate is seen to lie below this surface. Sandblasting removes most of the laitance layer from concrete, although it can be present as thin remnants at isolated locations. It was not present in Figures $4.1(\mathrm{c})$ or $4.1(\mathrm{~d})$.

Sandblasting and preheating the slab surface changed the surface composition from one that contained substantial carbonate to one that contained predominantly silicates and quartz. Preheating seemed to remove some carbonate minerals, probably by thermal decomposition. 


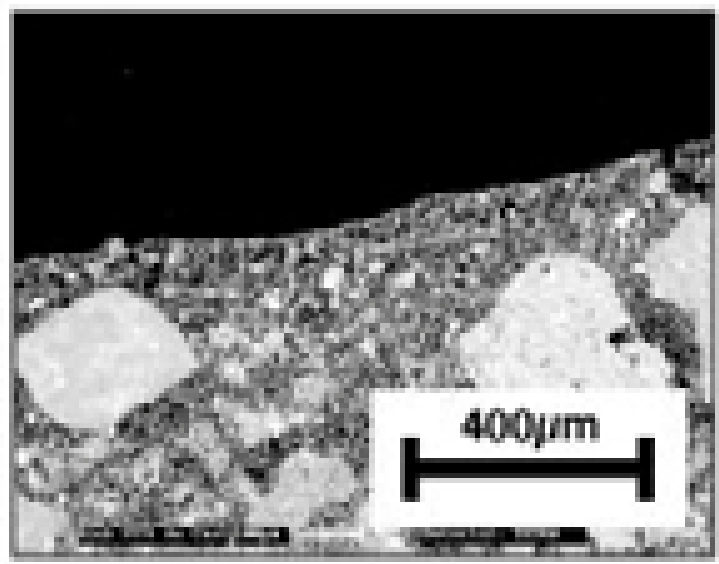

(a)

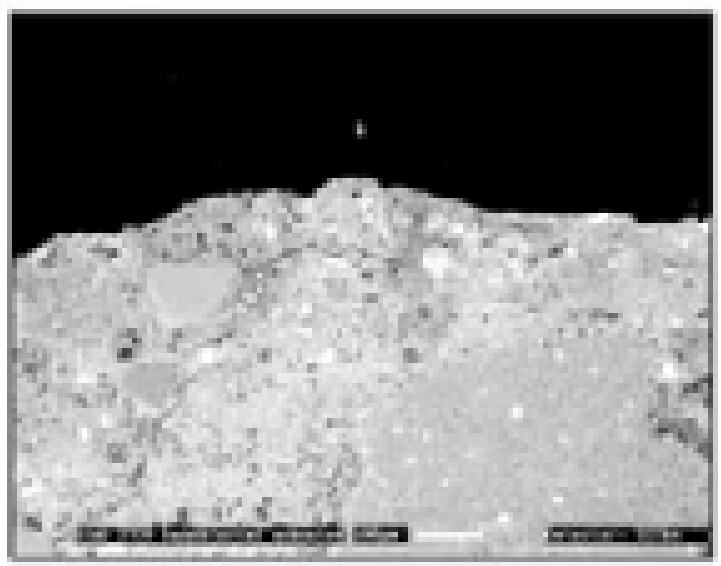

(c)

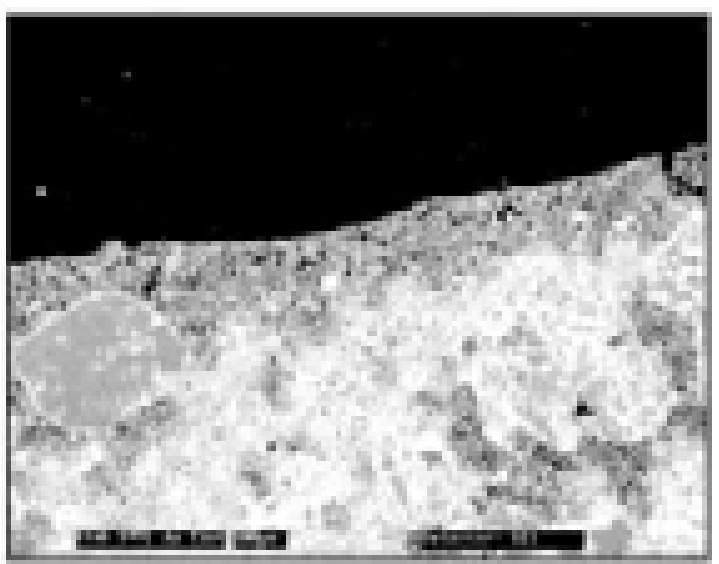

(bi)

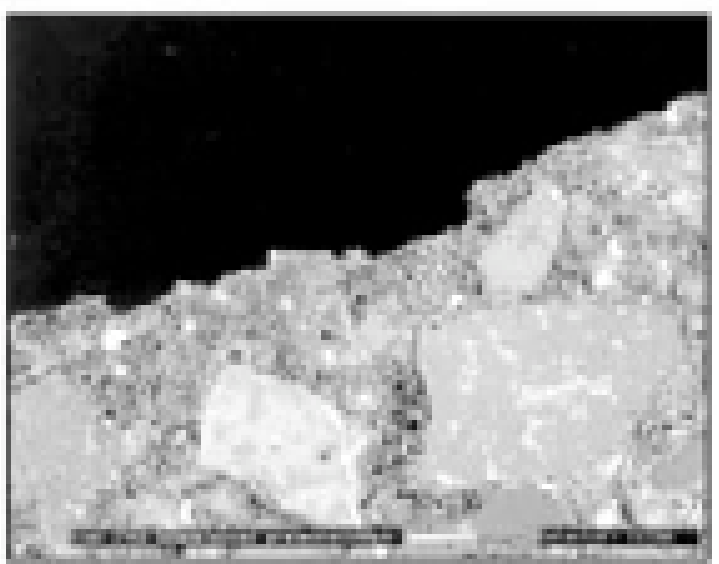

(d)

Figure 4.1: Multiple SEM photomicrographs of cross sections from uncoated slabs. (a) as cast, back scattered electron (BSE); (b) as cast, secondary electron (SE); (c) sandblasted, BSE; (d) sandblasted and preheated, BSE.

\subsubsection{Anode coating thickness}

The thickness of the $\mathrm{Zn}$ coating on all 56 slabs used in the first experiment was measured using an eddy current device. These results are shown in Figure 4.2 as averages and standard deviations at 12 specific locations on the slab. A template was used to reproduce the same positions (A-L) on all of the slabs. The average thickness ranged from $0.43-0.50 \mathrm{~mm}(17.1$ to 19.8 mils) with the majority near the center of the slabs at approximately $0.46 \mathrm{~mm}$ (18 mils). The target thickness was $0.5 \mathrm{~mm}$ ( 20 mils). The consistently higher thickness at the two ends of the slabs was caused by the way the robotically-controlled sprayer idled at the slabs ends when it changed direction. Bond strength measurements were always made at positions A-F and slab samples were cut either from $\mathrm{G}$ to I or from $\mathrm{J}$ to $\mathrm{L}$ for analysis of the anode-concrete interface. 


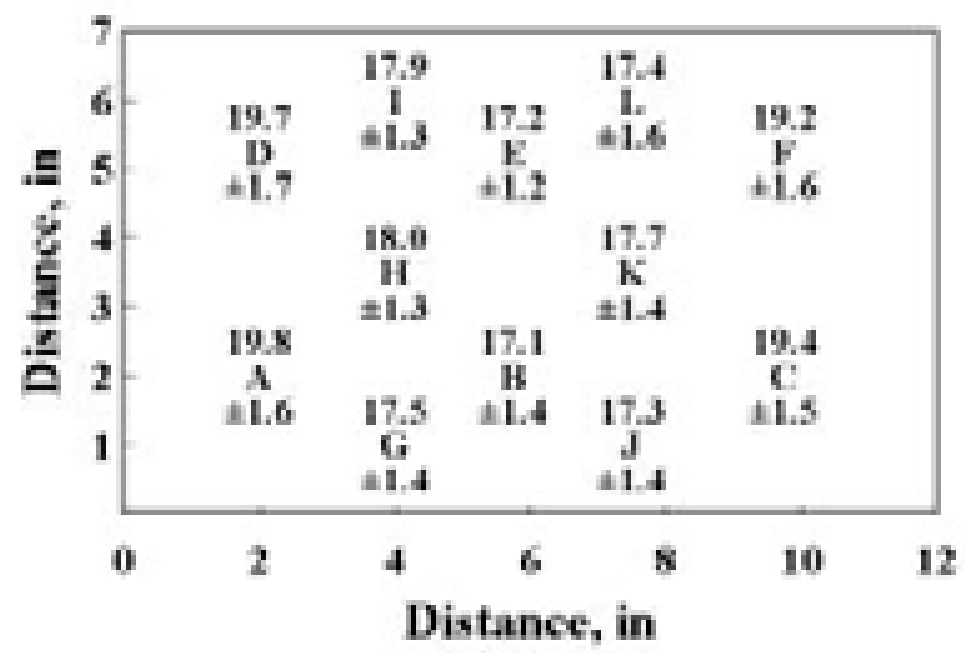

Figure 4.2: Location of measurements on 56 concrete slabs showing average and standard deviation values of TS Zn coating thickness from eddy current measurements

\subsubsection{Anode temperature}

Surface temperature versus time plots for thermal spraying the concrete slabs with $\mathrm{Zn}$ are given in Figure 4.3. The two curves are the temperature measured by the two thermocouples. The offset of the curves is a result of the time lag created by the two-inch separation of the thermocouples. The thermal spray head moved in a motion similar to a square wave. The speed of the spray head was $45.7 \mathrm{~cm} / \mathrm{s}$ (18 in/s) and the wave amplitude was $40.6 \mathrm{~cm}$ (16 in). The data acquisition system recorded 10 points per second.

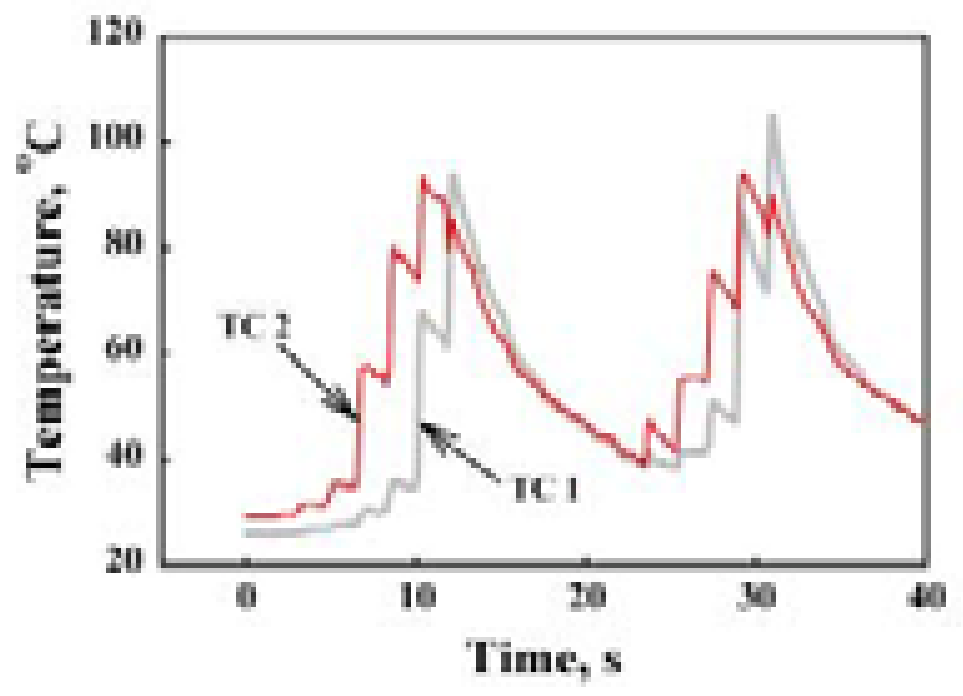

Figure 4.3: TS Zn coating surface temperature versus time for two thermocouples under the coating on the concrete slab 
The curves in Figure 4.3 indicate the surface of the concrete reached a temperature of approximately $90-100^{\circ} \mathrm{C}\left(194-212^{\circ} \mathrm{F}\right)$ within a few seconds when the spray head passed directly over the thermocouples. The surface cooled to temperatures less than $40^{\circ} \mathrm{C}\left(104^{\circ} \mathrm{F}\right)$ in about 10 seconds after the spray head passed. The jagged shape of the rising temperature curve was caused by adjacent passes of the spray head as it approached the thermocouple.

While temperatures of less than $100^{\circ} \mathrm{C}$ may cause some drying of the concrete surface, these temperatures appear insufficient to degrade properties of the concrete surface; also see Figure 4.1(d). In fact, Oregon DOT required the concrete surface be preheated to $120^{\circ} \mathrm{C}\left(250^{\circ} \mathrm{F}\right)$ prior to application of the TS Zn anode for both the Cape Creek and Yaquina Bay Bridge - Arches thermal spray projects, in an effort to improve anode long-term bond strength.

\subsection{ICCP PERFORMANCE}

The electrochemical performance of the TS Zn anode was examined in terms of the voltage or associated $\mathrm{CP}$ circuit resistance required to maintain a constant anodic current density, and of the coating permeability to water. Despite the fact that the test slabs were electrochemically aged in a room where the humidity was controlled to 80 to $85 \% \mathrm{RH}$, the slabs continually lost water during electrochemical aging by either evaporation or consumption. To avoid exceeding the compliance voltage of the current sources used in the aging experiment, it was necessary to periodically wet the $\mathrm{Zn}$ coatings with deionized water. Wetting was done by daily spraying a mist of water on the coating surface to form a continuous film. Since the anode aging was accelerated 15 times that used by Oregon DOT on coastal bridges, the daily spraying was roughly equivalent to a rain event every 15 days, not unreasonable for the Oregon coast.

The periodic wetting of the anode surface is similar to what has been referred to in the literature as "activating" the coating (Sagues and Powers 1995). The spraying of water onto the $\mathrm{Zn}$ surface was different from the procedure used by Brousseau (Brousseau, et al. 1994b). There the test slabs were placed in containers of a salt solution so that the bottoms were always wet and natural wetting and drying cycles did not occur. Typical circuit resistance curves for TS Zn anode CP systems are plotted in Figure 4.4 as a function of electrochemical age for the first (periodically wetted) and second (unwetted) experiments. The electrochemical age in this figure is also expressed in equivalent years at the Oregon DOT CP current density of $2.2 \mathrm{~mA} / \mathrm{m}^{2}$ for coastal bridges.

The saw-tooth pattern in Figure 4.4 was a result of the daily wetting and drying periods or cycles. A drop in the slab potential occurred when the coating surface was wetted; a rise occurred during drying. Two important features of the potential-charge record are: (1) the general rise in the minimum circuit resistance following each wetting cycle as aging progressed; and (2) the increase in the rate that circuit resistance rose during each drying period. When wetted within the first $300 \mathrm{kC} / \mathrm{m}^{2}\left(7.7 \mathrm{~A}-\mathrm{h} / \mathrm{ft}^{2}\right)$, circuit resistance fell to very low values, on the order of 10-50 $\Omega-\mathrm{m}^{2}$. Following this, when the slab began to dry, the circuit voltage rose less than one volt per slab per day (Covino, et al. 1995). In contrast, beyond $800 \mathrm{kC} / \mathrm{m}^{2}$ (20.6 A$\mathrm{h} / \mathrm{ft}^{2}$ ) the minimum circuit resistance rose to roughly $1 \mathrm{k} \Omega-\mathrm{m}^{2}$ and the rate of potential rise increased to $10-30 \mathrm{~V} / \mathrm{slab} /$ day. 


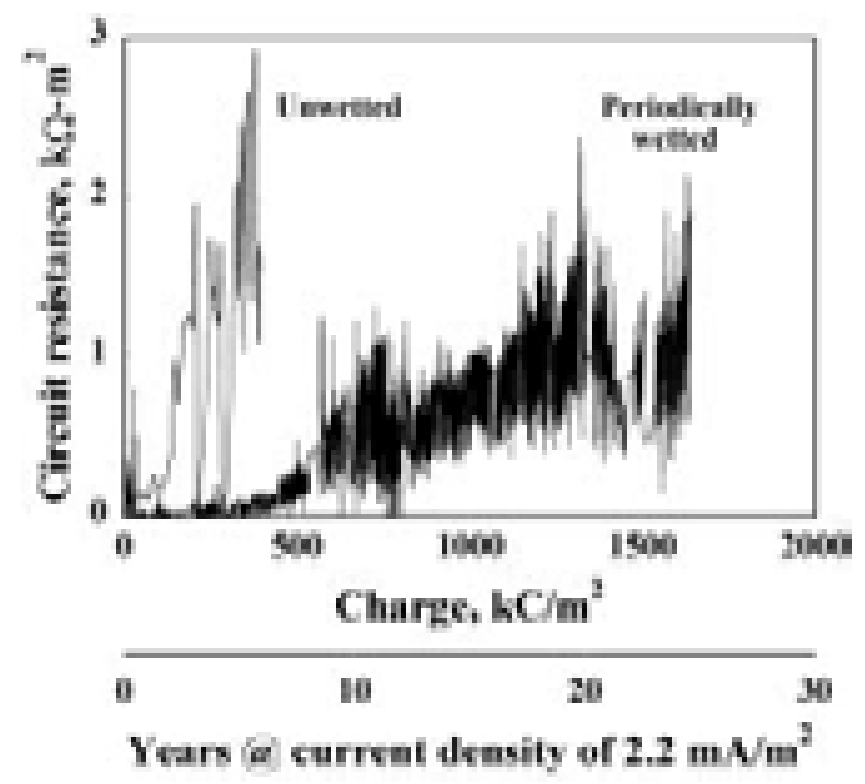

Figure 4.4: TS Zn anode circuit resistance versus electrochemical age for both periodically-wetted and un-wetted concrete slabs

At about $300 \mathrm{kC} / \mathrm{m}^{2}\left(7.7 \mathrm{~A}-\mathrm{h} / \mathrm{ft}^{2}\right)$, the electrochemical age where circuit resistance began to rise significantly, free water began pooling on the coating surface after wetting and remained there for increasingly longer periods. Thus, the ability of water to penetrate the TS Zn anode became increasingly more restricted as though the anode were becoming sealed. Figure 4.5 illustrates the time it took for the circuit voltage to rise during each drying period. The time dropped from 6 days to less than 1 days to rise to 25 volts when the electrochemical age increased from 207 to $391 \mathrm{kC} / \mathrm{m}^{2}$ (5.3 to $\left.10.1 \mathrm{~A}-\mathrm{h} / \mathrm{ft}^{2}\right)$.

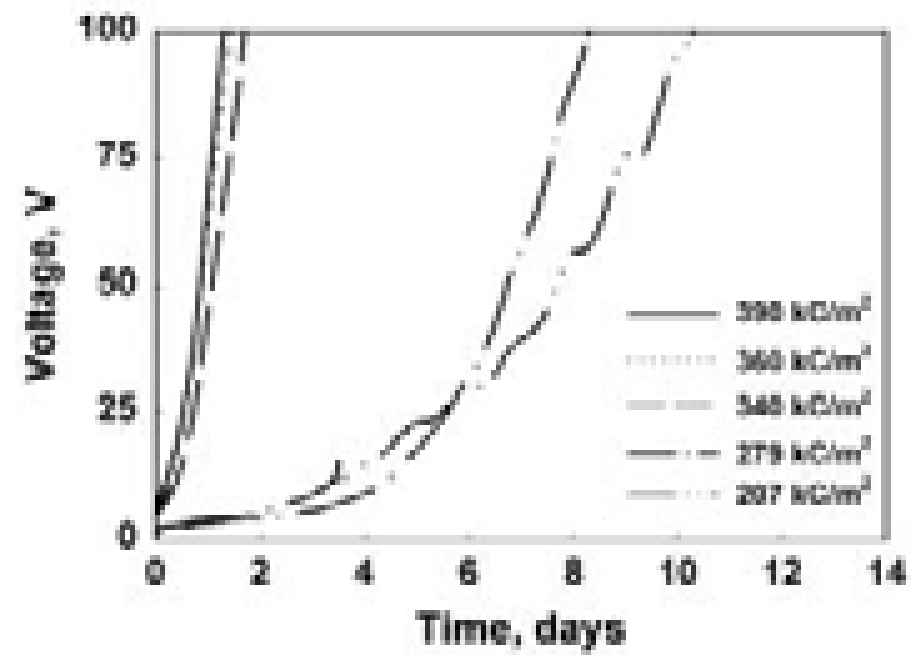

Figure 4.5: CP system voltage rise due to drying of the anode-concrete interface versus drying time for selected electrochemical ages 
When the concrete was wetted, the circuit potential decayed exponentially. With increasing electrochemical age, the slope of the voltage decay curve decreased, Figure 4.6 and Table 4.1, and it took proportionately longer for wetting to reduce the circuit voltage. The changes in voltage decay and voltage rise curves with aging suggests the gradual formation of a barrier layer at the zinc-concrete interface and the sealing of anode porosity with zinc minerals that both retards inward transport of moisture to the concrete and serves as an electrically insulating component of the CP circuit.

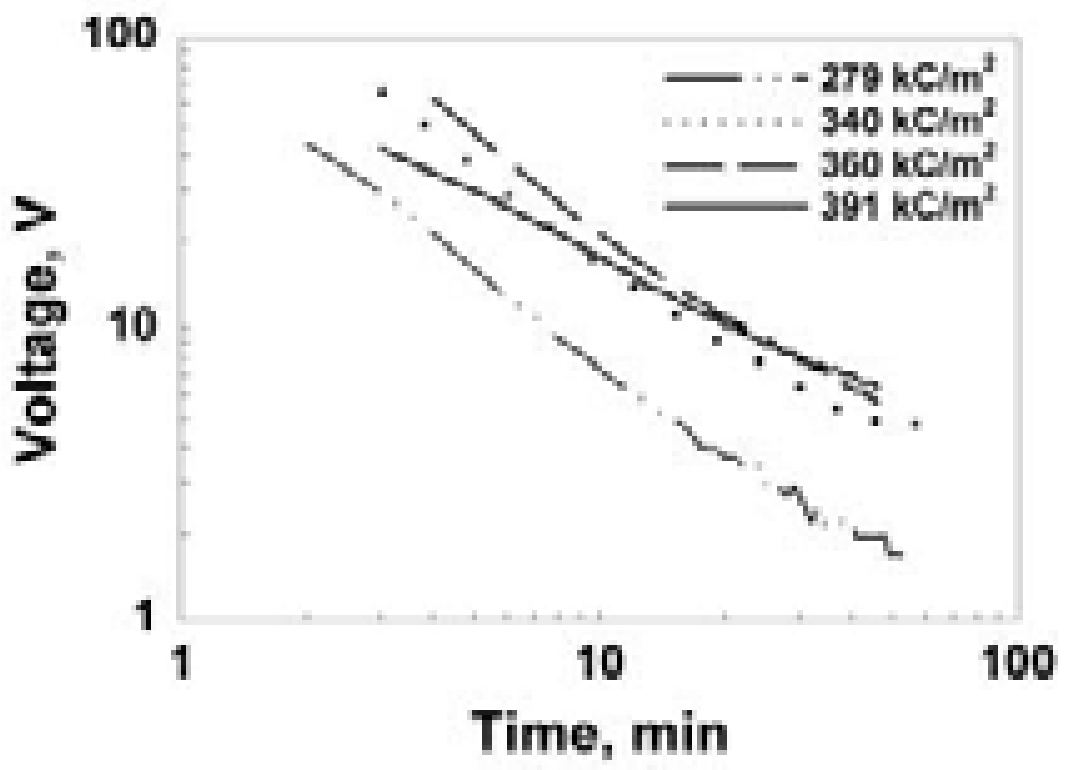

Figure 4.6: CP system voltage decay due to wetting of the anode-concrete interface versus elapsed time after wetting for selected electrochemical ages

Table 4.1: Voltage decay parameters for TS $\mathrm{Zn}$ anodes on periodically-wetted concrete slabs (based on Figure 4.6)

\begin{tabular}{c|c|c|c}
\hline $\begin{array}{c}\text { Charge, } \\
\mathbf{k C} / \mathbf{m}^{2}\end{array}$ & $\begin{array}{c}\text { Intercept, } \\
\text { volts }\end{array}$ & Slope & $\mathbf{R}^{\mathbf{2}}$ \\
\hline 279 & 73 & -0.9736 & 0.991 \\
\hline 340 & 113 & -0.8509 & 0.998 \\
\hline 360 & 128 & -0.8147 & 0.994 \\
\hline 391 & 88 & -0.6998 & 0.995 \\
\hline
\end{tabular}

\subsection{ANODE BOND STRENGTH}

Table 4.2 shows the tensile strength of uncoated (bare) concrete slabs. The as-cast, nonsandblasted slab had the lowest tensile strength and the failure was in the thin laitance layer on 
the slab surface observed by optical and electron microscopy, Figure 4.1. The sandblasted, unheated slab had the highest tensile strength of the bare slabs and the failure penetrated into the large aggregate of the concrete. Preheating lowered the tensile strength of the concrete by about $10 \%$, but the failure still penetrated into the large aggregate of the concrete.

Table 4.2: Pull strength of concrete in bare test slabs

\begin{tabular}{l|c|c}
\hline \multicolumn{1}{c|}{ Surface Treatment } & MPa (psi) ${ }^{1}$ & Std Dev \\
\hline As Cast & $2.63(381.5)$ & $\pm 0.65(94)$ \\
\hline Sandblasted, unheated & $3.18(461.3)$ & $\pm 0.50(73)$ \\
\hline Sandblasted, preheated & $2.83(410.5)$ & $\pm 0.47(68)$ \\
\hline${ }^{1}$ Average of twelve pulls
\end{tabular}

Table 4.3 shows the bond strength of $\mathrm{Zn}$ coatings on sandblasted concrete prior to and after natural aging (i.e., without either impressed current or galvanic current) for 57 and 134 days in the humidity and temperature controlled enclosure used in the first and second experiments. The average initial bond strength for the unheated slabs in the first experiment was $1.28 \mathrm{MPa}(185$ psi) and 2.29 $\mathrm{MPa}$ (331 psi) for the preheated slabs. In the second experiment, the initial bond strength for the unheated and preheated slabs was 1.72 $\mathrm{MPa}$ (249 psi) and 1.91 MPa (277 psi), respectively, were closer than in the first experiment. A bond strength increase from heating, as shown here, is consistent with published results (Brousseau, et al. 1994b). Clearly then, preheating increases the TS Zn anode bond strength compared to unheated slabs.

The cohesive strength of cured, uncoated (bare) sandblasted concrete slabs was 2.8-3.2 MPa (410-460 psi). Compared to this, the initial zinc anode bond strengths were well below the cohesive strength of the concrete. Visual observations show that bond failure for the unaged slabs was confined to the thin layer of concrete immediately adjacent to the $\mathrm{Zn}$. With natural aging, the bond strength increased in the absence of any significant electrochemical reaction and approached cohesive strength of uncoated, sandblasted concrete. Bond failure for the naturally aged slabs occurred well into the concrete, indicating that the $\mathrm{Zn}$ bond strength was comparable to or greater than the cohesive strength of the concrete. This may be a reflection of $\mathrm{Zn}$ reaction with moisture in the concrete, or with humid air absorbed by the coating. The $\mathrm{Zn}$ reaction zone leading to the increase in bond strength in the absence of CP must be thin. Later results will show that electrochemical aging during $\mathrm{CP}$ eventually negates this increase in bond strength. 
Table 4.3: Bond strength of naturally-aged TS $\mathrm{Zn}$ anodes on periodically-wetted concrete slabs

\begin{tabular}{c|c|c|c|c}
\hline $\begin{array}{c}\text { Pre-coating } \\
\text { Treatment }\end{array}$ & Experiment & $\begin{array}{c}\text { Days Aged with } \\
\text { Coating Present }\end{array}$ & MPa (psi) & $\begin{array}{c}\text { Std Dev } \\
\text { MPa (psi) }\end{array}$ \\
\hline Unheated & 2 & $0^{1}$ & $1.72(249)$ & $\pm 0.26(38)$ \\
\hline Unheated & 1 & $0^{2}$ & $1.28(185)$ & $\pm 0.12(17)$ \\
\hline Unheated & 2 & $57^{3}$ & $1.85(268)$ & $\pm 0.08(12)$ \\
\hline Unheated & 2 & $114^{2}$ & $2.32(336)$ & $\pm 0.45(65)$ \\
\hline Preheated & 2 & $0^{1}$ & $1.91(277)$ & $\pm 0.37(54)$ \\
\hline Preheated & 1 & $0^{2}$ & $2.29(331)$ & $\pm 0.45(64)$ \\
\hline Preheated & 2 & $57^{3}$ & $2.42(351)$ & $\pm 0.18(26)$ \\
\hline Preheated & 2 & $134^{2}$ & $2.93(424)$ & $\pm 0.19(28)$ \\
\hline $\begin{array}{l}\text { Average of 18 pulls } \\
\text { Average of 12 pulls } \\
\text { Average of 6 pulls }\end{array}$ & & & \\
\end{tabular}

$\mathrm{Zn}$ anode bond strength as a function of electrochemical age is shown in Figures 4.7a and 4.7b, respectively, for the preheated and unheated slabs periodically wetted in the first experiment. $\mathrm{Zn}$ anode bond strength as a function of electrochemical age is shown in Figures 4.8a and 4.8b, respectively, for the preheated and unheated zinc-coated slabs not wetted (unwetted) in the second experiment. Bond strengths for every slab tested are listed in Appendix A. The mean of six individual measurements are shown as a data point in these figures. The scatter in bond strength values at each aging time is typical of measurements on these types of samples. In spite of the scatter, it is evident that there are several trends associated with the data. These are:

- a higher initial bond strength for preheated slabs

- a decline in bond strength for the periodically-wetted slabs early in the aging process

- an increase in bond strength for the periodically-wetted slabs for greater ages to a maximum bond strength

- a decrease in bond strength beyond the maximum to a point of delamination (i.e., zero bond strength) for both unwetted and periodically wetted slabs

- periodic-wetting greatly extended the time to delamination compared to no wetting of the slabs. 


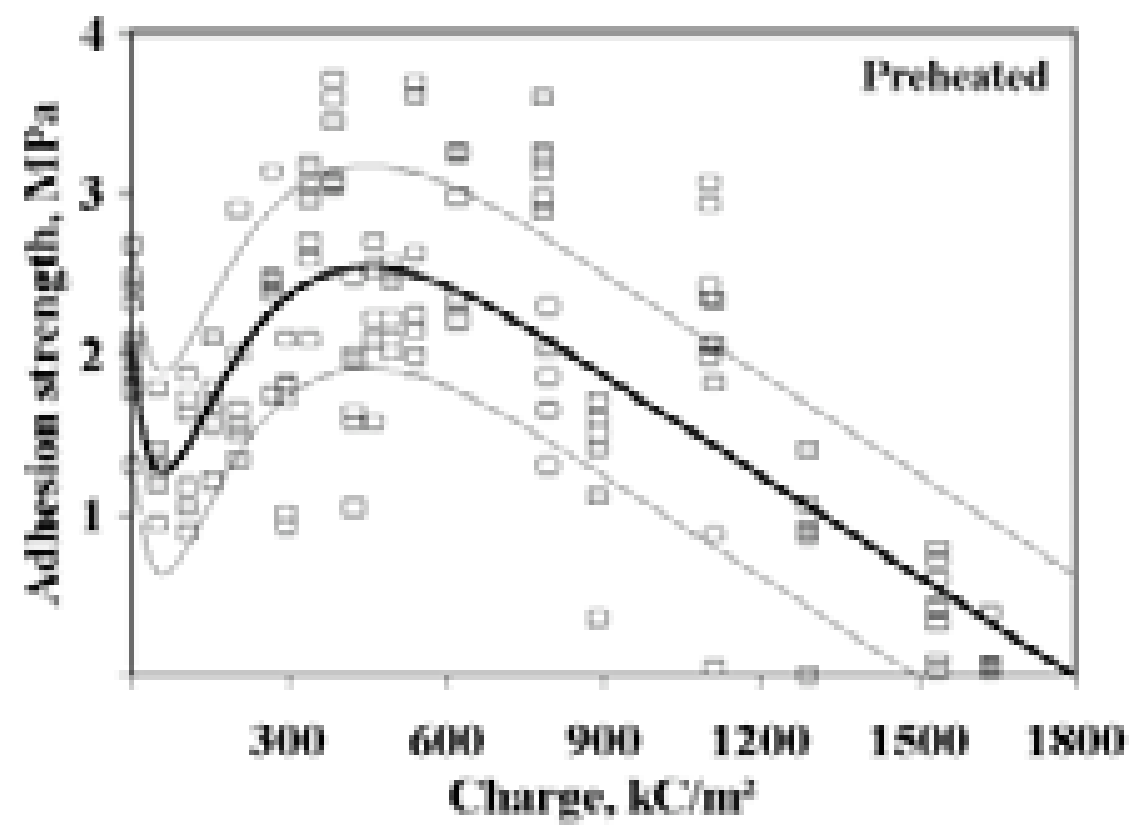

Figure 4.7a: Bond strength of the TS Zn anode on periodically-wetted, preheated concrete slabs versus electrochemical age

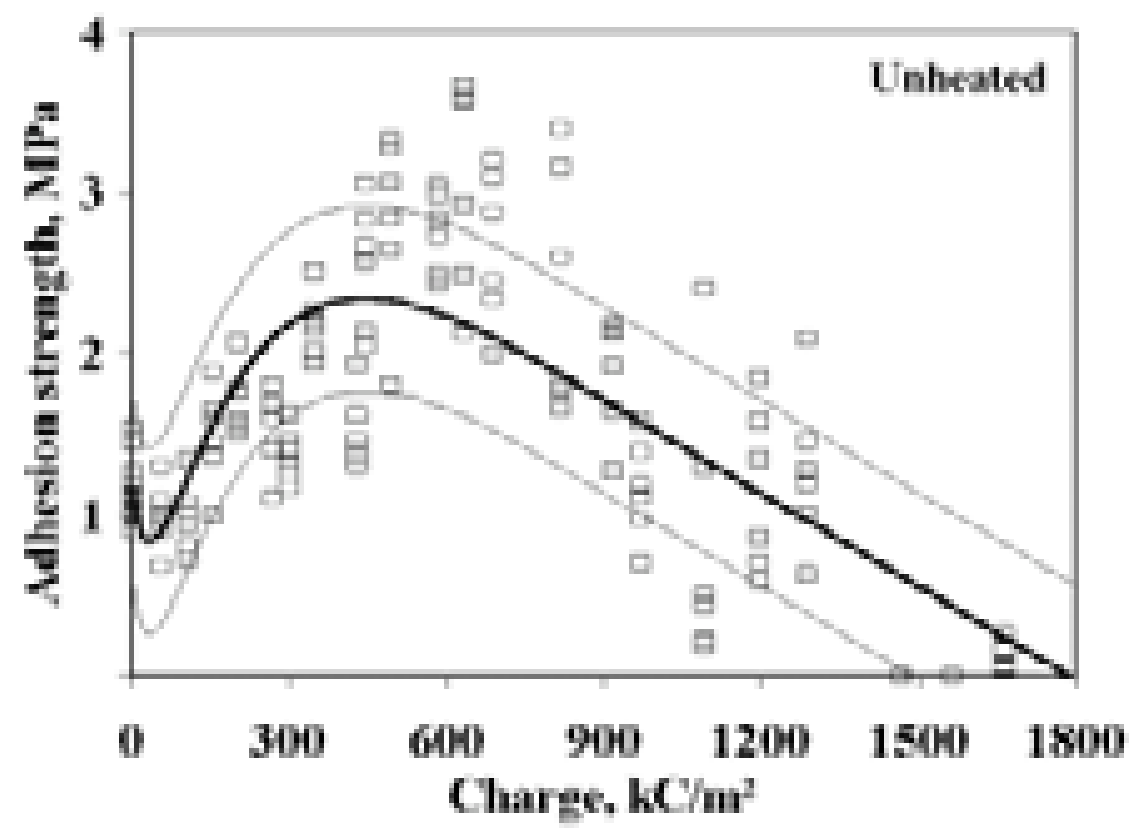

Figure 4.7b: Bond strength of the TS Zn anode on periodically-wetted, unheated concrete slabs versus electrochemical age 


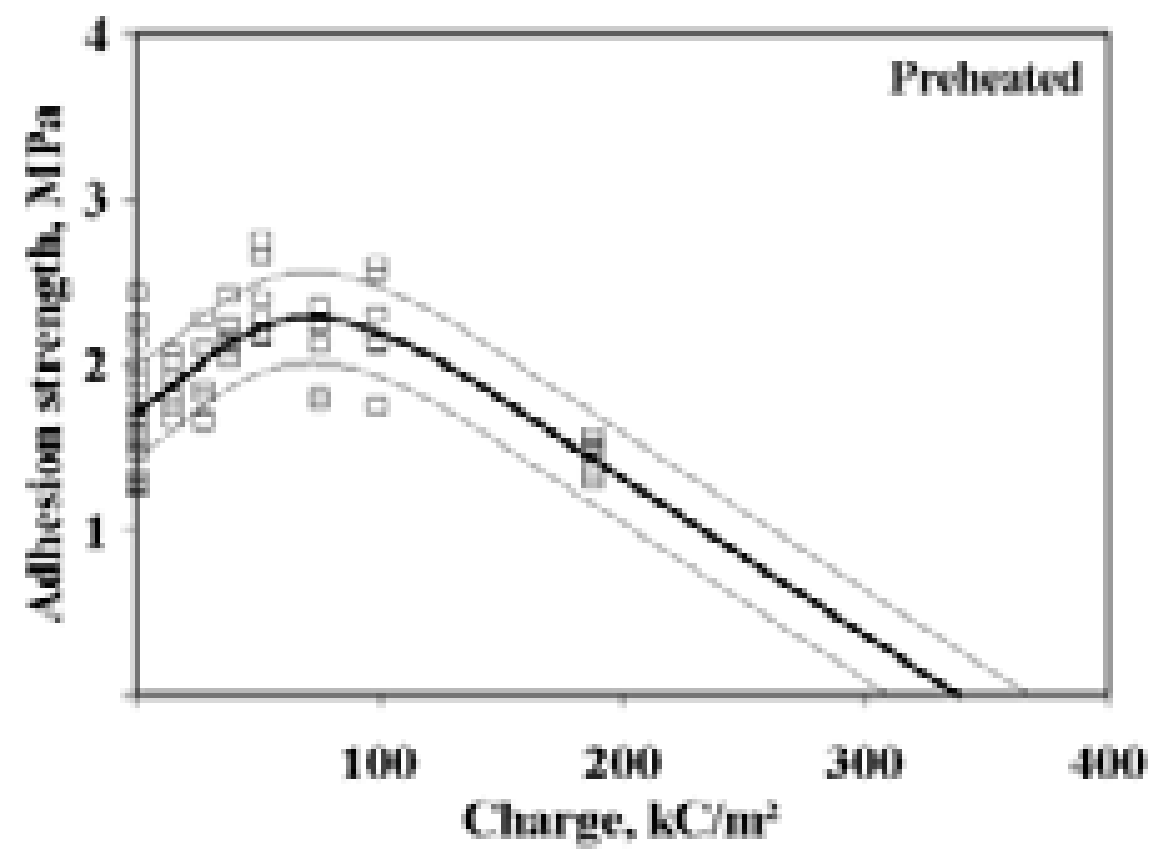

Figure 4.8a: Bond strength of the TS Zn anode on un-wetted, preheated concrete slabs versus electrochemical age

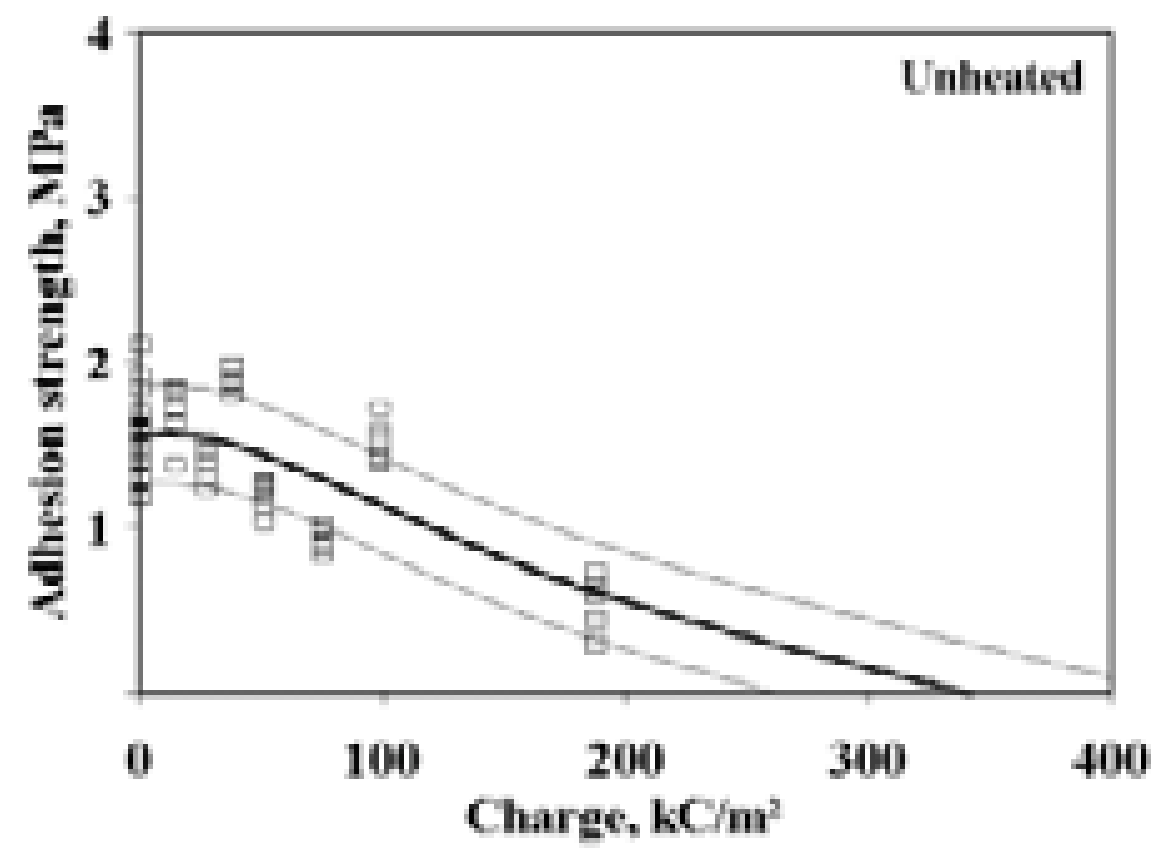

Figure 4.8b: Bond strength of the TS Zn anode on un-wetted, unheated concrete slabs versus electrochemical age 
To better understand the bond strength data and to provide a basis for predicting long-term behavior, bond strength (S) was empirically modeled as a function of the electrochemical age, where, for convenience, $\mathrm{C}$ was substituted for $\mathrm{EA}$ in the fitting equations. A least-squares fit of the data in Figures 4.7 and 4.8 gave Equations 4-1 and 4-2:

For $\mathrm{C} \leq 2 \mathrm{C}_{\mathrm{f}}$ :

$$
S=S_{i} \exp \left(-C / C_{m}\right)+S_{u}\left(C / C_{f}\right) \exp \left(1-C / C_{f}\right)
$$

For $\mathrm{C} \geq 2 \mathrm{C}_{\mathrm{f}}$ :

$$
S=\left(S_{u} / e\right)\left(4-C / C_{f}\right)
$$

The model parameters are given in Table 4.4. The fitted equations are the heavy solid curves in Figures 4.7 and 4.8; the dashed curves in the figures are the 70-percent confidence limits. It is clear from these confidence limits that the long-term bond strength of $\mathrm{Zn}$ was not statistically different whether the $\mathrm{Zn}$ was applied to preheated or unheated concrete. This was true for the case where electrochemical aging was carried out on periodically wetted concrete as in experiment 1, Figures $4.7 \mathrm{a}$ and $4.7 \mathrm{~b}$, and on unwetted concrete, Figures $4.8 \mathrm{a}$ and $4.8 \mathrm{~b}$. Early in the aging process there were some small differences in the bond strength of preheated and unheated slabs, but these differences were not significant in terms of the performance of the $\mathrm{Zn}$ anode. Thus, while preheating improved the initial bond strength, it did not have a lasting effect on the value of the long-term coating bond strength.

Equations 4-1 and 4-2 are plotted schematically in Figure 4.9 to define the parameters used in the equations and referred to in Table 4.4. $\mathrm{S}_{\mathrm{i}}$ is the average initial bond strength, a measured quantity given in Table 4.3 for time equals zero. The other parameters are: $\mathrm{S}_{\mathrm{u}}$, the ultimate, or maximum, bond strength of the coating; $\mathrm{C}_{\mathrm{m}}$, the charge associated with weakening the initial mechanical bond; and $\mathrm{C}_{\mathrm{f}}$, the charge or electrochemical age at the maximum bond strength. Along with parameter values, fitting statistics are given in Table 4.4. The estimated error of the data about the fitted curve was larger for the preheated slabs than for the unheated slabs in the first experiment. It was about the same in the second experiment. 


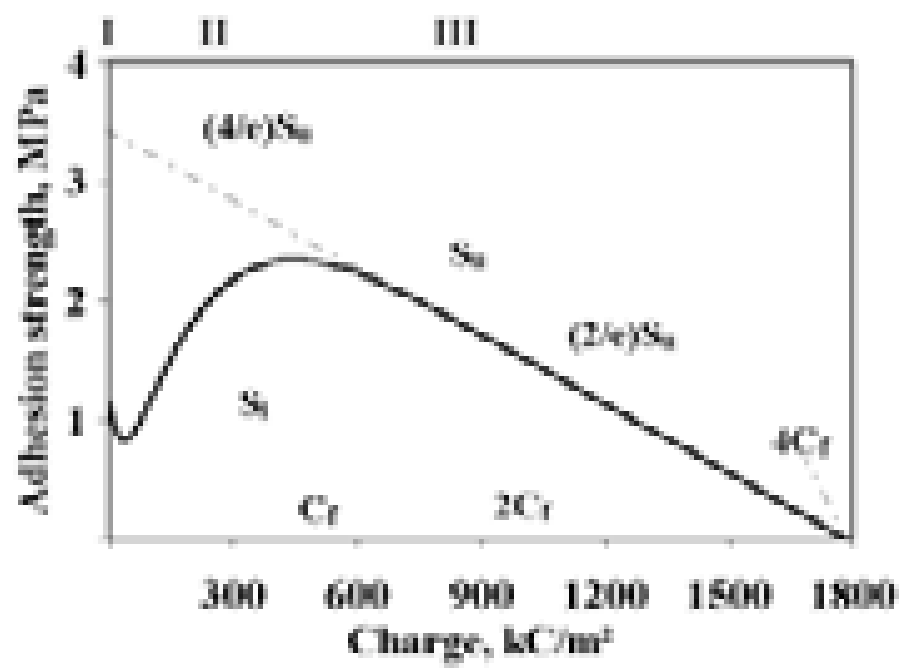

Figure 4.9: Model bond strength curve for electrochemically-aged TS $\mathrm{Zn}$ anodes on concrete slabs

Table 4.4: Model parameters for bond strength of TS $\mathrm{Zn}$ anodes on preheated and unheated concrete slabs in periodically-wetted and un-wetted experiments

\begin{tabular}{|c|c|c|c|c|}
\hline \multirow{3}{*}{$\begin{array}{l}\text { Variable or } \\
\text { statistic }\end{array}$} & \multicolumn{4}{|c|}{ Model parameters } \\
\hline & \multicolumn{2}{|c|}{ First Experiment } & \multicolumn{2}{|c|}{ Second Experiment } \\
\hline & $\begin{array}{c}\text { Preheated, } \\
\text { periodically-wetted }\end{array}$ & $\begin{array}{l}\text { Unheated, } \\
\text { periodically-wetted }\end{array}$ & $\begin{array}{c}\text { Preheated, } \\
\text { unwetted }\end{array}$ & $\begin{array}{l}\text { Unheated, } \\
\text { unwetted }\end{array}$ \\
\hline $\mathrm{S}_{\mathrm{i}}, \mathrm{MPa}$ (psi) & $2.29(332.2)$ & $1.28(185.7)$ & $1.91(277.1)$ & $1.72(249.5)$ \\
\hline $\mathrm{S}_{\mathrm{u}}, \mathrm{MPa}(\mathrm{psi})$ & $2.82(409.1)$ & $2.60(377.2)$ & $2.42(351.0)$ & $0.87(126.2)$ \\
\hline $\mathrm{C}_{\mathrm{m}}, \mathrm{kC} / \mathrm{m}^{2}$ & 40 & 31 & 27 & 69 \\
\hline $\mathrm{C}_{\mathrm{f}}, \mathrm{kC} / \mathrm{m}^{2}$ & 450 & 448 & 85 & 85 \\
\hline $4 \mathrm{C}_{\mathrm{f}}, \mathrm{kC} / \mathrm{m}^{2}$ & 1800 & 1792 & 340 & 340 \\
\hline $\begin{array}{l}\text { Estimated error, } \\
\qquad \mathrm{MPa} \text { (psi) }\end{array}$ & $0.65(94)$ & $0.59(86)$ & $0.28(41)$ & $0.30(44)$ \\
\hline Pseudo $\mathrm{R}^{2}$ & 0.57 & 0.62 & 0.50 & 0.51 \\
\hline $\begin{array}{l}\text { Corresponding } \\
\text { Figure }\end{array}$ & $4.7 \mathrm{a}$ & $4.7 b$ & $4.8 \mathrm{a}$ & $4.8 b$ \\
\hline
\end{tabular}

A discussion of the meaning of these parameters is best divided into the three regions indicated in Figure 4.9. Also, the discussion will be limited to the periodically wetted first experiment, Figures $4.7 \mathrm{a}$ and $4.7 \mathrm{~b}$. The bond strength of both the preheated and unheated slabs decreased below their initial values $\left(\mathrm{S}_{\mathrm{i}}\right)$ in Region $\mathrm{I}\left(0\right.$ to $\left.40 \mathrm{kC} / \mathrm{m}^{2}\right)$ as increasing charge was passed across the zinc-concrete interface. This decrease was greater for the preheated slabs. The bond strength reached a minimum for both types of slabs at about $50 \mathrm{kC} / \mathrm{m}^{2}\left(1.3 \mathrm{~A}-\mathrm{h} / \mathrm{ft}^{2}\right)$ and then began to 
increase for larger charge values. The first term of equation 4.1 describes this through an exponential decay function starting at the initial bond strength, $\mathrm{S}_{\mathrm{i}}$ and continuing to $\mathrm{C}_{\mathrm{m}}$, the charge or electrochemical age associated with the greatest weakening of the initial mechanical bond. This weakening is caused by the dissolution of $\mathrm{Zn}$ at the anode-concrete interface according to Equation 1-2.

Considerable strength remains however because there is sufficient "tooth" or roughness to the surface and the entire $\mathrm{Zn}$ anode area in contact with the concrete is not dissolved at the same time. A feature of the concrete surface referred to here as "anchor pits" (or "bug holes" in bridge vernacular) contributes to some small extent to the bond strength at this point. Anchor pits are irregularities in the concrete surface much larger in scale than "tooth" where gas bubbles broke through the surface. Thermal-sprayed $\mathrm{Zn}$ can fill, or partially fill, these places forming substantial anchors for the coating that are not greatly affected by aging since the mechanical locking of the coating at these sites is much greater than for "tooth." In Region I, the dissolved $\mathrm{Zn}$ forms a thin layer $(<0.02 \mathrm{~mm})$ of either $\mathrm{Zn}$ oxide or $\mathrm{Zn}$ hydroxide. This layer is not yet thick enough to significantly affect the transport of water through the $\mathrm{Zn}$ coating and the circuit resistance or slab voltage has not yet begun to rise.

Bond strengths for the preheated and unheated slabs became nearly identical in Region II (40 to $\left.450 \mathrm{kC} / \mathrm{m}^{2}\right)$ for electrochemical ages of about $200 \mathrm{kC} / \mathrm{m}^{2}\left(5.2 \mathrm{~A}-\mathrm{h} / \mathrm{ft}^{2}\right)$. Furthermore they increase to values greater than the initial bond strength, to values as high as $3 \mathrm{MPa}(435 \mathrm{psi})$ at an electrochemical age of about $600 \mathrm{kC} / \mathrm{m}^{2}\left(15.5 \mathrm{~A}-\mathrm{h} / \mathrm{ft}^{2}\right)$. The second term in equation 4.1 describes this rise in bond strength to peak at the ultimate bond strength, $S_{u} . S_{u}$ is associated with the growth of an adhesive reaction layer or corrosion product at the anode-concrete interface. Analyses of the interface show that there is a thickening of the $\mathrm{ZnO} / \mathrm{Zn}(\mathrm{OH})_{2}$ layer to about 0.1-0.2 mm (3.9-7.8 mils). In addition, the $\mathrm{Zn}$ interacts with the original cement paste by replacing $\mathrm{Ca}$ in the silicates and aluminates. This interaction and reformation of the cement paste is a form of secondary mineralization (the dissolution and reprecipitation of $\mathrm{Zn}$ reaction products). It allows cracks and pores within the cement paste to be filled and to help form a more substantial bond across the zinc-concrete interface. This is the basis for the increase in the bond strength in Region II. No significant differences between the bond strengths of preheated and unheated samples were observed in Region II. However, water applied to the $\mathrm{Zn}$ anode began pooling on the surface due to the formation of the thicker layer of $\mathrm{Zn}$ reaction products at the zinc anode-concrete interface. Furthermore, the circuit resistance or slab voltage also begins to increase in this region.

Another factor that can help explain the increase in bond strength in Region II is the strength of the concrete. The strength of concrete is important because the failure of the bond between the $\mathrm{Zn}$ anode and the concrete often occurs within the concrete. The stronger the concrete, the higher the measured bond strength could potentially be if the failure occurs in the concrete. Figure 4.10 is a plot of concrete compressive strength as a function of curing time for five types of ASTM-Type 1 concrete (Lynch 1989). Lines are drawn on this plot representing the 172 and 287 day period that elapsed after casting the slabs (see Table 2.1) and before the first and second experiments were begun, respectively. Note that electrochemical aging was begun during a period when concrete strength was increasing in both experiments. The slabs in the first experiment would have been at a lower starting strength, allowing for a greater strength gain than 
in the second experiment. This strength gain probably accounts for some of the increase in bond strength seen in Region II.

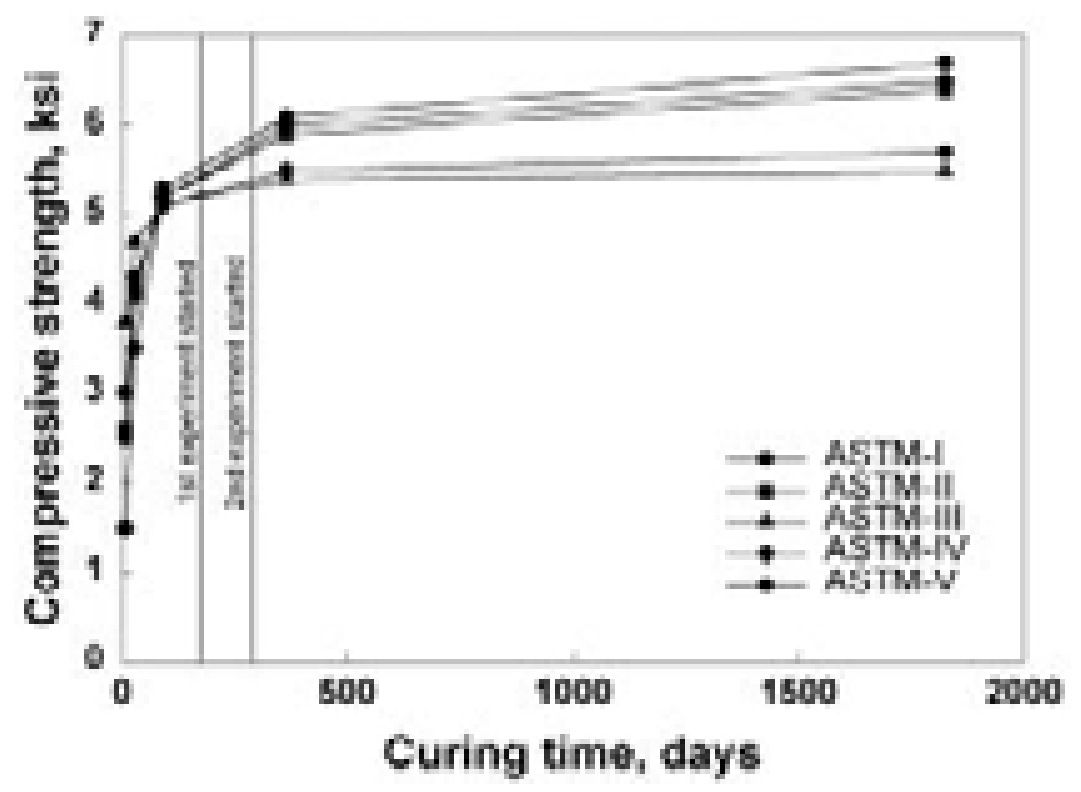

Figure 4.10: Effect of curing time on the compressive strength of five ASTM concretes

Region III (450 to $1800 \mathrm{kC} / \mathrm{m}^{2}$ ) begins at the maximum bond strength, $\mathrm{S}_{\mathrm{u}}$, and the bond strength declines with further electrochemical aging until it approaches zero. While the second term in equation 4.1 can describe the fall in bond strength, it was replaced by the linear function modeled by equation 4.2 because equation 4.1 predicts a slower drop than the data indicate. Equation 4.2 predicts a bond strength of zero at $4 \mathrm{C}_{\mathrm{f}} .4 \mathrm{C}_{\mathrm{f}}$ occurs at about $1800 \mathrm{kC} / \mathrm{m}^{2}\left(47 \mathrm{~A}-\mathrm{h} / \mathrm{ft}^{2}\right) \mathrm{f}$ or both the preheated and unheated slabs that were periodically wetted. This electrochemical age corresponds to 27 years of service at the levels of current density used by Oregon DOT on coastal bridges.

Characteristics of the zinc anode-concrete interface in this region are that water permeability is much lower than for unaged samples, the $\mathrm{pH}$ is not much different from that in Region II, and the operating voltages are substantially higher than those in Region I or II. While there appears to be a substantial resistive layer formed at the interface in Region II, temperature measurements at the interface showed less than a $0.5^{\circ} \mathrm{C}$ temperature rise from resistive heating. As a result, it is anticipated that drying of the slab is not due to resistive heating but rather due to corrosion product gradually sealing the concrete surface to further inflow of moisture from the environment.

Comparing the unwetted second experiment, Figures $4.8 \mathrm{a}$ and $4.8 \mathrm{~b}$, to the periodically wetted first experiment, Figures $4.7 \mathrm{a}$ and $4.7 \mathrm{~b}$, the unwetted experiment lacks Regions I and II (unheated) and Region I (preheated). Two possible explanations for this are: 
- Water was lacking during the critical time represented by Regions I and II where secondary mineralization should have occurred. In the absence of secondary mineralization, the associated strengthening mechanism also did not occur.

- The anodes in the second experiment aged naturally for twice the time of those in the first experiment before electrochemical aging was initiated. Thus, the initial bond strength would have been higher (see table 4.3) and the concrete would have cured longer (see Figure 4.11) giving a stronger concrete in the second experiment. In this way the contributions of Regions I and II to the bond strength curves would be minimized in the second experiment.

This simple degradation of bond strength with increases in electrochemical age for the unwetted experiment is in sharp contrast to results for the periodically-wetted experiment but in good agreement with previously published work (Brousseau, Arnott and Baldock 1994a) where bond strengths decreased rapidly after small amounts of charge were passed across the zinc-concrete interface.

The long-term results in Figures 4.7 and 4.8 are in good qualitative agreement with the practical experience of CALTRANS, where some delamination of $\mathrm{Zn}$ coatings occurred after roughly 10 years of service for TS Zn anodes on the Richmond-San Rafael Bridge. In fact, the value of $4 \mathrm{C}_{\mathrm{f}}$ from Table 4.4 suggests that both the heated and unheated anodes in the unwetted experiment would delaminate in as little as 5 years. As a point of reference, $200 \mathrm{kC} / \mathrm{m}^{2}\left(5.2 \mathrm{~A}-\mathrm{h} / \mathrm{ft}^{2}\right)$ is equivalent to roughly 3 years service for TS Zn anode ICCP at the current density of 0.0022 $\mathrm{A} / \mathrm{m}^{2}\left(0.2 \mathrm{~mA} / \mathrm{ft}^{2}\right)$ used by Oregon DOT.

Anode bond strengths near zero, observed in the late stages of aging for both periodically wetted and unwetted, preheated and unheated slabs, occur when there is significant delamination of the coating from the concrete. Since $\mathrm{ZnO}$ has a volume factor 1.6 times larger than $\mathrm{Zn}$, and $\mathrm{Zn}(\mathrm{OH})_{2}$ has a volume factor of 3.5 larger than Zn (Kubaschewski and Hopkins 1962), the presence of these compounds at the zinc-concrete interface can account for the loosening of the mechanical grip of the $\mathrm{Zn}$ coating and the reduction in the bond strength. The steady decline in the bond strength beyond the maximum simply represents the increasing growth of the $\mathrm{Zn}$ mineral layer at the anode-concrete interface. In some cases the $\mathrm{Zn}$ was still attached to the concrete at isolated points such as the anchor pits ("bug holes") noted earlier. Late in the life of the anode, the anchor pits contribute significantly to bonding of the anode to the concrete. In fact, even though much of the anode may be delaminated, the anchor pits provide sufficient attachment that they would keep the $\mathrm{Zn}$ anode from sloughing from the structure.

The charge parameters, $\mathrm{C}_{\mathrm{m}}$ and $\mathrm{C}_{\mathrm{f}}$, can be viewed as time constants for two processes, respectively:

- $\mathrm{C}_{\mathrm{m}}$ - weakening the initial mechanical bond,

- $\mathrm{C}_{\mathrm{f}}-$ growth of the $\mathrm{Zn}$ mineral layer at the anode-concrete interface.

Assuming $100 \%$ current efficiency and $100 \%$ coating density, the charge parameters are given in Table 4.5 as the equivalent thickness of $\mathrm{Zn}$ consumed during these processes. Expressed in this way, they suggest the coating thickness consumed by each process. Specifically, only a thin layer of $\mathrm{Zn}$ needs to dissolve to degrade the mechanical bond between coating and concrete. On 
the other hand, dissolution of roughly $25 \mu \mathrm{m}$ ( 1 mil) of coating provides sufficient $\mathrm{Zn}$ ions, when acted on by periodic wetting and drying and the associated secondary mineralization, to form an adherent layer between the $\mathrm{Zn}$ anode and concrete.

The charge parameters can also be viewed in terms of characteristic aging times in Table 4.5. For example in the first experiment, $\mathrm{C}_{\mathrm{m}}$ corresponds to 15 and 11 days, respectively, for preheated and unheated slabs in the periodically-wetted laboratory experiment or the equivalent of 0.60 and 0.47 years aging for Oregon DOT bridge $\mathrm{CP}$ systems. $\mathrm{C}_{\mathrm{f}}$ corresponds to 5.4 months aging time in the laboratory experiment or the equivalent of 6.8 years aging for Oregon DOT bridge CP systems. These times suggest periods over which the different processes are active. Comparing the second experiment to the first shows that $\mathrm{C}_{\mathrm{m}}$, the charge values associated with the weakening of the mechanical bond, are comparable. $\mathrm{C}_{\mathrm{f}}$, the charge associated with forming the highest bond strength, is considerably lower for the unwetted experiment than for periodically wetted experiment. This is consistent with the fact that lack of water and longer natural aging times make it difficult in the unwetted experiment for secondary mineralization to occur and develop the higher bond strength associated with secondary mineralization.

Table 4.5: Equivalent values of model parameters in Equations 4-1 and 4-2

\begin{tabular}{l|c|c|c|c|c|c}
\hline \multirow{2}{*}{ Condition } & \multicolumn{3}{|c|}{$\mathbf{C}_{\mathbf{m}}$} & & \multicolumn{3}{c}{$\mathbf{C}_{\mathbf{f}}$} \\
\cline { 2 - 8 } & $\mathbf{k C / \mathbf { m } ^ { 2 }}$ & $\mu \mathbf{m} \mathbf{Z n}$ & years $^{\mathbf{1}}$ & $\mathbf{k C / \mathbf { m } ^ { 2 }}$ & $\mu \mathbf{m} \mathbf{Z n}$ & years $^{\mathbf{1}}$ \\
\hline Periodically wetted/preheated & 40 & 1.9 & 0.60 & 450 & 21 & 6.8 \\
\hline Periodically wetted/unheated & 31 & 1.5 & 0.47 & 450 & 21 & 6.8 \\
\hline unwetted/preheated & 27 & 1.3 & 0.41 & 85 & 4 & 1.3 \\
\hline unwetted/unheated & 69 & 3.3 & 1.0 & 85 & 4 & 1.3 \\
\hline
\end{tabular}

${ }^{1}$ time at $2.2 \mathrm{~mA} / \mathrm{m}^{2}$ used by Oregon DOT for coastal bridge CP systems.

Equations 4.1 and 4.2 can be used to estimate bond strength for longer aging times. If one assumes that the coating service life is defined by the time when roughly $15 \%$ of the $\mathrm{Zn}$ coating has low or zero bond strength to the concrete, then the intercept of the lower confidence limit with the x-axis, obtained by extrapolation of Equation 4.1, defines the service life. For periodically wetted, preheated slabs this corresponds to a bond strength of $0.63 \mathrm{MPa}(91 \mathrm{psi})$ and a charge of roughly $2000 \mathrm{kC} / \mathrm{m}^{2}\left(51.6 \mathrm{~A}-\mathrm{h} / \mathrm{ft}^{2}\right)$, equivalent to about 27 years for impressed current CP service on the Oregon coast. The values are similar for unheated slabs. These projections are beyond the existing data and only suggest a possible outcome.

Finally, total coating thickness was shown by others (Howell 1992) to affect Zn bond strength by buildup of thermal stresses during application of the coating at a thickness greater than 9 mils $(0.23 \mathrm{~mm})$. The possibility of such behavior was examined in the present study and no such trend was observed.

A cross-section of aTS $\mathrm{Zn}$ anode-concrete interface following aging for $747 \mathrm{kC} / \mathrm{m}^{2}$ is shown in Figure 4.11. There is cracking in the cement paste and in the layer of zinc minerals that forms at the anode-concrete interface as the result of the anode reaction. Contrast this with the anodeconcrete interface for the unaged TS Zn anode where there was little cracking and good 
conformance of the coating with the concrete surface roughness, Figure 3.1. For both the unaged and aged anodes, there were no obvious differences between the interfaces for the preheated and the unheated slabs. In each case, the coating had a significant number of voids between splats within the anode with perhaps a 20 percent void volume. While the 2 -dimensional view in Figures 3.1 and 4.11 shows relatively few through-pores connecting the surface to the concrete, a 3-dimensional view would show interconnectivity of pores allowing moisture, salts, and air to move through the anode. The elongated splat structure is typical of $\mathrm{Zn}$ coatings produced by the thermal spray process.

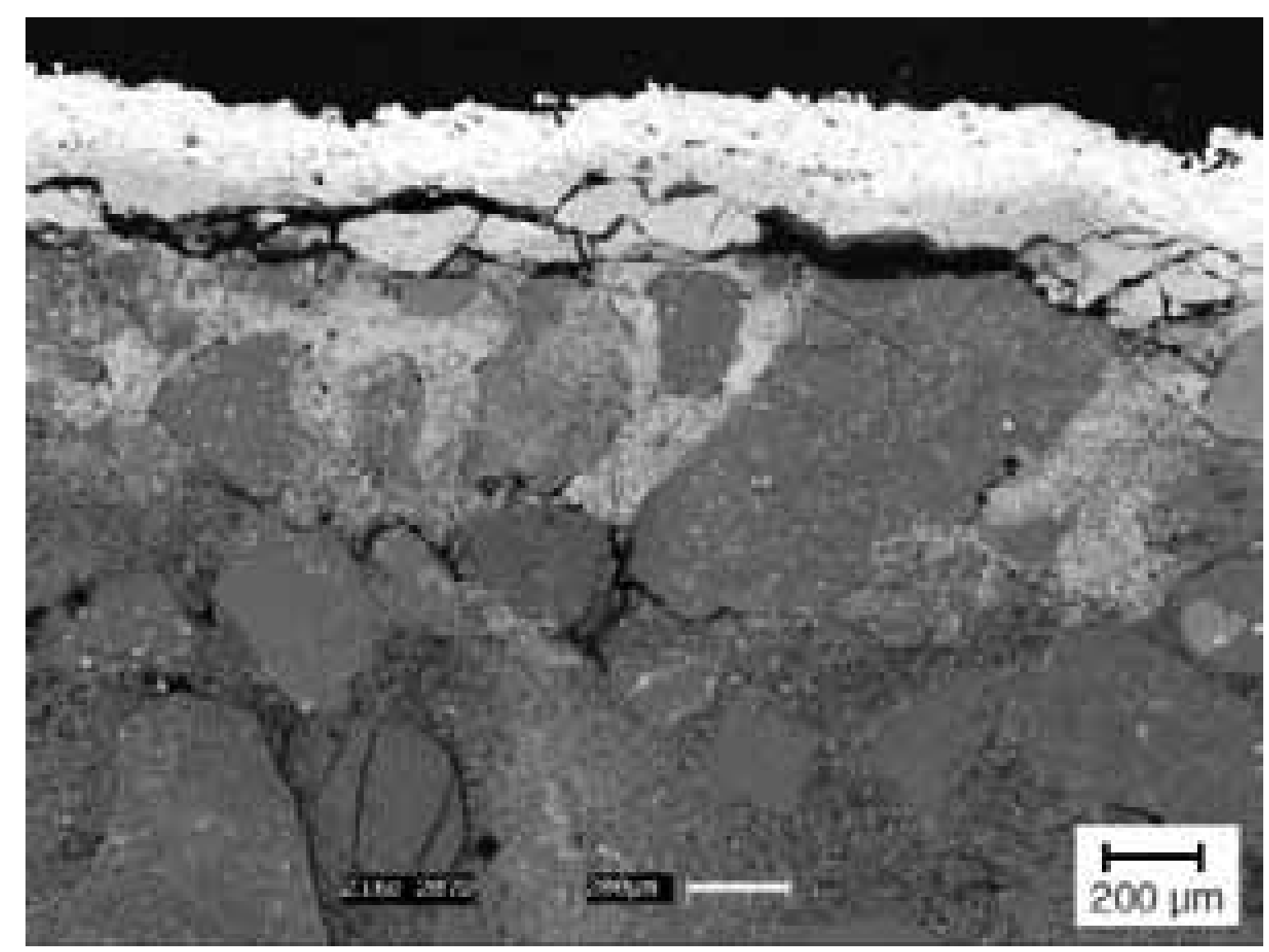

Figure 4.11: SEM photomicrograph showing cracking of periodically-wetted cement paste at the TS Zn anodeconcrete interface following $747 \mathrm{kC} / \mathrm{m}^{2}$ aging, the equivalent of 11.0 years at $0.0022 \mathrm{~A} / \mathrm{m}^{2}$

The primary failure mode for disbondment of aged $\mathrm{Zn}$ anodes from the concrete was cohesive fracture within a thin layer of the concrete immediately adjacent to the $\mathrm{Zn}$, Figure 4.11. As failure occurred, cracks propagated through the hardened cement paste and around sand particles, causing some pull-out of particles. The layer of concrete in which the failure occurs is roughly 0.05-0.20 mm (0.002-0.008 in) thick. This failure zone coincides with zones affected by the TS $\mathrm{Zn}$ anode reaction products. An almost totally delaminated TS $\mathrm{Zn}$ anode is shown in Figure 4.12 after aging for roughly $1800 \mathrm{kC} / \mathrm{m}^{2}$. In contrast, tensile failure of the underlying concrete, using the same test technique, produced massive pullout of the concrete matrix. This can be seen in 
Figure 4.13 which compares the tensile failure of the concrete (left) with that of a TS Zn anode originally bonded to concrete (right).

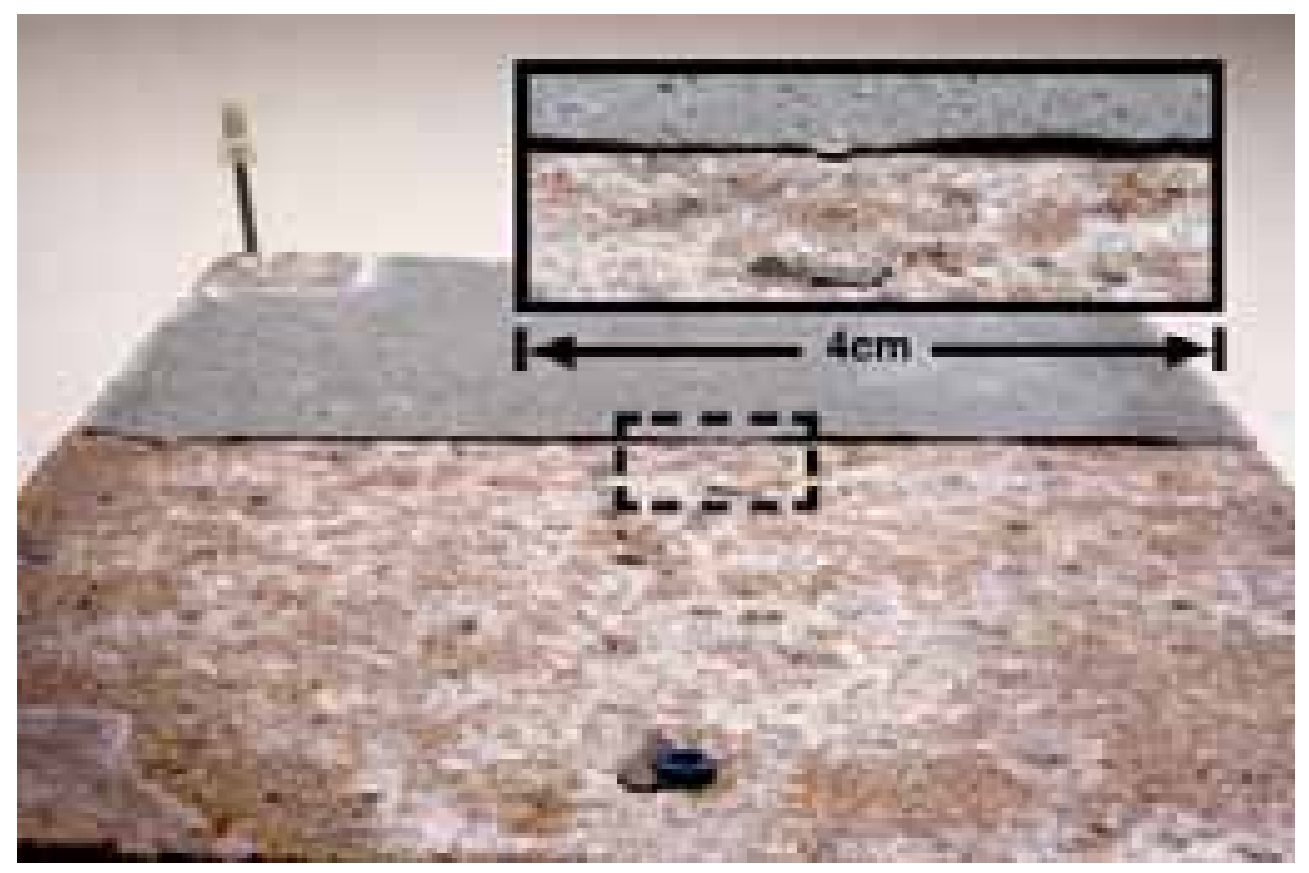

Figure 4.12: Delaminated TS Zn anode on periodically-wetted concrete slab following $\sim 1800 \mathrm{kC} / \mathrm{m}^{2}$ aging

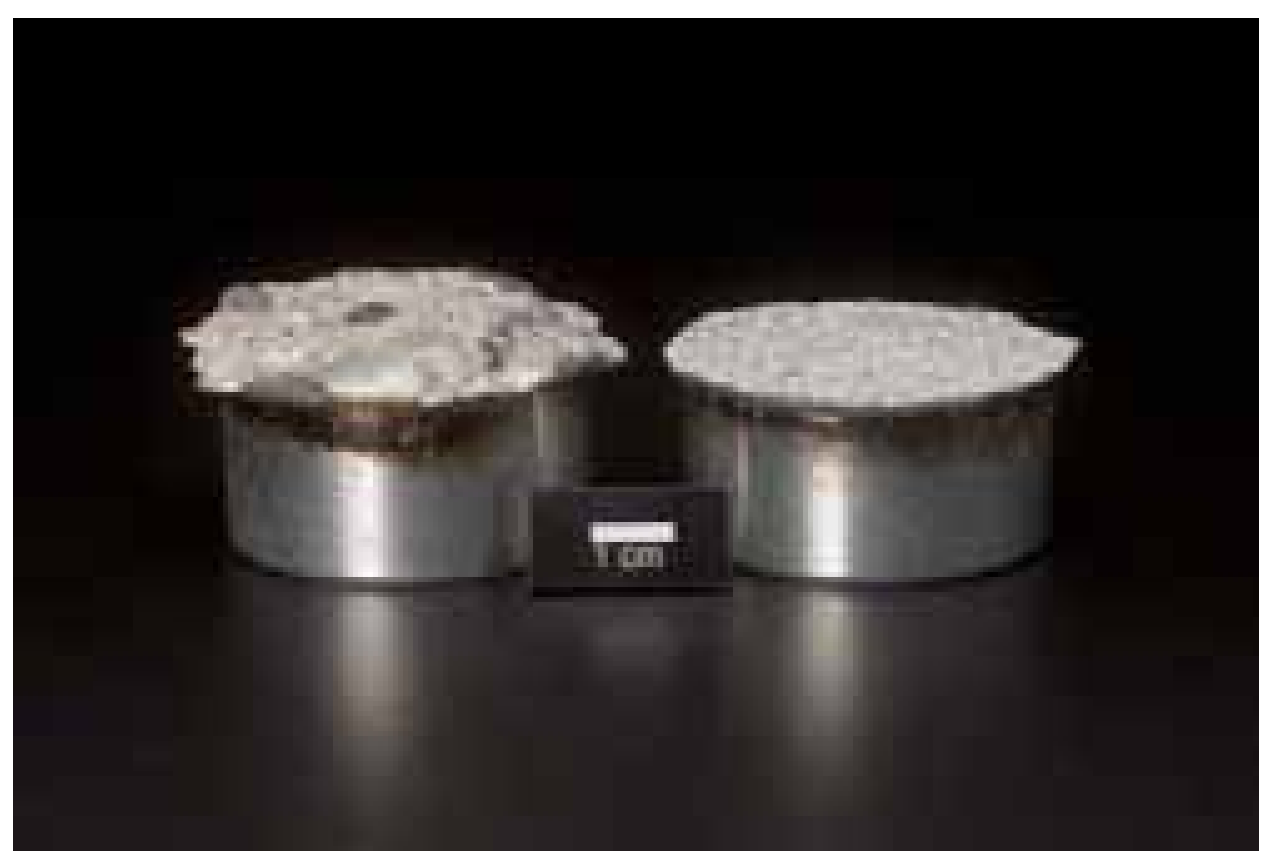

Figure 4.13: Pullout of concrete as a result of bond strength tests for bare concrete (left) and TS Zn coated concrete (right) 


\subsection{BULK CONCRETE CHEMISTRY}

The chemistry of the concrete used to make the slabs for the laboratory experiments was analyzed only as part of the ASEM analyses of the anode-concrete interface. Most line scans of the interfaces were continued well into unaltered cement paste in order to provide a comparison to altered cement paste at the anode-concrete interface. While the cement paste constituents $\mathrm{Ca}$, $\mathrm{Si}, \mathrm{Al}$, and $\mathrm{O}$ were typically analyzed, concrete composition is most often characterized in this report by the $\mathrm{Ca}$ and $\mathrm{O}$ concentrations. Table 4.6 shows that the $\mathrm{Ca}$ in unaltered concrete was approximately 18 atomic pct. This value was typical of the concrete slabs and is equivalent to a 6-bag mix. It compares well with the Ca concentration calculated using the concrete mix design in Table 2.2. Chloride concentrations, except where they were concentrated at the anodeconcrete interface (see Section 4.5), were typically low and often did not yield useful information at the spatial resolution of the ASEM.

Table 4.6: Nominal composition of cement paste (Bullard 1997a)

\begin{tabular}{c|c|c}
\hline Age, $\mathbf{k C} / \mathbf{m}^{2}$ & $\mathbf{C a}$, atomic \% $\left(\mathbf{k g} / \mathbf{m}^{\mathbf{3}}\right)$ & $\mathbf{O}$, atomic $\%\left(\mathbf{k g} / \mathbf{m}^{\mathbf{3}}\right)$ \\
\hline 27.1 & 18 & 75 \\
\hline 51 & 18 & 75 \\
\hline
\end{tabular}

\subsection{ANODE-CONCRETE INTERFACIAL CHEMISTRY}

The key to understanding the observed behavior of thermal-sprayed $\mathrm{Zn}$ anodes on concrete is to understand the chemistry of the anode-concrete interface. Many of the reported phenomena, bond strength changes, water permeability, voltage-electrochemical age response, etc., can be explained by the chemistry of this interface. It must be remembered, however, that the anodeconcrete interface is a heterogeneous region with a chemistry and mineralogy that is spatially nonuniform. Because of this, analytical results are highly dependent upon sampling, yet the types of analyses employed here (e.g., ASEM) are very time intensive and not conducive to high sampling rates. Consequently, the summary data presented here can show considerable variation, but they also demonstrate reproducible trends in the chemistry of the anode-concrete interface.

\subsubsection{Analytical scanning electron microscopy}

The anode-concrete interface of slabs from both the laboratory experiments were cross-sectioned and analyzed using x-ray mapping and WDS line scans. A back-scattered SEM photomicrograph of the zinc-concrete interface from a periodically wetted slab from the first experiment aged an equivalent of 9.4 years $\left(638 \mathrm{kC} / \mathrm{m}^{2}\right.$ or $\left.16.5 \mathrm{~A}-\mathrm{h} / \mathrm{ft}^{2}\right)$ is shown in Figure 4.14. This figure shows the $\mathrm{Zn}$ anode and three reaction zones identified as Zones 1-3. These zones are distinct regions that can be identified from WDS line scans based on changes in either Zn or $\mathrm{Ca}$ concentration. The white and light gray zones represent areas with high atomic number elements, primarily $\mathrm{Zn}$. The brightest zone is the $\mathrm{Zn}$ coating. Sand particles in the gray zone serve as markers for the original location of the cement paste in contact with the $\mathrm{Zn}$. The presence of $\mathrm{Zn}$ within this zone indicates reactions where $\mathrm{Zn}$ has modified the mineralogy of the original cement paste. The line defines the path the SEM electron beam took in a series of point- 
by-point chemical analyses of the anode-concrete interface. The dogleg in this path took the beam through cement paste between two sand particles.

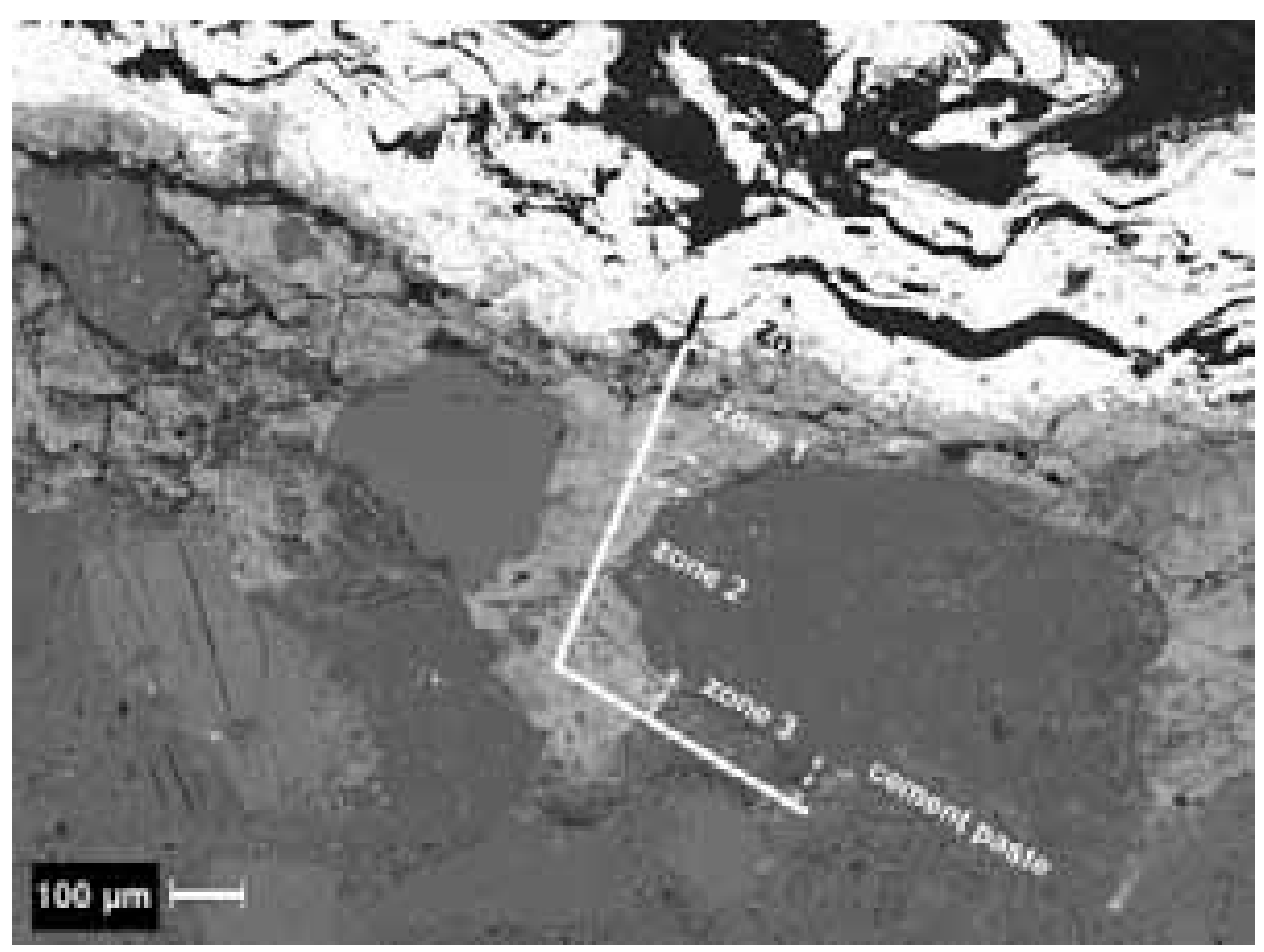

Figure 4.14: Back-scattered electron SEM photomicrograph of a cross-section of TS Zn anode on periodically-wetted concrete electrochemically aged for $640 \mathrm{kC} / \mathrm{m}^{2}$, the equivalent of 9.4 years at $0.0022 \mathrm{~A} / \mathrm{m}^{2}$; shows reaction zones.

The distribution of elements within the area of Figure 4.14 is shown by the maps of elemental concentration in Figures 4.15 a-d (Zn, O, Si and Ca, respectively) and 4.16 a-b (Cl and S, respectively). The brightest areas in these maps are richest in the identified element. Figure 4.15a shows the $\mathrm{Zn}$ coating and a reaction zone extending some distance into the cement paste containing $\mathrm{Zn}$ dissolution products. Figure $4.15 \mathrm{~b}$ shows that the reaction zone contains a significant amount of oxygen and, with Figure $4.15 \mathrm{c}$, confirms the location of sand particles near the coating interface. Figure $4.15 \mathrm{~d}$ shows the matrix of cement paste binding the quartz particles together. Most importantly, however, Figure $4.15 \mathrm{~d}$ shows that the Ca originally present within the reaction zones 1 and 2 has retreated and been replaced, as Figure 4.15a shows, by Zn. The $\mathrm{Ca}$ was leached from the reaction layer and redeposited deeper in the concrete as a result of the periodic wetting and drying and the associated secondary mineralization. A previous study showed that leaching of calcium hydroxide from cement paste results in a decrease in compressive strength and an increase in porosity of the cement paste (Carde and François 1997). 

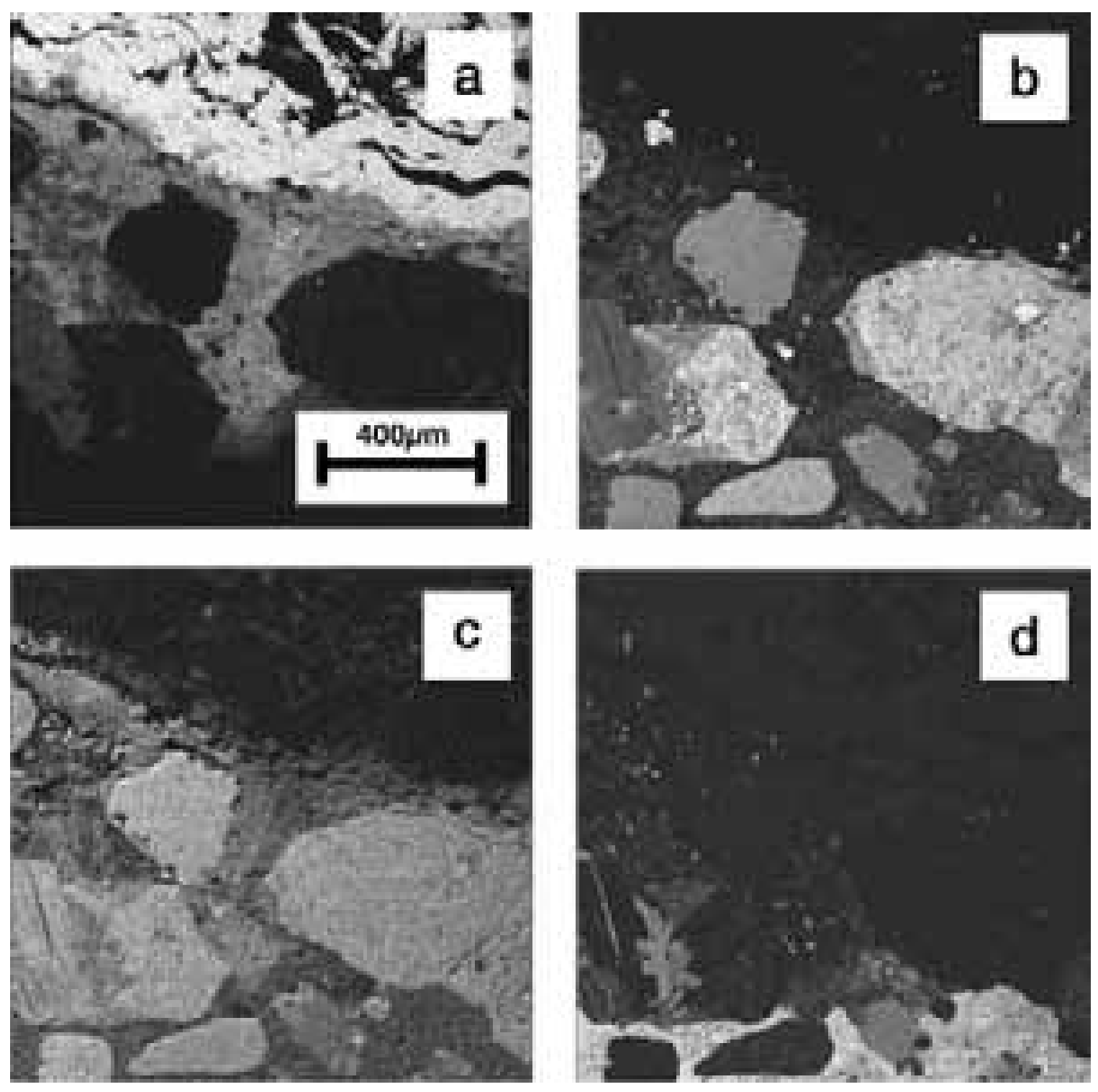

Figure 4.15: X-ray maps of elemental distributions at the Zn-concrete interface in Figure 4.14: (a) $\mathrm{Zn}$; (b) $\mathrm{O}$; (c) $\mathrm{Si}$; (d) $\mathrm{Ca}$

Figures 4.16a and 4.16b show $\mathrm{Cl}$ and $\mathrm{S}$ concentrated in the reaction zone adjacent to the $\mathrm{Zn}$ anode. These figures are evidence that chloride and sulfate ions migrate through the cement paste carrying part of the charge to the anode. The driving force for this enrichment is the potential gradient created by cathodic protection of the steel and the need to move charge through the concrete to maintain the necessary electrochemical reactions. The migration of $\mathrm{Cl}$ and $\mathrm{S}$ to the $\mathrm{Zn}$ was not uniform along the interface but was affected by the porosity of the cement paste and by aggregate particles that shield the $\mathrm{Zn}$ anode. The apparently high concentration of chloride and sulfate in zone 1 would suggest $\mathrm{Zn}$ hydroxy-chloride and -sulfate minerals were present within this region. 

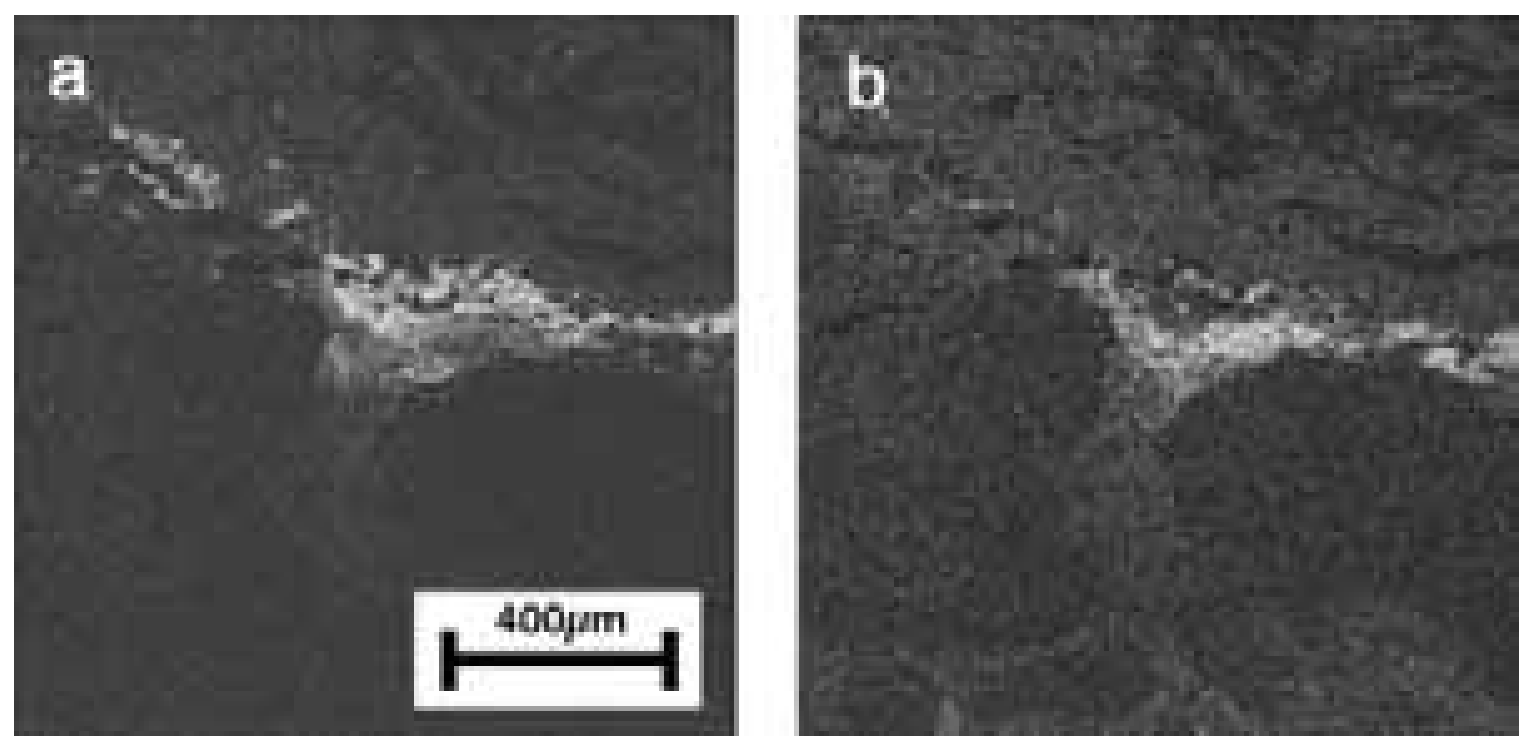

Figure 4.16: X-ray maps of elemental distributions at the Zn-concrete interface in Figure 4.14: (a) Cl; (b) S

A second BSE SEM photomicrograph and set of x-ray maps is given in Figure 4.17 for a TS Zn anode aged longer than that shown in Figures 4.14, 4.15 and 4.16. This second figure confirms the results show in the earlier figures, i.e., the growth of a zinc mineral layer at the anodeconcrete interface containing an elevated level of chloride, and a reaction zone depleted in calcium.

Figure 4.18 shows WDS scans for $\mathrm{Zn}$ and $\mathrm{O}$ concentrations along the line identified in Figure 4.14, beginning at the $\mathrm{Zn}$ anode, continuing through the reaction zone, and extending into the cement paste. Figure 4.19 shows WDS scans for $\mathrm{Cl}$ and $\mathrm{S}$ along the same line (the curve for $\mathrm{Zn}$ was added for reference). The reaction zone consists of the three chemically distinct zones characterized by decreasing concentrations of $\mathrm{Zn}$ in the cement paste (Covino, et al. 1997a). These three zones have been labeled on the analysis path in Figure 4.14 and correspond to those shown in Figure 4.18. Zone 1 is characterized by roughly equal atomic concentrations of $\mathrm{Zn}$ and O. Zone 2 has substantially higher O concentrations, lower $\mathrm{Zn}$ concentrations and negligible $\mathrm{Ca}$. By contrast, zone 3 contains low $\mathrm{Zn}$ concentrations and a significant amount of Ca. 


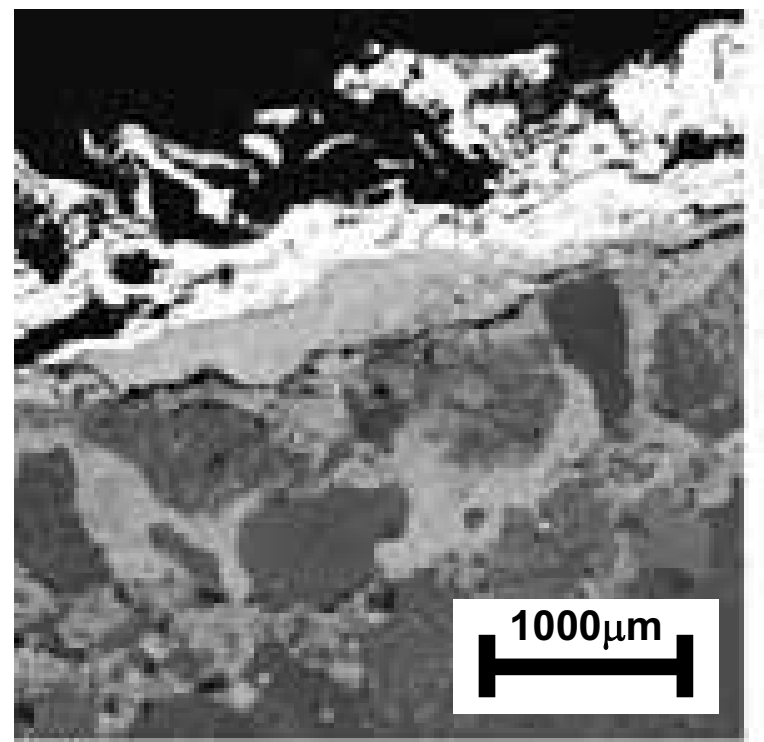

(a)

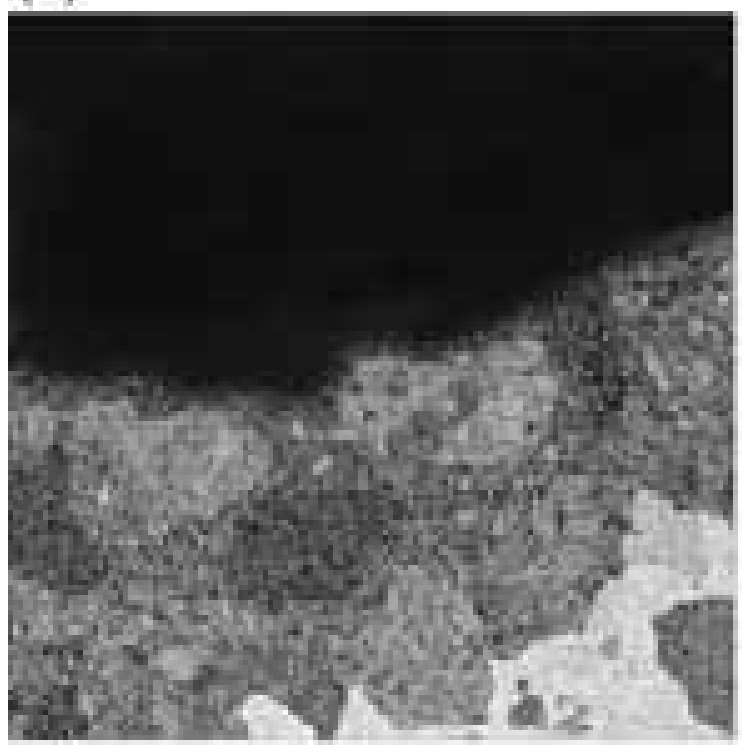

(c)

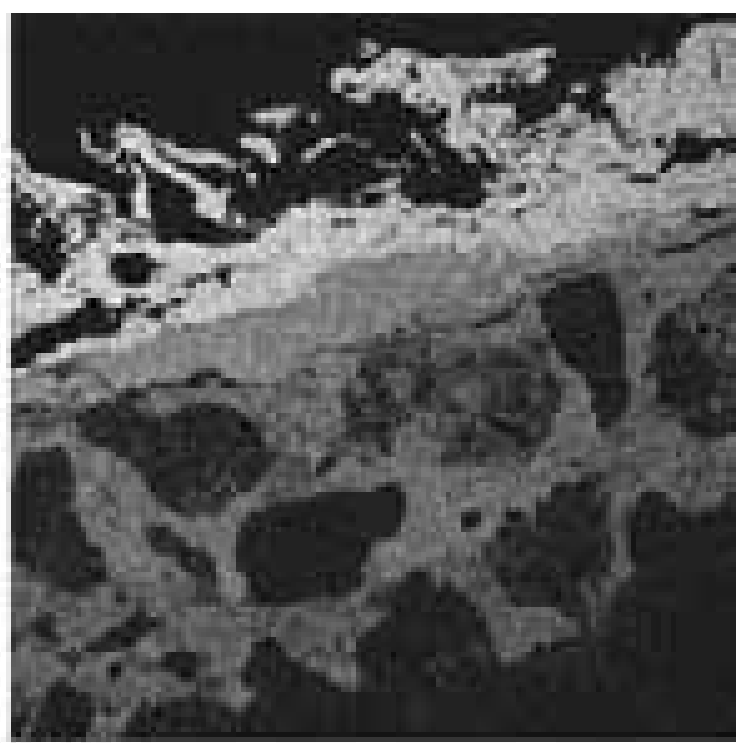

(b)

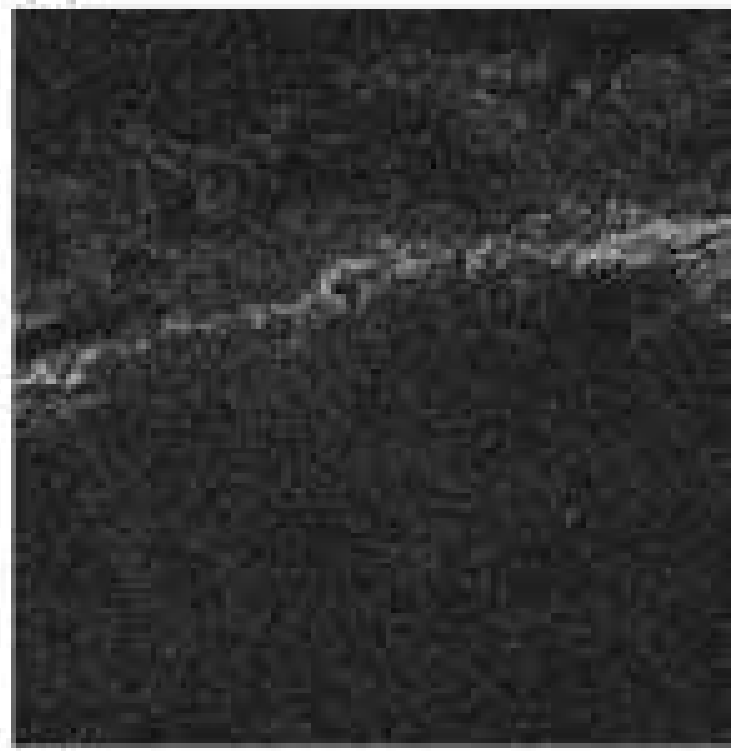

(d)

Figure 4.17: Cross-section of TS Zn anode on periodically-wetted concrete electrochemically aged for 1080 $\mathrm{kC} / \mathrm{m}^{2}$, the equivalent of 15.9 years at $0.0022 \mathrm{~A} / \mathrm{m}^{2}$ : (a) back-scattered electron SEM photomicrograph; and x-ray maps, (b) Zn, (c) Ca, (d) $\mathrm{Cl}$ 


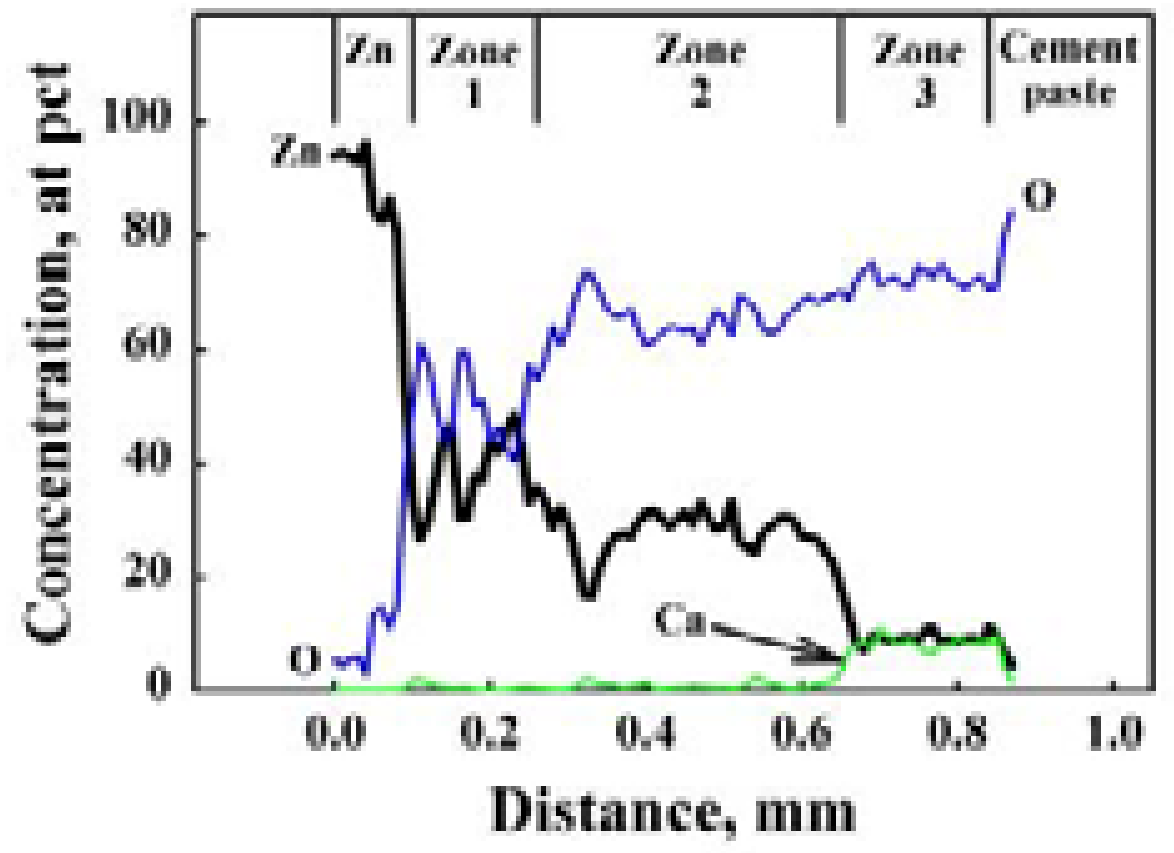

Figure 4.18: WDS concentration profiles for $\mathrm{Zn}, \mathrm{O}$, and $\mathrm{Ca}$ at the TS $\mathrm{Zn}$ anode-concrete interface in Figure 4.14

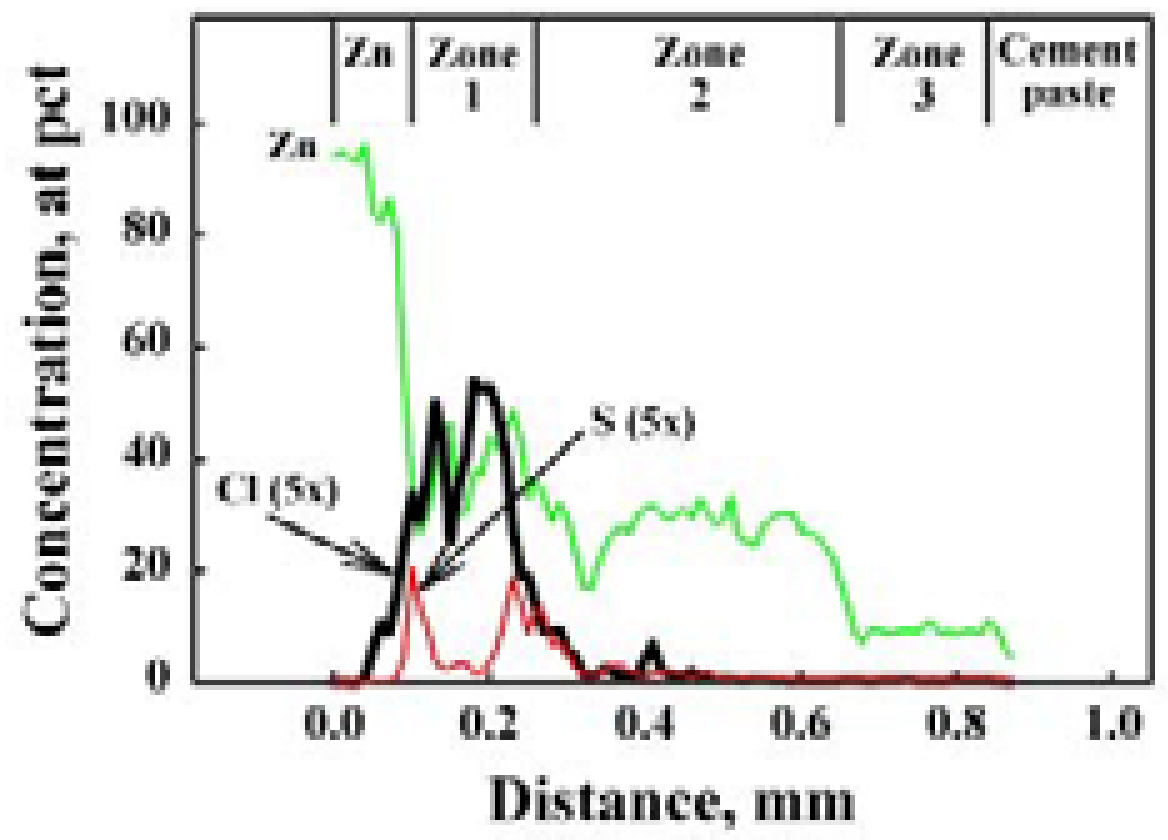

Figure 4.19: WDS concentration profiles of $\mathrm{Zn}, \mathrm{Cl}$ and $\mathrm{S}$ at the TS $\mathrm{Zn}$ anode-concrete interface in Figure 4.14 
Table 4.7 gives the thickness of the three reaction zones for a series of periodically-wetted anodes aged for progressively longer times. Zone 1 was not detected at the resolution of the scans for times shorter than 4 years, and was about $0.1 \mathrm{~mm}$ thick for longer times. Zone 2 grows with aging time, increasing from about $0.2 \mathrm{~mm}$ to $0.4 \mathrm{~mm}$ from 1.2 to 9.4 years. Zone 3 was not observed for aging times less than 9.4 years and represents a late-forming feature of the zincconcrete interface. Beyond zone 3 is unaltered cement paste. Line scans were made at a number of locations along the zinc-concrete interface of preheated slabs aged 1.2 to 9.4 years. While there were some differences in detail, the results for any given aging time were similar to those in Table 4.7.

\begin{tabular}{|c|c|c|c|}
\hline \multirow{2}{*}{$\begin{array}{c}\text { Electrochemical } \\
\text { Age, y } \\
\text { a.00022 A/m }\end{array}$} & \multicolumn{3}{|c|}{ Zone width, mm } \\
\hline & Zone 1 & Zone 2 & Zone 3 \\
\hline 0.0 & 0.00 & 0.00 & 0.00 \\
\hline 0.6 & $<0.02$ & 0.00 & 0.00 \\
\hline 1.2 & $<0.02$ & 0.18 & 0.00 \\
\hline 4.1 & 0.11 & 0.41 & 0.00 \\
\hline 9.4 & 0.15 & 0.40 & 0.21 \\
\hline
\end{tabular}

Assuming $\mathrm{Cl}$ and $\mathrm{S}$ are present as $\mathrm{ZnCl}_{2}$ and $\mathrm{ZnSO}_{4}$, the $\mathrm{Zn}$ and oxygen remaining as either zinc oxide or hydroxide can be calculated from the concentration profile in Figure 4.18. When this is done the average $\mathrm{O} / \mathrm{Zn}$ ratio for zone 1 is 1.4 , suggesting that zone 1 contains a mixture of $\mathrm{ZnO}$ and $\mathrm{Zn}(\mathrm{OH})_{2}$. The average $\mathrm{O} / \mathrm{Zn}$ ratios for zones 2 and 3 were 2.4 and 7.5, respectively. Average concentrations of $\mathrm{Ca}$ in zones 1 through 3 , and the cement paste were $0.6,0.8,8.2$, and 8.5 atomic $\%$, respectively. In view of this and the $\mathrm{O} / \mathrm{Zn}$ ratios, near total and partial replacement of $\mathrm{Ca}$ by $\mathrm{Zn}$ in the cement paste appears to have occurred in zones 2 and 3 . Furthermore, $\mathrm{Zn}$ appears to have commingled with the constituents of the cement paste in zones 1,2 , and 3 to form stable mineral species by substitution of $\mathrm{Zn}$ for $\mathrm{Ca}$. Based on the elemental analyses and similarities with the cement paste, these species are $(\mathrm{Ca}, \mathrm{Zn})$ silicate and $(\mathrm{Ca}, \mathrm{Zn})$ aluminate.

Enrichment factors for $\mathrm{Cl}$ and $\mathrm{S}$, compared to cement paste bulk concentrations of 0.016 and 0.105 atomic $\%$, were as high as 670 and 40 , respectively, for periodically wetted slabs aged an equivalent of 9.4 years. Chlorine and $\mathrm{S}$ were most heavily concentrated in zone 1, with significant concentrations in zone 2 also. Just as with the $\mathrm{Zn}, \mathrm{Ca}$ and $\mathrm{O}$ line scans, line scans for $\mathrm{Cl}$ and $\mathrm{S}$ will vary where along the interface the scan is made. While there was a fair amount of variability in the $\mathrm{Cl}$ and $\mathrm{S}$ concentration profiles for any aging time, the trend was an increase in the absolute amount of these elements at the interface with increasing aging time. This is illustrated by the $\mathrm{Cl}$ and $\mathrm{S}$ line scans for different aging times in Figures 4.20 and 4.21, respectively. The high chloride and sulfate ion concentrations at the zinc-concrete interface represent a more aggressive environment for the $\mathrm{Zn}$ than the original cement paste. In addition, the presence of a stable $\mathrm{ZnO}-\mathrm{Zn}(\mathrm{OH})_{2}$ layer adjacent to the $\mathrm{Zn}$ metal suggests that the $\mathrm{pH}$ at the zinc-concrete interface is well below that of the cement paste, perhaps as low as 8 or 9 
(Porter 1994). The enrichment of $\mathrm{Zn}$ in the $\mathrm{ZnO}-\mathrm{Zn}(\mathrm{OH})_{2}$ layer and in the cement paste is shown in Figure 4.22. Zn reaction products resulting from the $\mathrm{CP}$ process diffuse into the cement paste, build up at the interface, and increase as a function of electrochemical age.

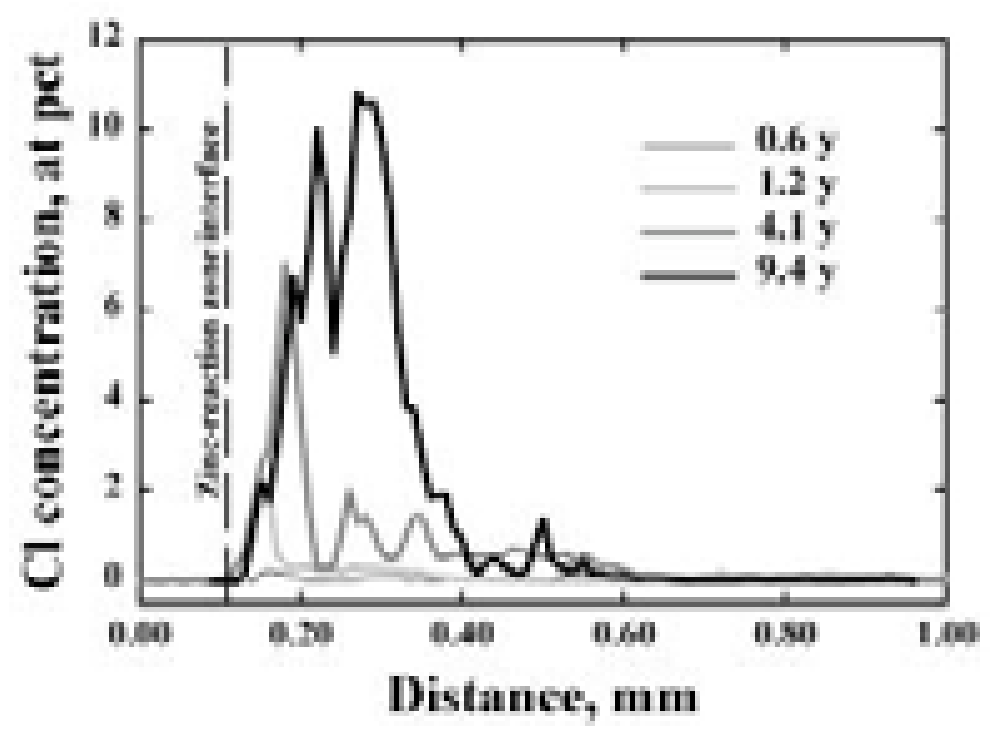

Figure 4.20: $\mathrm{Cl}$ concentration profiles as a function of TS $\mathrm{Zn}$ anode electrochemical age in years at $0.0022 \mathrm{~A} / \mathrm{m}^{2}$ for periodically-wetted concrete slabs

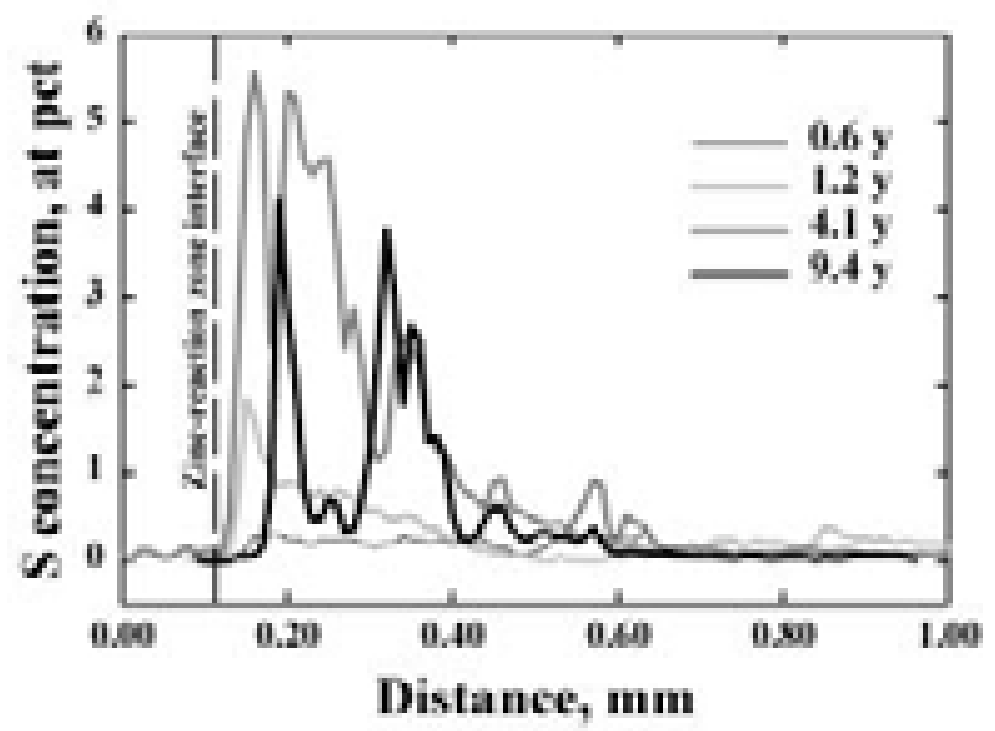

Figure 4.21: S profiles as a function of TS Zn anode electrochemical age in years at $0.0022 \mathrm{~A} / \mathrm{m}^{2}$ for periodically-wetted concrete slabs 


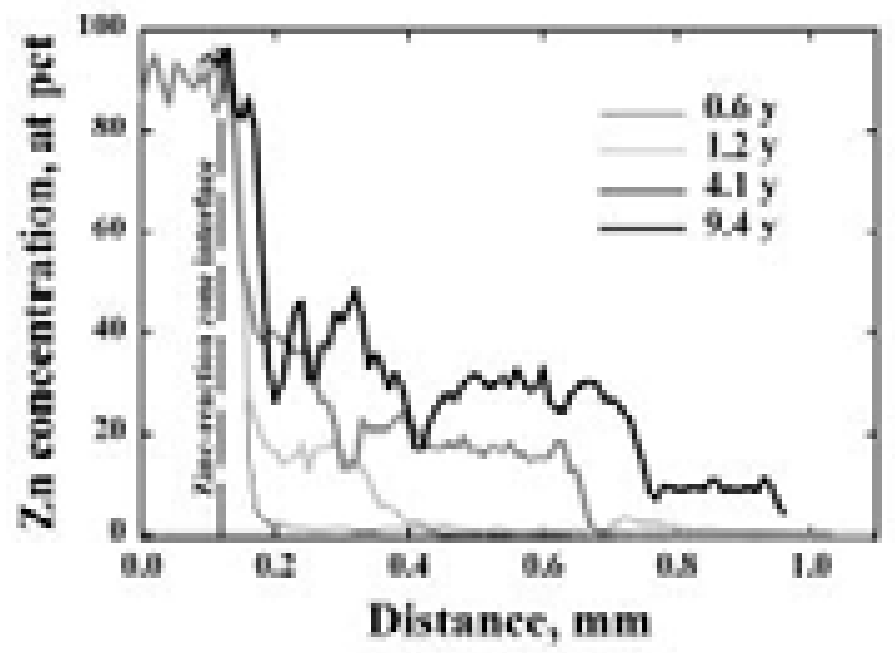

Figure 4.22: $\mathrm{Zn}$ profiles as a function of TS $\mathrm{Zn}$ anode electrochemical age in years at $0.0022 \mathrm{~A} / \mathrm{m}^{2}$ for periodically-wetted concrete slabs

A rough interpretation of the relative amounts of $\mathrm{O}, \mathrm{Cl}$, and $\mathrm{S}$ in zones 1 and 2 for a sample aged an equivalent of 4.1 years suggests that the fraction of charge carried by hydroxide, chloride and sulfate ions is 84,4 and $12 \%$, respectively. The overall trend of rising operating voltage with aging and more rapid voltage rise on drying would suggest reduced mobility of the charge carrying ions through zones 1 and 2, and increased resistance to ionic diffusion in the vicinity of the zinc-concrete interface.

Table 4.8: TS $\mathrm{Zn}$ anode-concrete interfacial chemistry

\begin{tabular}{|c|c|c|}
\hline Location & Characteristics & Possible Compounds \\
\hline Zn coating & metallic $\mathrm{Zn}$ & $\mathrm{Zn}$ \\
\hline Zone 1 & $\begin{array}{l}\mathrm{O} / \mathrm{Zn} \text { ratio } 1.4 \text { enriched in } \\
\mathrm{Cl}, \mathrm{S}\end{array}$ & $\begin{array}{l}\mathrm{ZnO} \\
\mathrm{Zn}(\mathrm{OH})_{2} \\
\mathrm{ZnSO}_{4} \\
\mathrm{ZnCl}_{2}\end{array}$ \\
\hline Zone 2 & $\begin{array}{l}\mathrm{O} / \mathrm{Zn} \text { ratio } 2.4 \text { enriched in } \\
\mathrm{Cl}, \mathrm{S} \\
\text { substantial } \mathrm{Si}\end{array}$ & $\begin{array}{l}(\mathrm{Ca}, \mathrm{Zn}) \text { silicate } \\
(\mathrm{Ca}, \mathrm{Zn}) \text { aluminate } \\
\mathrm{ZnSO}_{4} \\
\mathrm{ZnCl}_{2}\end{array}$ \\
\hline Zone 3 & $\begin{array}{l}\mathrm{O} / \mathrm{Zn} \text { ratio } 7.5 \\
\text { elevated } \mathrm{Cl} \\
\text { increased } \mathrm{Ca}\end{array}$ & $\begin{array}{l}(\mathrm{Ca}, \mathrm{Zn}) \text { silicate } \\
(\mathrm{Ca}, \mathrm{Zn}) \text { aluminate } \mathrm{ZnCl}_{2}\end{array}$ \\
\hline $\begin{array}{l}\text { Unaltered cement } \\
\text { paste }\end{array}$ & $\begin{array}{l}\text { high } \mathrm{Ca} \\
\text { low } \mathrm{Cl}, \mathrm{S} \\
\text { no } \mathrm{Zn}\end{array}$ & $\begin{array}{l}\text { Ca silicate } \\
\text { Ca aluminate }\end{array}$ \\
\hline
\end{tabular}


The interfacial chemistry results are summarized in Table 4.8 in terms of the generic nature of the compounds in each zone (Covino, et al. 1997a). The actual mineralogy of these zones is more complex and may involve, for example, in zone $1 \mathrm{Zn}$ hydroxychloride or hydroxysulfates. The sharp boundary between zone 3 and the cement paste suggests that solid-state diffusion of $\mathrm{Zn}$ or $\mathrm{Ca}$ across this boundary is minimal. On the other hand, the commingling of $\mathrm{Ca}$, $\mathrm{Si}$, and $\mathrm{Zn}$ in zones 2 and 3 represents secondary mineralization of the cement paste with the Zn anode dissolution products. In this process moisture from precipitation, dew, and salt spray passes through pores in the $\mathrm{Zn}$ anode and penetrates the cement paste dissolving minerals in the interfacial region. Elements such as Ca may be selectively leached from the slab during the process. Drying of the slab surface then dehydrates the interior layers. It is in this way the mineral layers of zones 1 through 3 are formed.

The ability of $\mathrm{Zn}$ to substitute for $\mathrm{Ca}$ in the cement paste is related to ion size and coordination number. Table 4.9 shows that the $\mathrm{Zn}$ ion is smaller than the $\mathrm{Ca}$ ion and has the same coordination number (Shannon 1976). This should make it easy for $\mathrm{Zn}$ to replace $\mathrm{Ca}$ in the cement paste as acidic products produced by, for example, reaction 1.2 dissolve the $\mathrm{Ca}$. Table 4.9 also shows that the ratio of the $\mathrm{Zn}$ ionic radius to that of oxygen is more similar to that of $\mathrm{Ca}$ than either $\mathrm{Al}$ or $\mathrm{Fe}$, which are other components of the cement paste.

Table 4.9: Metal ionic radii and radii ratios with respect to oxygen, for octahedral $(\mathrm{CN}=6)$ coordination (Shannon 1976)

\begin{tabular}{c|c|c|c}
\hline Cation & Charge & $\begin{array}{c}\text { Ionic Radius } \\
\mathbf{n m}\end{array}$ & $\begin{array}{c}\text { Radii Ratio } \\
\mathbf{r}_{\mathbf{x}} / \mathbf{r}_{\mathbf{0}}\end{array}$ \\
\hline $\mathrm{Zn}$ & 2 & 0.074 & 0.53 \\
\hline $\mathrm{Ca}$ & 2 & 0.100 & 0.71 \\
\hline $\mathrm{Al}$ & 3 & 0.054 & 0.39 \\
\hline $\mathrm{Fe}$ & 3 & 0.065 & 0.45 \\
\hline
\end{tabular}

The progressive mineral changes in the reaction zones would appear to explain the changes observed in bond strength, in anode CP system operation and in the water permeability with electrochemical age of the $\mathrm{Zn}$ anode. For example, bond strength initially decreases as $\mathrm{Zn}$ adjacent to the concrete is preferentially dissolved, replacing strong mechanical bond sites with a thin layer of weaker $\mathrm{Zn}$ rich mineral. Secondary mineralization of the $\mathrm{Zn}$ reaction product, through repeated wetting and drying, continually alters the distribution and nature of the mineral species near the zinc-concrete interface to commingle the $\mathrm{Zn}$ corrosion product with the cement paste. For a time these processes serve to improve the bond between the $\mathrm{Zn}$ and concrete. However, for long aging times, massive accumulation of $\mathrm{Zn}$ dissolution products, particularly the weak layer of $\mathrm{ZnO}$ and $\mathrm{Zn}(\mathrm{OH})_{2}$, eventually leads to an overall decrease in bond strength that is not expected to recover with further aging. Table 4.10 shows the ratio of the molar volume of a metal or compound to that of the metal component (Kubaschewski and Hopkins 1962). The volume ratios of the $\mathrm{Zn}$ compounds listed are from 38 to $191 \%$ higher than $\mathrm{Zn}$ itself. Thus, formation of these compounds at the $\mathrm{Zn}$-concrete interface would eventually force the anode away from the concrete and lead to anode delamination. 
Table 4.10: Molecular volumes of metals and compounds associated with anode-concrete interfacial chemistry (Kubaschewski and Hopkins 1962)

\begin{tabular}{c|c|c}
\hline Metal or Compound & $\begin{array}{c}\text { Molar Volume } \\
\mathbf{c m}^{\mathbf{3}}\end{array}$ & $\begin{array}{c}\text { Volume Ratio } \\
\mathbf{V}_{\text {compound }} / \mathbf{V}_{\text {metal }}\end{array}$ \\
\hline $\mathrm{Zn}$ & 9.1 & 1 \\
\hline $\mathrm{ZnO}$ & 14.2 & 1.55 \\
\hline$\alpha-\mathrm{Zn}(\mathrm{OH})_{2}$ & 14.6 & 1.60 \\
\hline$\varepsilon-\mathrm{Zn}(\mathrm{OH})_{2}$ & 12.6 & 1.38 \\
\hline $\mathrm{Zn}_{2} \mathrm{SiO}_{4}$ & 52.9 & 2.91 \\
\hline $\mathrm{Ca}$ & 26.2 & 1 \\
\hline $\mathrm{CaO}$ & 16.7 & 0.64 \\
\hline $\mathrm{Ca}(\mathrm{OH})_{2}$ & 33.2 & 1.28 \\
\hline $\mathrm{Ca}_{2} \mathrm{SiO}_{4}$ & 54.2 & 1.03 \\
\hline$\alpha-\mathrm{Fe}$ & 7.1 & 1 \\
\hline$\alpha-\mathrm{Fe}_{2} \mathrm{O}_{3}$ & 30.4 & 2.14 \\
\hline $\mathrm{Fe}_{3} \mathrm{O}_{4}$ & 44.7 & 2.10 \\
\hline & &
\end{tabular}

\subsubsection{Micro-pH}

Table 4.11 lists $\mathrm{pH}$ of the anode-concrete interface for a series of periodically wetted aged $\mathrm{Zn}$ anodes. The $\mathrm{pH}$ for zinc-concrete and the steel-concrete interfaces are shown plotted versus electrochemical age in Figure 4.23 versus electrochemical age. Solid symbols in this figure represent results from periodically wetted slabs and the open symbols represent results from unwetted slabs. There appears to be no difference between $\mathrm{pH}$-electrochemical age response of the periodically wetted and unwetted anode-concrete interface. In both cases, the $\mathrm{pH}$ falls rapidly with aging and levels out at a $\mathrm{pH}$ value around 7. The long-term value for preheated slabs appeared to be a little higher than that for the unheated slabs. 


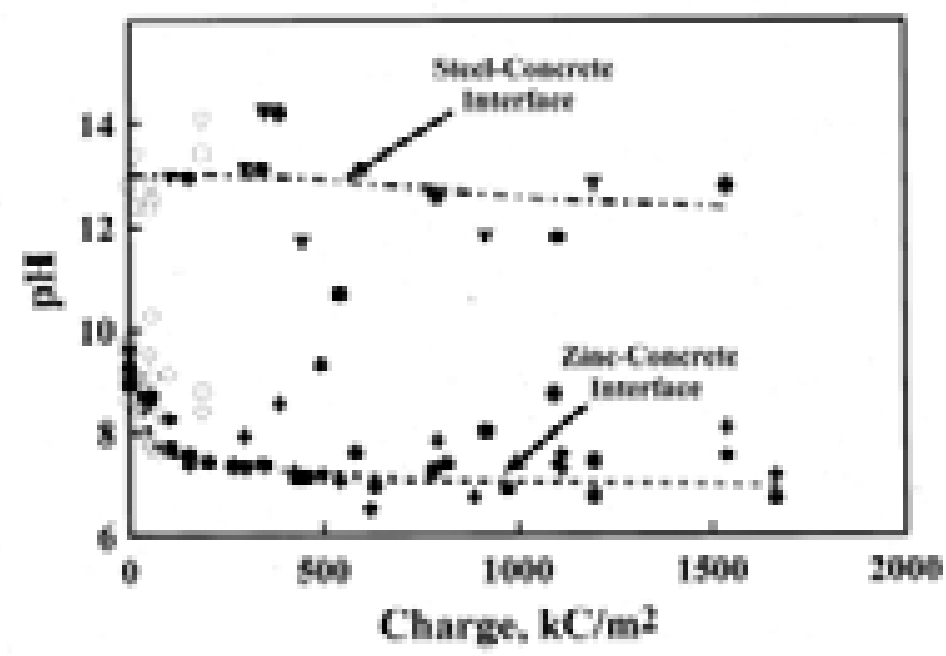

Figure 4.23: $\mathrm{pH}$ versus electrochemical age for TS $\mathrm{Zn}$ anode-concrete and steel-concrete interfaces for periodically-wetted concrete slabs

For the steel-concrete interface, $\mathrm{pH}$ values are relatively constant with aging both for the periodically wetted and the unwetted slabs. Some decline in $\mathrm{pH}$ is observed for long aging periods (comparable to 27 years service at a current of $0.0022 \mathrm{~A} / \mathrm{m}^{2}\left(0.2 \mathrm{~mA} / \mathrm{ft}^{2}\right)$, but the $\mathrm{pH}$ values were still high, with substantial buffering capacity in the concrete adjacent to the steel.

Table 4.11: Description of periodically-wetted laboratory samples analyzed

\begin{tabular}{|c|c|c|c|c|c|}
\hline $\begin{array}{c}\text { Sample } \\
\text { No. }\end{array}$ & $\begin{array}{c}\text { Sample } \\
\text { description }\end{array}$ & $\begin{array}{c}\text { Electrochemical } \\
\text { age, } \mathrm{yr}^{1}\end{array}$ & $\begin{array}{l}\mathrm{NaCl} \\
\mathrm{lb} / \mathrm{yd}^{3}\end{array}$ & $\begin{array}{c}\text { pH } \\
\text { Concrete side }\end{array}$ & $\begin{array}{c}\text { pH } \\
\text { Zn side }\end{array}$ \\
\hline 3192 & unheated & 0.8 & $5\left(4.3^{2}\right)$ & 8.86 & 8.72 \\
\hline 3240 & unheated & 5.1 & “" & 8.04 & 7.33 \\
\hline 3397 & unheated & 12 & “ & 7.71 & 7.37 \\
\hline 3622 & unheated & 18.9 & “ & 8.06 & 6.75 \\
\hline 3568 & preheated & 16.2 & “ & 8.19 & 7.36 \\
\hline 3570 & preheated & 16.2 & “ & 8.19 & 7.36 \\
\hline 3616 & preheated & 19 & “" & 8.06 & 7.25 \\
\hline 3618 & preheated & 19 & “ & 8.06 & 7.25 \\
\hline 3351 & unheated & 8.6 & $2\left(1.4^{2}\right)$ & 7.52 & 7.27 \\
\hline 3306 & preheated & 6.3 & “ & 7.88 & 6.91 \\
\hline 3345 & preheated & 8.6 & “ & 7.72 & 7.43 \\
\hline 3602 & preheated & 14.9 & “ & 8.07 & 8.24 \\
\hline 3628 & preheated & 17.8 & “ & 8.91 & 8.61 \\
\hline
\end{tabular}

\footnotetext{
${ }^{1}$ equivalent to aging at $0.0022 \mathrm{~A} / \mathrm{m}^{2}$.

2 actual analysis
} 


\subsubsection{X-ray diffraction}

White powder observed at the anode-concrete interface for after substantial electrochemical aging was analyzed using XRD analysis. The results showed the presence of primarily zincite $(\mathrm{ZnO})$ with minor amounts of wulfingite $\left(\mathrm{Zn}(\mathrm{OH})_{2}\right)$, simonkolleite $\left(\mathrm{Zn}_{5}(\mathrm{OH})_{8} \mathrm{Cl}_{2} \bullet \mathrm{H}_{2} \mathrm{O}\right)$ and hydrated $\mathrm{Zn}$ hydroxide sulfates $\left(\mathrm{Zn}_{4} \mathrm{SO}_{4}(\mathrm{OH})_{6} \bullet \mathrm{xH}_{2} \mathrm{O}\right)$. The presence of the last two compounds accounts for the significant increase in the $\mathrm{Cl}$ and $\mathrm{S}$ concentration at the interface, as shown in Figures 4.19 through 4.21.

\subsection{NONDESTRUCTIVE MEASUREMENTS}

Most CP systems, both thermal sprayed and those embedded in concrete, are installed with devices such as reference electrodes or null probes to monitor how well the system is protecting the rebar. In the case of ICCP systems, the current can be increased or decreased as necessary to properly protect the rebar. In the case of SACP systems, it is usually not possible to adjust the level of protection. In both systems, the $100 \mathrm{mV}$ depolarization criteria (NACE International 1996, RP0169-96) is usually used to determine if the rebar is being properly protected. With respect to the protection of the structure, therefore, these systems will continue to provide adequate protection as long as sufficient current can be provided by the anode. Sufficient current will continue to be provided as long as the anode has not been consumed, has not passivated, or has not delaminated from the concrete.

Owners of CP systems, however, need to know when an anode is approaching the end of its useful service life. In the case of TS Zn on concrete, limits to the service life are determined not by consumption of the anode, which has tended in the past to be only a fraction of the anode thickness, or by anode delamination, which occurs only over a long period of time. Instead, anode polarization, large potential drops across the anode-concrete interface resulting from the build up of resistive reaction products or minerals, may be the limiting factor. Polarization effects have been studied as a function of electrochemical age. Relatively fast, nondestructive tests (Covino, et al. 2000) that can determine the condition of the anode are discussed below.

\subsubsection{CP circuit resistance}

The variation of CP circuit resistance (see equation 3.2) with charge or electrochemical age (see equation 3.1) has been reported previously for accelerated laboratory aging experiments and for the ICCP of bridges such as the Cape Creek and Depoe Bay bridges on the Oregon coast and the Richmond-San Rafael Bridge in California (Bullard, et al. 1998). The circuit resistance of the laboratory slabs is shown in Figure 4.4. It can be seen that circuit resistance increases with increasing charge or electrochemical age and that this could be used to characterize the condition of the anodes.

Another parameter associated with electrochemical age is the anode bond strength, Figures 4.7a, $4.7 \mathrm{~b}, 4.8 \mathrm{a}$ and $4.8 \mathrm{~b}$. Figures $4.7 \mathrm{a}$ and $4.7 \mathrm{~b}$ for periodically-wetted concrete shows a linear decrease in bond strength after about $400 \mathrm{kC} / \mathrm{m}^{2}$ of electrochemical age, and after $90 \mathrm{kC} / \mathrm{m}^{2}$ in 
Figure 4.8a and 4.8b for unwetted concrete. The data in Figure 4.4 show roughly a linear increase in circuit resistance starting at about the same electrochemical ages for periodicallywetted and unwetted concrete. This would suggest that the changes in bond strength and circuit resistance are related to a common factor, i.e., the growth of a zinc mineral layer at the anodeconcrete interface.

Figure 4.24 shows the relationship between bond strength and circuit resistance (measured 24 hours before the slabs were removed from the experiment for the bond strength measurement). The plot shows circuit resistance increasing as bond strength decreases. This behavior corresponds to chemistry changes occurring at the $\mathrm{Zn}$-concrete interface due to electrochemical aging. Insulating $\mathrm{Zn}$ minerals are building up at the interface that cause the anode to lose strength while at the same time cause the circuit resistance to increase.

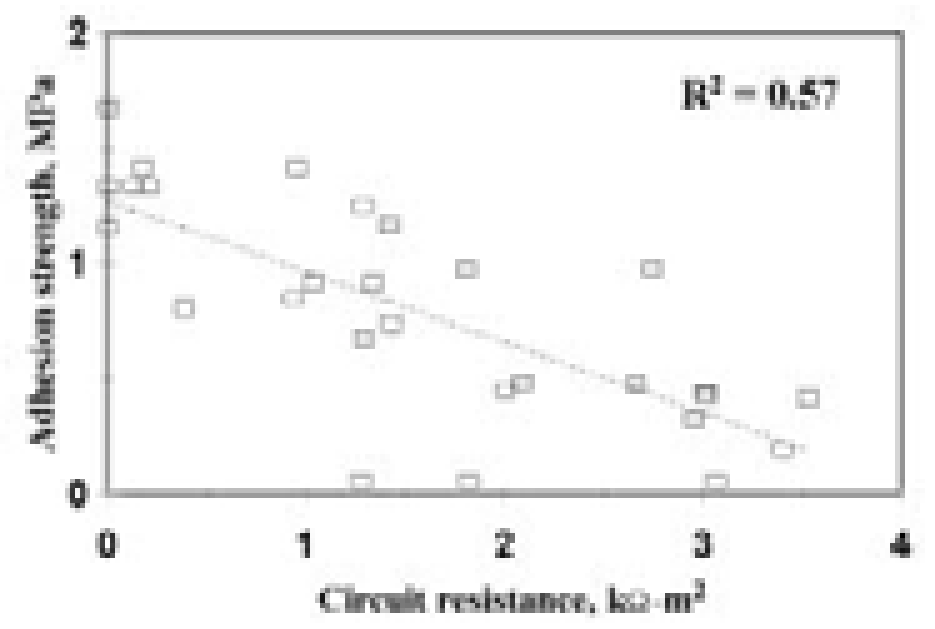

Figure 4.24: Relationship between CP system circuit resistance and TS Zn anode bond (adhesion) strength for periodically-wetted concrete slabs

\subsubsection{Anode coating resistance}

The resistance of the thermal spray anodes was measured using the device shown in Figure 3.12. This resistance can be converted to coating resistivity $(\rho)$, which is an intrinsic property of a coating. Changes that can affect the measured resistance and thus the calculated resistivity include:

1. changes in structure and composition as happens during thermal spraying;

2. external corrosion that can occur due to interaction with atmospheric constituents;

3. and thinning or consumption of the anode during electrochemical aging.

The first change will affect the resistivity because of the splat structure in the thermal-sprayed anode. Splats tend to have a more resistive contact to other splats than do grains in a metal 
produced using conventional melt technology. Thermal-sprayed $\mathrm{Zn}$ anodes are not known to oxidize heavily during the thermal spray operation, but thermal-sprayed Ti (Cramer, et al. 1998; Cramer, et al. 1999) does form oxides and nitrides when sprayed in either air or nitrogen. It is also likely that thermal spray anodes containing $\mathrm{Al}$ will oxidize more heavily than those without Al. It is for these reasons that the resistivity of thermal-sprayed anodes will be called an apparent resistivity $\left(\rho_{\mathrm{a}}\right)$. The average resistivity of thermal-sprayed $\mathrm{Zn}$ on several slabs prior to electrochemical aging was $22.1 \mu \Omega$-cm compared to the bulk resistivity $(\rho)$ of $\mathrm{Zn}$ metal of 5.9 $\mu \Omega$-cm (Weast 1979). Zn resistivity measured for $0.094 \mathrm{~mm}$ (3.7 mil) thick coatings on mortar was $5.9 \mu \Omega-\mathrm{cm}$ (Carello, Parks and Apostolos 1989).

Both external corrosion and consumption during electrochemical aging will reduce the amount of $\mathrm{Zn}$ in the anode. For external corrosion of the anode, the corrosion products will remain either adherent or be washed from the surface. The sharp contact points of the device shown in Figure 3.12 will ensure that contact is made to the metallic $\mathrm{Zn}$ for the resistance measurement. The resistance of the anode will increase as the anode thins, but the resistivity will be unchanged. For consumption of the anode during electrochemical aging, the $\mathrm{Zn}$ reaction products will migrate into the cement paste and/or build up as a layer between the anode and the cement paste. For both of these cases, the resistance of those layers will be much greater than the resistance of the remaining $\mathrm{Zn}$ anode. Because these resistances are in parallel, the resistance of the zinc mineral reaction product layers become insignificant compared to the resistance of the $\mathrm{Zn}$ anode. The resistivity of the $\mathrm{Zn}$ anode will remain unchanged and the resistance will increase as the anode thins. Data showing the increase in anode resistance with electrochemical age are presented in Figure 4.25 along with the equation and line that represent a least-squares fit of the data.

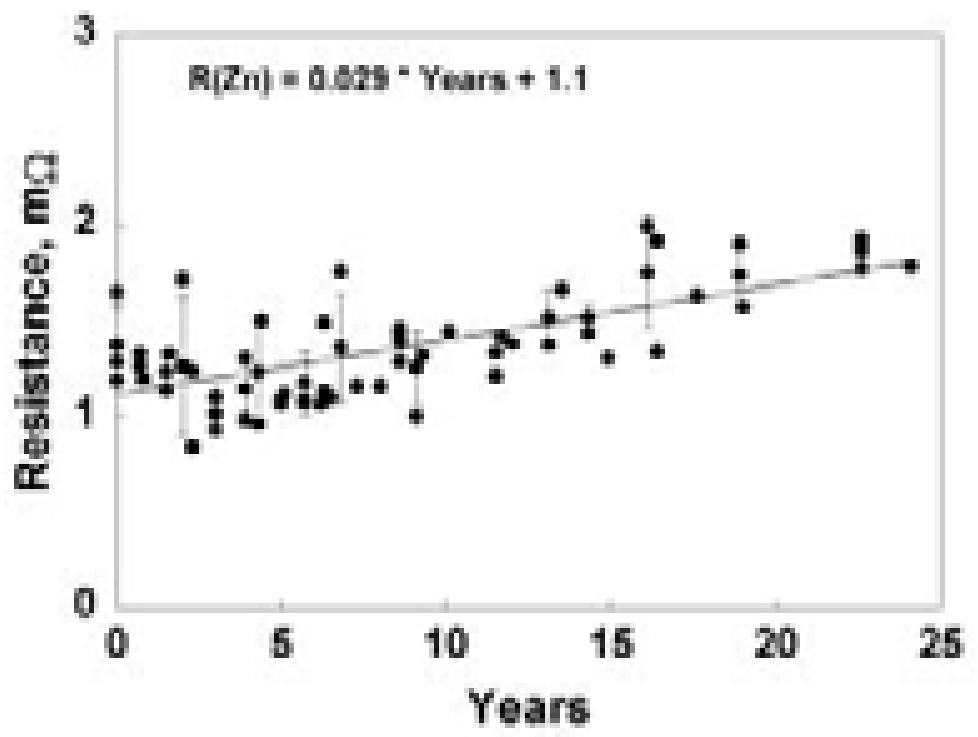

Figure 4.25: Surface resistance of TS Zn anode as a function of electrochemical age in years at $0.0022 \mathrm{~A} / \mathrm{m}^{2}$ for periodically-wetted concrete slabs 
An indication of the loss of anode thickness with electrochemical age can be determined from the resistance data in Figure 4.25. A simplified equation for calculating resistivity is:

$$
\text { apparent resistivity }\left(\rho_{a}\right)=\text { resistance }(r) \times \text { coating thickness }(t)
$$

For the thermal spray $\mathrm{Zn}$ anode the average value of $\rho_{\mathrm{a}}$ for unaged thermal spray $\mathrm{Zn}$ anodes was measured as $22.1 \mu \Omega-\mathrm{cm}$. Assuming that the resistivity of the zinc metal in the anodes does not change with aging (a reasonable assumption) then:

$$
\text { coating thickness }(t)=\rho_{\mathrm{a}} / \text { resistance }(\mathbf{r})
$$

Using this equation with the data in Figure 4.25 gives the thickness of the $\mathrm{Zn}$ anode at the respective electrochemical age. The results of these calculations are given in Figure 4.26 as a function of electrochemical age along with a line representing a least-squares fit of the data, i.e.,

$$
\text { Coating thickness }(t)=19.7-0.32 \times\left(\text { years service at } 2.2 \mathrm{~mA} / \mathrm{m}^{2}\right)
$$

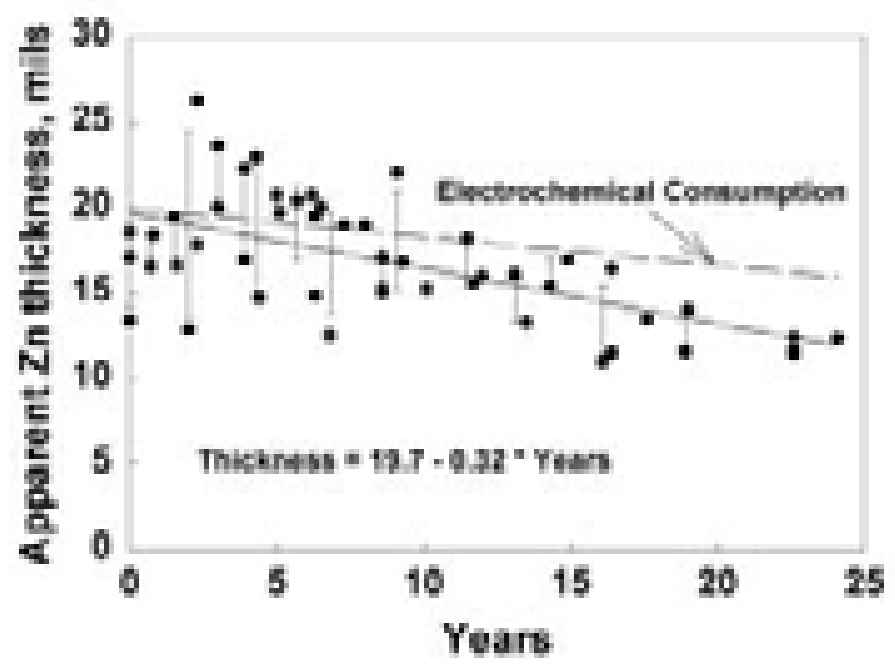

Figure 4.26: Apparent TS Zn anode thickness as a function of electrochemical age in years at $0.0022 \mathrm{~A} / \mathrm{m}^{2}$

The equation agrees well with know experimental details, predicting the nominal 20 mil coating thickness would in fact be 19.7 mils prior to electrochemical aging. The line labeled electrochemical consumption was drawn by assuming all of the CP current caused dissolution of a TS Zn anode that was $80 \%$ of theoretical density. The two curves diverge, indicating that the amount of $\mathrm{Zn}$ consumed electrochemically was about $50 \%$ of that predicted by the resistance measurements. Possible explanations for this difference are:

- The thermal spray $\mathrm{Zn}$ anode dissolves both chemically and electrochemically during CP. Data reported for the thermal-sprayed $\mathrm{Zn}$ anode on the Richmond-San Rafael 
Bridge (Bullard, et al. 1998) showed corrosion of the outer surface of the anode. This was not, however, observed in the accelerated laboratory studies. However, anode reaction products at the anode-concrete interface may include some produced by chemical corrosion, but these would not be distinguishable from those resulting from electrochemical dissolution.

- The discrepancy between the two lines may include factors such as the roughness of the concrete surface, variations in the thickness of the anode, and non-uniform dissolution of the anode.

\subsubsection{CP circuit ac resistance}

The measurement of circuit resistance (see Section 4.6.1) is a dc measurement. This type of measurement often includes resistances from polarization of surfaces such as the electrodes. To eliminate polarization effects, ac resistance measurement technique was chosen. The ac resistance between the anode and the steel mesh includes resistance in the anode, resistance at the anode-concrete interface, resistance within the concrete between the anode and the steel mesh, resistance at the steel-concrete interface, and resistance within the steel mesh. Despite all of these resistances, the changes in ac resistance measurements are due primarily to chemistry changes within the anode and at the anode-concrete interface (see Section 6.1).

The AC resistivity of thermal spray $\mathrm{Zn}$ anodes aged for the equivalent of up to 20 years at 0.0022 $\mathrm{A} / \mathrm{m}^{2}$ is given in Figure 4.27. The error bars in the figure represent the standard deviation of multiple measurements at similar electrochemical ages. The results show that the AC resistivity increases with increasing electrochemical age. These changes in resistivity are due to the oxidation of the $\mathrm{Zn}$ anode at the $\mathrm{Zn}$-concrete interface and to changes in the chemistry of the cement paste involving the substitution of $\mathrm{Zn}$ dissolution products for $\mathrm{Ca}$.

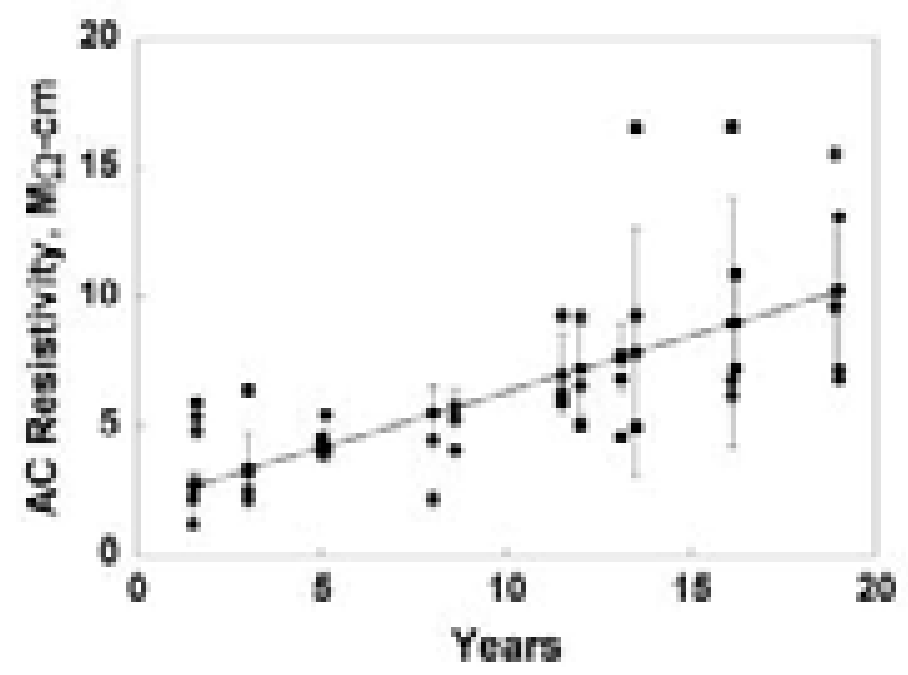

Figure 4.27: Volume average AC resistivity of material between the TS $\mathrm{Zn}$ anode and the steel as a function of electrochemical age in years at $0.0022 \mathrm{~A} / \mathrm{m}^{2}$; average includes zinc minerals at anode, altered and unaltered concrete, and corrosion film on steel. 


\subsubsection{Anode air permeability}

Measurements of the permeability of the ceramic porosity standards in Table 3.2 are shown as a function of maximum pore diameter in Figure 4.28. The curves represent approximate isoporosity lines based on a limited number of porosity standards. Also plotted is the pressure at the flow rate transducer. Ideally, the flow rate should be measured at a constant pressure at the transducer. In the region between $0.1 \mu \mathrm{m}(0.004 \mathrm{mil})$ and $1.0 \mu \mathrm{m}(0.04 \mathrm{mil})$ pore diameter, the pressure is constant and there is a unique relationship between porosity and flow rate. However, beyond this pore diameter the transducer pressure increases and the flow rate is no longer uniquely related to porosity. As a consequence, surface air permeability measurements as presently made do not appear to give useful results except for a very limited range of pore diameters.

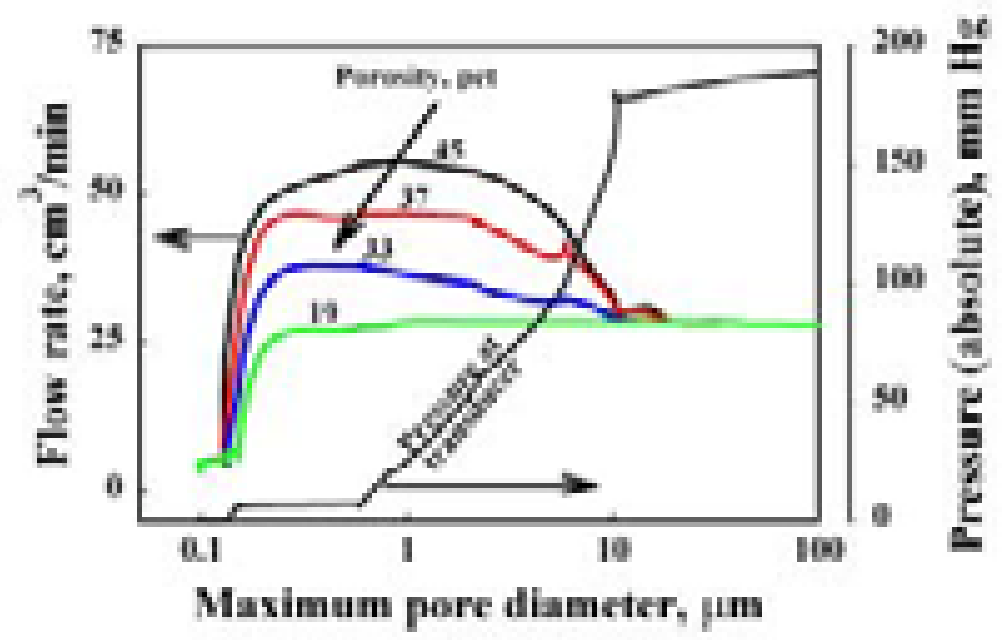

Figure 4.28: Surface air permeability determined using ceramic disc porosity standards as a function of maximum pore diameter and percent pore volume (porosity).

Surface air permeability measurements were made on a large number of slabs. These results are shown in Figure 4.29. Only in the vacuum range 776 to $750 \mathrm{~mm} \mathrm{Hg}$ do the measurements appear to conform to the narrow range of conditions shown in figure 4.28 to give a unique relationship between flow rate and porosity. The surface air permeability data have little value at lower vacuum pressures. The technique is intriguing but not useful at present. 


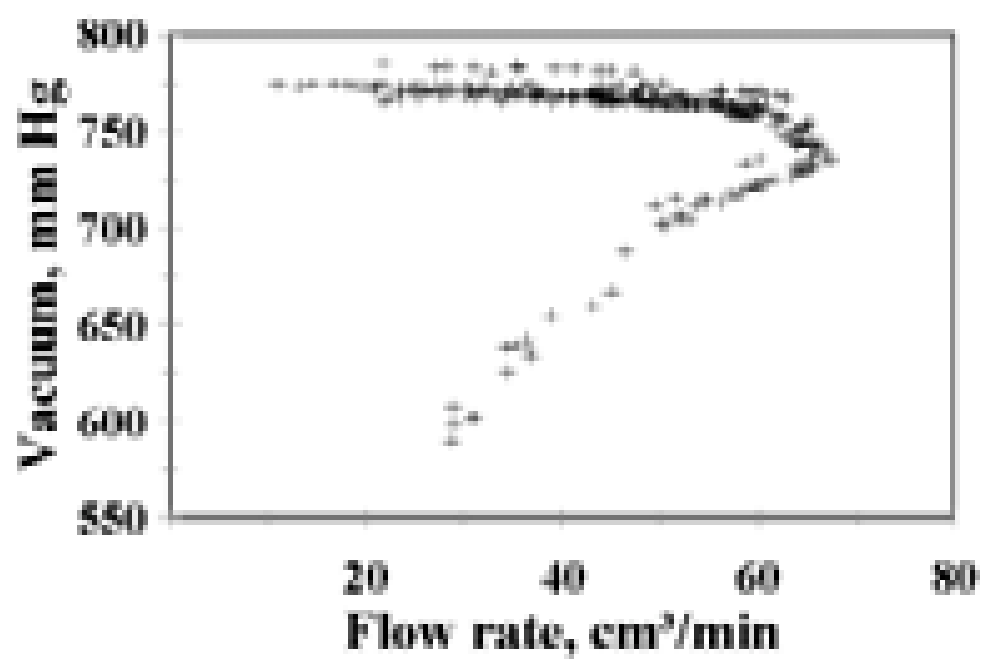

Figure 4.29: Surface air permeability vacuum pressure for TS Zn anodes on periodicallywetted concrete slabs as a function of airflow rate through the instrument

\subsubsection{Anode water permeability}

At an electrochemical age where minimum circuit resistance began rising significantly (Figure 4.4), free water began pooling on the coating surface after wetting and remained for increasingly longer periods, i.e., the ability of water to permeate the $\mathrm{Zn}$ coating became progressively more restricted. Figure 4.30 shows how aging affected the transport of water through the $\mathrm{Zn}$ anode. Presumably this was due to changes in the chemistry and mineralogy of the anode-concrete interface. Aging affects not only the initial rate of water movement through the interface but also long term movement over several weeks. However, the initial rate represents the time period corresponding to the observed pooling of water on the coating surface. Calculation of initial slopes from Figure 4.30 shows the water permeation rate decreased from $3100 \mathrm{ml} / \mathrm{m}^{2}$-day before aging to $420 \mathrm{ml} / \mathrm{m}^{2}$-day after aging $83 \mathrm{kC} / \mathrm{m}^{2}\left(2.1 \mathrm{~A}-\mathrm{h} / \mathrm{ft}^{2}\right)$.

Buildup of reaction products in Zone 1 and secondary mineralization in Zones 2 and 3 would progressively seal the anode to water permeation. Observations of water remaining on the $\mathrm{Zn}$ anode surface after wetting and the measured decrease in the water permeation rate through the coating, Figure 4.30, support this interpretation. 


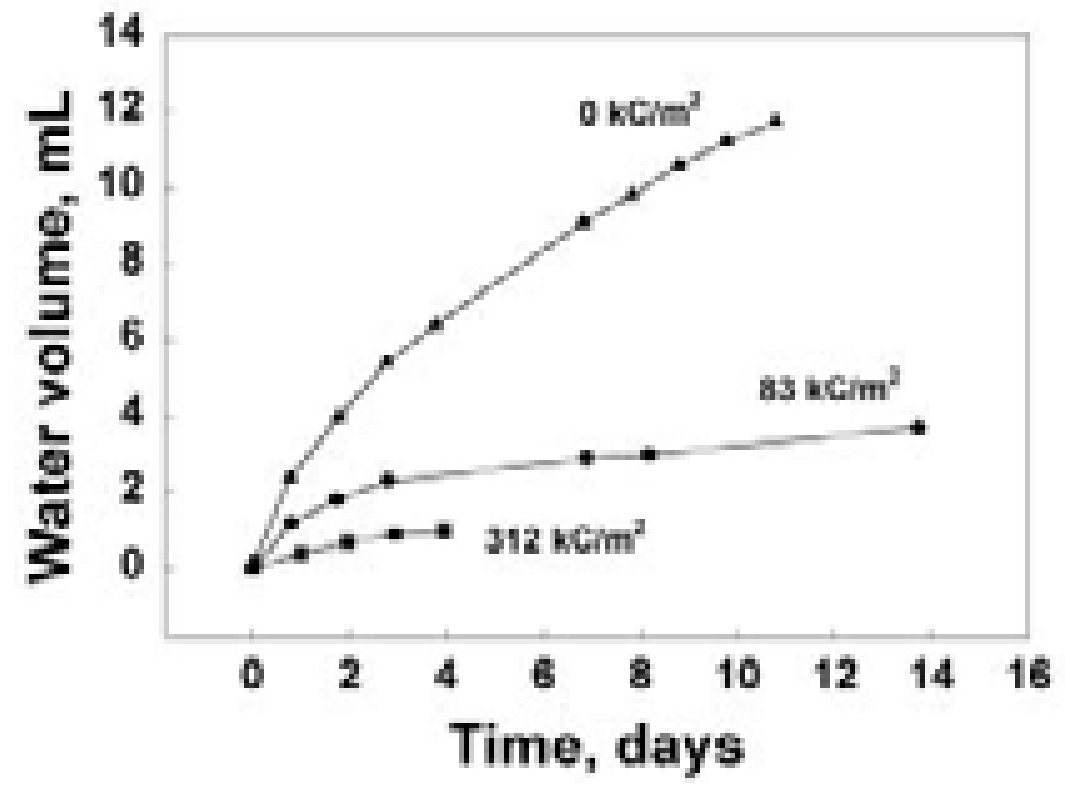

Figure 4.30: Permeability of water through TS Zn anode on periodically-wetted concrete slabs as a function of electrochemical age 


\subsection{FIELD AGING STUDIES -- RESULTS}

\subsection{CP PERFORMANCE}

The performance and behavior of thermal-sprayed $\mathrm{Zn}$ anode $\mathrm{CP}$ systems in actual use on bridges and other structures in comparison to the accelerated laboratory experiments is of considerable interest. Similarities would suggest that the long-term consequences of aging observed in the laboratory, such as effects on circuit resistance, water permeability, bond strength, coating consumption, and anode-concrete interfacial chemistry, and ways to characterize an aging anode may be applicable to real structures. Actual bond strength values for the Yaquina Bay Bridge, Depoe Bay Bridge, and Big Creek Bridge measure during anode installation are in Appendix B.

\subsubsection{ICCP}

Impressed current cathodic protection systems can involve either a consumable or nonconsumable anode. A consumable anode produces metal reaction products that can accumulate at the anode-concrete interface and a non-consumable anode produces no metal reaction products that can build up at the anode-concrete interface. The current delivered by these systems can be adjusted within a rectifier. The amount of voltage needed to protect a structure is based on the amount of current needed to reduce the rebar corrosion rate according to an established standard.

Cathodic protection circuit resistance (see equation 3.2) is affected by polarization of the anode and the cathode. Polarization is the process of retarding or accelerating an electrochemical reaction through physical or chemical factors (Fontana and Greene 1978). Polarization of the cathode is desirable; polarization of the anode is not. Polarization of the cathode is affected by the availability of oxygen and water, which can be restricted by impermeable coatings on the concrete surface or the use of newer more dense types of concrete. Polarization of the anode is affected by the lack of water and the buildup of reaction products near the anode. CP anodes used in soils are often packaged with a specific backfill that acts as a sink for the anode reaction products to minimize anode polarization. For thermal spray anodes on reinforced concrete structures, the only sink available for reaction products is the cement paste. As shown above in section 4.5.1, $\mathrm{Zn}$ does diffuse into cement paste to a certain degree while gradually growing a layer of $\mathrm{ZnO} / \mathrm{Zn}(\mathrm{OH})_{2}$ at the anode-concrete interface. These reaction products polarize the anode and cause the circuit resistance to increase.

CP circuit resistance as a function of electrochemical age is given below for several bridges in Oregon and California and for the CALTRANS silane study where thermal-sprayed $\mathrm{Zn}$ anodes are in use. 


\subsubsection{CALTRANS laboratory silane study}

CALTRANS conducted a study to determine if a silane coating on reinforced concrete structures would keep additional chlorides from entering the structure. The slabs were aged at a current density of $0.0036-2.7 \mathrm{~A} / \mathrm{m}^{2}\left(0.33-248 \mathrm{~mA} / \mathrm{ft}^{2}\right)$. The resulting circuit resistance is shown plotted in Figure 5.1 as a function of electrochemical age. The untreated concrete slab had the lowest circuit resistance and both slabs coated with silane exhibited large increases in circuit resistance after more than $500 \mathrm{kC} / \mathrm{m}^{2}$ of electrochemical aging. The silane proved to be an effective surface sealant that caused excessive polarization of both the anode and the cathode by limiting ingress of not only chlorides but water and oxygen. As a consequence, the CP circuit resistance rose, thereby increasing the voltage needed to maintain the protection current.

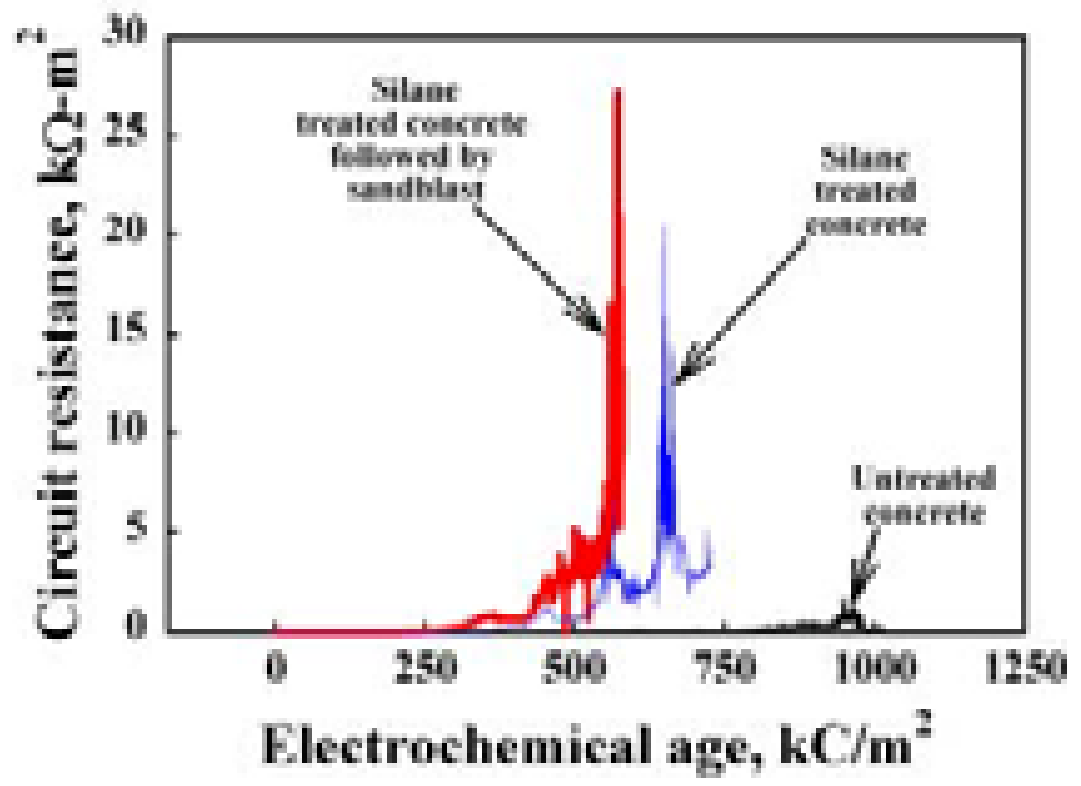

Figure 5.1: Circuit resistance as a function of electrochemical age for slabs from CALTRANS laboratory silane experiment; measurements on each slab were for the same time period.

\subsubsection{Richmond-San Rafael Bridge}

Some of the operating characteristics of the thermal-sprayed $\mathrm{Zn}$ anodes on the RichmondSan Rafael Bridge (Carello, Parks and Apostolos 1989) are tabulated in Table 5.1. These anodes were applied to the bridge as bands around the pier. The bands were operated in parallel with each other using voltage control, as opposed to current control typically used in Oregon on coastal ICCP systems. The CP system voltage need to maintain the protection current is shown in Figure 5.2 as a function of the years the system was in operation. Three major adjustments were made in the operating voltage. Initially it was 
about $3 \mathrm{~V}$. After a couple of years it was increased to 7-10 V. Near the end the voltage was increased to $15-16 \mathrm{~V}$ before the system was shut down.

Table 5.1: TS Zn anodes on the Richmond-San Rafael Bridge (Carello, et al. 1989)

\begin{tabular}{|c|c|c|c|c|}
\hline Band & CP timeline & $\begin{array}{c}2.5 \mathrm{hr} \text { Depolarization } \\
\mathrm{mV}\end{array}$ & $\begin{array}{c}\text { CP current } \\
\mathbf{A} / \mathbf{m}^{2}\left(\mathbf{m A} / \mathbf{f t}^{2}\right)\end{array}$ & $\begin{array}{c}\text { Height above Water } \\
\text { m (ft) }\end{array}$ \\
\hline 1 & Jan 1983-Jan 1994 & $52-110$ & $0.0044(0.41)$ & $3-4.2(10-14)$ \\
\hline 2 & Jan 1983-Jan 1994 & 75 & $0.0049(0.46)$ & $4.4-5.6(14.5-18.5)$ \\
\hline 3 & Jan 1983-Jan 1994 & $43-93$ & $0.0034(0.32)$ & $5.8-7.0(19-23)$ \\
\hline 4 & Jan 1983-Jan 1994 & $48-88$ & $0.0045(0.42)$ & $7.2-8.4(23.5-27.5)$ \\
\hline Barrel & Jan 1983-Jan 1994 & Sacrificial & $0.01-0.001(0.9-0.09)$ & $0-3(0-10)$ \\
\hline
\end{tabular}

${ }^{1}$ Average for the period 8/83 - 3/87

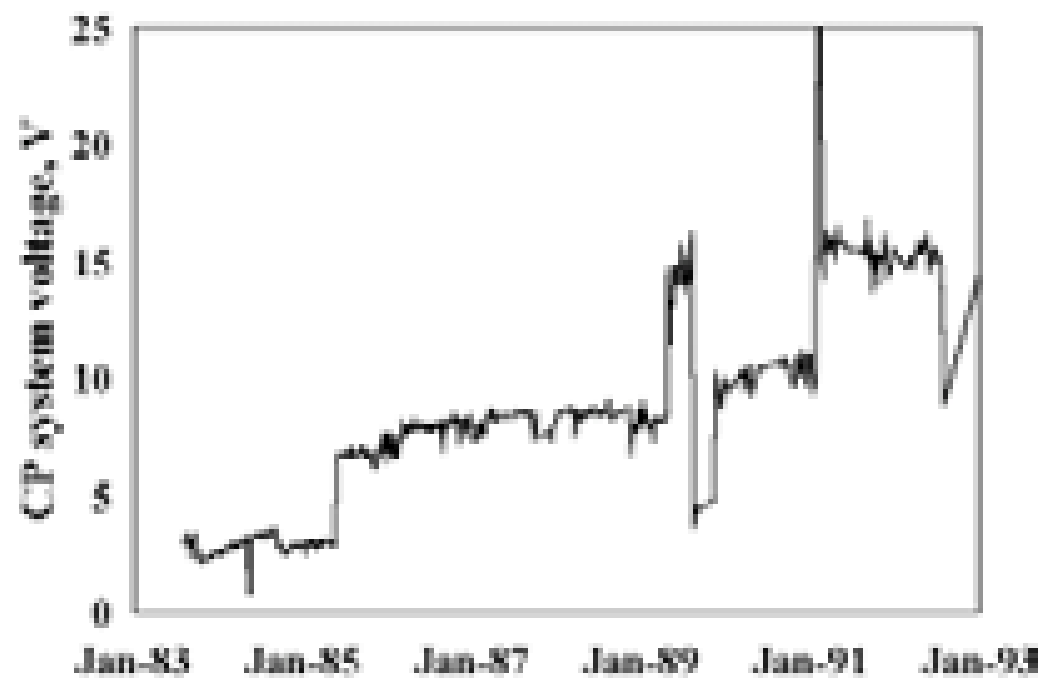

Figure 5.2: ICCP system voltage for the TS Zn bands (zones) on the south column, pier 4 of the Richmond-San Rafael Bridge (CA).

The circuit resistance of bands 1 and 4 over this period is shown in Figure 5.3 as a function of service time and in Figure 5.4 as a function of electrochemical age. The resistance of band 1 increased slowly, reaching $4 \mathrm{k} \Omega-\mathrm{m}^{2}$ within 6 years $\left(700 \mathrm{kC} / \mathrm{m}^{2}\right)$, and $8 \mathrm{kohm}-\mathrm{m}^{2}$ in an additional 4 years $\left(1100 \mathrm{kC} / \mathrm{m}^{2}\right)$. The periodic rise and fall of the circuit resistance reflects seasonal variations of moisture within the concrete delivered by fog, precipitation, and humidity. The circuit resistance of band 4 increased much more rapidly, reaching $8 \mathrm{k} \Omega-\mathrm{m}^{2}$ within 4 years $\left(450 \mathrm{kC} / \mathrm{m}^{2}\right)$ and exceeded $28 \mathrm{k} \Omega-\mathrm{m}^{2}$ at the end of 10 years $\left(900 \mathrm{kC} / \mathrm{m}^{2}\right)$. This is more than a factor of three greater than the circuit resistance of band 1. It reflects the fact that band 1 is in a wetter environment being 
closer to the water than band 4 and less sheltered by the deck above the bands. The seasonal fluctuations in circuit resistance for band 4 are greatly exaggerated compared to those for band 1 reflecting much drier conditions immediately under the bridge deck during part of the year. When wetted, the circuit resistances of band 1 and 4 approach roughly the same low values.

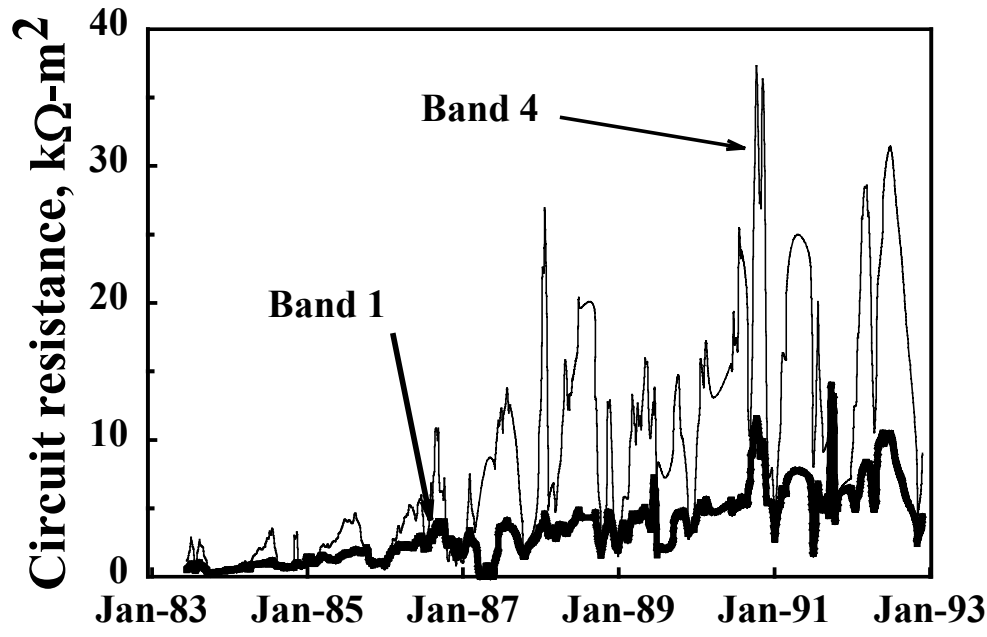

Figure 5.3: Circuit resistance as a function of time for TS $\mathrm{Zn}$ anode bands (zones) 1 and 4 on the south column, pier 4 of the Richmond-San Rafael Bridge

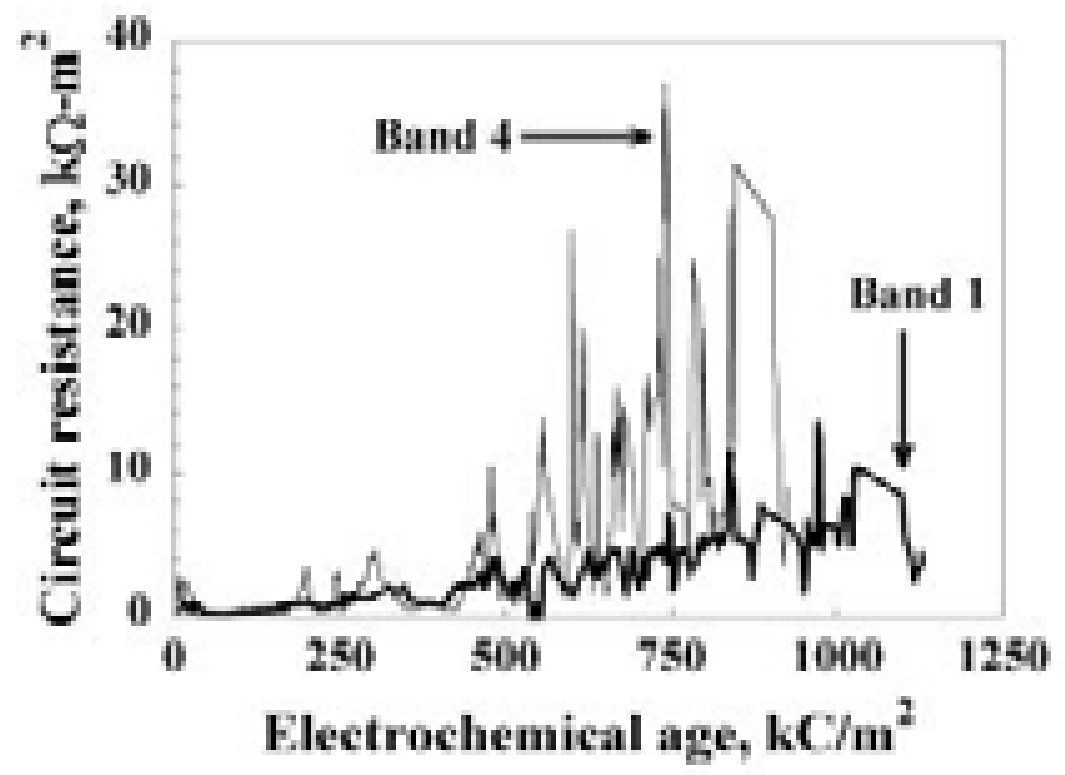

Figure 5.4: Circuit resistance as a function of electrochemical age for TS Zn anode bands (zones) 1 and 4 on the south column, pier 4 of the Richmond-San Rafael Bridge 
The minimum resistance for both bands 1 and 4 rises gradually at roughly the same rate. Laboratory research has shown that the rise in the minimum circuit resistance is associated with anode polarization due to mineral formation from $\mathrm{Zn}$ dissolution products at the zinc-concrete interface (Bullard, et al. 1997a).

The current density of band 4 , along with monthly precipitation measurements made at the bridge, are plotted in Figure 5.5 as a function of time. The peaks in current density coincide identically with the peaks in precipitation over the 10 year service period, indicating operation of the ICCP system was strongly affected by local climatic conditions, specifically precipitation.

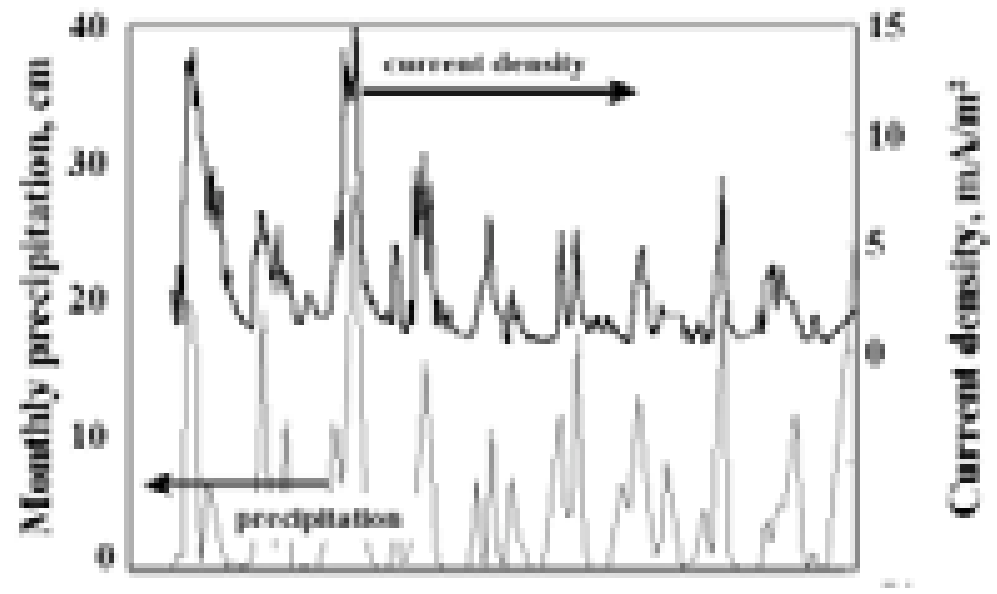

Jan 4 Jan 85 Jan 87 Jan 89 Jan 91 Jan 93

Figure 5.5: Current density and monthly precipitation as a function of time for TS Zn anode band (zones) 4 on the south column, pier 4 of the Richmond-San Rafael Bridge

\subsubsection{Cape Creek Bridge}

Cathodic protection system currents and voltages, expressed as a circuit resistance for ICCP zones 11 and 15 of the Cape Creek Bridge, are shown in Figure 5.6. Zone 11 is on the underside of the bridge deck and remains wet for long periods of time; zone 15 is on the west (ocean) face of bridge columns and experiences extreme wetting-drying cycles. The circuit resistance of zones 11 and 15 are similar for the first year of operation. Thereafter, they diverge with continued electrochemical aging.

Both zones respond to seasonal wetting and drying, with the circuit resistance substantially lower during the wet periods, typically November through March on the Oregon coast. During the drier periods of late spring, summer, and early fall, zone 15 circuit resistance rises to values about twice those of zone 11. This rise reflects the substantially drier conditions at the $\mathrm{Zn}$ anode for zone 15 compared to zone 11 . It also reflects differences in secondary mineralization occurring at the zinc-concrete interface, 
differences arising from the moisture content of the concrete and from the intensity and extent of the wetting-drying cycle.
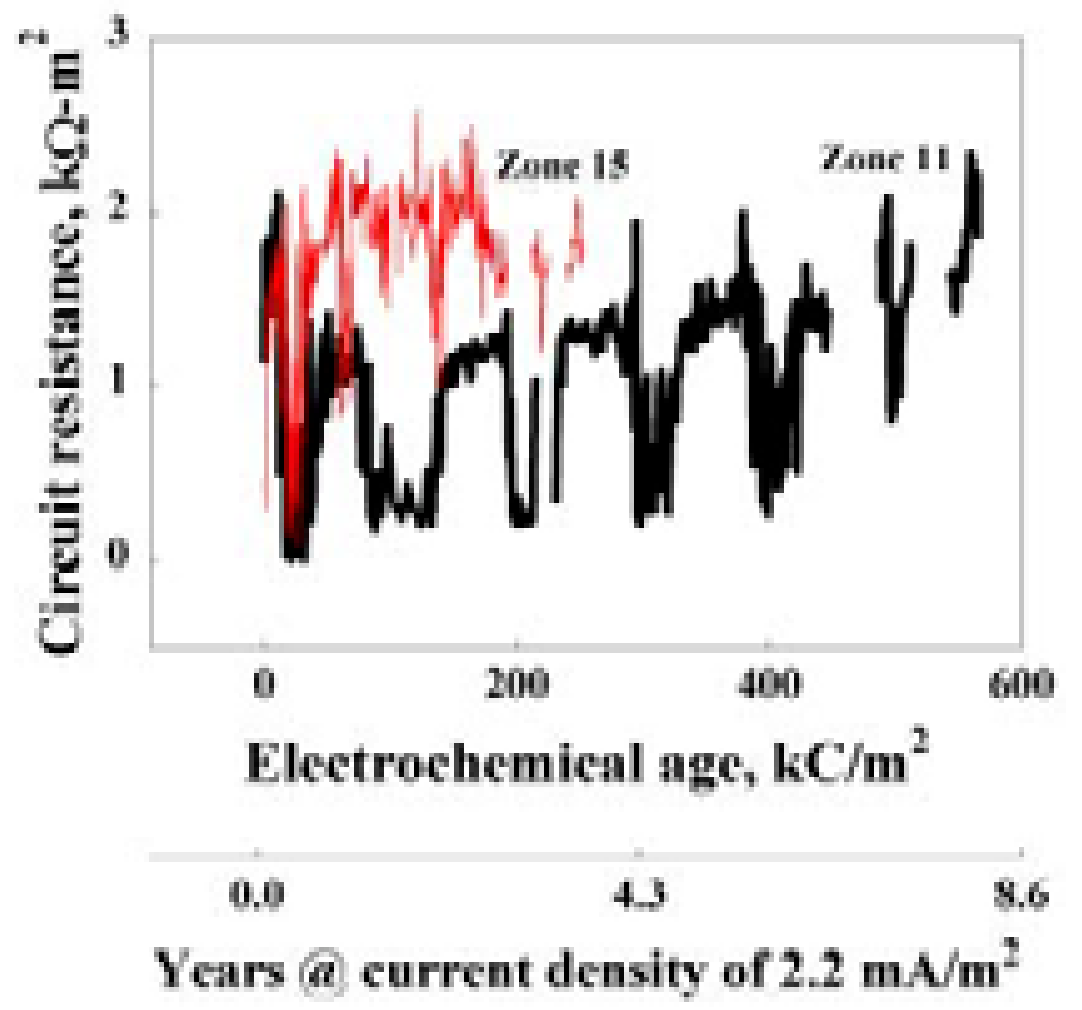

Figure 5.6: Circuit resistance as a function of TS Zn electrochemical age for ICCP zones 11 and 15 on the Cape Creek Bridge; measurements on each zone were for the same time period.

Table 5.2 gives minimum CP system voltages for the two zones for a period of four years (Covino, et al. 1997a). The minimum voltage risees with operating time. This reflects the accumulation of $\mathrm{Zn}$ dissolution products at the zinc-concrete interface and the modification of these dissolution products and the cement paste by secondary mineralization.

Table 5.2: Performance of TS $\mathrm{Zn}$ anodes on zones 11 and 15 of the Cape Creek Bridge

\begin{tabular}{c|c|c}
\hline \multirow{2}{*}{ year } & \multicolumn{2}{|c}{ Minimum zone voltage, $\mathbf{V}$} \\
\cline { 2 - 3 } & ICCP zone 11 & ICCP zone 15 \\
\hline 1992 & $<0.10$ & $<0.10$ \\
\hline 1993 & 0.40 & 0.32 \\
\hline 1994 & 0.47 & 0.87 \\
\hline 1995 & 1.23 & 1.86 \\
\hline
\end{tabular}




\subsubsection{Depoe Bay Bridge}

The circuit resistance versus electrochemical age behavior of two ICCP zones on the Depoe Bay Bridge is shown in Figure 5.7. Zone 13 is a boldly exposed part of the bridge seeing frequent wetting and drying cycles, which are reflected in variations in the zone circuit resistance. Zone 14 is thermal-sprayed catalyzed Ti anode in a more sheltered part of the bridge, but with a very different response to humidity and wet/dry cycles. The zone is catalyzed by cobalt nitrate (Cramer, et al. 1999, McGill, et al. 1999) and the zone performance is relatively unaffected by the delivery of moisture to the anode. The performance of the titanium anode depends upon moisture to sustain the anode reaction, but there is more than enough delivered in humid air to satisfy the anode requirements.
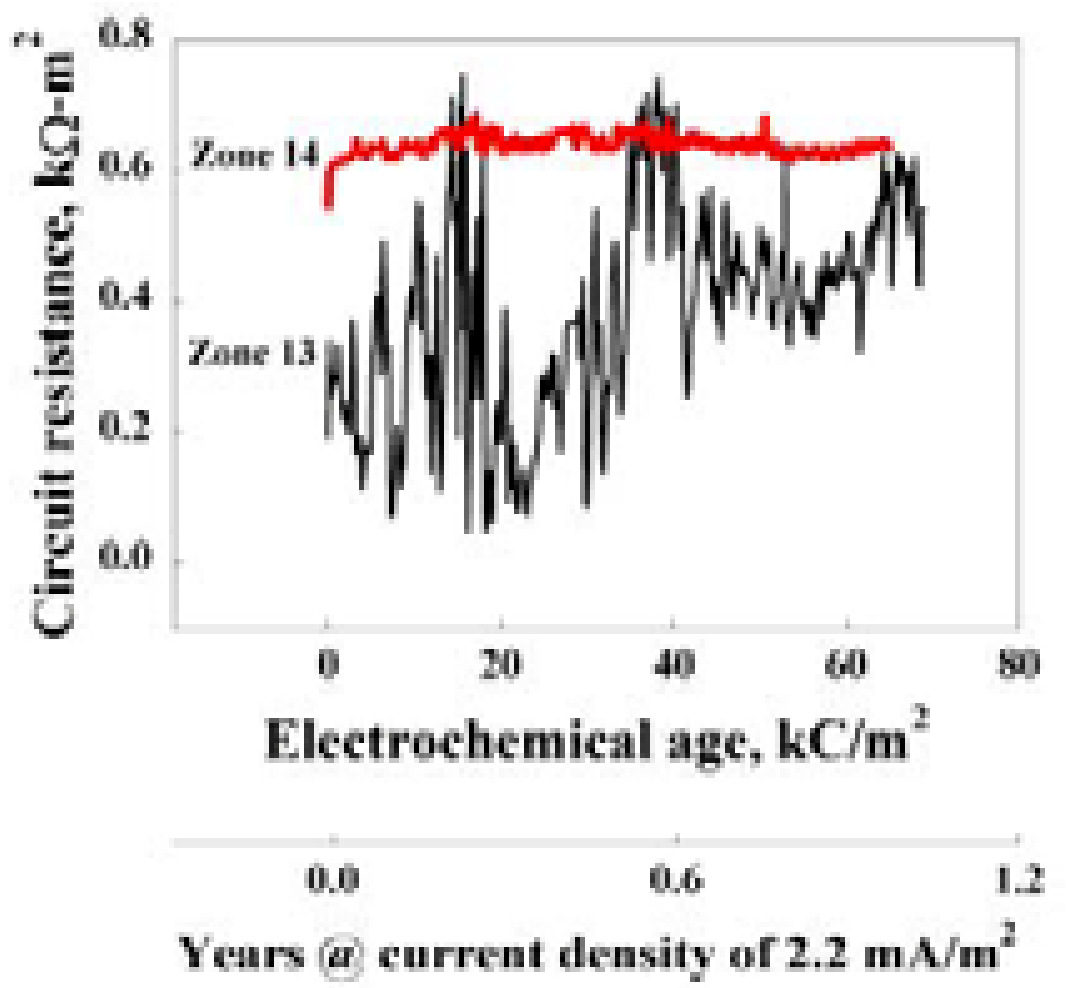

Figure 5.7: Circuit resistance as a function of electrochemical age for ICCP zones 13 (TS Zn anode) and 14 (TS Ti anode) on the Depoe Bay Bridge; measurements on each zone were for the same time period.

\subsubsection{Yaquina Bay Bridge}

Figure 5.8 shows the circuit resistance of two control zones, zones 10 and 14, located on the south approach to the Yaquina Bay Bridge. Both zones are over land, but zone 14 is much closer to the bay than zone 10 and in a moister environment, hence the lower circuit resistance. Zones 11 and 13 lie between the two control zones and were treated with a humectant that enhances the moisture level at the anode-concrete interface. The 
effect of the humectant was to greatly reduce the circuit resistance for the treated zones in comparison to the controls on either side.
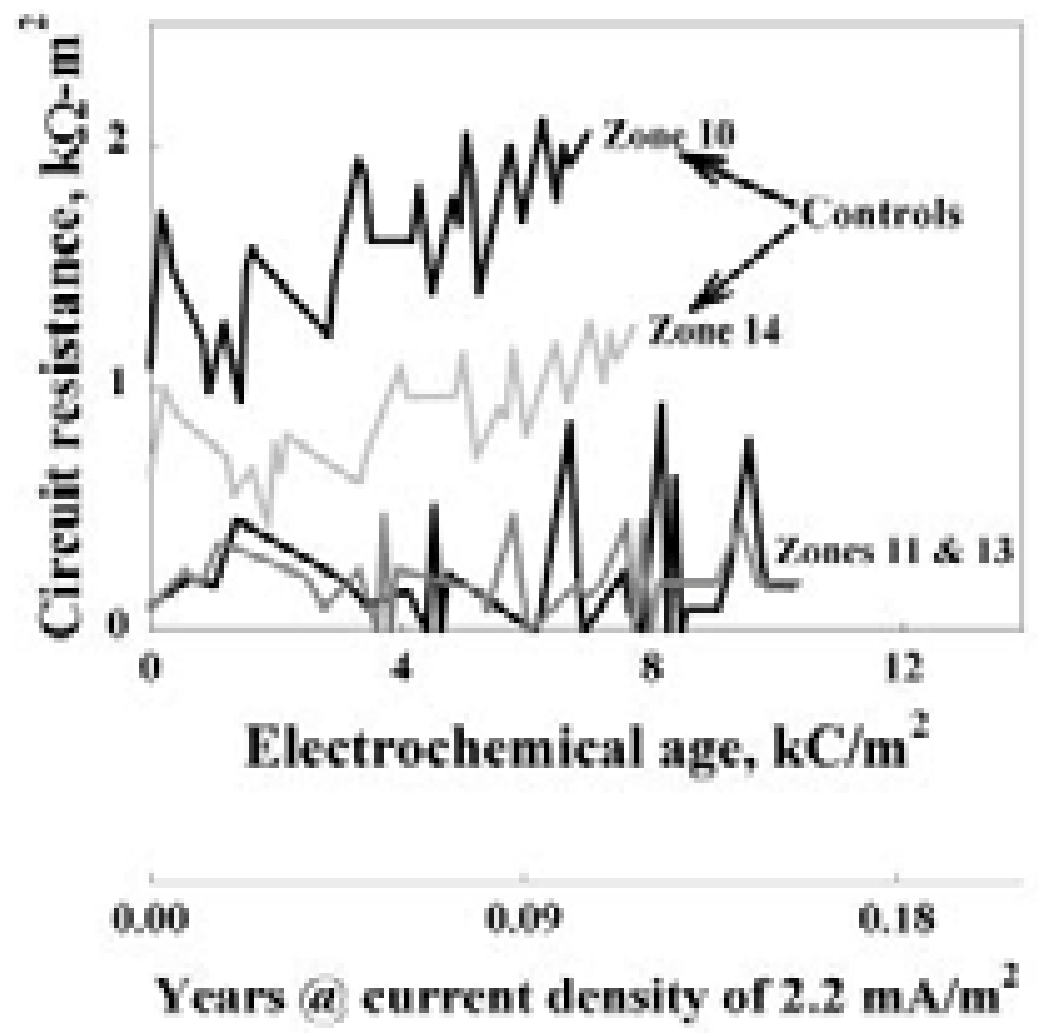

Figure 5.8: Circuit resistance as a function of TS Zn electrochemical age for humectant-treated ICCP zones 11 and 13 and control ICCP zones 10 and 14 on the Yaquina Bay Bridge; measurements on each zone were for the same time period.

\subsubsection{East Camino Under-crossing}

The behavior of the ICCP anodes installed on the deck and soffit of the East Camino Under-crossing is shown in Figure 5.9. The high resistance peaks for the soffit suggest it can become substantially drier than the deck at times. There are regular variations in the circuit resistance that appear to be related to seasonal changes in the local climate. 


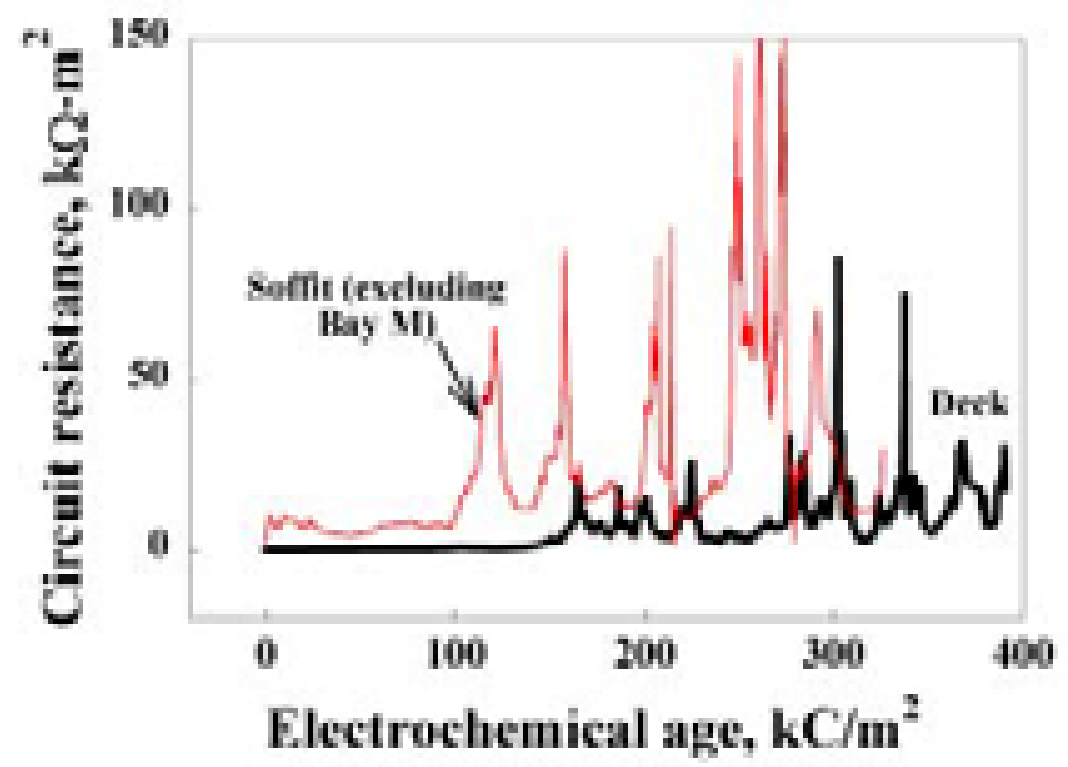

Figure 5.9: Circuit resistance as a function of TS Zn electrochemical age for the soffit and deck of the East Camino Under-crossing; measurements on each zone were for the same time period.

\subsubsection{SACP}

Sacrificial anode (galvanic) current cathodic protection systems always involve the use of a consumable anode. As with ICCP systems, a consumable anode produces reaction products that can accumulate at the anode-concrete interface. The current delivered by these systems is related to the potential difference between the galvanic pair, and the polarization of the anode and cathode. Galvanic current as a function of electrochemical age is examined below for the Richmond-San Rafael Bridge in California.

\subsubsection{Richmond-San Rafael Bridge}

The galvanic current density, along with monthly precipitation measurements made at the bridge, are given in Figure 5.10 as a function of service time for the barrel at the base of the south column of pier 4 (see Figure 2.10). The current density decreased from a high of $0.01 \mathrm{~A} / \mathrm{m}^{2}$ to $0.001 \mathrm{~A} / \mathrm{m}^{2}$ after approximately $700 \mathrm{kC} / \mathrm{m}^{2}$ of aging, Table 5.1 . The periodic current variations were due to seasonal variations in weather conditions. During the first 3 years, the higher output coincided with the wetter months. However, for longer service times interestingly, the precipitation peaks and current peaks were out of phase.

Much of the decrease in current density towards the end of the 10 years was due to consumption of the $\mathrm{Zn}$ anode on the barrel that reduced the area of available $\mathrm{Zn}$. In April 1997, four years after the anode was disabled, it was observed that almost all of the $\mathrm{Zn}$ anode, especially that directly over the rebar, was gone. There was no evidence of concrete delamination over the rebar. In other words, the SACP anode had worked well. 


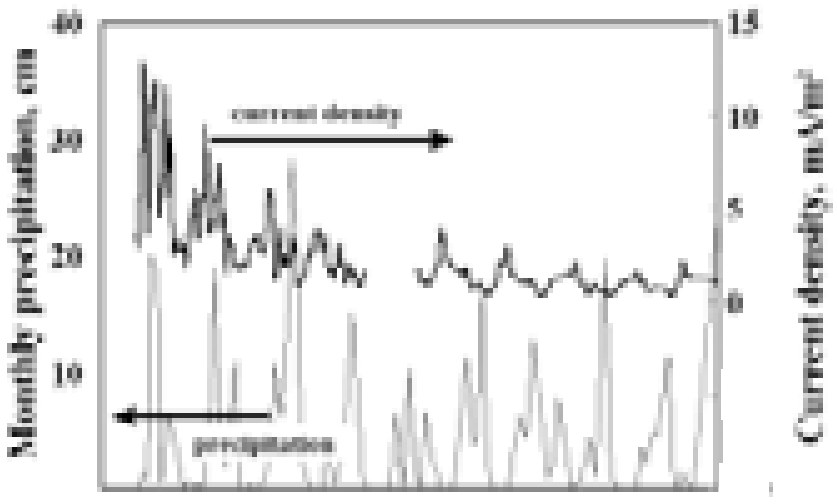

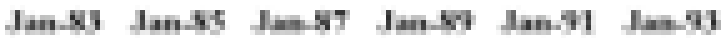

Figure 5.10: Current density and monthly precipitation as a function of time for TS Zn SACP anode on the barrel at the base of the south column, pier 4 of the Richmond-San Rafael Bridge.

It would have worked well again had it been given a light sandblasting and another layer of TS Zn. There was still zinc available on the concrete between the rebar but the resistance of this electrical circuit path became increasingly higher and current output fell.

\subsection{ANODE BOND STRENGTH}

A good bond between the $\mathrm{Zn}$ anode and concrete prevents the anode from delaminating and maintains the contact necessary for a complete $\mathrm{CP}$ circuit. $\mathrm{Zn}$ anode bond strengths measured on four bridges soon after thermal spraying and prior to electrochemical aging are discussed here and compiled in Appendix B. Average values are listed in Table 5.3. Average values are remarkably similar for three of the bridges, and these values are similar to the initial bond strength values measured on the laboratory slabs.

Table 5.3: Average initial bond strength of TS Zn anodes on selected bridges

\begin{tabular}{c|c}
\hline Bridge & $\begin{array}{c}\text { Bond strength } \pm \text { std dev, } \\
\text { MPa }(\mathbf{p s i})\end{array}$ \\
\hline Cape Creek & NA \\
\hline Yaquina Bay & $1.46 \pm 0.44(212 \pm 64)$ \\
\hline Depoe Bay & $1.44 \pm 0.41(209 \pm 60)$ \\
\hline Big Creek & $1.47 \pm 0.7(213 \pm 101)$ \\
\hline Richmond-San Rafael & $1.93(280)$ \\
\hline Cape Perpetua & NA \\
\hline
\end{tabular}

$\mathrm{NA}=$ Not Available 


\subsubsection{Richmond-San Rafael Bridge}

The bond strengths of the four Zn anodes on pier 4 of the Richmond-San Rafael Bridge were measured in April 1997. All bond strength measurements are tabulated in Table 5.4 and averages for each band are plotted in Figure 5.11 as a function of height above sea level. This data supports laboratory results indicating drier environments (higher on the bridge pier) led to poor long-term bond strengths. Band 4 is well above the water in a sheltered location under the bridge deck not readily exposed to the weather. On the other hand, zinc on the barrel of the south column of pier 4 (operated as a SACP anode) had the highest bond strength of any well-aged anode measured in the field or laboratory studies.

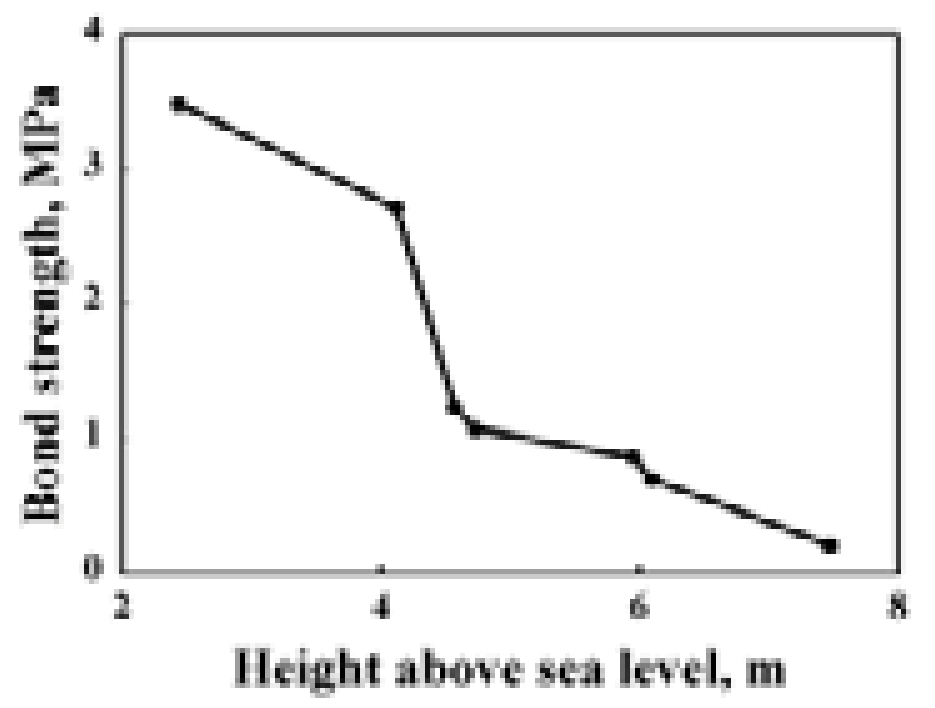

Figure 5.11: Bond strength of the TS Zn anodes on the south column, pier 4 of the Richmond-San Rafael Bridge as a function of height above the sea level, after $\sim 10$ years service. 
Table 5.4: Bond strength of TS Zn anodes on the Richmond-San Rafael Bridge

\begin{tabular}{|c|c|c|c|c|}
\hline \multirow[t]{2}{*}{ Anode } & \multirow{2}{*}{$\mathbf{C P}$} & \multicolumn{2}{|c|}{$\begin{array}{c}\text { Coating Bond Strength, } \\
\text { MPa (psi) }\end{array}$} & \multirow{2}{*}{$\begin{array}{l}\text { anode-concrete } \\
\text { interface } \mathrm{pH}\end{array}$} \\
\hline & & East face & North face & \\
\hline \multicolumn{5}{|c|}{ Initial (May 1983) } \\
\hline average & none & \multicolumn{2}{|c|}{$1.9(280)$} & --- \\
\hline range & none & \multicolumn{2}{|c|}{$1.0-3.5(150-500)$} & $8.9-9.8$ \\
\hline \multicolumn{5}{|c|}{ Aged (April 1997) } \\
\hline Barrel & SACP & - & $3.5(504)$ & 10.0 \\
\hline Band 1 - bottom & ICCP & - & $0.4(54)$ & $6.6-9.0$ \\
\hline Band 1 - top & “ & $1.2(172)$ & $2.7(394)$ & --- \\
\hline Band 2 - bottom & “ & $0.1(12)$ & $1.2(180)$ & $6.9-10.6$ \\
\hline Band 2 - top & “ & $2.6(380)$ & $1.1(156)$ & --- \\
\hline Band 3 - bottom & “ & $0.7(97)$ & $0.9(125)$ & $7.0-7.9$ \\
\hline Band 3 - top & “ & $0.5(78)$ & $0.7(101)$ & --- \\
\hline Band 4 - bottom & “ & $0.4(55)$ & $0.2(31)$ & $6.7-7.6$ \\
\hline Band 4 - top & “ & $0.2(31)$ & $0(0)$ & --- \\
\hline
\end{tabular}

\subsection{BULK CONCRETE CHEMISTRY}

Concrete mix designs for bridges discussed in this report are tabulated in Table 5.5. Actual mix designs for the Oregon bridges were not available, except for the Rocky Point Viaduct. The mix design for the laboratory slabs (Table 2.2) was one that would approximate the composition of concrete found in older coastal bridges exposed for a long time to salt deposition from the marine environment. This is the value reported in the Table 5.4 for the Cape Creek Bridge, Yaquina Bay Bridge, Depoe Bay Bridge, Big Creek Bridge, and the Cape Perpetua Viaduct as provided by Oregon DOT. Salt was not intentionally added to the concrete mixes used in the construction of Oregon's historic coastal bridges. [However, salt is typically added to patch concrete in bridge restorations to prevent macro-cell activity resulting from chloride concentration cells.] Chloride contents of concrete samples from bridges included in this report after extended exposure to the marine environment (or deicing salts, in the case of the East Camino Undercrossing) are listed in Table 5.6 (Covino, et al. 1997d). The chloride values were determined from the analyses of bridge core samples. 
Table 5.5: Concrete mix design for selected bridges

\begin{tabular}{c|c|c|c|c}
\hline Bridge & Sand, lbs & Aggregate, lbs & Cement, lbs & Water, lbs \\
\hline Cape Creek Bridge & 1624 & 1550 & 570 & 275 \\
\hline Yaquina Bay Bridge & 1624 & 1550 & 570 & 275 \\
\hline Depoe Bay Bridge & 1624 & 1550 & 570 & 275 \\
\hline Big Creek Bridge & 1624 & 1550 & 570 & 275 \\
\hline Cape Perpetua Viaduct & 1624 & 1550 & 570 & 275 \\
\hline Rocky Point Viaduct & 1076 & 2148 & 593 & 313 \\
\hline
\end{tabular}

$\mathrm{NA}=$ Not Available

Table 5.6: Description of field samples analyzed

\begin{tabular}{|c|c|c|c|c|c|c|}
\hline $\begin{array}{c}\text { Sample } \\
\text { No. } \\
\end{array}$ & Sample source & $\begin{array}{c}\text { Sample } \\
\text { description }\end{array}$ & $\begin{array}{c}\text { Electrochemical } \\
\text { age, } y^{1}\end{array}$ & $\begin{array}{c}\mathrm{Cl} \\
\mathrm{kg} / \mathrm{m}^{3}\left(\mathrm{lb} / \mathrm{yd}^{3}\right)\end{array}$ & $\begin{array}{c}\text { pH } \\
\text { Concrete side } \\
\end{array}$ & $\begin{array}{c}\text { pH } \\
\text { Zn side }\end{array}$ \\
\hline 3550 & Cape Creek Br & ICCP, orig. & 3.7 & $5.31(8.85)^{2}$ & 12.43 & 10.36 \\
\hline 3551 & Cape Creek Br & ICCP, orig. & 3.7 & NA & 13.0 & 9.72 \\
\hline 3552 & Cape Creek Br & ICCP, patch & 3.7 & $0.64(1.07)^{2}$ & 12.16 & NA \\
\hline 3553 & Cape Creek Br & SACP, orig. & 3.7 & NA & 12.46 & 8.66 \\
\hline 3554 & Cape Creek Br & SACP, patch & 3.7 & NA & 13.2 & 10.14 \\
\hline 3555 & Cape Creek Br & ICCP, orig. & 3.7 & NA & 12.16 & 9.37 \\
\hline 3608 & East Camino & ICCP, soffit & 10 & $1.76(2.93)^{2}$ & 11.43 & 9.48 \\
\hline 3609 & CALTRANS & ICCP, untreated & 0.6 & NA & NA & NA \\
\hline 3610 & CALTRANS & ICCP, silane+SB & 0.6 & NA & NA & NA \\
\hline 3611 & CALTRANS & $\mathrm{ICCP}$, silane $+\mathrm{SB}$ & 0.6 & NA & 10.55 & 7.97 \\
\hline 3612 & CALTRANS & ICCP, silane & 0.6 & NA & NA & NA \\
\hline 3613 & CALTRANS & ICCP, silane & 0.6 & NA & NA & NA \\
\hline 3614 & Longbird $\mathrm{Br}$ & $\begin{array}{l}\text { galvanized, } \\
\text { sidewalk }\end{array}$ & $46^{3}$ & NA & 13.36 & 9.5 \\
\hline 3615 & Longbird $\mathrm{Br}$ & $\begin{array}{c}\text { Galvanized, } \\
\text { abutment }\end{array}$ & $46^{3}$ & $4.92(8.21)^{2}$ & 13.30 & 10.46 \\
\hline
\end{tabular}

${ }^{1}$ equivalent to aging at $0.0022 \mathrm{~A} / \mathrm{m}^{2} \quad{ }^{2}$ actual analysis $\quad{ }^{3}$ actual years exposure $\quad$ NA $=$ Not Available

Chloride profiles to a depth of $10 \mathrm{~cm}$ (3.9 in) determined from analysis of concrete powder samples are reported for 3 bands and the barrel of the south column of Pier 4 of the RichmondSan Rafael Bridge in Figure 5.12. The results show low concentrations of salt in the concrete for the lower three anode zones. This suggests that chloride was extracted from the structure by CP and that deposited salt was blocked from further penetration by the development of a less permeable layer of zinc minerals within the anode and at the anode-concrete interface. At a 
depth of approximately $2.5 \mathrm{~cm}(1 \mathrm{in})$ and deeper the salt concentration was below the minimum needed $\left(0.72 \mathrm{~kg} / \mathrm{m}^{3}\left(1.2 \mathrm{lbs} / \mathrm{yd}^{3}\right)\right)$ to initiate corrosion of rebar or shear stirrups, this despite the fact that the column was well exposed to salt spray and aerosols from the bay. In contrast, the salt concentration in the barrel was much higher and well above the threshold level to initiate corrosion. Never-the-less, no cracking of the concrete on the barrel was observed, suggesting as noted earlier that this SACP zone was working well to protect the rebar.

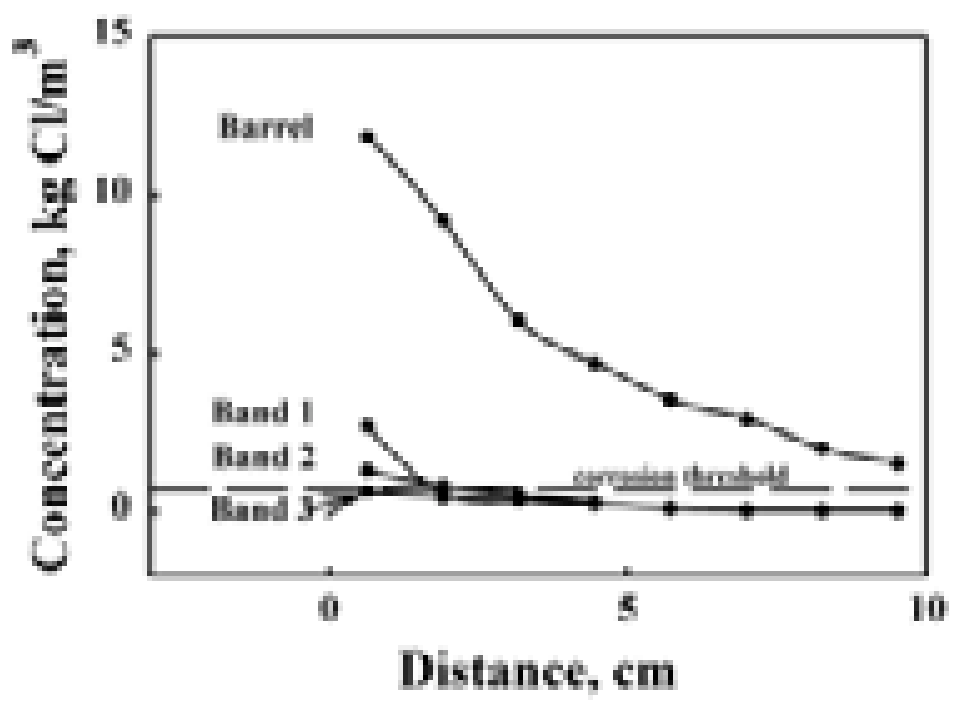

Figure 5.12: Chloride concentration profiles for TS $\mathrm{Zn}$ anodes on the south column, pier 4 of the Richmond-San Rafael Bridge, after $\sim 10$ years service.

Figures 5.13 and 5.14 show chloride distributions for original and patch concrete, respectively, and rebar (R) and shear stirrup (S) locations, for beams from the Rocky Point Viaduct (Covino, et al. 1997c; Cramer, et al. 2000; Cramer, et al. 2002a). The data is presented for comparison to that in Figure 5.12. The Rocky Point Viaduct was located approximately $25 \mathrm{~m}$ east of and $35 \mathrm{~m}$ above the Pacific Ocean. There was more salt in the Rocky Point Viaduct beams than in bands 1 through 3 on the Richmond-San Rafael Bridge pier despite the fact that the anodes on the Richmond-San Rafael Bridge pier were substantially closer to the water than the beams on the Rocky Point Viaduct. Again, this suggests that chloride was extracted from the structure by CP and that deposited salt was blocked from further penetration by the development of a less permeable layer of zinc minerals within the anode and at the anode-concrete interface. 


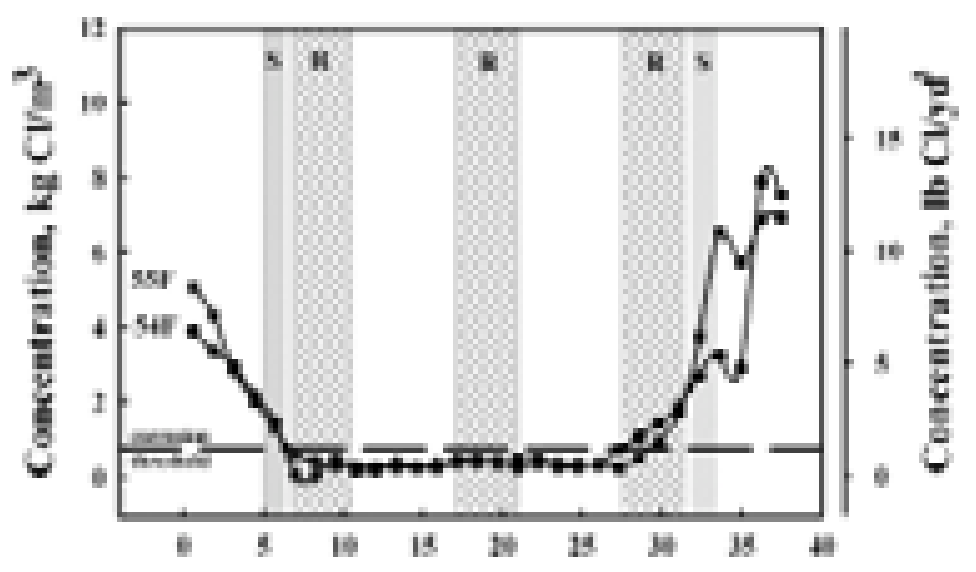

Dhbance Irom Mcat bide, cm

Figure 5.13: Chloride concentration profiles for original concrete in beam A1 of the Rocky Point Viaduct after 40 years service on the Oregon coast.

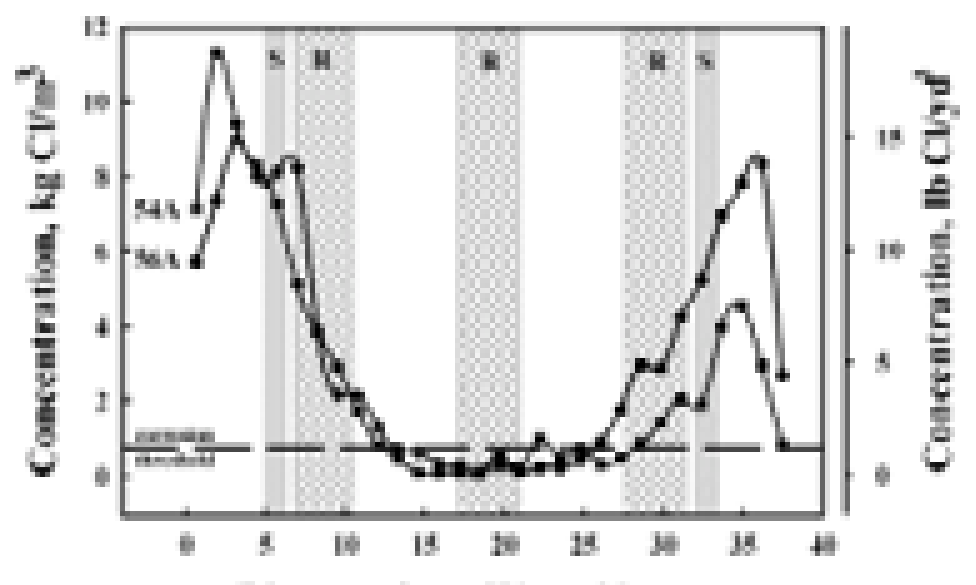

Dhatace from West side, em

Figure 5.14: Chloride concentration profiles for patch concrete in beam A1 of the Rocky Point Viaduct after 40 years service on the Oregon coast. 


\subsection{ANODE-CONCRETE INTERFACIAL CHEMISTRY}

\subsubsection{Analytical scanning electron microscopy}

5.4.1.1 ICCP

\subsection{Richmond-San Rafael Bridge}

Figure 5.15 is the result of an SEM examination of the anode-concrete interface from band 1 on the Richmond-San Rafael Bridge. Figure 5.15a is a BSE image of the interface, showing light and dark regions based on atomic number (high atomic numbers are brighter).

Figures 5.15b-d are $\mathrm{x}$-ray maps of the distribution of $\mathrm{Zn}, \mathrm{Ca}$, and $\mathrm{Cl}$ at the interface. Figure $5.15 \mathrm{~b}$ shows that much of the anode (bright area) was not consumed, despite over 12 years of service. The darker gray areas on either side of the metallic $\mathrm{Zn}$ represent $\mathrm{Zn}$ consumed by the $\mathrm{CP}$ anodic reaction at the anodeconcrete interface and $\mathrm{Zn}$ consumed by atmospheric corrosion on the outside of the anode. In addition, $\mathrm{Zn}$ dissolution products at the anode-concrete interface have diffused into the cement paste.

In Figure $5.15 \mathrm{c}$ there is a region of the cement paste where $\mathrm{Ca}$ is depleted, the same region that $\mathrm{Zn}$ has diffused into. This is considered to be a reaction zone where the chemistry of the cement paste is altered by acidification, i.e., dissolution and removal of $\mathrm{Ca}$ from the cement paste.

In Figure 5.15d, chlorides are concentrated at the anode-concrete interface and on the outer surface at the anode-corrosion product interface. All of these effects, except for the $\mathrm{Zn}$ atmospheric corrosion products on the outer surface of the anode, were observed with the laboratory slabs. After 12 years service, the anode was shut down not because the anode had been consumed, but because higher system voltages were required to provide effective protection of the rebar. The higher system voltages were a consequence of the increasingly thick layer of insulating $\mathrm{Zn}$ minerals at the anode-concrete interface.

WDS line scans through the same area of band 1 as shown in Figure 5.15a are plotted for $\mathrm{Zn}, \mathrm{Ca}, \mathrm{Cl}$, and $\mathrm{O}$ in Figures 5.16. Similar line scans are shown in Figure 5.17 for band 2. Both figures are plotted from the same starting point, the region of $\mathrm{Zn}$ corrosion on the outer surface of the $\mathrm{Zn}$ anode. The data show (moving from left to right) a $\mathrm{Zn} / \mathrm{O} / \mathrm{Cl}$ atmospheric corrosion product on the outer surface of the anode, a region of unconsumed anode, a zone I type of region (see Figure 4.15) where $\mathrm{Zn}: \mathrm{O}$ is approximately 1:1, and a region where $\mathrm{Zn}$ has diffused into the cement paste that includes depleted $\mathrm{Ca}$ and an elevated level of $\mathrm{Cl}$ (the $\mathrm{Cl}$ concentrations are shown in Figures 5.16 and 5.17 at five times their actual concentration). 


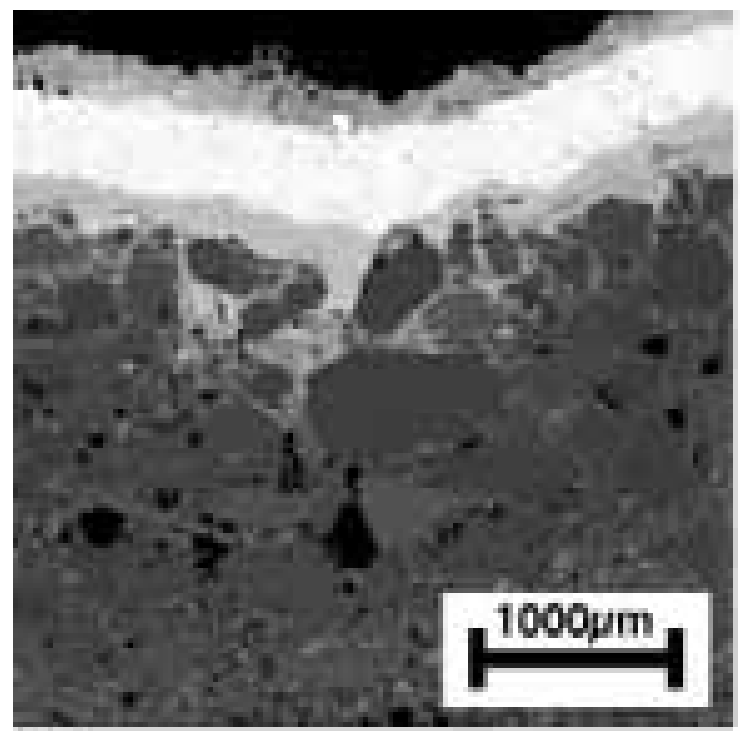

(a)

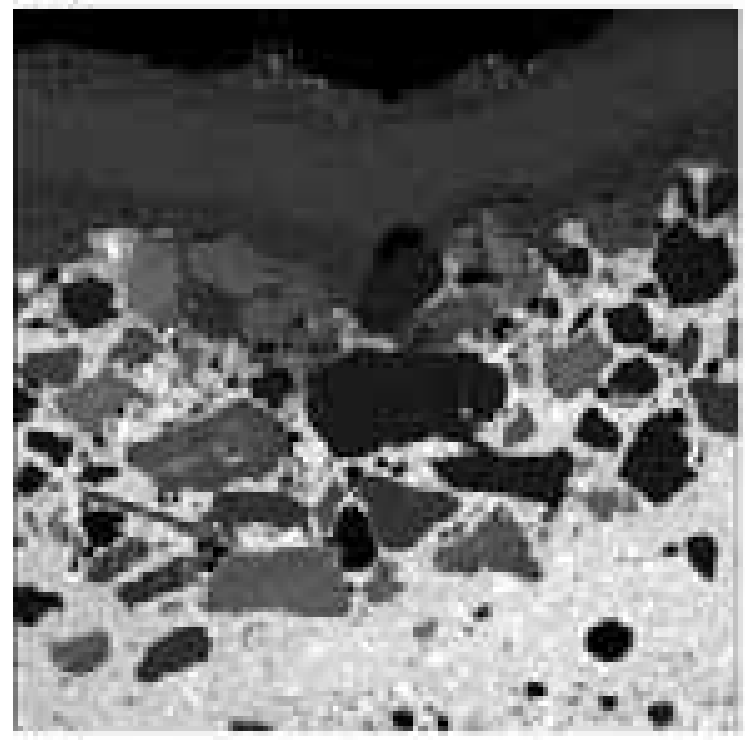

(c)

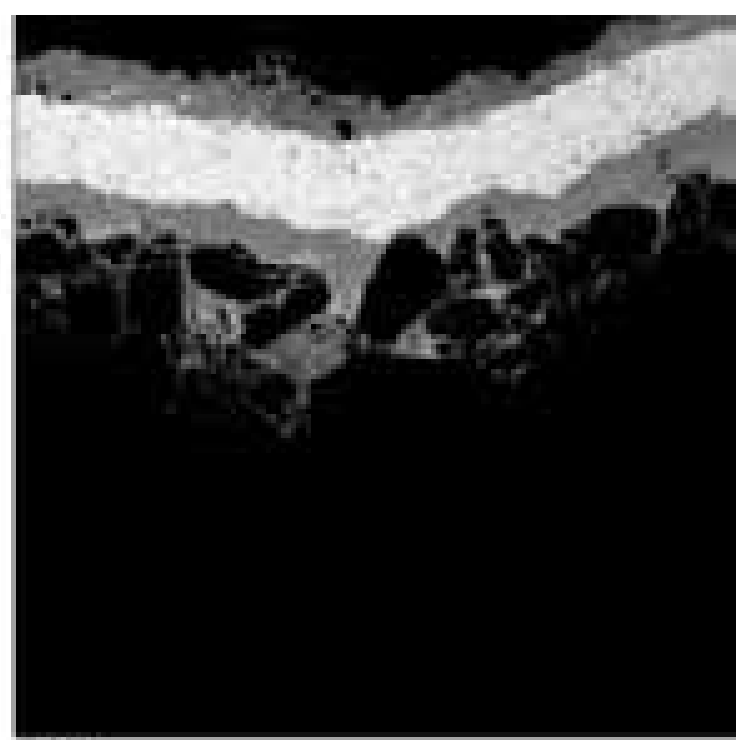

(b)

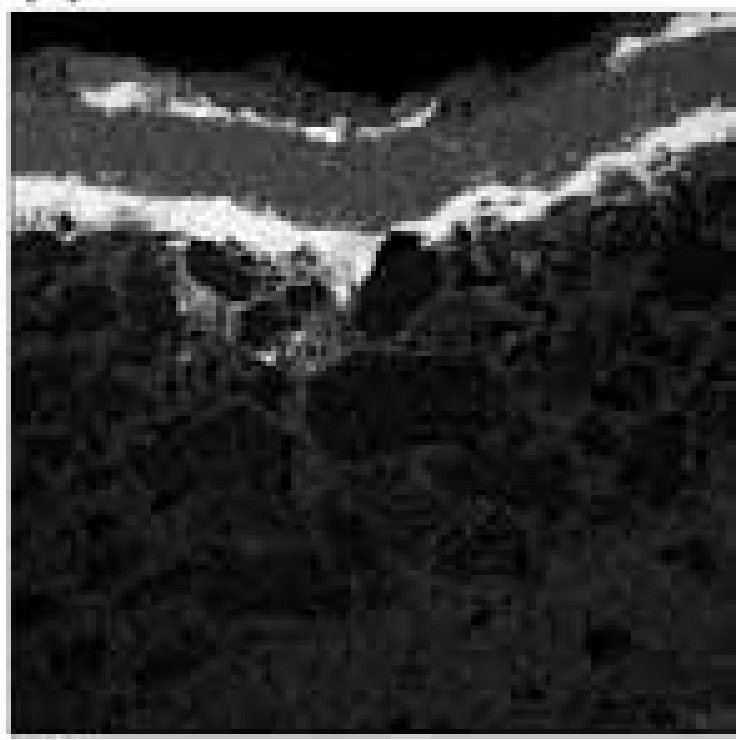

(d)

Figure 5.15: BSE photomicrograph and x-ray maps of TS Zn anode-concrete interface of Richmond-San Rafael Bridge, band 1 after aging $\sim 1200 \mathrm{kC} / \mathrm{m}^{2}$ service or $\sim 10$ years service: (a) BSE photomicrograph; (b) $\mathrm{Zn}$; (c) $\mathrm{Ca}$; (d) $\mathrm{Cl}$. 


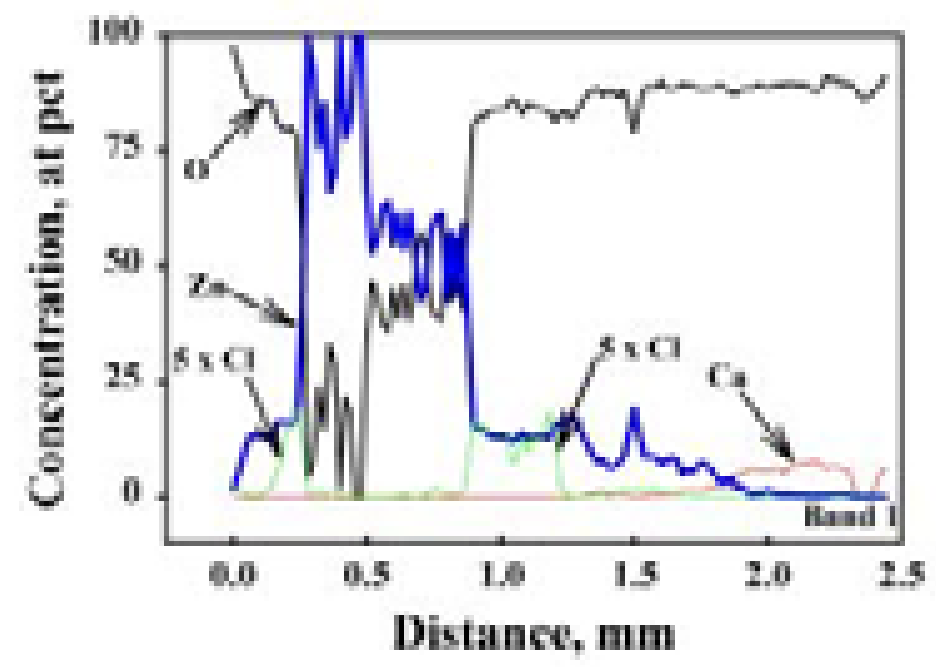

Figure 5.16: WDS line scan for $\mathrm{Zn}, \mathrm{O}, \mathrm{Ca}$, and $\mathrm{Cl}$ across the TS $\mathrm{Zn}$ anodeconcrete interface for the Richmond-San Rafael Bridge, band 1 after aging $\sim 1200 \mathrm{kC} / \mathrm{m}^{2}$ or $\sim 10$ years service.

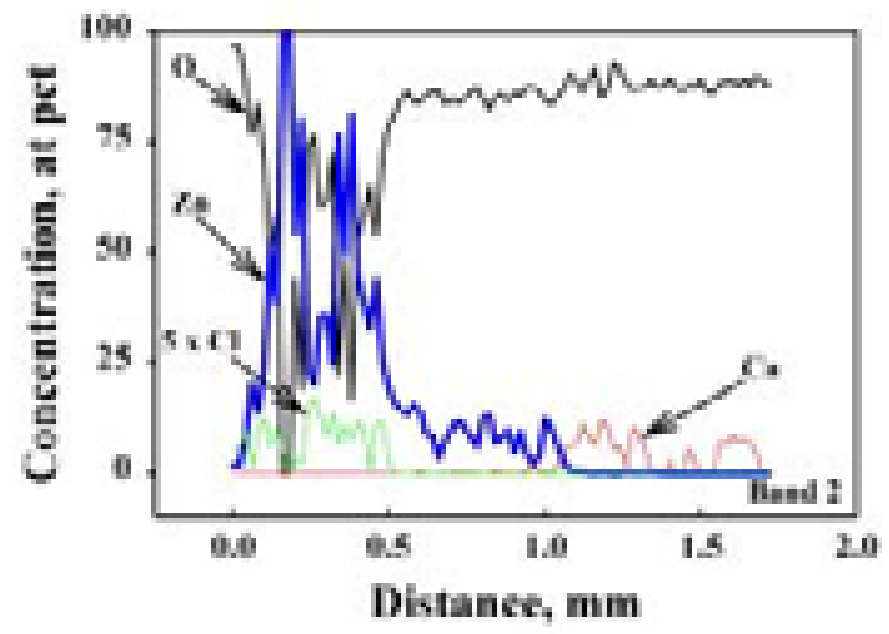

Figure 5.17: WDS line scan for $\mathrm{Zn}, \mathrm{O}, \mathrm{Ca}$, and $\mathrm{Cl}$ across the TS $\mathrm{Zn}$ anodeconcrete interface for the Richmond-San Rafael Bridge, band 2 after aging $\sim 950 \mathrm{kC} / \mathrm{m}^{2}$ or $\sim 10$ years service.

\subsection{CALTRANS Laboratory Study}

Cracks within the cement paste and boundaries between aggregate and cement paste provide pathways for charge transfer and ion migration through the zone of silane treatment. This is shown in Figure 5.18 by the backscattered-electron SEM image and by elemental maps for $\mathrm{Zn}, \mathrm{O}$, and $\mathrm{Cl}$. They show an interface free of 
$\mathrm{Zn}$ in the cement paste. However, a deep crack penetrates the cement paste and follows the boundary of an aggregate particle. Based on the element maps, this crack is filled with Zn, Figure 5.18(b), and Cl, Figure 5.18(d). A line scan across the crack showed $\mathrm{O}$ and $\mathrm{Zn}$ were present in equimolar quantities and there was an elevated level of $\mathrm{Cl}$. The mineral filling the crack was $\mathrm{ZnO}$ or more likely a $\mathrm{Zn}$ hydroxychloride.

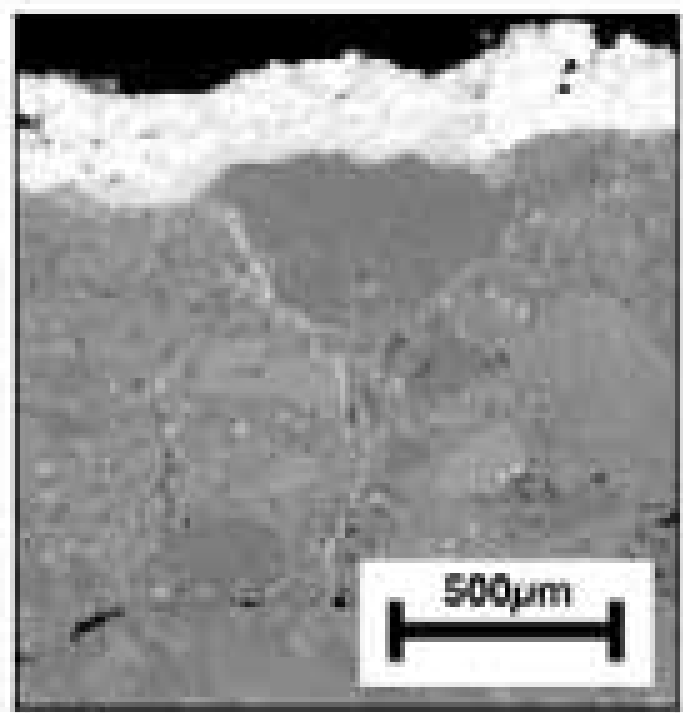

(a)

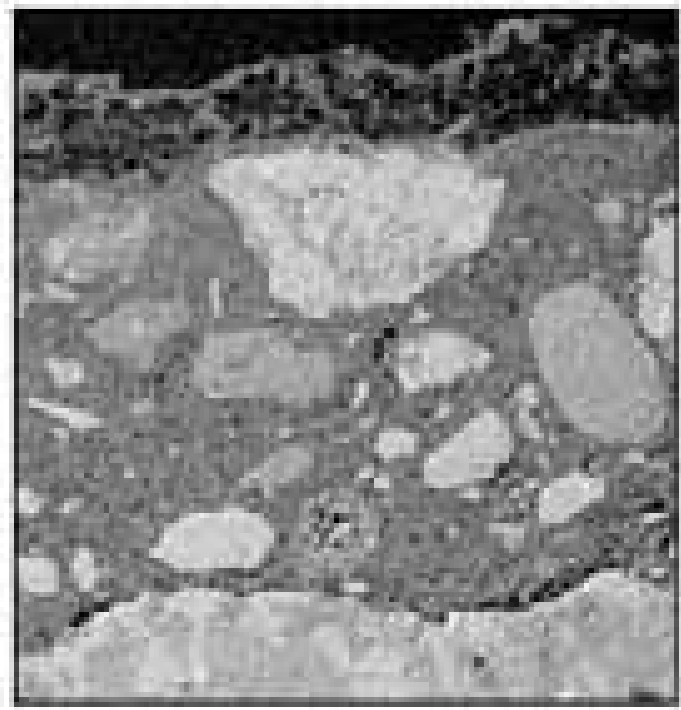

(c)

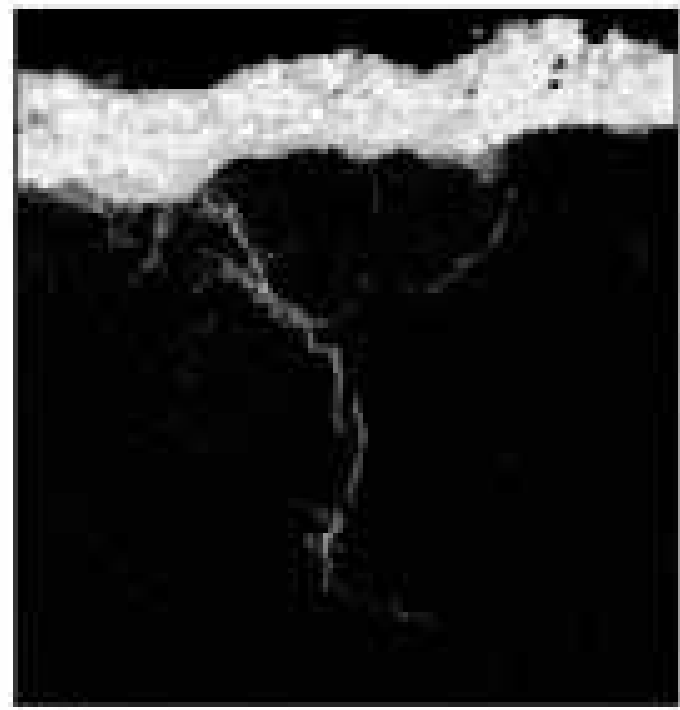

(b)

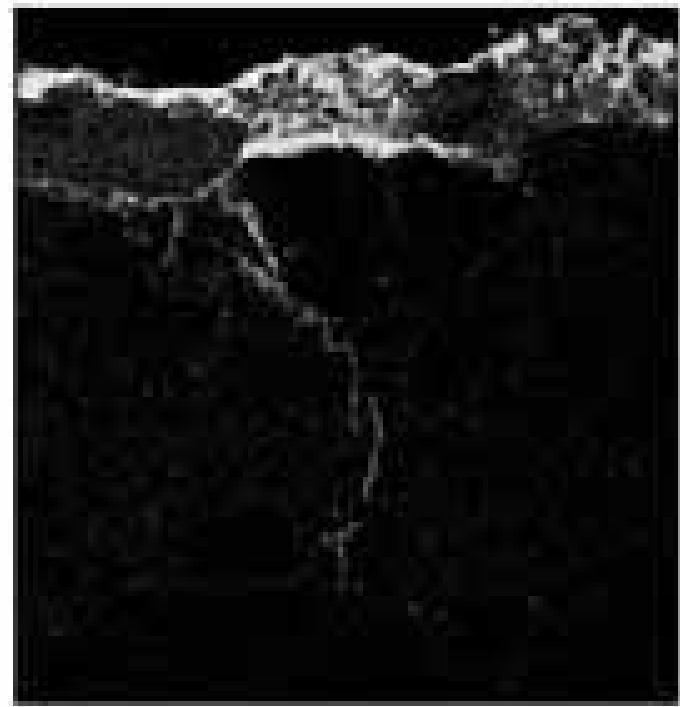

(d)

Figure 5.18: BSE photomicrograph and x-ray maps of TS Zn anode-concrete interface for concrete slab treated with silane but not sandblasted, then aged $700 \mathrm{kC} / \mathrm{m}^{2}$ : (a) BSE photomicrograph; (b) $\mathrm{Zn}$; (c) $\mathrm{Si}$; (d) $\mathrm{Cl}$. 
CALTRANS observed that silane treatment increased the voltage needed to maintain the CP current (Parks 1990). The high potentials required to maintain the current occurred because defects in the treatment and porous regions in the concrete were the only areas that provide avenues for charge transfer and ion migration. This is shown by a typical element depth profile for the silane-treated slabs, Figure 5.19. It is evident from the lack of $\mathrm{Zn}$ in the cement paste that the silane treatment greatly reduced the transport of charge to and from the $\mathrm{Zn}$ anode. Light sandblasting of the silane treated surface reduced the $\mathrm{CP}$ voltage requirements. Voltage requirements were lowest in the absence of the silane treatment. The difference can be seen in Figure 5.20 for the silane-treated concrete that had been sandblasted. It shows a substantial reaction zone at the anode-concrete interface and a more typical amount of $\mathrm{Zn}$ in the cement paste. $\mathrm{Zn}$ concentration profiles are shown in Figure 5.21 for silane-treated concrete with no sandblasting and with sandblasting. The silane treatment effectively prevented the zinc coating from being consumed and performing as an anode.

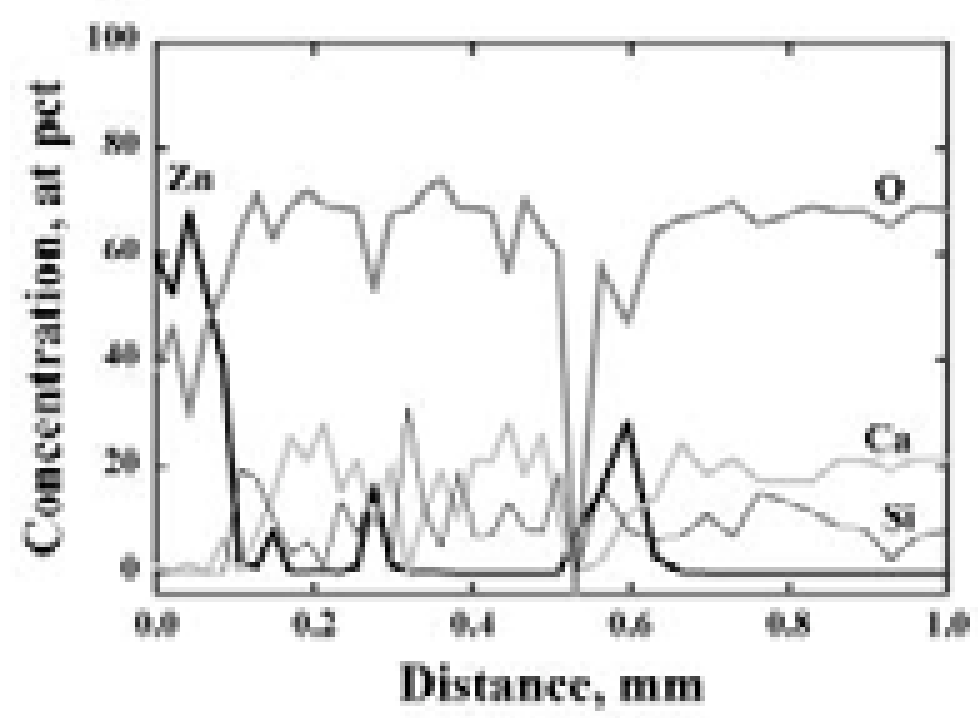

Figure 5.19: WDS line scan for $\mathrm{Zn}, \mathrm{O}, \mathrm{Ca}$, and $\mathrm{Si}$ across the TS $\mathrm{Zn}$ anodeconcrete interface for concrete slab treated with silane but not sandblasted, then aged $\sim 700 \mathrm{kC} / \mathrm{m}^{2}$ 


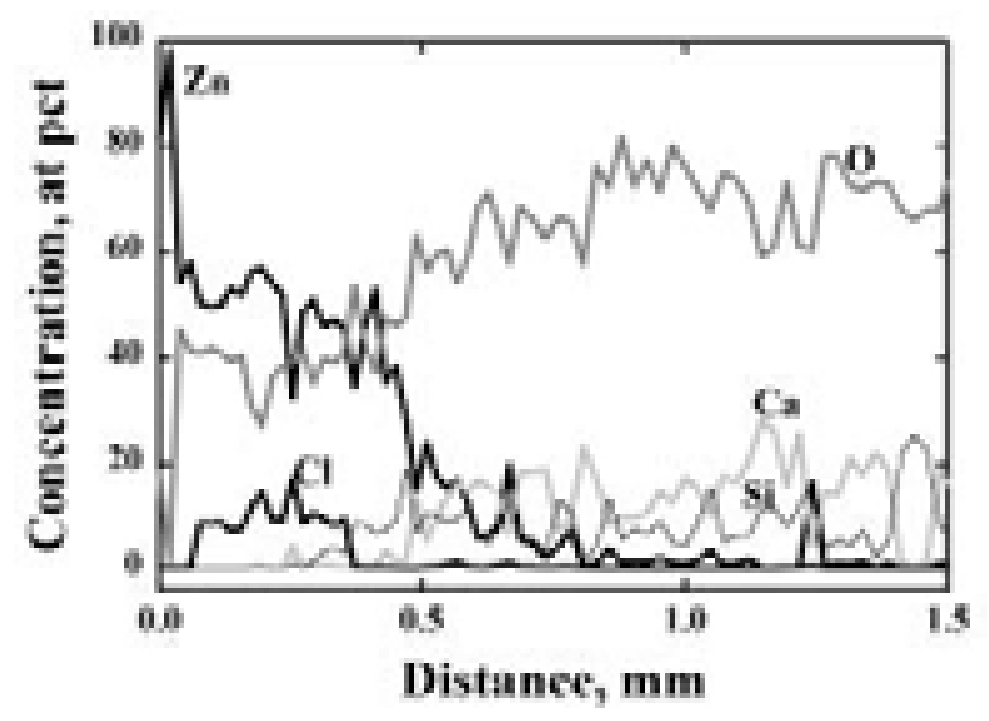

Figure 5.20: WDS line scan for $\mathrm{Zn}, \mathrm{O}, \mathrm{Ca}, \mathrm{Si}$, and $\mathrm{Cl}$ across the TS $\mathrm{Zn}$ anode-concrete interface for concrete slab treated with silane and sandblasted, then aged $\sim 600 \mathrm{kC} / \mathrm{m}^{2}$.

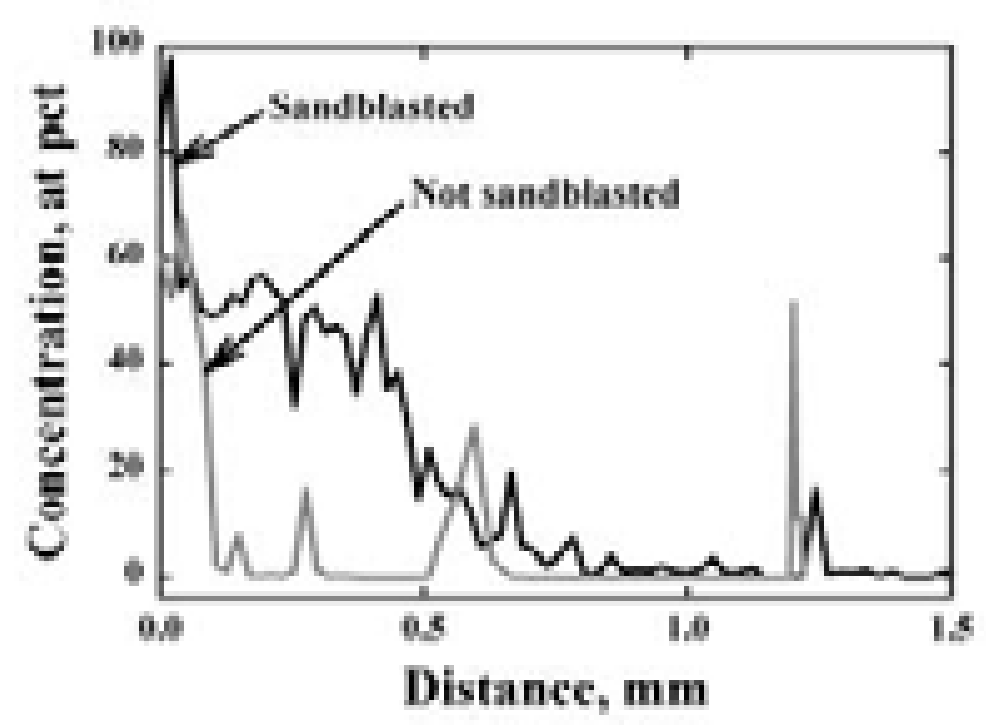

Figure 5.21: Effect of sandblasting on the WDS line scan for $\mathrm{Zn}$ across the TS $\mathrm{Zn}$ anode-concrete interface for concrete slabs treated with silane.

\subsection{East Camino Undercrossing}

An element depth profile for a sample of the anode-concrete interface from the soffit of the East Camino Undercrossing is shown in Figure 5.22. The width of the reaction zone is about $0.5 \mathrm{~mm}$. The chloride profile suggests that the $\mathrm{Zn}$ metal splats are interlaced with regions of $\mathrm{Zn}$ corrosion product (distance $<0.5 \mathrm{~mm}$ ), 
probably a Zn hydroxychloride filing the pore spaces within the $\mathrm{Zn}$ anode. Chloride accumulated at a maximum concentration of 8-9 atomic \% in the reaction zone and in pore spaces within the $\mathrm{Zn}$ anode. The reaction zone appears characteristic of zone 1 behavior (see Figures 4.14 and 4.18) with no evidence of zone 2 or zone 3 behavior.

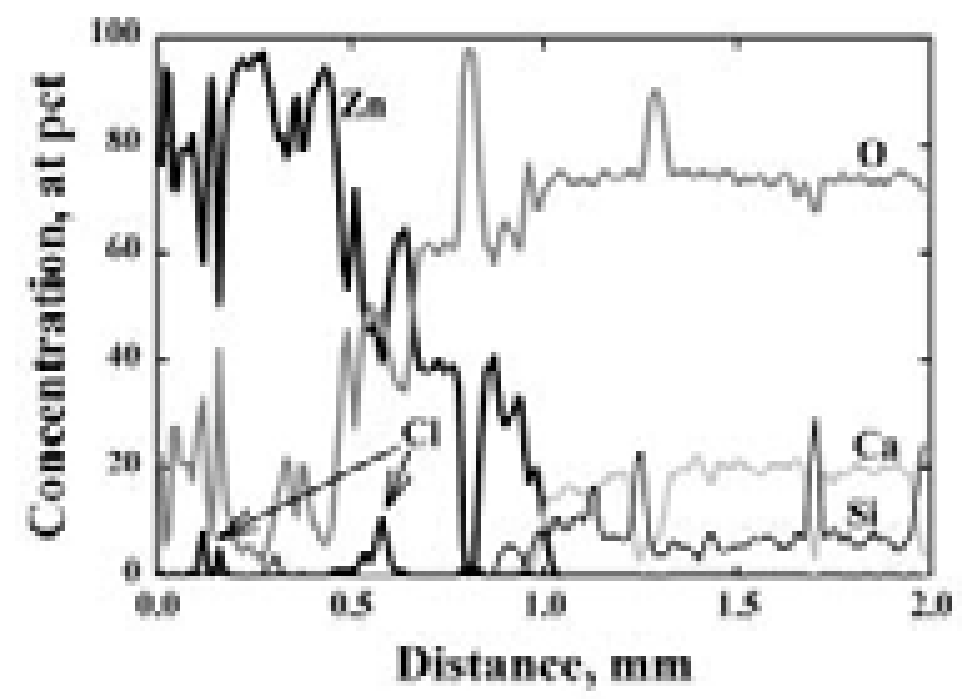

Figure 5.22: WDS line scan for $\mathrm{Zn}, \mathrm{O}, \mathrm{Ca}, \mathrm{Si}$, and $\mathrm{Cl}$ across the TS $\mathrm{Zn}$ anode-concrete interface for the soffit of East Camino Under-crossing aged $\sim 330 \mathrm{kC} / \mathrm{m}^{2}$.

\subsection{Cape Creek Bridge}

Element depth profiles were recorded for the six Cape Creek Bridge samples listed in Table 5.6. The electrochemical age of the ICCP zones corresponded to 3.7 years of actual service. While the samples represent diverse conditions on the bridge, the major differences were between ICCP and SACP, and between original concrete and patch concrete. There was no difference in interfacial chemistry for the ICCP zones on original concrete.

Figure 5.23 is the WDS depth profile of the interface for sample 3550 , an ICCP zone in original concrete. The interface consists of a $0.04 \mathrm{~mm}(0.0016 \mathrm{in})$ wide region characteristic of zone 1 behavior (see Figures 4.14 and 4.18) containing slightly more $\mathrm{Zn}$ than oxygen and with 6-8 atomic \% Cl. Figure 5.24 is the WDS depth profile of the interface for sample 3552 , an ICCP zone in patch concrete. The patch concrete reaction zone was similar in width and composition to that of the original concrete but contained less $\mathrm{Cl}(2-3$ atomic $\% \mathrm{Cl})$. Thus, $\mathrm{Zn}$ reactions and mineral formation appear to be similar in both original and patch concrete. The lower chloride in the patch concrete appears to reflect the shorter time the patch concrete was exposed to the coastal environment. This is confirmed by separate $\mathrm{Cl}$ measurements reported in Table 5.6, which shows the patch concrete 
contained $0.64 \mathrm{~kg} / \mathrm{m}^{3}\left(1.07 \mathrm{lb} / \mathrm{yd}^{3}\right)$ chloride while the original concrete contained $5.31 \mathrm{~kg} / \mathrm{m}^{3}\left(8.85 \mathrm{lb} / \mathrm{yd}^{3}\right)$ chloride. This difference in chloride concentrations may have had an effect on the $\mathrm{Zn}$ chloride minerals formed at the anode-concrete interface and the interfacial $\mathrm{pH}$.

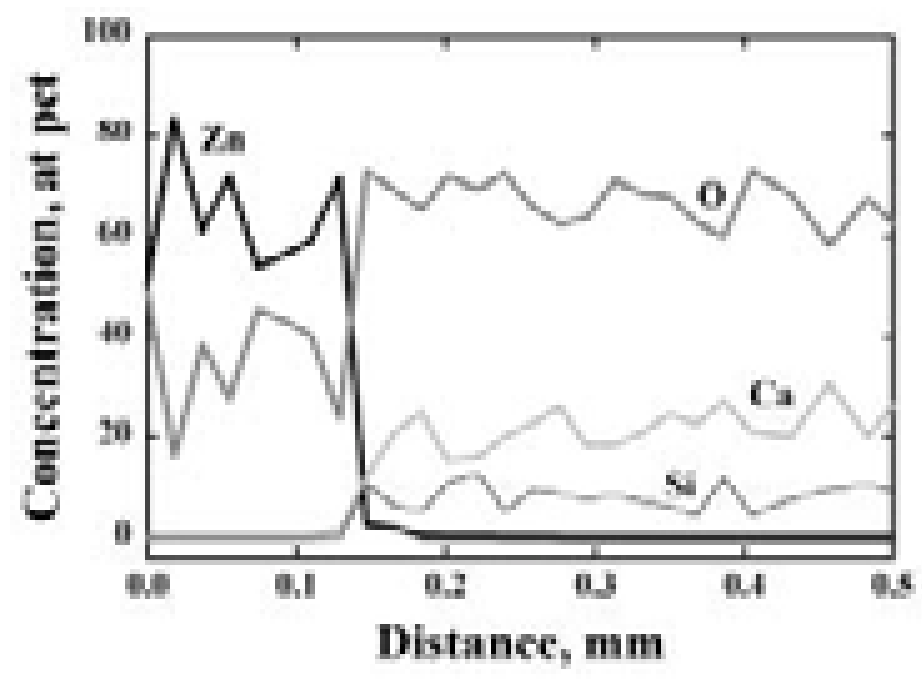

Figure 5.23: WDS line scan for $\mathrm{Zn}, \mathrm{O}, \mathrm{Ca}$, and $\mathrm{Si}$, across the TS $\mathrm{Zn}$ anode-concrete interface for original concrete on the Cape Creek

Bridge after about 3.7 years in ICCP service at $0.0022 \mathrm{~A} / \mathrm{m}^{2}$.

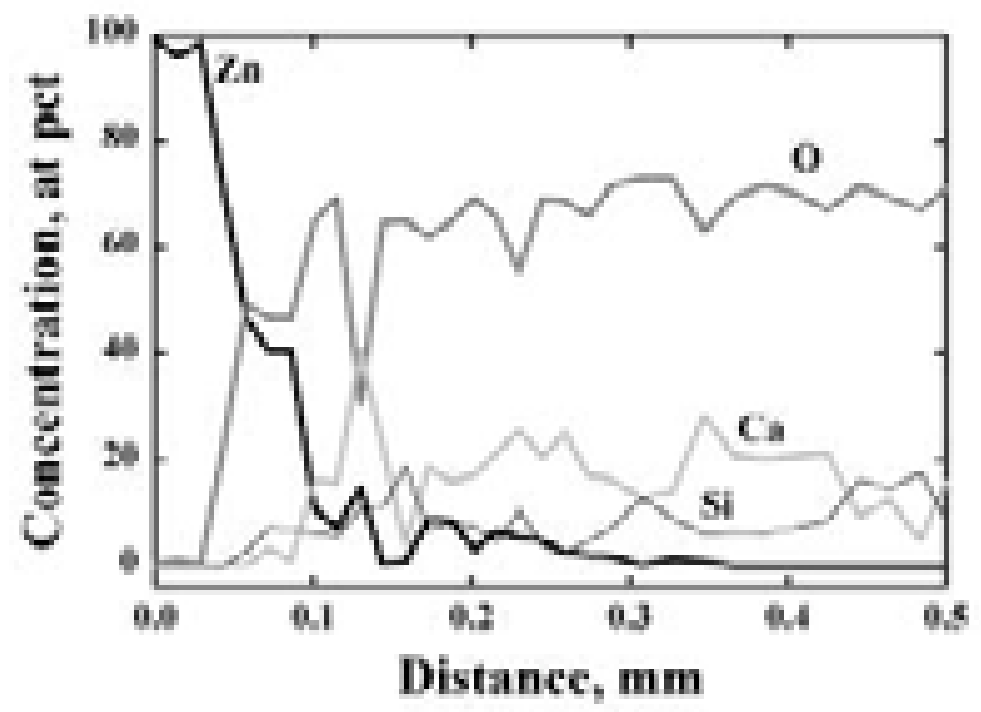

Figure 5.24: WDS line scan for $\mathrm{Zn}, \mathrm{O}, \mathrm{Ca}$, and $\mathrm{Si}$, across the TS $\mathrm{Zn}$ anode-concrete interface for patch concrete on the Cape Creek Bridge after about 3.7 years in ICCP service at $0.0022 \mathrm{~A} / \mathrm{m}^{2}$. 


\subsubsection{SACP}

\subsection{Richmond-San Rafael Bridge}

Figure 5.25 is a SEM photomicrograph of the $\mathrm{Zn}$ anode-concrete interface of the barrel at the base of the south column of Pier 4 of the Richmond-San Rafael Bridge. Figure 5.26 is a BSE and $\mathrm{x}$-ray map for $\mathrm{Zn}, \mathrm{Ca}$, and $\mathrm{Cl}$ of another location along the interface shown in Figure 5.25. Figure 5.27 is a line scan across the interface. A similar line scan is shown for another cross-section of the interface in Figure 5.28. The figures show a zinc atmospheric corrosion film (the darker gray band in Figures 5.25 and 5.26) on the exterior of the anode. A thick layer of $\mathrm{Zn}$ minerals containing some metallic $\mathrm{Zn}$ has replaced the $\mathrm{Zn}$ anode, the bright band in Figures 5.25 and 5.26. The line scans show the outer atmospheric corrosion product is $\mathrm{Zn}$ oxide containing, depending on location, some $\mathrm{Cl}$. X-ray maps and line scans also showed the presence of sulfur in the atmospheric corrosion film. The $\mathrm{Zn}$ mineral replacing the metallic anode was roughly equal concentrations of $\mathrm{Zn}$ and $\mathrm{O}$, with some bands of metallic $\mathrm{Zn}$ still remaining. Unlike aged ICCP anodes, there was practically no diffusion of $\mathrm{Zn}$ into the cement paste and no evidence of a reaction zone in the cement paste. There was little evidence of cracking along the anode-concrete interface, a factor that may contribute to the very high bond strength measured for the SACP anode.

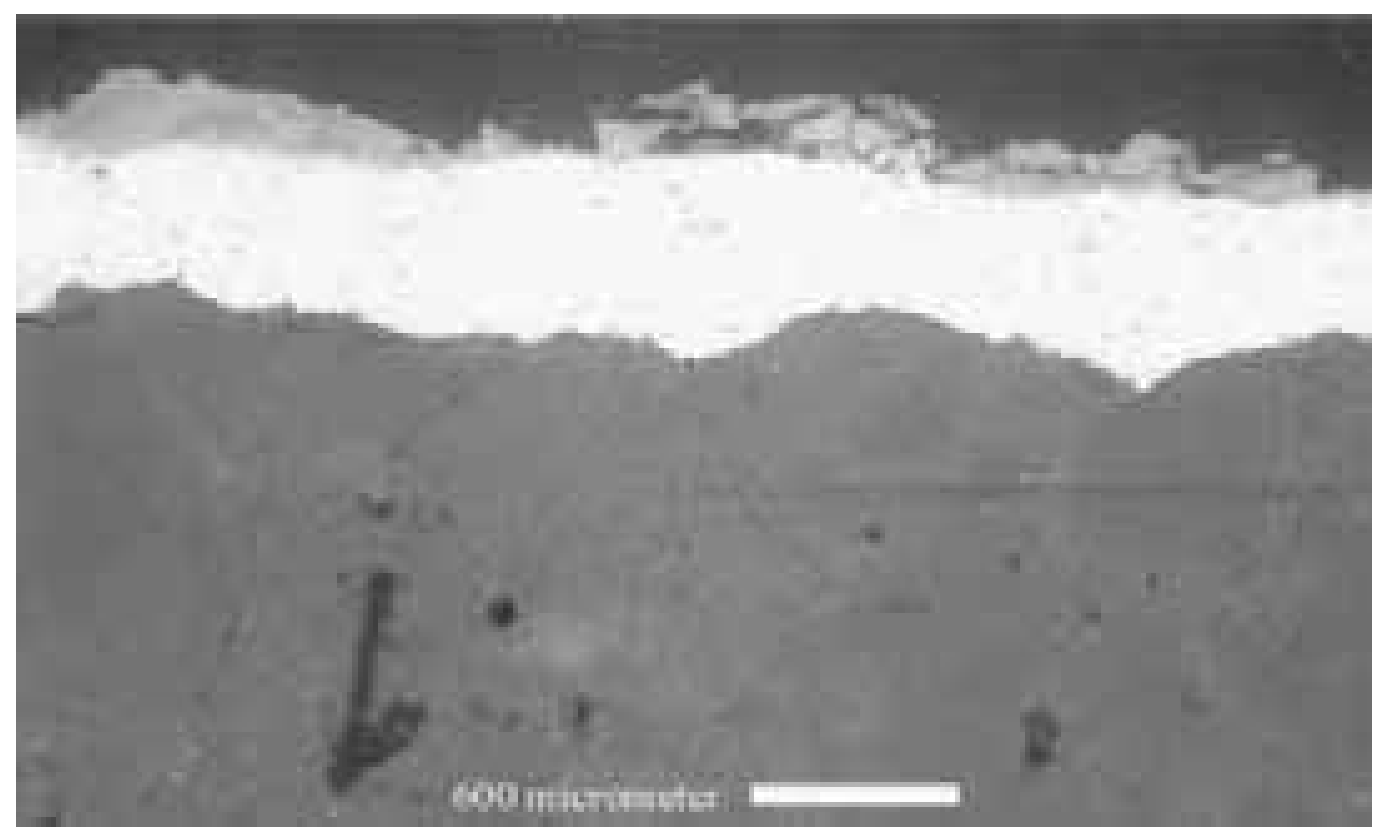

Figure 5.25: SEM photomicrograph of TS Zn anode-concrete interface for the Richmond-San Rafael Bridge SACP zone on the barrel of the south column aged $\sim 700 \mathrm{kC} / \mathrm{m}^{2}$ or $\sim 10$ years service. 

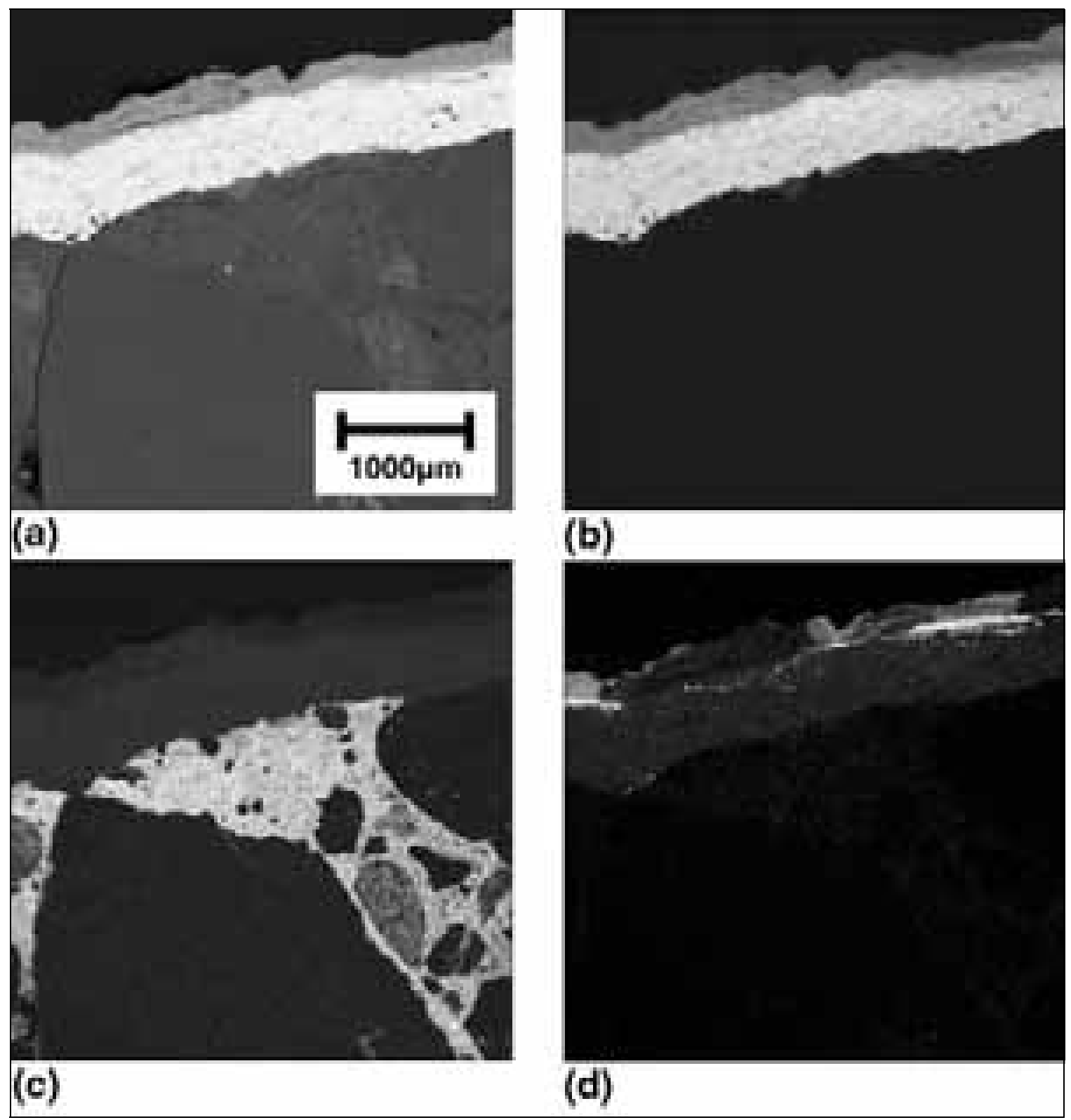

Figure 5.26: BSE photomicrograph and x-ray maps of TS Zn anode-concrete interface for the RichmondSan Rafael Bridge SACP zone on the barrel of the south column aged $\sim 700 \mathrm{kC} / \mathrm{m}^{2}$ or $\sim 10$ years service:

(a) BSE photomicrograph; (b) $\mathrm{Zn}$; (c) $\mathrm{Ca}$; (d) $\mathrm{Cl}$.. 


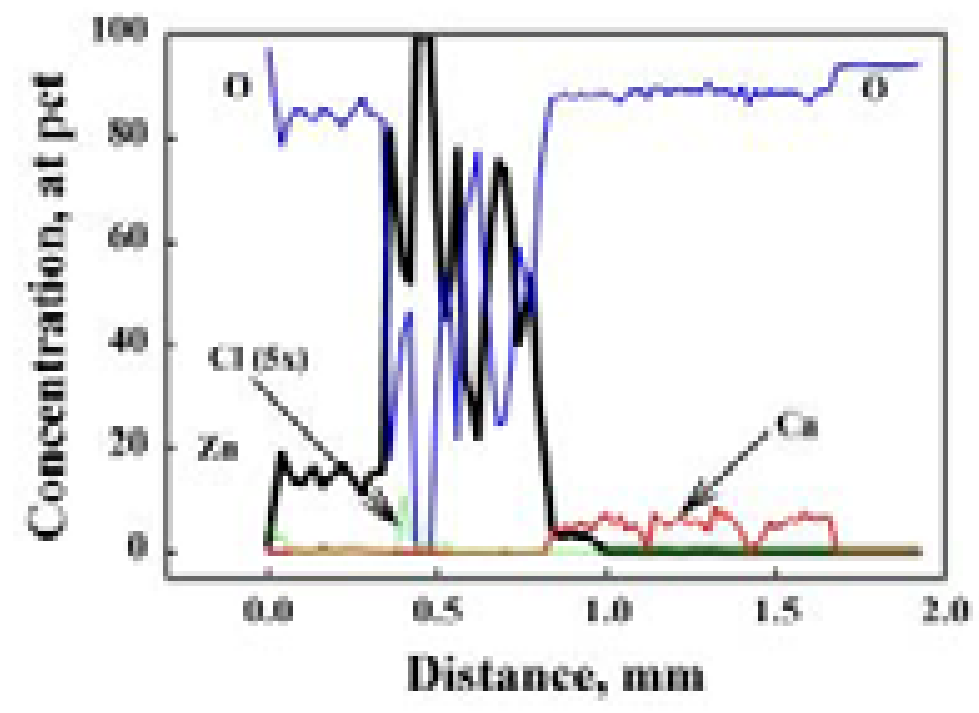

Figure 5.27: WDS line scan for $\mathrm{Zn}, \mathrm{O}, \mathrm{Ca}$, and $\mathrm{Cl}$ across the TS $\mathrm{Zn}$ anodeconcrete interface for the Richmond-San Rafael Bridge SACP zone on the barrel of the south column aged $\sim 700 \mathrm{kC} / \mathrm{m}^{2}$ or $\sim 10$ years service.

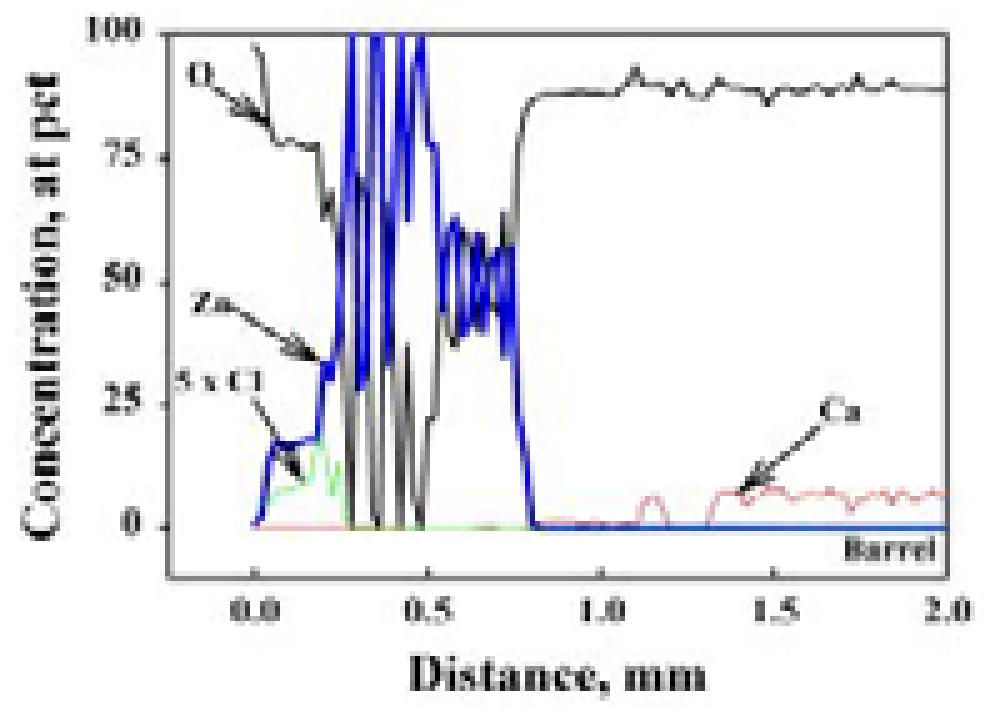

Figure 5.28: WDS line scan for $\mathrm{Zn}, \mathrm{O}, \mathrm{Ca}$, and $\mathrm{Cl}$ across another area of the TS $\mathrm{Zn}$ anode-concrete interface for the Richmond-San Rafael Bridge SACP zone on the barrel of the south column aged $\sim 700 \mathrm{kC} / \mathrm{m}^{2}$ or $\sim 10$ years service.

\subsection{Cape Creek Bridge}

Figure 5.29 is the WDS depth profile of the reaction zone for sample 3553, a $\mathrm{SACP}$ zone in original concrete. This figure shows that there is no reaction zone 
and no chloride accumulation at the anode-concrete interface. The interface for this sample is similar to that for unaged laboratory $\mathrm{Zn}$ anodes on concrete. This was also the result for sample 3554, another SACP sample from a different location. The absence of a reaction zone suggests that SACP currents are significantly lower than those for ICCP zones and that electrochemical aging of the SACP system proceeds at a much slower rate. If SACP provides adequate protection of the rebar over the system service life, these results suggest the service life of SACP systems may be substantially greater than that of ICCP systems. It may also support the concept of intermittent $\mathrm{CP}$ where $\mathrm{CP}$ is applied only when corrosion rates exceed a threshold level requiring the reapplication of $\mathrm{CP}$.

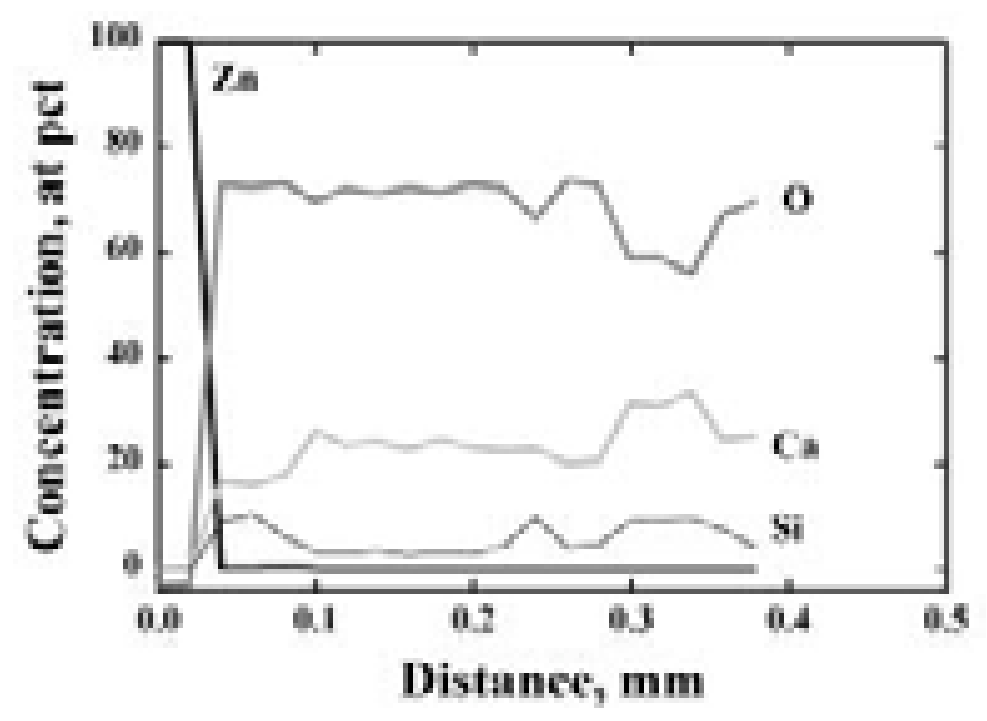

Figure 5.29: WDS line scan for Zn, O, Ca, and Si across the TS Zn anode-concrete interface for a SACP zone on the Cape Creek Bridge after aging about 3.7 years.

\subsection{Longbird Bridge}

Electrochemical aging of galvanized rebar in the sidewalk and abutment of the Longbird Bridge was substantially different from that observed for $\mathrm{Zn}$ anodes in ICCP and SACP zones on coastal bridges. The results are included here because no external power supply was used to provide protection to the rebar, i.e., $\mathrm{Zn}$ dissolution was caused by a galvanic couple between the coating and the rebar. However, while the galvanized rebar was still in good condition (and it was after 46 years), the $\mathrm{Zn}$ /steel area ratio was much higher for the galvanized rebar than for SACP $\mathrm{Zn}$ anodes on reinforced concrete bridges. Another difference was the Zn coating on the galvanized rebar had a much more varied composition than the thermal-sprayed $\mathrm{Zn}$ anode on the bridges. Galvanized coatings on steel can 
contain up to four $\mathrm{Zn}-\mathrm{Fe}$ alloy layers, ranging from pure $\mathrm{Zn}$ to several $\mathrm{Zn}-\mathrm{Fe}$ intermetallics (Yeomans 1993).

Figures 5.30 and 5.31 show cross-sections of the galvanized rebar in concrete removed from the Longbird Bridge after 46 years service. Figure 5.30 shows a section of a No.6 rebar from the abutment of the Longbird Bridge where some of the galvanized coating has corroded and the corrosion product has migrated into the cement paste. Figure 5.31 shows a section of smaller rebar from the sidewalk of the Longbird Bridge where little of the zinc coating has corroded.

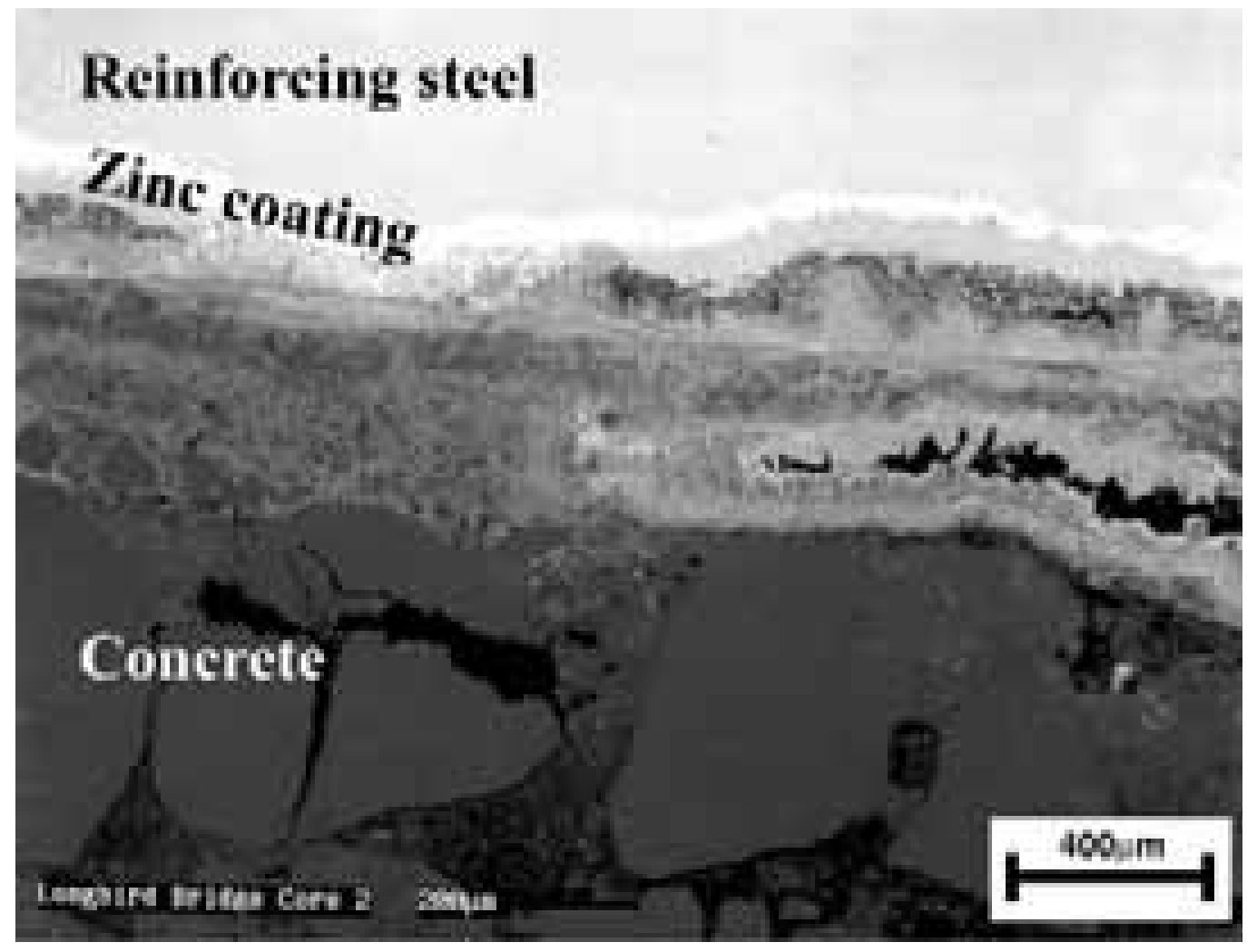

Figure 5.30: SEM photomicrograph of galvanized rebar-concrete interface from the abutment of the Longbird Bridge after 46 years service. 


\section{Concrete}

\section{Zine coating}

\section{Reinforcing steel}

Figure 5.31: SEM photomicrograph of galvanized rebar-concrete interface from the sidewalk of the Longbird Bridge after 46 years service.

Figures 5.32 and 5.33 show element depth profiles for sample 3614, the small round galvanized rebar from the sidewalk of the Longbird Bridge shown in Figure 5.31. These are two of six line scans performed on the sample and are representative of the steel-Zn-concrete interface. After 46 years service, the coating on the rebar was nominally $0.15 \mathrm{~mm}$ (6 mil) thick and composed primarily of the delta phase (ILZRO 1978; ILZRO 1980). The $\zeta$ (zeta) phase and pure $\mathrm{Zn}$ appeared to have dissolved. Analyses showed an average coating thickness of $0.125 \mathrm{~mm}$ ( $5 \mathrm{mil}$ ), with a range of 0 to $0.188 \mathrm{~mm}$ ( 0 to $7 \mathrm{mil}$ ) (ILZRO 1978; ILZRO 1980). At the Zn coating-concrete interface there was a narrow region about $0.05 \mathrm{~mm}$ wide where dissolved $\mathrm{Zn}$ diffused into the cement paste. Figure 5.33 shows this region in somewhat greater detail and suggests that it contains $\mathrm{ZnO}$ and $(\mathrm{Zn}, \mathrm{Ca})$ minerals. Beyond this region, $\mathrm{Zn}$ was present in the cement paste at a level for about 2-3 atomic \% for some distance (more than 0.25 $\mathrm{mm}$ ) into the concrete. There was no evidence of cracking along the interface. 


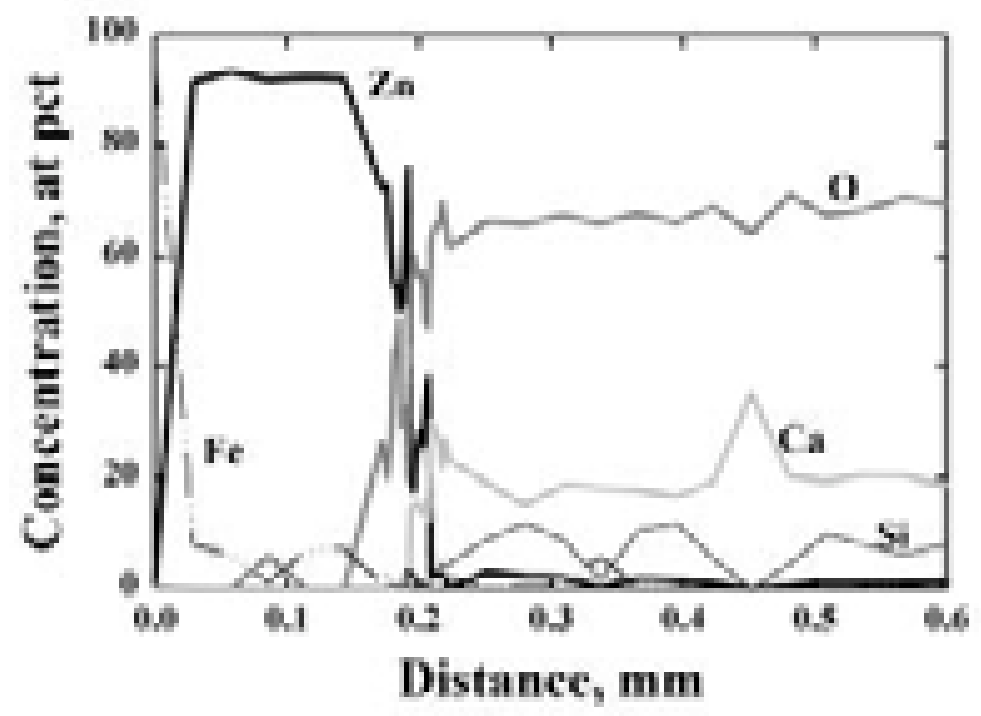

Figure 5.32: WDS line scan for $\mathrm{Zn}, \mathrm{Fe}, \mathrm{O}, \mathrm{Ca}$, and $\mathrm{Si}$ across the galvanized rebar-concrete interface for rebar from the sidewalk of the Longbird Bridge after 46 years service.

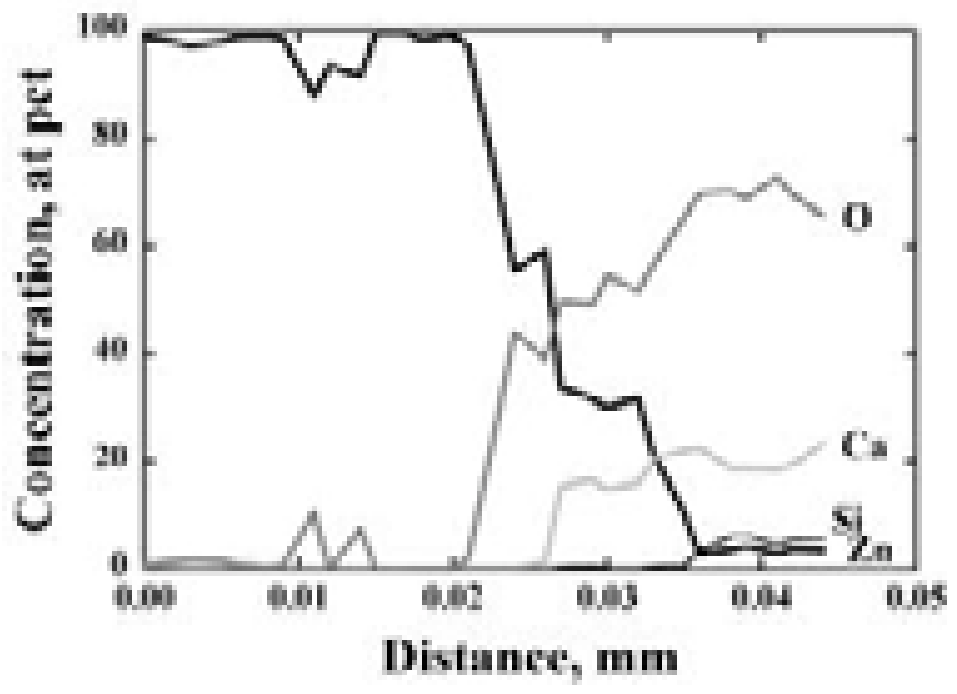

Figure 5.33: WDS line scan for $\mathrm{Zn}, \mathrm{O}, \mathrm{Ca}$, and $\mathrm{Si}$ across a second location on the galvanized rebar-concrete interface for rebar from the sidewalk of the Longbird Bridge after 46 years service.

Figure 5.34 shows the element depth profile for sample 3615 , the no. 6 galvanized rebar (3/4 in) from the abutment of the Longbird Bridge shown in Figure 5.30. Much of the coating has been consumed; about $0.03 \mathrm{~mm}$ remains. Analyses at other locations along the cross-section gave $\mathrm{Zn}$ thicknesses of about $0.15 \mathrm{~mm}$ (6 mil), within the range reported previously (ILZRO 1978; ILZRO 1980). A fairly 
large reaction zone, about $0.1 \mathrm{~mm}$ (4 mil) thick, exists at the anode-concrete interface where $\mathrm{Zn}$ and oxygen are present at roughly equal concentrations suggesting the $\mathrm{Zn}$ mineral present at the interface is $\mathrm{ZnO}$. There is no evidence of $\mathrm{Ca}$ in this zone. The existence of $\mathrm{Ca}$ hydroxyzincate has been suggested by others (Yeomans 1993) and there is some evidence to suggest a $(\mathrm{Ca}, \mathrm{Zn})$ oxide or hydroxide at the interface between the $\mathrm{ZnO}$ and concrete. There were some voids, Figure 5.30, but little evidence of cracking along the zinc-concrete interface due to the presence of the $\mathrm{Zn}$ reaction products.

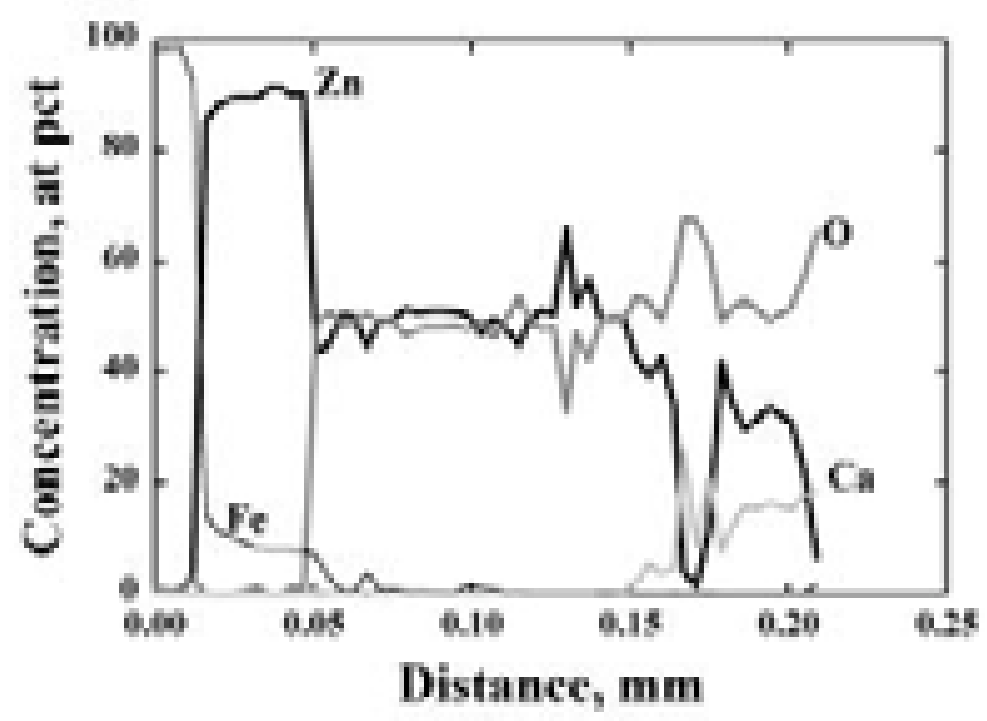

Figure 5.34: WDS line scan for $\mathrm{Zn}, \mathrm{Fe}, \mathrm{O}$, and $\mathrm{Ca}$ across the galvanized rebar-concrete interface for rebar from the abutment of the Longbird Bridge after 46 years service.

\subsubsection{Micro-pH}

Figure 5.35 shows a plot of the $\mathrm{pH}$ at the $\mathrm{Zn}$-concrete interface as a function of height above sea level for pier 4 of the Richmond-San Rafael Bridge. The $\mathrm{pH}$ tended to be lower for the upper bands that were in generally a drier environment. $\mathrm{pH}$ values range from a minimum of 6.5 to a maximum of 10.5 , which was roughly the range observed for aged laboratory slabs, Figure 4.23 . 


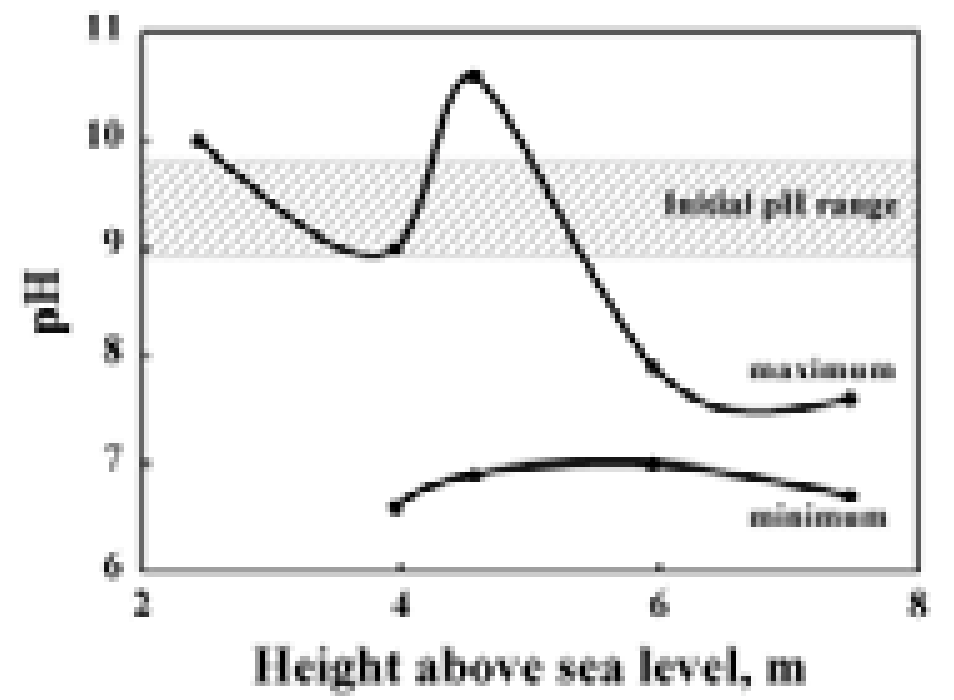

Figure 5.35: $\mathrm{pH}$ as a function of height above sea level for the TS $\mathrm{Zn}$ anode ICCP bands (zones) on the Richmond-San Rafael Bridge after $\sim 10$ years service.

\subsubsection{X-ray diffraction}

X-ray diffraction analyses of surface samples from an ICCP zone of the Cape Creek Bridge on the Oregon Coast showed the presence of simonkolleite, hydrated $\mathrm{Zn}$ hydroxide sulfates, and hydrozincite, i.e., zinc hydroxycarbonate. These results agree well with the minerals produced in the laboratory studies, Table 4.8 and section 4.5.3. 


\subsection{MODELING ZINC ANODE OPERATION}

A model of zinc anode operation is developed from the information presented in this report. Since the work focused on ICCP anodes, much of the detail addresses that type of anode. Results from accelerated laboratory tests provide much of the detail.

The difference between laboratory accelerated ICCP tests and typical Oregon DOT bridge CP operating conditions is the contrast between electrochemical reaction rates and transport and chemical process rates. The laboratory tests are accelerated in terms of the anode electrochemical reactions, not in terms of transport and chemical processes. Furthermore, while considered accelerated in terms of Oregon bridge CP operating conditions, the laboratory tests would not have been accelerated compared to anode current densities approved for use in other installations (NACE International 1990), current densities as high as $0.108 \mathrm{~A} / \mathrm{m}^{2}\left(0.010 \mathrm{~A} / \mathrm{ft}^{2}\right)$. Evidence from field installations of $\mathrm{Zn} \mathrm{ICCP}$ anodes suggests that the accelerated tests represent a "worst case" for Oregon DOT coastal bridge CP operation. Anodes at typical Oregon DOT operating conditions may not display aging effects on bond strength and circuit resistance to the extent or as quickly as observed in the accelerated tests. That would benefit the service life of $\mathrm{Zn}$ anodes currently installed on Oregon's coastal bridges.

The difference between ICCP anodes and SACP anodes is also the contrast between electrochemical rates and transport and chemical process rates. Electrochemical, transport and chemical processes are fundamentally the same for both ICCP and SACP. The difference is the degree of control available to manipulate the electrochemical reaction. Considerable control is available for ICCP; little control is available for SACP other than manipulating the environment of the electrodes and anode/cathode area ratio. As a consequence, ICCP is addressed here before SACP.

Changes in anode bond strength and CP system circuit resistance are the two anode operating characteristics that are most important to the bridge owner. By definition, since they meet bridge owner acceptance criteria at the time of installation, both are at acceptable levels when the CP system is energized. If they were to remain at these levels throughout the CP system life, the only factor of concern to the bridge owner would be the $\mathrm{Zn}$ anode consumption rate. However, changes in bond strength and circuit resistance occur over time as the result of changes in the chemistry of the anode-concrete interface. These changes affect the long-term operation of the $\mathrm{CP}$ system. They can be roughly quantified in terms of the anode electrochemical age, a more cumbersome metric than anode service time but more representative of the condition of the anode-concrete interface. The changes can be roughly modeled in terms of an electrical circuit with impedance contributions from the CP system elements. Thus, anode performance is presented here in terms of changes in contributions to $\mathrm{CP}$ system impedance, using electrochemical age $\left(\mathrm{kC} / \mathrm{m}^{2}\right)$ as the metric to define anode operation regimes. 


\subsection{CP CIRCUIT RESISTANCE}

An equivalent circuit representing the impedance elements between a conductive coating anode and the rebar in a reinforced concrete CP system is given in Figure 6.1. The elements for the steel rebar and concrete are those typically specified (Jafar, Dawson and John 1993; Mansfeld, et al. 1993), as are those for the TS Zn anode (Zhang 1996). However, an additional element has been added for the reaction zone at the anode-concrete interface where the concrete has been modified by acidification. Thus, the equivalent circuit contains the following elements:

1. TS Zn anode - a Randles circuit, with a double layer capacitance, $\mathrm{C}_{\mathrm{dl}, \mathrm{a}}$, in parallel with a charge transfer resistance, $R_{c t, a}$, representing the electrochemical dissolution of zinc and a Warburg resistance, $\mathrm{W}_{\mathrm{a}}$, representing diffusion resistance through the zinc-rich mineral layer that forms at the anode (Zhang 1996).

2. Concrete at the anode-concrete interface - a reaction zone capacitance, $\mathrm{C}_{\mathrm{rz}}$, in parallel with a reaction zone resistance, $\mathrm{R}_{\mathrm{rz}}$, representing dielectric effects in the concrete layer modified by acidification and leading to a calcium-depleted layer of cement paste.

3. Unaltered or bulk concrete - a solution resistance, $\mathrm{R}_{\mathrm{s}}$, representing charge transport through the concrete (Jafar, Dawson and John 1993; Mansfeld, et al. 1993; Zhang 1996).

4. Concrete at rebar-concrete interface - a film capacitance, $\mathrm{C}_{\mathrm{f}, \mathrm{r}}$, in parallel with a film resistance, $\mathrm{R}_{\mathrm{f}, \mathrm{r}}$, representing effects of a lime-rich dielectric film that may form on the rebar (Jafar, Dawson and John 1993).

5. Steel rebar -- a Randles circuit, with a double layer capacitance, $\mathrm{C}_{\mathrm{dl}, \mathrm{r}}$, in parallel with a charge transfer resistance, $R_{c t, r}$, representing the electrochemical dissolution of the steel rebar and a Warburg resistance, $\mathrm{W}_{\mathrm{r}}$, representing a diffusion resistance through the iron rust layer that forms on the rebar (Jafar, Dawson and John 1993; Mansfeld, et al. 1993).

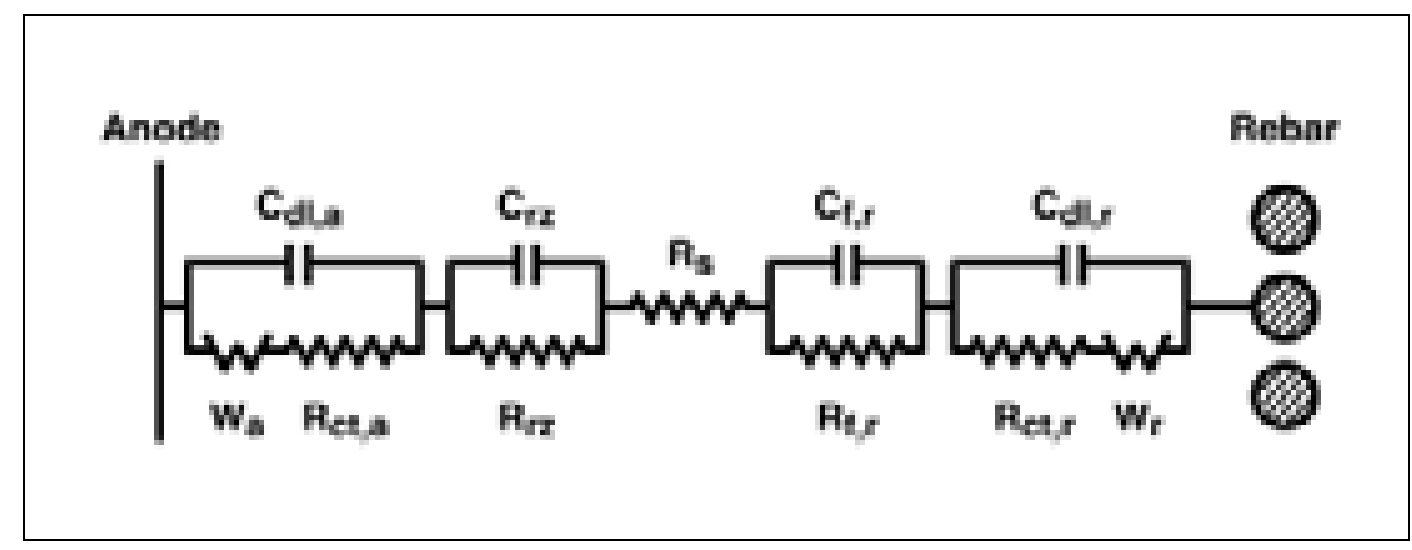

Figure 6.1: Equivalent circuit for ICCP between TS Zn anode and rebar. A Randles-circuit approximates the response of the anode-concrete and rebar-concrete interfaces. 
In the limit as the frequency approaches zero, i.e., direct-current, the capacitors behave as open circuits and the circuit impedance is equal to the dc circuit resistance, equation 3.2, and given by the following resistive element contributions:

$$
\mathbf{C R}=\mathbf{W}_{\mathrm{a}}+\mathbf{R}_{\mathrm{ct}, \mathrm{a}}+\mathbf{R}_{\mathrm{rz}}+\mathbf{R}_{\mathrm{s}}+\mathbf{R}_{\mathrm{f}, \mathrm{r}}+\mathbf{R}_{\mathrm{ct}, \mathrm{r}}+\mathbf{W}_{\mathbf{r}}
$$

Values of charge transfer resistance $\mathbf{R}_{\mathbf{c t}}$ are on the order of $1000-500,000 \mathrm{ohm}-\mathrm{cm}^{2}$, or 0.1 to 50 ohm- $\mathrm{m}^{2}$ for steel in concrete (Jafar, Dawson and John 1993; Mansfeld, et al. 1993) and 100-500 ohm-cm ${ }^{2}$ or 0.01 to $0.05 \mathrm{ohm}-\mathrm{m}^{2}$ for zinc (Zhang 1996). These are small compared to circuit resistances on the order of 100 to $100,000 \mathrm{ohm}-\mathrm{m}^{2}$ measured for some of the laboratory and field CP systems given in this report. Some of the resistive elements $\left(\mathbf{R}_{\mathbf{s}}, \mathbf{R}_{\mathbf{f}, \mathbf{r}}, \mathbf{R}_{\mathbf{c t}, \mathbf{r}}, \mathbf{W}_{\mathbf{r}}\right)$ while variable with respect to time (and wetting), are not variable with respect to electrochemical age because their chemistry does not change (except for wetting effects). Consequently, the systematic rise in circuit resistance with electrochemical age is confined largely to the diffusional resistance at the TS $\mathrm{Zn}$ anode, $\mathbf{W}_{\mathbf{a}}$, and in the reaction zone, $\mathbf{R}_{\mathbf{r z}}$. The seasonal effects involve a larger group of resistive elements: $\mathbf{W}_{\mathbf{a}}, \mathbf{R}_{\mathbf{r z}}$, and $\mathbf{R}_{\mathbf{s}}$, with $\mathbf{R}_{\mathbf{s}}$ having a diminishingly important role with increasing age. Thus, the large seasonal variations in circuit resistance seen for the Richmond-San Rafael Bridge near the end of the 10 year period, Figure 5.3, are primarily due to the effect of wetting on $\mathbf{W}_{\mathbf{a}}$ and $\mathbf{R}_{\mathbf{r z}}$.

\subsection{ICCP OPERATION}

The environmental factor that has the greatest effect on anode performance is presence of moisture in the concrete structure, particularly in the vicinity of the anode-concrete interface. Moisture can be delivered to the structure in precipitation, dew, fog, or humid air. Two accelerated experiments are described in this report, the first with periodic wetting and the second without wetting. Periodic wetting was done at a rate that would translate to about one rain event every 15 days at the current density Oregon DOT typically operates coastal ICCP anodes. This is a reasonable coastal precipitation frequency and is the standard by which the periodically-wetted model is defined.

The periodically-wetted model will be divided into five regimes of electrochemical age: initial $\left(0 \mathrm{kC} / \mathrm{m}^{2}\right)$, early $\left(0\right.$ to $\left.40 \mathrm{kC} / \mathrm{m}^{2}\right)$, middle $\left(40\right.$ to $\left.450 \mathrm{kC} / \mathrm{m}^{2}\right)$, late $\left(450\right.$ to $\left.1800 \mathrm{kC} / \mathrm{m}^{2}\right)$, and final (beyond $1800 \mathrm{kC} / \mathrm{m}^{2}$ ). These ranges correspond to those found in the empirical bond strength model, Equations 4.1 and 4.2, and the bond strength model parameters in Table 4.4 for periodically-wetted anodes.

initial (0 $\mathrm{kC} / \mathrm{m}^{2}$ or $\left.0 \mathrm{~A}-\mathrm{h} / \mathrm{ft}^{2}\right)$

Bond strength - The zinc anode is mechanically bonded to the concrete. The bond is created by zinc penetrating into the "tooth" of the concrete produced by light sandblasting. Initial bond strengths range from 1.2 to $2 \mathrm{MPa}$ (170 to $300 \mathrm{psi}$ ) with the higher bond strengths produced by preheating the concrete. Bond failures occur primarily in the concrete. Bond strength values may be even higher if the concrete cures to higher tensile strength. 
Circuit resistance - The initial circuit resistance is 200 to $600 \mathrm{ohm}-\mathrm{m}^{2}$ and varies with moisture in the concrete, being higher when the concrete is drier. Important resistive circuit elements are $\mathbf{R}_{\mathbf{c t}, \mathbf{a}}, \mathbf{R}_{\mathbf{s}}, \mathbf{R}_{\mathbf{f}, \mathbf{r}}, \mathbf{R}_{\mathbf{c t}, \mathbf{r}}$ and $\mathbf{W}_{\mathbf{r}}$.

Anode-concrete interfacial chemistry - No reaction between the anode and concrete. $\mathrm{pH}$ of the interface is $12-13$.

Anode condition - The anode is highly permeable to water and gases.

\section{early (0 to $40 \mathrm{kC} / \mathrm{m}^{2}$ or 0 to $1.0 \mathrm{~A}-\mathrm{h} / \mathrm{ft}^{2}$ )}

Bond strength - Zinc is consumed at the anode-concrete interface decreasing the mechanical bond. Bond strength values fall to a minimum of 1.0 to $1.2 \mathrm{MPa}$ (150 to 170 psi). If concrete is not fully cured initially, this decrease may be masked by the increase in concrete tensile strength.

Circuit resistance - The circuit resistance remains at around 200 to $600 \mathrm{ohm}-\mathrm{m}^{2}$ and varies with moisture in the concrete, being higher when the concrete is drier. Important resistive circuit elements are $\mathbf{R}_{\mathbf{c t}, \mathbf{a}}, \mathbf{R}_{\mathbf{s}}, \mathbf{R}_{\mathbf{f}, \mathbf{r}}, \mathbf{R}_{\mathbf{c t}, \mathbf{r}}$ and $\mathbf{W}_{\mathbf{r}}$.

Anode-concrete interfacial chemistry - A zinc oxide/hydroxide layer begins developing. $\mathrm{pH}$ of the interface decreases to 8-9 as the result of acidification, reaction 1.3 .

Anode condition - The anode is permeable to water and gases.

\section{middle (40 to $450 \mathrm{kC} / \mathrm{m}^{2}$ or 1.0 to $11.6 \mathrm{~A}-\mathrm{h} / \mathrm{ft}^{2}$ )}

Bond strength - Considerable zinc is consumed at the anode-concrete interface. However, secondary mineralization integrates zinc minerals at the interface with the concrete and the anode, thus improving the mechanical bond and increasing the bond strength. Bond strength increases to a maximum of 2.3 to $2.6 \mathrm{MPa}$ (330 to $380 \mathrm{psi}$ ). Bond failures occur increasingly in the zinc mineral layer at the interface.

Circuit resistance - The circuit resistance remains under about $1 \mathrm{kohm}-\mathrm{m}^{2}$. However, during dry periods it can rise to increasingly larger values with age. Important resistive circuit elements are $\mathbf{W}_{\mathbf{a}}, \mathbf{R}_{\mathrm{ct}, \mathbf{a}}, \mathbf{R}_{\mathbf{r z}}, \mathbf{R}_{\mathbf{s}}, \mathbf{R}_{\mathbf{f}, \mathbf{r}}, \mathbf{R}_{\mathbf{c t}, \mathbf{r}}$, and $\mathbf{W}_{\mathbf{r}}$.

Anode-concrete interfacial chemistry - A substantial zinc mineral layer is present at the interface. Mineral constituents immediately adjacent to the anode include zinc oxide/hydroxide, zinc hydroxycarbonate, zinc hydroxychloride, and zinc hydroxysulfate, the latter two produced by electro-migration of chloride and sulfate ions from within the concrete to the anode. A reaction zone develops in the cement paste with $\mathrm{Zn}$ replacing $\mathrm{Ca}$ and forming a $(\mathrm{Ca}, \mathrm{Zn})$ aluminosilicate. The $\mathrm{pH}$ decreases to 6.5 to 8 .

Anode condition - Pores in the anode are filling up with zinc minerals, primarily zinc oxide and hydroxide. The anode is relatively impermeable to water and gases due to the decreased porosity of the anode and to the zinc mineral layer formed at the anodeconcrete interface.

\section{late (450 to $1800 \mathrm{kC} / \mathrm{m}^{2}$ or 11.6 to $46.5 \mathrm{~A}-\mathrm{h} / \mathrm{ft}^{2}$ )}

Bond strength - The anode bond strength decreases monotonically to zero at about 1800 $\mathrm{kC} / \mathrm{m}^{2}$, equivalent to about 27 years service at the Oregon DOT current density of 0.0022 $\mathrm{A} / \mathrm{m}^{2}$ for coastal bridge ICCP systems. Preheating the concrete at the time of application has no effect on the bond strength in this regime. Substantial areas of disbondment 
develop at the anode-concrete interface late in this regime and the failures are almost entirely in the zinc mineral layer at the interface.

Circuit resistance - The minimum circuit resistance during periods of wet concrete gradually rises with age from about $1 \mathrm{kohm}-\mathrm{m}^{2}$ to $5 \mathrm{kohm}-\mathrm{m}^{2}$ or more. During drier periods, the circuit resistance rises rapidly to values of 5 to $35 \mathrm{kohm}-\mathrm{m}^{2}$. During drier periods, circuit resistance values are sufficiently high that the CP operating voltage is also quite high. Important resistive circuit elements are $\mathbf{W}_{\mathbf{a}}$ and $\mathbf{R}_{\mathbf{r z}}$.

Anode-concrete interfacial chemistry - A substantial zinc mineral layer is present at the interface similar to that formed in the middle age period. The $\mathrm{pH}$ remains at 6.5 to 8 .

Anode condition - The anode is impermeable to water and gases.

\section{final (beyond $1800 \mathrm{kC} / \mathrm{m}^{2}$ or $46.5 \mathrm{~A}-\mathrm{h} / \mathrm{ft}^{2}$ )}

Bond strength - While the anode is largely disbonded, it remains attached to the concrete at discrete locations called anchor pits (or "bug holes" in bridge vernacular) where the anode extends into cavities in the concrete surface. As a result, the anode does not slough from the surface.

Circuit resistance - Disbondment leads to ever smaller anode areas carrying the charge for electrochemical reactions and to increasing circuit resistance. Important resistive circuit elements are $\mathbf{W}_{\mathbf{a}}$ and $\mathbf{R}_{\mathbf{r z}} \cdot$

Anode-concrete interfacial chemistry - Similar to that formed in the late regime.

Anode condition - At most, only about $0.20 \mathrm{~mm}$ ( 5 mils) of anode thickness has been consumed.

The model for other anode wetting frequencies, including unwetted anodes, are as infinitely varied as the wetting histories of the anode. However, the model just described for periodicallywetted anodes contains the key features of each of these anodes and gives insight into the effects to be expected as TS Zn anodes on coastal bridges age. For sheltered environments where conditions are expected to be drier, the effects of aging are accelerated because secondary mineralization of anode dissolution products and diffusion of anions and cations is more restricted.

For the un-wetted model the five regimes of electrochemical age are: initial $\left(0 \mathrm{kC} / \mathrm{m}^{2}\right)$, early $(0$ to $30 \mathrm{kC} / \mathrm{m}^{2}$ ), middle ( 30 to $85 \mathrm{kC} / \mathrm{m}^{2}$ ), late $\left(85\right.$ to $340 \mathrm{kC} / \mathrm{m}^{2}$ ), and final (beyond $340 \mathrm{kC} / \mathrm{m}^{2}$ ). These ranges correspond to those found in the empirical bond strength model, Equations 4.1 and 4.2, and the bond strength model parameters in Table 4.4 for un-wetted TS Zn anodes.

initial (0 $\mathrm{kC} / \mathrm{m}^{2}$ or $\left.0 \mathrm{~A}-\mathrm{h} / \mathrm{ft}^{2}\right)$

Same as for the periodically-wetted model, with bond strength values of 1.2 to $2.2 \mathrm{MPa}$ (170 to $320 \mathrm{psi}$ ).

early (0 to $30 \mathrm{kC} / \mathrm{m}^{2}$ or 0 to $\left.0.75 \mathrm{~A}-\mathrm{h} / \mathrm{ft}^{2}\right)$

Bond strength - Bond strength values remain unchanged or rise.

Circuit resistance -- Important resistive circuit elements are $\mathbf{R}_{\mathbf{c t}, \mathbf{a}}, \mathbf{R}_{\mathbf{s}}, \mathbf{R}_{\mathbf{f}, \mathbf{r},}, \mathbf{R}_{\mathbf{c t}, \mathbf{r}}$ and $\mathbf{W}_{\mathbf{r}}$.

middle (30 to $85 \mathrm{kC} / \mathrm{m}^{2}$ or 0.75 to $2.2 \mathrm{~A}-\mathrm{h} / \mathrm{ft}^{2}$ ) 
Bond strength - Bond strength reaches a maximum of $2.3 \mathrm{MPa}(330 \mathrm{psi})$ for preheated concrete.

Circuit resistance - The circuit resistance rises to very large values within this age period. Important resistive circuit elements are $\mathbf{W}_{\mathbf{a}}$ and $\mathbf{R}_{\mathbf{r z}}$.

Anode-concrete interfacial chemistry - An insulating zinc oxide layer forms, with no evidence of secondary mineralization, zinc hydroychloride or hydroxysulfate minerals, or modification of the cement paste. Zinc does not penetrate the cement paste.

late (85 to $340 \mathrm{kC} / \mathrm{m}^{2}$ or 2.2 to $8.8 \mathrm{~A}-\mathrm{h} / \mathrm{ft}^{2}$ )

Bond strength - Bond strength decreases monotonically to zero at about $340 \mathrm{kC} / \mathrm{m}^{2}$, equivalent to about 5 years service at the Oregon DOT current density of $0.0022 \mathrm{~A} / \mathrm{m}^{2}$ for coastal bridge ICCP systems.

Circuit resistance -- Important resistive circuit elements are $\mathbf{W}_{\mathbf{a}}$ and $\mathbf{R}_{\mathbf{r z}}$ •

final (beyond $340 \mathrm{kC} / \mathrm{m}^{2}$ or $8.8 \mathrm{~A}-\mathrm{h} / \mathrm{ft}^{2}$ )

Same as for the periodically-wetted model.

\subsection{SACP OPERATION}

SACP zones on the Cape Creek Bridge formed by shorts between the zinc anode and the rebar cannot be characterized in terms of conventional CP measurements (rebar depolarization, protection current) because the anode and cathode were not separable. Only where the anode and cathode are separated, as in the case of the SACP TS Zn anode on the Cape Perpetua Viaduct or where a window has been constructed in a SACP zone, can the anode performance be characterized as was done for ICCP anodes. When this is possible, a model such as used for the ICCP data should also apply to the SACP data. The difficulty is the lack of SACP electrochemical age data, particularly current output data.

It might be expected that a SACP anode would perform in a similar way to the ICCP anode. However, in two ways this was not the case. After significant aging, the bond strength of the SACP anode was much higher than for the ICCP anode of comparable age. In addition, there was no diffusion of $\mathrm{Zn}$ into the cement paste for the SACP anode. Despite the sparseness of SACP data in this report, a periodically-wetted model was developed for SACP similar to that used for ICCP.

initial (0 $\mathrm{kC} / \mathrm{m}^{2}$ or $\left.0 \mathrm{~A}-\mathrm{h} / \mathrm{ft}^{2}\right)$

Bond strength - Same as for ICCP.

Current output - At a maximum; may be as high as $10-12 \mathrm{~mA} / \mathrm{m}^{2}$.

Anode-concrete interfacial chemistry - Same as for ICCP.

Anode condition - Same as for ICCP.

early (0 to $40 \mathrm{kC} / \mathrm{m}^{2}$ or 0 to $1.0 \mathrm{~A}-\mathrm{h} / \mathrm{ft}^{2}$ )

Bond strength - No data.

Current output - Decreases gradually; increases during periods of wetness.

Anode-concrete interfacial chemistry - No data. 
Anode condition - No data; expected to be similar to that for ICCP.

middle (40 to $450 \mathrm{kC} / \mathrm{m}^{2}$ or 1.0 to $11.6 \mathrm{~A}-\mathrm{h} / \mathrm{ft}^{2}$ )

Bond strength - No data.

Current output - Continues to decline; increases during periods of wetness.

Anode-concrete interfacial chemistry - There is practically no diffusion of $\mathrm{Zn}$ into the cement paste.

Anode condition - No data.

late (450 to $1800 \mathrm{kC} / \mathrm{m}^{2}$ or 11.6 to $46.5 \mathrm{~A}-\mathrm{h} / \mathrm{ft}^{2}$ )

Bond strength - Very high bond strength; about 3.5 MPa (500 psi).

Current output - Levels out at around $1 \mathrm{~mA} / \mathrm{m}^{2}$; increases during periods of wetness. Anode-concrete interfacial chemistry - Zinc mineral layer is largely $\mathrm{ZnO}$. There is practically no diffusion of $\mathrm{Zn}$ into the cement paste. There is no reaction zone in the cement paste where $\mathrm{Zn}$ has replace $\mathrm{Ca}$. $\mathrm{pH}$ of the interface is 10.0.

Anode condition - The anode was entirely consumed immediately over the rebar and the concrete was bare. $\mathrm{Zn}$ anode remained on the concrete surface between where the rebar was located outlining the rebar location on the concrete surface. Most of the zinc that remained had been converted into $\mathrm{ZnO}$.

final (beyond $1800 \mathrm{kC} / \mathrm{m}^{2}$ or $46.5 \mathrm{~A}-\mathrm{h} / \mathrm{ft}^{2}$ )

Bond strength - No data.

Current output - No data.

Anode-concrete interfacial chemistry - No data.

Anode condition - No data. 


\subsection{ZINC ANODE PERFORMANCE}

The model of $\mathrm{Zn}$ anode operation provides a basis for assessing the performance of the thermalsprayed $\mathrm{Zn}$ anode in terms of ICCP and SACP operation and service life. The $\mathrm{Zn}$ anode will also be compared with a solvent-based acrylic carbon paint anode (Cramer, et al. 2002b) and a Cocatalyzed thermal-sprayed Ti anode (Cramer, et al. 1999; McGill, et al. 1999) currently in demonstration projects on Oregon coastal bridges.

Typical thermal-spray parameters for application of the anode are (Cramer, et al. 2002a; Rogers 2000): $0.48 \mathrm{~mm}$ (3/16 in) diameter Zn wire; dc current - $400 \mathrm{~A}$; dc voltage - $27 \mathrm{~V}$; deposition rate $-56 \mathrm{~kg} / \mathrm{h}(124 \mathrm{lb} / \mathrm{h})$ and deposition efficiency $-64 \%$. An X-Y spray pattern gives a Zn anode of fairly uniform thickness with an average of 0.43-0.50 mm (17-20 mils). Maximum temperature of the $\mathrm{Zn}$ thermal-sprayed concrete surface is $90-100^{\circ} \mathrm{C}$.

\subsection{ICCP OPERATION}

The TS Zn anode functions effectively in bridge ICCP systems to distribute current to rebar in complex geometries. Like most ICCP anodes for reinforced concrete, the anode-concrete interface is acidified with aging. Based largely on laboratory tests, acidification and the accompanying growth of a zinc mineral layer at the interface results in a decrease in bond strength and increase in circuit resistance with increase in age. These changes may be slower to appear in actual service at the current density that Oregon DOT typically operates coastal CP systems, $0.0022 \mathrm{~A} / \mathrm{m}^{2}\left(0.2 \mathrm{~mA} / \mathrm{ft}^{2}\right)$. Moisture in the concrete, particularly at the anode-concrete interface, is a key factor in reducing circuit resistance. The anode may perform less effectively in a drier environment when the circuit resistance tends to be high.

Preheating of the concrete surface prior to TS $\mathrm{Zn}$ anode application is not effective as it yields no long-term benefit to anode performance. However, the practice should be to spray only when the concrete surface is dry, as determined by the relative humidity of the spray environment. This is achieved by the environmental enclosures currently used in spraying coastal bridges.

An anode coating thickness of $0.60 \mathrm{~mm}$ (15 mils) should be adequate for bridge applications as only $0.20 \mathrm{~mm}$ ( 5 mils) is consumed by the electrochemical reaction in $25-30$ years service. Factors that reduce the average anode current density will increase the service life of the anode. Periodic monitoring of anode performance, as Oregon DOT is presently doing, is necessary to identify aging effects in actual CP service.

\subsection{SACP OPERATION}

SACP anodes formed by shorts between the anode and rebar or by direct spraying of the zinc anode over exposed rebar provide few opportunities to assess how effectively the anodes are protecting the rebar. Applied by the same standards as for an ICCP zone, i.e., preventing shorts 
between anode and rebar, the performance of the SACP zone can be evaluated using the same criteria as for ICCP anodes. Early in the operation of the SACP anode current output may be high and it may be necessary slow the anode reaction. Anode output current typically decreases with time as a zinc mineral layer grows at the anode-concrete interface. Anodes may become very adherent with age.

\subsection{ANODE SERVICE LIFE}

The service life of the thermal sprayed $\mathrm{Zn}$ anode can be determined by at least three criteria:

(1) time for the anode to be consumed;

(2) time for the bond strength to reach zero; or

(3) time for the circuit resistance to reach a level where operating voltages are too high.

With $0.66 \mathrm{~mm}$ (15 mil) thick anodes, criterion (1) is probably not a factor as consumption rates are slow relative to other estimates of anode service. The service life defined by criterion (2) is approximately 27 years at a CP current density of $0.0022 \mathrm{~A} / \mathrm{m}^{2}\left(0.2 \mathrm{~mA} / \mathrm{ft}^{2}\right)$ for periodicallywetted anodes.

No service life estimate has been made based on criterion (3). However, this may be the more important criterion since circuit resistance for periodically-wetted TS Zn anodes can rise significantly after $450 \mathrm{kC} / \mathrm{m}^{2}$, about 7 years at the typical Oregon DOT ICCP current density for coastal bridges. Service life is substantially shortened by dry conditions, which lead to high circuit resistance and low bond strength at times much shorter than for periodically-wetted anodes.

\subsection{COMPARISON WITH OTHER CONDUCTIVE COATING ANODES}

The performance of three types of conductive coating anodes in use on Oregon DOT reinforced concrete coastal bridges is compared in Table 7.1. The carbon anode is the only one with anode reactions that result in reduced acidification of the anode-concrete interface (Cramer, et al. $2002 b$ ). This is the oxidation reaction that converts $\mathrm{Cl}$ ions to chlorine or hypochloric acid; these compounds are vented as gases from the system through the porous anode layer. The catalyzed $\mathrm{Ti}$ anode is the least sensitive to changes in moisture content of the concrete or environment (Covino, et al. 1997b). The anode has a flat response to humidity down to $20 \%$, indicating the anode obtains sufficient water from moisture in air to support the anode reaction. At 15 years exposure (relative to Oregon DOT's bridge ICCP current density), the TS Zn anode had the highest bond strength. The TS Zn anode exhibits more basic interfacial $\mathrm{pH}$ values than the carbon or $\mathrm{Ti}$ anodes. Both the carbon and the $\mathrm{Ti}$ anodes exhibit low circuit resistance, $\leq 1000$ ohm- $\mathrm{m}^{2}$, over the full extent of their service to date. On the other hand, the TS Zn anode circuit resistance is initially as low as that for the $\mathrm{C}$ and Ti anodes. However, with time the TS Zn anode circuit resistance can rise to substantial values depending on age and moisture content of the concrete. 
Table 7.1 Comparison of thermal-sprayed $\mathrm{Zn}$ anode with other conductive coating anodes

\begin{tabular}{|c|c|c|c|}
\hline Property & TS Zn ${ }^{1}$ & $\begin{array}{c}\text { Co-catalyzed } \\
\text { TS Ti }\end{array}$ & $\begin{array}{l}\text { Solvent-based } \\
\text { acrylic C paint }\end{array}$ \\
\hline Anode reactant & $\mathrm{Zn}$ & $\mathrm{H}_{2} \mathrm{O}$ & $\mathrm{C}, \mathrm{Cl}, \mathrm{H}_{2} \mathrm{O}$ \\
\hline Consumable anode & yes & no & partly \\
\hline Sensitive to moisture content of concrete & very & moderate & moderate \\
\hline Fifteen year bond strength, $\mathrm{MPa}$ (psi) & $\begin{array}{c}1.2-1.6 \\
(130-170)\end{array}$ & $\begin{array}{c}0.26-0.35 \\
(38-50)\end{array}$ & $\begin{array}{c}0.39-0.62 \\
(57-90)\end{array}$ \\
\hline Fifteen year anode-concrete interfacial $\mathrm{pH}$ & $6.5-8$ & $5.7-7.7$ & $5.4-7.8$ \\
\hline Circuit resistance, ohm- $\mathrm{m}^{2}$ & $\begin{array}{c}200 \rightarrow 5,000 \text { to } \\
35,000\end{array}$ & $\sim 600$ & $\sim 1000$ \\
\hline $\begin{array}{l}\text { Cost of CP installation including environmental } \\
\text { enclosure, but not including concrete repairs, } 1997 \\
\text { \$US per } \mathrm{m}^{2}\end{array}$ & $\begin{array}{l}\$ 184.70- \\
\$ 114.70\end{array}$ & $\$ 104.84$ & $\begin{array}{l}\$ 218.40 \\
(\$ 37.70 \text { based on } \\
\text { parking garages })\end{array}$ \\
\hline Service life, years & $\sim 27$ & $23++$ & $15++$ \\
\hline
\end{tabular}

\footnotetext{
${ }^{1}$ See APPENDIX E for more on the installation costs for TS Zn anodes.
}

$++=$ actual service life is expected to exceed the values shown.

The costs of CP installation have been adjusted to 1997 \$US and include the cost of environmental enclosures to prevent over-spray from entering the environment and to maintain dry conditions on the surface of the structure while the anode was applied (Cramer, et al. 2002b; Holcomb and Cryer 1998; McGill, et al. 1999). The costs for the Ti and C paint anodes are for small demonstration projects; they are expected to be lower on full-scale projects. In fact, industrial applications of $\mathrm{C}$ paint anodes on parking garages give substantially lower costs (Gummow 2001).

The $\mathrm{Zn}$ anode service life was base on bond strength for a periodically wetted anode. The Ti anode service life estimate was based on circuit resistance and the nearly constant nature of this value in laboratory tests for the equivalent of 23 years, with no sign the circuit resistance would increase significantly beyond that time. The $\mathrm{C}$ paint anode service life estimate was based on years of actual service; the anode continues to perform satisfactorily on the Oregon coast. 


\subsection{CONCLUSIONS AND RECOMMENDATIONS}

\subsection{CONCLUSIONS}

\section{$\underline{\text { Anode Performance }}$}

- ICCP and SACP TS Zn anode performance is successfully characterized by a model using electrochemical age rather than service time as the controlling parameter.

- The TS Zn anode functions effectively in bridge ICCP systems to distribute current to rebar in complex geometries.

- The TS Zn anode compares favorably to that of other conductive coating anodes in application cost, performance and service life.

- Laboratory and field studies of TS Zn anode service gave similar results. Laboratory results based on accelerated ICCP tests can be considered as "worst case" examples of what may occur in the field at Oregon DOT coastal bridge CP conditions.

- TS Zn anode electrochemical aging effects may be less pronounced in bridge service than observed in the laboratory studies because effects of accelerated anode dissolution will have more time to dissipate and equilibrate with natural processes in the bridge environment.

\section{Anode Bond Strength}

- Light sand blasting of the concrete surface to remove the laitance layer and loose concrete is necessary to successful application of the TS Zn anode.

- Preheating clean and dry concrete surfaces prior to applying the TS Zn anode is not necessary to ensure high bond strength over the service life of the anode. The initial beneficial effects of preheating disappear with increasing electrochemical age.

- Based on bond strength, the service life of the TS Zn anode operated at the Oregon DOT typical ICCP current density of $0.0022 \mathrm{~A} / \mathrm{m}^{2}$ is approximately 27 years.

- About $0.20 \mathrm{~mm}$ (5 mil) of a TS Zn anode 0.47-0.60 mm (12-15 mils) thick will be consumed in a 27 year service life at an ICCP current density of $0.0022 \mathrm{~A} / \mathrm{m}^{2}$.

- TS Zn anode bond strength and ICCP circuit resistance, both of which can limit service life, are linearly related.

- When TS Zn anode bond strength has decreased to essentially zero, the anode will be prevented from peeling from the structure by the presence of anchor pits attaching the coating to the concrete.

\section{Circuit Resistance: ICCP}

- The initial TS Zn anode circuit resistance is on the order of 200 to $600 \Omega-\mathrm{m}^{2}$.

- Circuit resistance remains relatively low during the early and middle stages of anode service but can increase substantially during the late stage of service. 
- The rise in circuit resistance at the late stage of service is largely due to diffusional resistance through zinc minerals formed by anode dissolution and by the growing resistance of the cement paste reaction zone affected by acidification.

- Moisture in concrete significantly affects the circuit resistance at the early stages of anode aging, but moisture in zinc mineral at the anode-concrete interface and the cement paste reaction zone formed by acidification become the predominant seasonal effects as aging increases. Circuit resistance values are substantially higher in drier environments.

- The high value of circuit resistance is one of the important factors affecting service life of the TS Zn ICCP anode.

\section{Current Output: SACP}

- The initial TS Zn anode current output can be on the order of $10 \mathrm{~mA} / \mathrm{m}^{2}$ during wet conditions.

- A limit on the high initial current output early in the operation of the SACP TS ZN anode may be necessary to extend its service life.

- Moisture in concrete significantly affects the current and leads to seasonal changes reflecting wetter and drier conditions. Values are substantially lower during drier conditions.

- The low value of current output as aging progresses is one of the important factors affecting service life of the TS Zn SACP anode.

\section{ICCP Anode-Concrete Interfacial Chemistry}

- Interfacial $\mathrm{pH}$ falls quickly to values on the order of $\mathrm{pH}$ 6-8 during the middle stage of periodically-wetted anode service.

- Extensive migration of $\mathrm{Zn}$ into the cement paste occurs during consumption of the TS Zn anode for periodically-wetted anodes; very little occurs for un-wetted anode.

- Migration of $\mathrm{Cl}$ and $\mathrm{S}$ from the cement paste to the anode-concrete interface occurs occurs with aging of the periodically-wetted TS Zn anode.

- Zn hydroxychloride and hydroxysulfate minerals, in addition to the $\mathrm{ZnO}$ and $\mathrm{Zn}(\mathrm{OH})_{2}$, form at the TS $\mathrm{Zn}$ anode as the result of $\mathrm{Zn}$ consumption.

- Acidification of the interface leads to a reaction zone with a substantially reduced level of $\mathrm{Ca}$ where the cement paste has been altered to form $(\mathrm{Ca}, \mathrm{Zn})$ aluminum silicate.

\section{SACP Anode-Concrete Interfacial Chemistry}

- Interfacial $\mathrm{pH}$ remains substantially higher with electrochemical age than for ICCP service, on the order of $\mathrm{pH} 10$ during the late stage of TS $\mathrm{Zn}$ anode service.

- Practically no migration of Zn into the cement paste occurs during consumption of the TS $\mathrm{Zn}$ anode, nor is there any migration of $\mathrm{Cl}$ and $\mathrm{S}$ from the cement paste to the interface.

- The primary $\mathrm{Zn}$ mineral formed on consumption of the anode is $\mathrm{ZnO}$. In particularly wet conditions, atmospheric corrosion of the anode external surface can occur, contributing significantly to the loss of anode material and leaving a layer of $\mathrm{Zn}$ hydroxychloride and hydroxysulfate minerals on the TS Zn anode surface. 


\section{Destructive Anode Evaluation Techniques}

- Interfacial $\mathrm{pH}$ changes little with electrochemical age once the TS $\mathrm{Zn}$ anode has been in ICCP service for a couple of years, i.e., beyond the "early" stage of anode service.

- Interfacial chemistry is a useful diagnostic technique for understanding the effects of anode aging, but not a particularly useful means for monitoring anode condition.

- Bond strength is a simple and effect means for monitoring the progress of TS $\mathrm{Zn}$ anode electrochemical aging. Assuming acceptable initial bond strength, low bond strength is an indicator of considerable electrochemical age in ICCP service. In SACP service the bond strength may actually increase substantially with age.

\section{Nondestructive Anode Evaluation Techniques}

- ICCP system dc circuit resistance is an effective in-service technique for monitoring the condition of the TS Zn anode. Changes in the chemistry of the anode-concrete interface relative to initial conditions result in an increase in the circuit resistance. However, the measurement is strongly dependent upon moisture content of the concrete during the early stages of aging, and of moisture content of at the anode-concrete interface for the later stages of aging. Substantial CP system performance data is needed to establish trends.

- SACP system current output is an effective in-service technique for monitoring the condition of the TS Zn anode. Changes in the chemistry of the anode-concrete interface relative to initial conditions result in a decrease in the current output. However, the measurement is strongly dependent upon moisture content of the concrete and substantial data is needed to establish trends.

- TS Zn anode surface resistance is a relatively insensitive indicator of anode electrochemical age or the metallic $\mathrm{Zn}$ remaining in the anode.

- Surface air permeability is not an effective indicator of TS Zn anode porosity.

\subsection{RECOMMENDATIONS}

In view of the study results, the following recommendations are made:

1. Rehabilitation of reinforced concrete bridges, particularly historic bridges, followed by cathodic protection using TS Zn anodes is an effective strategy for protecting the State's public resources.

2. Preheating of concrete surfaces prior to applying TS $\mathrm{Zn}$ is not necessary for long-term bond strength or performance of either ICCP or SACP systems on reinforced concrete bridges.

3. The thickness of TS Zn anodes can be limited to 12-15 mils when the current density is that typically used by Oregon DOT on coastal ICCP installations, $\sim 0.0022 \mathrm{~A} / \mathrm{m}^{2}$.

4. Routine monitoring of the zones in bridge cathodic protection systems by measuring voltage and current, as Oregon DOT presently does, provides a basis for assessing the performance and remaining service life of $\mathrm{Zn}$ anodes by allowing the computation of circuit resistance and 
electrochemical age for ICCP systems and current output and electrochemical age for SACP systems.

5. Bond strength measurements perhaps once every 5 years would provide an effective measure of the condition of in-service TS $\mathrm{Zn}$ anodes on coastal bridges.

6. Examination of the TS Zn anode-concrete interface is a useful diagnostic tool that can be used sparingly to establish the condition of in-service $\mathrm{Zn}$ anodes on coastal bridges.

7. SACP systems should be installed with the same care as ICCP systems, i.e., the TS Zn anodes should be electrically isolated from the rebar, so that system performance can be monitored and, should the need arise, the system can be converted to ICCP. Otherwise, the methods available for assessing system performance are inadequate and unproven.

8. Intermittent operation of ICCP and SACP systems may increase TS Zn anode service life by reducing the average current, thereby reducing acidification of the anode-concrete interface and the formation of a resistive layer of $\mathrm{Zn}$ minerals at the interface.

9. Procedures that increase the amount of moisture at the TS Zn anode-concrete interface such application of humectants should continue to be studied or tried on a larger scale.

10. Criteria for evaluating and ranking the condition of in-service TS Zn anodes as part of a bridge evaluation program are needed.

11. Determining whether CP is needed when a bridge is relatively dry, i.e., when electrical paths in the concrete are very resistive, would provide another basis for managing anode current density and perhaps reducing it.

12. Determination of the minimum protection current to protect rebar in concrete would establish how much $\mathrm{CP}$ currents could be reduced without putting bridges at risk.

13. Routine monitoring is needed to assess the condition and service life of TS Zn anodes and determine whether aging effects appear as suggested by the accelerated laboratory tests or more slowly.

14. Non-uniform current distribution on the TS Zn anode will lead to non-uniform aging of the anode. To some extent non-uniform aging effects can be predicted from the data in this report. It is recommended that the effect of non-uniform aging on bond strength measurements or the criteria for locating bond strength tests should be assessed. 


\subsection{REFERENCES}

AASHTO. 1995. Sampling and testing for chloride ion in concrete and concrete raw materials. Standard specifications for transportation materials and methods of sampling and testing, 17th ed., part II. no. T 260-94. Washington, DC.

Allan, M. L. 1995. Probability of corrosion induced cracking in reinforced concrete. Cement and concrete research 25: 1179-1190.

Apostolos, J. A. 1984. Cathodic protection of reinforced concrete by using metallized coatings and conductive paints. Record no. 962. pp. 22-28. Transportation Research Record: Washington, DC.

Apostolos, J. A., Parks, D. M., and Carello, R. A. 1987. Cathodic protection of reinforced concrete using metallized zinc. Materials performance 26(12): 22-28.

ASTM. 1996. Standard test method for calibration of thermocouples by comparison techniques. Annual book of ASTM standards, vol. 14.03. E220-86(1996)e1. West Conshohocken, PA.

ASTM. 1999. Standard test method for maximum pore diameter and permeability of rigid porous filters for laboratory use. Annual book of ASTM standards, vol. 14.04. E128-99. West Conshohocken, PA.

Baeckmann, W. von, Schwenk, W., and Prinz, W. 1997. Cathodic Corrosion Protection. Gulf Publishing Co. Houston TX., pp. 88-107.

Bennett, J. E. and Martin, B. L. 1987. The Elgard mesh system. In Seminar on corrosion in concrete - practical aspects of control by cathodic protection, pp. 5.1-5.18. London UK: London Press Centre.

Broomfield, J. P. 1997. Corrosion of Steel in Concrete, E\&FN Spon (Chapman \& Hall), London UK, $240 \mathrm{pp}$.

Brousseau, R., Arnott, M., and Baldock, B. 1994a. Arc sprayed zinc on reinforced concrete. ILZRO Project Report ZE-390, Ottawa, Ontario: National Research Council of Canada.

Brousseau, R., Arnott, M., and Dallaire, S. 1993. The adhesion of metallized zinc coatings on concrete. In Corrosion/93, no. 93331. Houston, TX: NACE.

Brousseau, R., Dallaire, S., Arnott, M., Baldock, B., and Allard, J. 1994b. Adhesion of thermally sprayed zinc on reinforced concrete. ILZRO Project Report ZE-399, Ottawa, Ontario: National Research Council of Canada. 
Bullard, S. J., Covino, B. S., Jr., Cramer, S. D., Holcomb, G. R., and McGill, G. E. 1997a. Bond strength of thermal-sprayed zinc on concrete during early electrochemical aging. In Corrosion/97, no. 97232. Houston, TX: NACE International.

Bullard, S. J., Cramer, S. D., Covino, B. S., Jr., Holcomb, G. R., McGill, G. E., Cryer, C. B., and Reis, R. 1997b. Thermal-sprayed zinc anodes: laboratory and field studies. In Expanding coatings knowledge worldwide, SSPC 97-09, pp. 309-319. Pittsburgh, PA: Steel Structures Painting Council.

Bullard, S. J., Cramer, S. D., Covino, B. S., Jr., Holcomb, G. R., McGill, G. E., and Reis, R. 1998. Thermal-sprayed anodes for cathodic protection of reinforced concrete bridges. In Concrete Under Severe Conditions 2-Environment and Loading, pp. 959-968. London, UK: E\&FN Spon.

Cairns, M. A. 1980. Estimation of chronically safe zinc concentrations with steelhead trout (Salmo gairdneri) emphasizing ventilatory responses, pp. 10-11. Masters Thesis, Oregon State University, Corvallis, OR.

Carde, C. and François, R. 1997. Effect of the leaching of calcium hydroxide from cement paste on mechanical and physical properties. Cement and concrete research 27(4): pp. 539-550.

Carello, R.A., and Parks, D. M. 1992. Cathodic Protection of Reinforced Concrete Bridge Deck and Soffit Using Metallized Zinc. Report no. FHWA/CA/TL-91/05, Sacramento CA: California Department of Transportation (CALTRANS).

Carello, R. A., Parks, D. M., and Apostolos, J. A. 1989. Development, testing, and field application of metallized cathodic protection coatings on reinforced concrete substructures. Report no. FHWA/CA/TL-89/04, Sacramento, CA: California Department of Transportation (CALTRANS).

Concrete repair digest. 1994. Vol. 6, no. 5: 292.

Concrete Society. 1989. Cathodic protection of reinforced concrete. Technical Report no. 36, London UK: Concrete Society/Corrosion Engineering Association.

Covino, B. S., Jr., Bullard, S. J., Holcomb, G. R., Cramer, S. D., McGill, G. E., and Cryer, C. B. 1995. Factors affecting the bonding of arc-sprayed zinc to concrete. In Balancing economics and compliance for maintaining protective coatings, p. 115. Pittsburgh, PA: Steel Structures Painting Council.

Covino, B. S., Jr., Bullard, S. J., Holcomb, G. R., Cramer, S. D., McGill, G. E., and Cryer, C. B. 1997a. Bond strength of electrochemically-aged arc-spray coatings on concrete. Corrosion 53(5): $399-411$.

Covino, B. S., Jr., Cramer, S. D., Holcomb, G. R., Bullard, S. J., and McGill, G. E. 1997b. Characterization of electrochemically-aged thermal spray titanium coatings on concrete. In Thermal Spray: A United Forum for Scientific and Technological Advances, ed. C.C. Berndt, pp. 151-160. Materials Park, OH: ASM International. 
Covino, B. S., Jr., Cramer, S. D., Holcomb, G. R., Bullard, S. J., and McGill, G. E.. 1997c. Corrosion failure of the Rocky Point viaduct-initial evaluation. In Proceedings of the 30th annual IMS convention, pp. 157-166. Materials Park, OH: International Metallographic Society.

Covino, B. S., Jr., Bullard, S. J., Cramer, S. D., Holcomb, G.R., McGill, G. E., Cryer, C. B., Stoneman, A., and Carter, R. R. 1997d. Interfacial Chemistry of Zinc Anodes for Reinforced Concrete Structures, Paper no. 97233, CORROSION/97, NACE International, Houston TX, 20 pp.

Covino, B. S., Jr., Cramer, S. D., Holcomb, G. R., Bullard, S. J., McGill, G. E., and Cryer, C. B. 1996a. Factors affecting thermal-sprayed zinc anodes on concrete. In Proceedings of the 13th International Corrosion Congress, vol. 1. Melbourne, Australia: Australasian Corrosion Association.

Covino, B. S., Jr., Cramer, S. D., Holcomb, G. R., Bullard, S. J., McGill, G. E., and Cryer, C. B. 1996b. Thermal-sprayed zinc anodes for cathodic protection of reinforced concrete structures In Materials for the New Millennium, ed. K. P. Chong, pp. 1512-1521. Washington, DC: American Society of Civil Engineers.

Covino, B. S., Jr, Russell, J. H., Bullard, S. J., Holcomb, G. R., and Cramer, S. D. 2000. Nondestructive evaluation of thermal spray cathodic protection anodes. Corrosion/2000, Paper no. 00811, Houston, TX: NACE International.

Cramer, S. D., Bullard, S. J., Covino, B. S., Jr., Holcomb, G. R., Russell, J. H., Cryer, C.B., and Laylor, H. M. 2002b. Carbon paint anode for reinforced concrete bridges in coastal environments. Corrosion/2002, Paper no. 02265, Houston TX: NACE International.

Cramer, S. D., Bullard, S. J., Holcomb, G. R., and Covino, B. S., Jr. 1998. Arc-sprayed titanium anode for cathodic protection of reinforcing steel in coastal concrete bridges. In Proceedings of the 30th annual IMS convention, pp. 89-100. Materials Park, OH: International Metallographic Society.

Cramer, S. D., Covino, B. S., Jr., Bullard, S. J., Holcomb, G. R., Russell, J. H., Nelson, F. J., Laylor, H. M., and Soltesz, S. M. 2002a. Corrosion prevention and remediation strategies for reinforced concrete coastal bridges. Journal of Cement and Concrete Composites, Vol. 24, No. 1, pp. 93-109.

Cramer, S. D., Covino, B. S., Jr., Holcomb, G. R., Bullard, S. J., Collins, W. K., Govier, R. D., Wilson, R. D., and Laylor, H. M. 1999. Thermal-sprayed titanium anode for cathodic protection of reinforced concrete bridges. Journal of Thermal Spray Technology 8(1): 133-145.

Cramer, S. D., Covino, B. S., Jr., Holcomb, G. R., Bullard, S. J., Dahlin, C. M., Summers, C. A., Laylor, H. M., and Soltesz, S. M. 2000. Evaluation of Rocky Point Viaduct Concrete BeamFinal Report. Project SPR 381, FHWA-OR-RD-00-18, Federal Highway Administration, Washington D.C. 80 pp.

Fontana, M. G. and Greene, N. D. 1978. Corrosion Engineering, 2nd ed., p. 207. New York, NY: McGraw-Hill Book Co. 
Gummow, R. A. 2001. Personal communication, available from S.D. Cramer, Albany Research Center, USDOE, 1450 Queen Avenue S.W., Albany OR 97321.

Holcomb, G. R. 1996. Countercurrent gaseous diffusion model of oxidation through a porous coating. Corrosion, 52(7): 531-539.

Holcomb, G.R., Bullard, S.J., Covino, B.S. Jr., Cramer, S.D., Cryer, C.B. and McGill, G.E. 1996. Electrochemical Aging of Thermal-Sprayed Zinc Anodes on Concrete, Proceedings of 9th National Thermal Spray Conference, in Thermal Spray: Practical Solutions for Engineering Problems, C.C. Berndt, Ed., ASM International, Metals Park, OH, pp. 185-192.

Holcomb, G. R. and Cryer, C. B. 1998. Cost of impressed current cathodic protection for coastal Oregon bridges. Materials Performance, 37(7): 22-26.

Howell, K. M. 1992. Evaluating bond strength of metal coatings over concrete surfaces. Materials Performance, 48(7): 29-32.

ILZRO. 1978. Galvanized reinforcement in concrete containing chlorides. International Lead and Zinc Research Organization, Research Triangle Park, NC, p. 12.

ILZRO. 1980. Galvanized reinforcement for concrete II. International Lead and Zinc Research Organization, Research Triangle Park, NC, p. 119.

Jackson, D. 1997. Cathodic bridge protection is more affordable than ever. Focus September: p. 5 .

Jafar, M.I., Dawson, J.L., and John, D. G. 1993. Electrochemical Impedance and Harmonic Analysis Measurements on Steel in Concrete, Electrochemical Impedance Analysis and Interpretation, STP 1188, J.R. Scully, D. C. Silverman, and M. W. Kendig, eds, American Society for Testing and Materials, Philadelphia, pp. 384-403.

Kramer, O. R. 1989. Feasibility of cathodic protection for reinforced concrete deck structure with two layers of reinforcing bar. In 3rd International Conference on Deterioration and Repair of Concrete in the Arabian Gulf, vol. 1, pp. 255-269. Bahrain: CIRIA.

Kubaschewski, O. and Hopkins, B. E. 1962. Oxidation of metals and alloys. pp. 215, 254.

London, UK: Butterworths.

Lynch, C. T., ed. 1989. Practical handbook of materials science. p. 190. Boca Raton, FL: CRC Press.

Mansfeld, F., Shih, H., Greene, H. and Tsai, C. H. 1993. Analysis of EIS Data for Common Corrosion Processes, Electrochemical Impedance Analysis and Interpretation, STP 1188, J.R. Scully, D. C. Silverman, and M. W. Kendig, eds, American Society for Testing and Materials, Philadelphia, pp. 384-403.

McGill, G. E., Cramer, S. D., Covino, B. S., Jr., Bullard, S. J., Holcomb, G. R., Collins, W. K., Govier, R. D., and Wilson, R. D. 1999. Field application of an arc-sprayed titanium anode for 
cathodic protection of reinforcing steel in concrete-final report. SPR 365, FHWA-OR-RD-9913. Washington, DC: Oregon Department of Transportation and Federal Highway Administration.

Mudd, C. J., Mussinelli, G. L., Tettamanti, M., and Pediferri, P. 1988. Cathodic protection of steel in concrete. Materials Performance 27(9): pp. 18-24.

Mussinelli, G., Tettamanti, M., and Pedeferri, P. 1987. The effect of current density on anode behavior and on concrete in the anode region. In 2nd international conference on deterioration and repair of reinforced concrete in the Arabian gulf, vol. 1, pp. 99-120. Bahrain: CIRIA.

NACE International. 1990. Cathodic Protection of Reinforcing Steel in Atmospherically Exposed Concrete Structures, Standard RP0290-90, NACE International, Houston TX, 11pp.

NACE International. 1996. Control of External Corrosion on Underground or Submerged Metallic Piping Systems, Standard RP0169-96, NACE International, Houston TX.

Ogino, C. and Yang, G-Y. 1978. Requirement of rainbow trout for dietary zinc. Bull. Jap. Soc. Sci. Fish. 44: 1015-1018.

Parks, D. M. 1990. Cathodic Protection through Silane Treated Concrete Laboratory Test Specimens, Report no. F89TL01-631147-39080, Sacramento CA: California Department of Transportation (CALTRANS).

Polland, J. S. and Page, J. A. 1988. Investigation of chloride migration in reinforced concrete under application of cathodic protection. Report no. ME-87-11, Downsview, Ontario: Ontario Ministry of Transportation.

Pourbaix, M. 1966. Atlas of electrochemical equilibria in aqueous solutions. New York, NY: Pergamon Press.

Powers, R. G., Sagues, A. A., and Murase, T. 1992. Sprayed-zinc-galvanic anodes for the cathodic protection of reinforcing steel in concrete. In Materials: performance and prevention of deficiencies and failures, ed. T. White, pp. 732-747. New York, NY: American Society of Civil Engineers.

Rogers, F. 2000. Benefits and technology developed to arc spray 3/16" (4.8 mm) diameter wires used for corrosion protection of steel. International Thermal Spray Conference 2000, May 2000, Montreal, Quebec, Canada.

Sagues, A. A. and Powers, R. G. 1995. Sprayed-zinc sacrificial anodes for reinforced concrete in marine service. In Corrosion/95, no. 95515, Houston, TX: NACE International.

Schell, H. C., Manning, D. G., and Clear, K. C. 1984. Cathodic protection of bridge substructures: Burlington Bay skyway test site, initial performance of systems 1 to 4. no. 962, pp. 38-50. Washington, DC: Transportation Research Record.

Shannon, R. D., 1976, Acta Crystal., A32:751-767 
Shreir, L. L. and Hayfield, P. C. S. 1986. Impressed current anodes. In Cathodic protection: theory and practice. eds. V. Ashworth and C. J. L. Booker. Chichester, UK: Ellis Horwood.

Skidmore, J. F. and Tovell, P. W. A. 1972. Toxic effects of zinc sulfate on the gills of rainbow trout. Water Res. 6: 217-230.

Smith, D. A., James B. Norman and Pieter T. Dykman. 1989. Historic Highway Bridges of Oregon, Oregon Historical Society Press, Portland OR, 323 pp.

Stratfull, R. F. 1959. Progress report on inhibiting the corrosion of steel in a concrete bridge. Corrosion 15(6): 331t-334t.

Uhlig, H. H. 1977. Corrosion and corrosion control, 2nd ed. New York, NY: John Wiley \& Sons.

U.S. Bureau of Labor Statistics. 1997. Consumer Price Index for all Urban Consumers, Series CUUROOOOSAO. Washington, DC: U.S. Department of Labor.

U.S. FHWA-SHRP. 1995. Showcase Workshop on Concrete Durability, FHWA-SA-96-025. Washington, DC: U.S. Department of Transportation.

Vrable, J. B. 1977. Cathodic protection for reinforced concrete bridge decks. NCHRP Report 180. Washington, DC: Transportation Research Board.

Weale, C. J. 1992. Cathodic protection of reinforced concrete anodic processes in cements and related electrolytes. Thesis no. DX 185652. West Yorkshire, UK: The British Library.

Weast, R. C., ed. 1979, CRC handbook of chemistry and physics, 60th ed., pp. D187-D188. Cleveland, OH: The Chemical Rubber Company.

West, R. E. and Hime, W. G. 1985. Chloride profiles in salty concrete. Materials performance 24(7): 29-37.

Whiting, D. and Cady, P. D. 1993. Method for field measurement of concrete permeability. In Condition evaluation of concrete bridges relative to reinforcement corrosion. vol. 7, SHRP-S329. Washington, DC: Strategic Highway Research Program, National Research Council.

Wyatt, B. S. 1989. Anode systems for cathodic protection of reinforced concrete. Paper read at $2^{\text {nd }}$ International Conference of Cathodic protection-theory and practice, Paper no. 23, 26-28 June 26-28, 1989, Stratford-upon-Avon, UK.

Yeomans, S. R. 1993. Considerations of the characteristics and use of coated steel reinforcement in concrete. NISTIR report number 5211; Washington, DC: NIST, U.S. Department of Commerce.

Zhang, X. G. 1996. Corrosion and Electrochemistry of Zinc, Plenum Press, New York NY, 474 pp. 


\section{APPENDICES}





\section{APPENDIX A: TABULATED LABORATORY BOND STRENGTH MEASUREMENTS}





\section{Appendix A: Tabulated Laboratory Bond Strength Measurements}

\begin{tabular}{|c|c|c|c|}
\hline Concrete Slab No. & $\begin{array}{l}\text { Electrochemical Age, } \\
\mathrm{kC} / \mathrm{m}^{2}\end{array}$ & $\begin{array}{l}\text { Equivalent Anode Age } \\
\text { @ } 0.2 \mathrm{ma} / \mathrm{ft}^{2}, \text { years }\end{array}$ & $\begin{array}{c}\text { Anode Bond Strength, } \\
\mathrm{MPa}(\mathrm{psi})\end{array}$ \\
\hline \multicolumn{4}{|c|}{ Periodically-wetted, preheated concrete slabs containing 5 pcy NaCl: } \\
\hline 1 & 0.0 & 0.0 & $1.97(285.9)$ \\
\hline 2 & 0.0 & 0.0 & $2.60(376.7)$ \\
\hline 5 & 48.8 & 0.6 & $1.46(212.3)$ \\
\hline 17 & 104.4 & 1.2 & $1.54(224.0)$ \\
\hline 12 & 153.3 & 1.8 & $1.85(269.0)$ \\
\hline 11 & 203.3 & 2.4 & $2.03(294.2)$ \\
\hline 21 & 266.0 & 3.2 & $2.70(391.8)$ \\
\hline 25 & 294.8 & 3.5 & $1.73(251.6)$ \\
\hline 6 & 338.9 & 4.1 & $3.07(444.8)$ \\
\hline 3 & 383.88 & 4.6 & $3.69(534.8)$ \\
\hline 23 & 423.5 & 5.1 & $1.98(287.3)$ \\
\hline 15 & 460.2 & 5.5 & $2.44(354.5)$ \\
\hline 10 & 496.3 & 5.9 & $2.56(371.9)$ \\
\hline 18 & 541.6 & 6.5 & $3.02(437.7)$ \\
\hline 14 & 621.1 & 7.4 & $3.00(435.5)$ \\
\hline 20 & 783.4 & 9.4 & $3.52(511.1)$ \\
\hline 4 & 793.3 & 9.5 & $2.00(289.9)$ \\
\hline 8 & 887.8 & 10.6 & $1.43(206.7)$ \\
\hline 22 & 1102.0 & 13.2 & 2.74 (397.6) \\
\hline 13 & 1111.3 & 13.3 & $1.33(193.1)$ \\
\hline 19 & 1289.5 & 15.4 & 0.95 (137.9) \\
\hline 7 & 1536.9 & 18.4 & $0.16(23.4)$ \\
\hline 24 & 1536.9 & 18.4 & $0.61(88.3)$ \\
\hline 16 & 1636.4 & 19.6 & $0.12(17.9)$ \\
\hline
\end{tabular}




\begin{tabular}{|c|c|c|c|}
\hline Concrete Slab No. & $\begin{array}{l}\text { Electrochemical Age, } \\
\mathrm{kC} / \mathrm{m}^{2}\end{array}$ & $\begin{array}{l}\text { Equivalent Anode Age } \\
@ 0.2 \mathrm{ma} / \mathrm{ft}^{2} \text {, years }\end{array}$ & $\begin{array}{c}\text { Anode Bond Strength, } \\
\mathrm{MPa}(\mathrm{psi})\end{array}$ \\
\hline \multicolumn{4}{|c|}{ Periodically-wetted, unheated concrete slabs containing 5 pcy NaCl: } \\
\hline 26 & 0.0 & 0.0 & $1.36(197.2)$ \\
\hline 27 & 0.0 & 0.0 & $1.19(172.8)$ \\
\hline 32 & 54.7 & 0.7 & $1.11(160.5)$ \\
\hline 28 & 106.21 & 1.3 & $1.09(158.7)$ \\
\hline 43 & 153.68 & 1.8 & $1.65(239.8)$ \\
\hline 41 & 202.1 & 2.4 & $1.90(275.2)$ \\
\hline 31 & 266.0 & 3.2 & $1.72(249.1)$ \\
\hline 34 & 298.57 & 3.6 & $1.53(221.6)$ \\
\hline 39 & 346.9 & 4.2 & $2.42(350.9)$ \\
\hline 30 & 429.0 & 5.1 & $1.68(244.0)$ \\
\hline 38 & 444.0 & 5.3 & $2.83(410.8)$ \\
\hline 36 & 492.1 & 5.9 & 3.14454 .9() \\
\hline 49 & 582.5 & 7.0 & $3.06(443.9)$ \\
\hline 50 & 632.9 & 7.6 & $3.40(492.4)$ \\
\hline 40 & 687.12 & 8.2 & $2.95(428.2)$ \\
\hline 42 & 816.5 & 9.8 & $2.66(385.3)$ \\
\hline 33 & 916.9 & 11.0 & $2.09(302.6)$ \\
\hline 37 & 971.1 & 11.6 & $1.29(186.6)$ \\
\hline 46 & 1092.2 & 13.1 & $0.94(135.7)$ \\
\hline 29 & 1195.4 & 14.3 & $1.28(186.1)$ \\
\hline 47 & 1286.2 & 15.4 & $1.42(205.5)$ \\
\hline 35 & 1468.7 & 17.6 & 0.0 - delaminated \\
\hline 44 & 1563.3 & 18.7 & 0.0 - delaminated \\
\hline 48 & 1663.6 & 19.9 & $0.12(17.8)$ \\
\hline
\end{tabular}




\begin{tabular}{|c|c|c|c|}
\hline Concrete Slab No. & $\begin{array}{l}\text { Electrochemical Age, } \\
\mathrm{kC} / \mathrm{m}^{2}\end{array}$ & $\begin{array}{c}\text { Equivalent Anode Age } \\
\text { @ } 0.2 \mathrm{ma} / \mathrm{ft}^{2} \text {, years }\end{array}$ & $\begin{array}{c}\text { Anode Bond Strength, } \\
\mathrm{MPa}(\mathrm{psi})\end{array}$ \\
\hline \multicolumn{4}{|c|}{ Periodically-wetted, preheated concrete slabs containing 2 pcy NaCl: } \\
\hline 55 & 429.9 & 5.1 & $330.7(2.28)$ \\
\hline 57 & 582.5 & 7.0 & $263.1(1.81)$ \\
\hline 56 & 1011.5 & 12.1 & $261.3(1.80)$ \\
\hline 53 & 1111.3 & 13.3 & $149.5(1.03)$ \\
\hline 54 & 1211.6 & 14.5 & $24.9(0.17)$ \\
\hline 52 & 1590.1 & 19.0 & 0.0 - delaminated \\
\hline 51 & 1690.0 & 20.2 & $30.0(0.21)$ \\
\hline \multicolumn{4}{|c|}{ Periodically-wetted, unheated concrete slabs containing 2 pcy NaCl: } \\
\hline 58 & 582.5 & 7.0 & $1.27(184.5)$ \\
\hline 59 & 1590.1 & 19.0 & 0.0 - delaminated \\
\hline \multicolumn{4}{|c|}{ Unwetted, preheated, concrete slabs containing 5 pcy NaCl: } \\
\hline 100 & 0.0 & 0.0 & $1.97(285.7)$ \\
\hline 101 & 0.0 & 0.0 & $1.57(228.2)$ \\
\hline 110 & 0.0 & 0.0 & $2.18(316.2)$ \\
\hline 108 & 14.5 & 0.2 & $2.07(300.4)$ \\
\hline 105 & 27.0 & 0.4 & $2.10(305.0)$ \\
\hline 102 & 37.5 & 0.6 & $2.42(351.5)$ \\
\hline 109 & 51.1 & 0.8 & $2.67(387.6)$ \\
\hline 104 & 75.0 & 1.1 & $2.32(336.5)$ \\
\hline 103 & 99.0 & 1.5 & $2.49(360.5)$ \\
\hline 106 & 187.5 & 2.8 & $1.61(233.3)$ \\
\hline
\end{tabular}




\begin{tabular}{c|c|c|c}
\hline Concrete Slab No. & $\begin{array}{c}\text { Electrochemical Age, } \\
\mathrm{kC} / \mathrm{m}^{2}\end{array}$ & $\begin{array}{c}\text { Equivalent Anode Age } \\
\text { @ } 0.2 \mathrm{ma} / \mathrm{ft}^{2}, \text { years }\end{array}$ & $\begin{array}{c}\text { Anode Bond Strength, } \\
\mathrm{MPa}(\mathrm{psi})\end{array}$ \\
\hline \multicolumn{4}{|c}{ Unwetted, unheated concrete slabs containing 5 pcy $\mathrm{NaCl}:$} \\
\hline 116 & 0 & 0 & $1.60(231.4)$ \\
\hline 117 & 0 & 0 & $1.70(246.1)$ \\
\hline 126 & 0 & 0 & $1.88(272.2)$ \\
\hline 121 & 14.5 & 0.2 & $1.89(273.9)$ \\
\hline 119 & 27.0 & 0.4 & $1.54(223.1)$ \\
\hline 124 & 37.5 & 0.6 & $2.11(305.6)$ \\
\hline 120 & 51.1 & 0.8 & $1.34(193.9)$ \\
\hline 118 & 75.0 & 1.1 & $1.01(146.0)$ \\
\hline 125 & 99.0 & 1.5 & $1.70(246.6)$ \\
\hline 123 & 187.5 & 2.8 & $0.62(90.1)$ \\
\hline
\end{tabular}

Unwetted, preheated concrete slabs containing $5 \mathrm{pcy} \mathrm{NaCl}$, natural aging:

\begin{tabular}{c|c|c|c}
\hline 111 & 0 & 70 days & $2.42(351.4)$ \\
\hline 113 & 0 & 147 days & $3.01(437.3)$ \\
\hline 115 & 0 & 147 days & $2.84(412.1)$ \\
\hline 112 & 0 & 651 days & $2.91(422.9)$ \\
\hline
\end{tabular}

Unwetted, unheated concrete slabs containing 5 pcy NaCl, natural aging:

\begin{tabular}{c|c|c|c}
\hline 130 & 0 & 70 days & $1.85(268.1)$ \\
\hline 128 & 0 & 651 days & $2.38(345.6)$ \\
\hline 127 & $? ?$ & & \\
\hline
\end{tabular}

Unwetted, preheated concrete slabs containing 5 pcy NaCl, No Zn, sandblasted:

\begin{tabular}{l|l|l|l}
\hline 132 & 0 & 0 & $2.99(433.3)$ \\
\hline 133 & 0 & 0 & $2.67(387.9)$ \\
\hline
\end{tabular}

Unwetted, unheated concrete slabs containing 5 pcy NaCl, No Zn, sandblasted:

\begin{tabular}{l|l|l|l}
\hline 134 & 0 & 0 & $3.17(459.7)$ \\
\hline 135 & 0 & 0 & $3.18(461.6)$ \\
\hline
\end{tabular}

Unwetted, unheated concrete slabs containing 5 pcy NaCl, No Zn, No sandblast:

\begin{tabular}{c|c|c|c}
\hline 136 & 0 & 0 & $2.18(316.6)$ \\
\hline 137 & 0 & 0 & $3.07(445.4)$ \\
\hline
\end{tabular}




\section{APPENDIX B: TABULATED INITIAL FIELD BOND STRENGTH AND COATING THICKNESS MEASUREMENTS}





\section{Appendix B: Tabulated Initial Field Bond Strength and Coating Thickness Measurements}

\begin{tabular}{|c|c|c|c|c|}
\hline Date & Location & Zone & psi & Mils \\
\hline $03 / 30 / 93$ & West arch west side between col 2 and 3 & 19 & 192 & 26 \\
\hline$\overline{04 / 06 / 93}$ & West col 5 sidewalk support south face & 19 & 167 & 26 \\
\hline $03 / 30 / 93$ & North pedestal of col 4 west side & 19 & 229 & 20 \\
\hline$\overline{04 / 06 / 93}$ & West col 5 sidewalk support south face & 19 & 281 & 18 \\
\hline $03 / 22 / 93$ & Col 4 west north face of arch pedestal & 19 & 192 & 22 \\
\hline$\overline{04 / 01 / 93}$ & East face of west arch between pier $8 \& \operatorname{col} 2$ & 19 & 281 & 23 \\
\hline$\overline{04 / 01 / 93}$ & West side of west half of strut 2 & 19 & 81 & 35 \\
\hline$\overline{03 / 26 / 93}$ & Col 2 east face west col & 19 & 155 & 22 \\
\hline$\overline{04 / 01 / 93}$ & North face west col 26.5 from flare & 19 & 196 & 19 \\
\hline$\overline{03 / 29 / 93}$ & Col 3 west near stage floor near col flare & 19 & 285 & 32 \\
\hline$\overline{04 / 06 / 93}$ & West col 4 side walk support south face & 19 & 192 & 20 \\
\hline $03 / 30 / 93$ & West col 3 west face & 19 & 148 & 20 \\
\hline$\overline{04 / 01 / 93}$ & East face of east arch near pier 8 & 20 & 170 & 19 \\
\hline$\overline{03 / 29 / 93}$ & Col 2 east, south face above pedestal & 20 & 189 & 22 \\
\hline$\overline{04 / 05 / 93}$ & East col 4 arch pedestal south face & 20 & 170 & 30 \\
\hline$\overline{04 / 05 / 93}$ & East sidewalk beam bay 1 & 20 & 229 & 20 \\
\hline$\overline{04 / 05 / 93}$ & South side walk bracket col 6 east & 20 & 270 & 19 \\
\hline$\overline{04 / 02 / 93}$ & East face of east arch between col 2 and 3 & 20 & 199 & 18 \\
\hline$\overline{04 / 02 / 93}$ & Col 2 east face from level 7 & 20 & 159 & 18 \\
\hline$\overline{04 / 02 / 93}$ & East arch top between pier $8 \& \operatorname{col} 2$ & 20 & 288 & 19 \\
\hline$\overline{03 / 29 / 93}$ & Col 2 east, south face on pedestal & 20 & 229 & 23 \\
\hline $03 / 23 / 93$ & Col 5 arch pedestal south face (east) & 20 & 107 & 20 \\
\hline$\overline{04 / 05 / 93}$ & East col 4 stage floor to arch pedestal east & 20 & 148 & 24 \\
\hline$\overline{04 / 09 / 93}$ & Bay 4 beam 1 bottom & 22 & 263 & 22 \\
\hline $04 / 08 / 93$ & Bay 5 west soffit & 22 & 130 & 25 \\
\hline $04 / 07 / 93$ & Bay 1 beam 3 west face & 22 & 192 & 25 \\
\hline$\overline{04 / 08 / 93}$ & Bay 6 beam 1 west face & 22 & 199 & 33 \\
\hline$\overline{04 / 07 / 93}$ & Bay 1 beam 2 east face & 22 & 226 & 25 \\
\hline $04 / 08 / 93$ & Bay 2 beam 4 west face & 22 & 266 & 20 \\
\hline$\overline{04 / 09 / 93}$ & Bay 3 beam 5 east face & 22 & 369 & 21 \\
\hline$\overline{04 / 09 / 93}$ & North face of col 6 web beam & 22 & 281 & 21 \\
\hline$\overline{04 / 09 / 93}$ & Bay 3 beam 2 bottom & 22 & 159 & 24 \\
\hline $04 / 09 / 93$ & Bay 2 beam 1 east face & 22 & 207 & 29 \\
\hline$\overline{04 / 07 / 93}$ & Bay 1 beam 1 east face & 22 & 295 & 25 \\
\hline
\end{tabular}




\section{Yaquina Bay Bridge}

\begin{tabular}{|c|c|c|c|c|}
\hline Date & Location & Zone & psi & Mils \\
\hline $04 / 09 / 93$ & Nw part of soffit of bay 2 & 22 & 273 & 26 \\
\hline$\overline{04 / 06 / 93}$ & Deck section bay 1 beam 3 west face & 22 & 255 & 22 \\
\hline $04 / 09 / 93$ & Bay 3 deck sec between beams 3 and 4 & 22 & 233 & 23 \\
\hline $05 / 17 / 93$ & North face pier 8 middle arch & 23 & 229 & 27 \\
\hline $05 / 25 / 93$ & West top of arch between col 9 an 10 & 23 & 236 & 24 \\
\hline $05 / 19 / 93$ & Strut 11 southwest side & 23 & 189 & 27 \\
\hline $05 / 18 / 93$ & West face pier 8 near level 3 & 23 & 170 & 22 \\
\hline$\overline{05 / 20 / 93}$ & Col 11 north face near level 7 & 23 & 332 & 26 \\
\hline $05 / 20 / 93$ & Col 11 west face of pedestal & 23 & 159 & 22 \\
\hline $05 / 26 / 93$ & Arch east face col 10 to $\operatorname{col} 9$ & 24 & 181 & 20 \\
\hline $05 / 27 / 93$ & Arch east face, col 8 to $\operatorname{col} 7$ & 24 & 155 & 21 \\
\hline $05 / 27 / 93$ & Arch east face, col 8 to col 9 & 24 & 295 & 19 \\
\hline $05 / 27 / 93$ & Col 8 south face & 24 & 192 & 19 \\
\hline$\overline{05 / 24 / 93}$ & West face of east col 10 near level 9 & 24 & 236 & 24 \\
\hline $05 / 17 / 93$ & West face pier 8 column & 24 & 126 & 31 \\
\hline $05 / 25 / 93$ & East col 10 arch pedestal north face & 24 & 236 & 20 \\
\hline $05 / 20 / 93$ & Col 11 east face near arch pedestal & 24 & 185 & 25 \\
\hline $05 / 25 / 93$ & Strut $\# 9$ southeast face & 24 & 140 & 25 \\
\hline $05 / 25 / 93$ & Strut \#9 southeast face & 24 & 163 & 23 \\
\hline$\overline{07 / 21 / 93}$ & Col 3-4 arch west face & 25 & 115 & 32 \\
\hline $07 / 27 / 93$ & Col 3 web beam $w$ face & 25 & 163 & 21 \\
\hline $07 / 20 / 93$ & Col 4 arch pedestal east face & 25 & 103 & 21 \\
\hline $07 / 12 / 93$ & South face pier 7 column & 25 & 196 & 18 \\
\hline $07 / 12 / 93$ & East face of pier 7 column & 25 & 199 & 20 \\
\hline $07 / 13 / 93$ & West face of pier 7 & 25 & 299 & 19 \\
\hline$\overline{07 / 19 / 93}$ & Col 2west face & 25 & 81 & 22 \\
\hline $07 / 28 / 93$ & Col 2 web beam $n$ face & 25 & 126 & 24 \\
\hline $07 / 14 / 93$ & Arch bottom between pier 7 and col 2 & 25 & 107 & 23 \\
\hline $07 / 27 / 93$ & Col 6 web beam s face & 25 & 222 & 20 \\
\hline $07 / 16 / 93$ & Col 3 stage floor to col flare north face & 26 & 177 & 23 \\
\hline $07 / 15 / 93$ & Arch west face between col 2 and col 3 & 26 & 133 & 21 \\
\hline $07 / 22 / 93$ & Col 5 web beam s face & 26 & 177 & 23 \\
\hline $07 / 15 / 93$ & Column 2 south face & 26 & 78 & 21 \\
\hline $07 / 14 / 93$ & Inter rib strut bottom at col 2 & 26 & 118 & 21 \\
\hline $07 / 12 / 93$ & East face of pier column & 26 & 214 & 21 \\
\hline $07 / 19 / 93$ & Col 2 east face & 26 & 199 & 24 \\
\hline $07 / 09 / 93$ & Top middle of web wall & 26 & 181 & 19 \\
\hline $07 / 21 / 93$ & Col 4 s face 8.6 above pedestal & 26 & 199 & 20 \\
\hline
\end{tabular}




\begin{tabular}{|c|c|c|c|c|}
\hline \multicolumn{5}{|c|}{ Yaquina Bay Bridge } \\
\hline Date & Location & Zone & psi & Mils \\
\hline $07 / 16 / 93$ & Col 3 column flare north face & 26 & 185 & 23 \\
\hline$\overline{07 / 15 / 93}$ & Column 2 south face & 26 & 107 & 24 \\
\hline $07 / 27 / 93$ & Col 2 web beam $\mathrm{s}$ face & 26 & 159 & 20 \\
\hline $07 / 15 / 93$ & Col 2 arch pedestal south face & 26 & 74 & 24 \\
\hline$\overline{07 / 21 / 93}$ & Col 6 mid span arch $w$ face & 26 & 85 & 23 \\
\hline $07 / 19 / 93$ & Col 3 arch pedestal east face & 26 & 170 & 23 \\
\hline $05 / 28 / 93$ & Col 11 east sidewalk support south face & 27 & 303 & 21 \\
\hline $05 / 28 / 93$ & South face col 11 web beam & 27 & 189 & 24 \\
\hline $06 / 01 / 93$ & Bay 9 beam 3 bottom & 27 & 222 & 24 \\
\hline $05 / 28 / 93$ & Bay 11 deck between beams 4 and 5 & 27 & 325 & 19 \\
\hline $05 / 27 / 93$ & Bay 11 east sidewalk beam west face & 27 & 167 & 22 \\
\hline $06 / 01 / 93$ & Bay 10 beam 2 bottom & 27 & 236 & 22 \\
\hline $06 / 01 / 93$ & Bay 10 beam 2 west & 27 & 214 & 19 \\
\hline $05 / 28 / 93$ & Bay 11 west sidewalk beam & 27 & 181 & 20 \\
\hline $06 / 01 / 93$ & Bay 10 beam 5 east face & 27 & 277 & 23 \\
\hline $06 / 03 / 93$ & Bay 6 beam 3 east & 28 & 303 & 20 \\
\hline $06 / 02 / 93$ & Column 7 south face & 28 & 214 & 18 \\
\hline $06 / 02 / 93$ & Bay 8 beam 2 east face & 28 & 362 & 20 \\
\hline $06 / 03 / 93$ & Bay 6 beam 2 west & 28 & 203 & 19 \\
\hline $06 / 03 / 93$ & Bay 6 beam 1 bottom & 28 & 189 & 18 \\
\hline $06 / 03 / 93$ & Bay 6 sidewalk soffit west & 28 & 163 & 19 \\
\hline $07 / 22 / 93$ & Bay 5 east beam bottom & 29 & 285 & 18 \\
\hline $07 / 26 / 93$ & Bay 5 west sidewalk beam & 29 & 130 & 47 \\
\hline $07 / 26 / 93$ & Bay 4 west sidewalk beam & 29 & 159 & 24 \\
\hline $07 / 22 / 93$ & Bay 5 east beam e face & 29 & 207 & 18 \\
\hline $07 / 22 / 93$ & Col 6 east sidewalk s face & 29 & 174 & 20 \\
\hline $07 / 23 / 93$ & Bay 5 middle beam bottom & 29 & 207 & 22 \\
\hline $07 / 23 / 93$ & Bay 2 e soffit & 30 & 115 & 22 \\
\hline $07 / 26 / 93$ & Bay 3 e middle beam $w$ face & 30 & 177 & 25 \\
\hline $07 / 28 / 93$ & Bay 1 west beam e face & 30 & 189 & 25 \\
\hline $07 / 27 / 93$ & Bay 2 beam 4 e face & 30 & 159 & 22 \\
\hline $07 / 27 / 93$ & Bay 2 beam 2 e face & 30 & 130 & 30 \\
\hline $07 / 26 / 93$ & Bay 3 east middle beam e face & 30 & 81 & 24 \\
\hline $07 / 27 / 93$ & Col 3 web beam $n$ face & 30 & 218 & 23 \\
\hline $09 / 02 / 93$ & col 9 west face & 31 & 192 & 21 \\
\hline $09 / 01 / 93$ & col 10 arch west face & 31 & 70 & 26 \\
\hline $09 / 01 / 93$ & col 9 strut south face & 31 & 133 & 21 \\
\hline $09 / 01 / 93$ & col 9 south face & 31 & 255 & 41 \\
\hline
\end{tabular}




\begin{tabular}{|c|c|c|c|c|}
\hline Date & Location & Zone & psi & Mils \\
\hline $09 / 01 / 93$ & col 9 north face & 31 & 189 & 22 \\
\hline $08 / 31 / 93$ & pier 7 - col 11 arch top & 31 & 226 & 24 \\
\hline $09 / 01 / 93$ & col 10- 9 arch east face & 31 & 137 & 20 \\
\hline $09 / 01 / 93$ & col 9 strut bottom south face & 31 & 214 & 24 \\
\hline $08 / 31 / 93$ & col 10 east face & 31 & 192 & 30 \\
\hline $08 / 31 / 93$ & col 11 arch north face & 31 & 263 & 20 \\
\hline $08 / 31 / 93$ & col 11 east face & 31 & 218 & 19 \\
\hline $09 / 03 / 93$ & col 11 web beam west face & 31 & 115 & 24 \\
\hline $09 / 02 / 93$ & col 10 ???? & 31 & 218 & 20 \\
\hline $09 / 02 / 93$ & col 10 west face & 31 & 177 & 20 \\
\hline $08 / 31 / 93$ & col 11 south face & 31 & 240 & 23 \\
\hline $08 / 30 / 93$ & col 11 pedestal east face & 32 & 155 & 20 \\
\hline $08 / 31 / 93$ & col 10 south face & 32 & 214 & 27 \\
\hline $08 / 30 / 93$ & col 11 north face & 32 & 181 & 20 \\
\hline $09 / 02 / 93$ & col 11 web beam east & 32 & 203 & 22 \\
\hline $09 / 01 / 93$ & col 9 north face & 32 & 148 & 32 \\
\hline $09 / 02 / 93$ & col 11 east face & 32 & 155 & 18 \\
\hline $08 / 31 / 93$ & col 11 west face & 32 & 177 & 19 \\
\hline $09 / 01 / 93$ & col 10 strut bottom (1'-8") & 32 & 159 & 20 \\
\hline $09 / 02 / 93$ & col 9 east face & 32 & 244 & 18 \\
\hline $09 / 02 / 93$ & col 11 east face & 32 & 163 & 19 \\
\hline $08 / 31 / 93$ & col 11 north face & 32 & 192 & 20 \\
\hline $08 / 31 / 93$ & col 10 strut top (1'-8") & 32 & 159 & 20 \\
\hline $09 / 01 / 93$ & col 9 west face & 32 & 100 & 23 \\
\hline $09 / 01 / 93$ & col 10 strut bottom (1'-8") & 32 & 148 & 22 \\
\hline$\overline{08 / 30 / 93}$ & col 11 arch east face & 32 & 140 & 21 \\
\hline $08 / 31 / 93$ & col 10 west face & 32 & 126 & 27 \\
\hline $10 / 07 / 93$ & West arch, column 7 to column 6 arch bottom & 33 & 89 & 22 \\
\hline$\overline{10 / 07 / 93}$ & West arch, column 7 to column 6 arch bottom & 33 & 181 & 21 \\
\hline $10 / 14 / 93$ & north face column 8 web beam & 33 & 270 & 22 \\
\hline$\overline{10 / 13 / 93}$ & West column 8 stage floor to arch, north face & 33 & 207 & 26 \\
\hline $10 / 08 / 93$ & East arch, column 8 to column 7 west face & 33 & 189 & 28 \\
\hline $10 / 07 / 93$ & East arch, column 9 to column 8 , arch west face & 33 & 181 & 21 \\
\hline $10 / 07 / 93$ & East arch between col 6 and 5 west face & 33 & 218 & 19 \\
\hline$\overline{10 / 07 / 93}$ & East column 8 stage floor to arch east face & 33 & 220 & 19 \\
\hline $10 / 14 / 93$ & north face column 8 web beam & 33 & 355 & 20 \\
\hline $10 / 13 / 93$ & West column 6 web beam section north face & 33 & 226 & 19 \\
\hline$\overline{10 / 07 / 93}$ & East arch column 7 to column 6 arch bottom & 33 & 118 & 20 \\
\hline
\end{tabular}




\section{Yaquina Bay Bridge}

\begin{tabular}{|c|c|c|c|c|}
\hline Date & Location & Zone & psi & Mils \\
\hline$\overline{10 / 07 / 93}$ & East arch, column 9 to column 8 , arch top & 33 & 115 & 22 \\
\hline$\overline{10 / 13 / 93}$ & Bottom face column 8 web beam & 33 & 249 & 18 \\
\hline$\overline{10 / 08 / 93}$ & west arch, column 7 to column 6 , arch east face & 33 & 174 & 22 \\
\hline$\overline{10 / 07 / 93}$ & East arch, column 9 to column 8 , arch top & 33 & 133 & 19 \\
\hline $10 / 13 / 93$ & West column 8 web beam section north face & 33 & 255 & 25 \\
\hline $10 / 14 / 93$ & East column 6 stage floor to arch south face & 33 & 111 & 40 \\
\hline $10 / 07 / 93$ & West arch, column 9 to column 8 , arch top & 33 & 126 & 28 \\
\hline $10 / 08 / 93$ & East col 8 stage floor to arch west face & 33 & 118 & 23 \\
\hline$\overline{12 / 02 / 93}$ & Column 2, elev 66.05 to 58.05 east face & 34 & 189 & 24 \\
\hline$\overline{12 / 09 / 93}$ & Column 4 south face & 34 & 281 & 22 \\
\hline $11 / 30 / 93$ & Arch between pier 6 and col 2 west face & 34 & 203 & 23 \\
\hline$\overline{11 / 30 / 93}$ & Arch between pier 6 and col 2 east face & 34 & 155 & 23 \\
\hline$\overline{12 / 09 / 93}$ & Arch between col 3 and col 4 top & 34 & 329 & 20 \\
\hline$\overline{12 / 03 / 93}$ & Column 2, arch pedestal, south face & 34 & 266 & 22 \\
\hline$\overline{12 / 09 / 93}$ & Column 4 east face & 34 & 155 & 22 \\
\hline$\overline{12 / 02 / 93}$ & Column 2, elev 74.05 to 66.05 north face & 34 & 189 & 22 \\
\hline $12 / 03 / 93$ & Column 2 , elev 82.05 to 74.05 south face & 34 & 236 & 21 \\
\hline$\overline{12 / 02 / 93}$ & Column 2, elev 58.05 to arch pedestal north face & 34 & 167 & 19 \\
\hline $11 / 30 / 93$ & South face pier 6 top mid. arch web wall & 35 & 196 & 20 \\
\hline$\overline{12 / 02 / 93}$ & Column 2, elev 66.05 to 58.05 east face & 35 & 122 & 29 \\
\hline$\overline{12 / 06 / 93}$ & Column 2 inter rib strut top edge & 35 & 209 & 30 \\
\hline$\overline{11 / 21 / 93}$ & West face pier 6 elev 35.93 to 43.93 & 35 & 137 & 25 \\
\hline$\overline{11 / 21 / 93}$ & West face arch pedestal lower triangle & 35 & 189 & 23 \\
\hline$\overline{12 / 15 / 93}$ & Column 3 web beam section north face & 35 & 207 & 25 \\
\hline$\overline{12 / 09 / 93}$ & Arch bottom col 4 to col 5 north half & 35 & 362 & 21 \\
\hline$\overline{12 / 02 / 93}$ & South face pier 6 col., elev 90.99 to boot $\mathrm{m}$ stage floor & 35 & 133 & 24 \\
\hline $12 / 09 / 93$ & Column 489.54 to arch pedestal north face & 35 & 247 & 19 \\
\hline$\overline{12 / 07 / 93}$ & Column 3 elev 73.12 to arch pedestal east face & 35 & 295 & 23 \\
\hline $12 / 03 / 93$ & Arch between col 2 and col 3 east face & 35 & 229 & 20 \\
\hline$\overline{12 / 07 / 93}$ & Column 3 column flare to elev 81.12 (flare- $8 \mathrm{ft}$ ) east face & 35 & 233 & 27 \\
\hline $12 / 03 / 93$ & Column 2 , elev 82.05 to 74.05 west face & 35 & 89 & 23 \\
\hline $11 / 23 / 93$ & West face pier 6 pedestal & 35 & 167 & 24 \\
\hline $12 / 06 / 93$ & Column 3 stage floor to $\mathrm{n} / \mathrm{s}$ column flare west face & 35 & 310 & 22 \\
\hline $11 / 29 / 93$ & North face pier 6 top mid arch web wall & 35 & 111 & 24 \\
\hline $09 / 09 / 93$ & bay 8 east middle beam east face & 36 & 233 & 21 \\
\hline $09 / 08 / 93$ & bay 8 west beam west face & 36 & 155 & 19 \\
\hline $09 / 08 / 93$ & beam 2 bottom bay 9 & 36 & 189 & 19 \\
\hline$\overline{09 / 08 / 93}$ & bay 8 deck between beam $2 \& 3$ & 36 & 170 & 27 \\
\hline
\end{tabular}




\section{Yaquina Bay Bridge}

\begin{tabular}{|c|c|c|c|c|}
\hline Date & Location & Zone & psi & Mils \\
\hline $09 / 08 / 93$ & col 9 west sidewalk support north face & 36 & 199 & 24 \\
\hline$\overline{09 / 08 / 93}$ & bay 9 beam 5 west face & 36 & 307 & 23 \\
\hline $09 / 09 / 93$ & bay 8 east beam west face & 36 & 177 & 27 \\
\hline $09 / 02 / 93$ & bay 8 east beam east face & 36 & 81 & 24 \\
\hline $09 / 09 / 93$ & bay 8 middle beam east face & 36 & 214 & 25 \\
\hline $09 / 07 / 93$ & col 10 west sidewalk south face & 36 & 107 & 23 \\
\hline $09 / 09 / 93$ & bay 8 east middle beam bottom & 36 & 203 & 24 \\
\hline$\overline{09 / 08 / 93}$ & bay 8 west sidewalk beam & 36 & 199 & 26 \\
\hline $09 / 08 / 93$ & bay 10 deck between beam $3 \& 4$ & 36 & 299 & 20 \\
\hline $09 / 08 / 93$ & bay 9 deck between beams $2 \& 3$ & 36 & 163 & 21 \\
\hline $10 / 13 / 93$ & East column 6 web beam section east face & 37 & 159 & 21 \\
\hline $10 / 14 / 93$ & Bay 7 beam 2 east face & 37 & 291 & 21 \\
\hline $10 / 15 / 93$ & bottom face col 6 web beam & 37 & 226 & 29 \\
\hline$\overline{10 / 14 / 93}$ & Bay 6 beam 5 east face & 37 & 236 & 27 \\
\hline $10 / 13 / 93$ & East column 6 web beam section east face & 37 & 133 & 22 \\
\hline $10 / 13 / 93$ & Bay 5 east sidewalk beam & 37 & 192 & 25 \\
\hline $10 / 15 / 93$ & Bay 5 west soffit & 37 & 78 & 22 \\
\hline $10 / 13 / 93$ & Column 8 east sidewalk support south face & 37 & 189 & 27 \\
\hline $10 / 15 / 93$ & Bay 7 deck between beams 3 and 4 & 37 & 170 & 24 \\
\hline $10 / 14 / 93$ & north face column 6 web beam & 37 & 229 & 19 \\
\hline$\overline{10 / 14 / 93}$ & col 7 east sidewalk bracket north face & 37 & 181 & 18 \\
\hline $10 / 14 / 93$ & Bay 7 deck between beams 2 and 3 & 37 & 207 & 20 \\
\hline $10 / 14 / 93$ & Bay 7 deck between beams 3 and 4 & 37 & 163 & 21 \\
\hline 10/14/93 & column 8 east sidewalk support north face & 37 & 244 & 22 \\
\hline $10 / 15 / 93$ & South face column 6 web beam & 37 & 299 & 18 \\
\hline$\overline{12 / 15 / 93}$ & Bay 2 beam 1 east face & 38 & 259 & 24 \\
\hline$\overline{12 / 13 / 93}$ & Bay 4 beam 4 east face & 38 & 225 & 24 \\
\hline $12 / 13 / 93$ & Bay 4 beam 4 east face & 38 & 321 & 20 \\
\hline$\overline{12 / 14 / 93}$ & Bay 4 west sidewalk soffit & 38 & 118 & 23 \\
\hline $12 / 14 / 93$ & Bay 4 beam 2 east face & 38 & 259 & 22 \\
\hline $12 / 10 / 93$ & Bay 3 east sidewalk soffit & 38 & 329 & 21 \\
\hline $12 / 14 / 93$ & Bay 3 west sidewalk beam & 38 & 185 & 23 \\
\hline$\overline{12 / 15 / 93}$ & Bay 2 beam 4 east face & 38 & 170 & 23 \\
\hline$\overline{12 / 14 / 93}$ & Bay 1 west sidewalk soffit & 38 & 96 & 19 \\
\hline $12 / 10 / 93$ & Bay 1 east sidewalk beam & 38 & 240 & 18 \\
\hline $12 / 14 / 93$ & Bay 4 beam 3 west face & 38 & 218 & 23 \\
\hline$\overline{12 / 14 / 93}$ & Bay 4 beam 3 east face & 38 & 255 & 25 \\
\hline$\overline{12 / 16 / 93}$ & bay 1 beam 1 east face & 38 & 197 & 28 \\
\hline
\end{tabular}




\section{Yaquina Bay Bridge}

\begin{tabular}{|c|c|c|c|c|}
\hline Date & Location & Zone & psi & Mils \\
\hline$\overline{12 / 14 / 93}$ & Bay 4 west sidewalk beam & 38 & 295 & 20 \\
\hline$\overline{01 / 26 / 94}$ & Column 11 elev 76.04 to 68.04 east face & 39 & 240 & 18 \\
\hline $01 / 28 / 94$ & Column 1087.10 to 81.10 (flare $-6 \mathrm{ft}$ ) north face & 39 & 255 & 23 \\
\hline $01 / 27 / 94$ & Column 1087.10 to 81.10 (flare $-6 \mathrm{ft}$ ) south face & 39 & 295 & 19 \\
\hline $01 / 26 / 94$ & Column 11 elev 84.04 to 76.04 west face & 39 & 218 & 20 \\
\hline $01 / 26 / 94$ & Column 11 elev 60.04 to arch pedestal south face & 39 & 192 & 18 \\
\hline$\overline{02 / 14 / 94}$ & Column 09 web beam section north face & 39 & 263 & 18 \\
\hline $01 / 31 / 94$ & Column 1087.10 to 81.10 (flare $-6 \mathrm{ft}$ ) west face & 39 & 233 & 23 \\
\hline $01 / 28 / 94$ & Arch between col 11 and col 10 bottom north half & 39 & 288 & 18 \\
\hline $02 / 01 / 94$ & Column 9 stage floor to 95.51 (floor $-6 \mathrm{ft}$ ) east face & 39 & 211 & 19 \\
\hline $01 / 27 / 94$ & Column 10 stage floor to $\mathrm{n} / \mathrm{s}$ column flare east face & 39 & 281 & 19 \\
\hline $01 / 28 / 94$ & Column 10 inter rib strut south face & 39 & 222 & 23 \\
\hline $02 / 08 / 94$ & Column 10 web beam section north face & 39 & 236 & 18 \\
\hline$\overline{02 / 14 / 94}$ & Column 10 web beam section north face & 40 & 236 & 21 \\
\hline $01 / 27 / 94$ & Column 11 stage floor to $\mathrm{n} / \mathrm{s}$ column flare north face & 40 & 248 & 22 \\
\hline $01 / 26 / 94$ & Column 11 inter rib strut north face & 40 & 148 & 21 \\
\hline $02 / 10 / 94$ & Column 9 web beam section east face & 40 & 196 & 25 \\
\hline $01 / 27 / 94$ & Arch col 11 to col 10 east face & 40 & 96 & 23 \\
\hline $01 / 28 / 94$ & Column 10 arch pedestal east face & 40 & 251 & 34 \\
\hline $01 / 28 / 94$ & Column 10 arch pedestal east face & 40 & 340 & 28 \\
\hline $01 / 27 / 94$ & Arch col 11 to col 10 east face & 40 & 192 & 22 \\
\hline $01 / 26 / 94$ & Column 11 stage floor to $\mathrm{n} / \mathrm{s}$ column flare south face & 40 & 281 & 23 \\
\hline $01 / 26 / 94$ & Column 11 column flare to elev 84.04 (flare $-8 \mathrm{ft}$.)west face & 40 & 181 & 28 \\
\hline $04 / 01 / 94$ & Bottom face column 8 web beam & 41 & 181 & 25 \\
\hline $03 / 30 / 94$ & East column 8 web beam section north face & 41 & 199 & 24 \\
\hline $04 / 04 / 94$ & West column 5 web beam section south face & 41 & 170 & 26 \\
\hline $04 / 04 / 94$ & East column 5 web beam section north face & 41 & 259 & 19 \\
\hline $04 / 04 / 94$ & East column 5 web beam section south face & 41 & 174 & 29 \\
\hline $03 / 24 / 94$ & West column 8 stage floor to arch north face & 41 & 199 & 21 \\
\hline $03 / 24 / 94$ & West column 8 stage floor to arch east face & 41 & 303 & 25 \\
\hline $03 / 22 / 94$ & West arch, east face, between col 7 and 6 & 41 & 96 & 26 \\
\hline $03 / 23 / 94$ & West arch bottom between col 5 and 6 & 41 & 314 & 26 \\
\hline $03 / 24 / 94$ & East column 8 stage floor to arch west face & 41 & 214 & 20 \\
\hline $03 / 24 / 94$ & East arch, east face col 7 to col 6 & 41 & 226 & 21 \\
\hline $03 / 24 / 94$ & East arch, east face col 7 to $\operatorname{col} 6$ & 41 & 226 & 20 \\
\hline $03 / 25 / 94$ & East arch, arch top col 7 to col 6 & 41 & 355 & 20 \\
\hline $03 / 23 / 94$ & East arch, east face col 6 to col 5 & 41 & 369 & 18 \\
\hline$\overline{03 / 23 / 94}$ & East arch, east face col 6 to $\operatorname{col} 5$ & 41 & 281 & 23 \\
\hline
\end{tabular}




\section{Yaquina Bay Bridge}

\begin{tabular}{|c|c|c|c|c|}
\hline Date & Location & Zone & psi & Mils \\
\hline $03 / 23 / 94$ & East arch south half arch top col 4 to 5 & 41 & 369 & 21 \\
\hline $03 / 23 / 94$ & East col 5 stage floor to pedestal top east face & 41 & 310 & 23 \\
\hline $03 / 22 / 94$ & East col 5 stage floor to pedestal top south face & 41 & 266 & 24 \\
\hline $03 / 21 / 94$ & East col 5 stage floor to pedestal top west face & 41 & 181 & 24 \\
\hline $03 / 23 / 94$ & East col 5 pedestal top to arch south face & 41 & 177 & 39 \\
\hline $03 / 21 / 94$ & East col 5 pedestal top to arch west face & 41 & 240 & 19 \\
\hline $05 / 09 / 94$ & Column 2 web beam section south face & 42 & 255 & 20 \\
\hline $05 / 17 / 94$ & Column 2 column flare to elevation 93.53 (flare $-8 \mathrm{ft}$ ) east face & 42 & 203 & 18 \\
\hline $05 / 19 / 94$ & Column 2 elev 77.53 to 69.53 west face & 42 & 222 & 25 \\
\hline $05 / 17 / 94$ & Column 2 elevation 61.53 to arch pedestal east face & 42 & 251 & 26 \\
\hline$\overline{05 / 19 / 94}$ & Pier 5 to column 2 arch top & 42 & 295 & 24 \\
\hline$\overline{05 / 16 / 94}$ & Column 3 arch pedestal north face & 42 & 189 & 24 \\
\hline$\overline{05 / 12 / 94}$ & Column 494.78 to arch pedestal north face & 42 & 189 & 27 \\
\hline$\overline{05 / 06 / 94}$ & Column 4 web beam section north face & 43 & 277 & 20 \\
\hline $05 / 18 / 94$ & Col 2 stage floor to $\mathrm{n} / \mathrm{s}$ column flare east face & 43 & 199 & 22 \\
\hline $05 / 20 / 94$ & Pier 5 to column 2 arch bottom north half & 43 & 163 & 22 \\
\hline $05 / 18 / 94$ & Column 2 interrib strut south face & 43 & 207 & 20 \\
\hline $05 / 16 / 94$ & Col 3 stage floor to $\mathrm{n} / \mathrm{s}$ column flare north face & 43 & 133 & 25 \\
\hline $05 / 13 / 94$ & Col 3 stage floor to $\mathrm{n} / \mathrm{s}$ column flare south face & 43 & 148 & 27 \\
\hline $05 / 13 / 94$ & Col 3 stage floor to $\mathrm{n} / \mathrm{s}$ column flare west face & 43 & 233 & 21 \\
\hline $05 / 13 / 94$ & Col 3 stage floor to $\mathrm{n} / \mathrm{s}$ column flare west face & 43 & 310 & 19 \\
\hline $05 / 13 / 94$ & Col 3 elev 88.47 to 84.47 east face & 43 & 181 & 26 \\
\hline $05 / 16 / 94$ & Col 3 arch pedestal south face & 43 & 263 & 25 \\
\hline $05 / 11 / 94$ & Col 4100.78 to 94.78 south face & 43 & 170 & 26 \\
\hline $05 / 13 / 94$ & Column 3 to column 4 arch bottom & 43 & 167 & 20 \\
\hline $05 / 23 / 94$ & Pier 5 east col east face arch pedestal upper triangle & 44 & 369 & 18 \\
\hline $05 / 20 / 94$ & South face pier five lower web beam & 44 & 199 & 19 \\
\hline $05 / 23 / 94$ & west face pier 5 e col el 27.84 to 35.93 (pedestal top up 4") & 44 & 148 & 24 \\
\hline $05 / 24 / 94$ & North face pier 5 column elev 43.93 to 51.93 & 44 & 81 & 18 \\
\hline $05 / 24 / 94$ & North face pier 5 e column elev 82.99 to 90.99 & 44 & 89 & 24 \\
\hline $05 / 23 / 94$ & South face pier 5 e column elev 82.99 to 90.99 & 44 & 259 & 22 \\
\hline $02 / 14 / 94$ & Bottom face column 10 web beam & 45 & 292 & 18 \\
\hline $02 / 07 / 94$ & Bay 8 beam 3 west face & 45 & 159 & 23 \\
\hline $02 / 07 / 94$ & Bay 8 west sidewalk soffit & 45 & 233 & 31 \\
\hline $02 / 11 / 94$ & Bay 10 beam 1 west face & 45 & 332 & 27 \\
\hline $02 / 04 / 94$ & Bay 8 beam 2 west face & 45 & 203 & 24 \\
\hline $02 / 04 / 94$ & Bay 8 beam 1 west face & 45 & 163 & 27 \\
\hline $02 / 14 / 94$ & Bottom face column 11 web beam & 45 & 192 & 30 \\
\hline
\end{tabular}




\begin{tabular}{|c|c|c|c|c|}
\hline \multicolumn{5}{|c|}{ Yaquina Bay Bridge } \\
\hline Date & Location & Zone & psi & Mils \\
\hline $02 / 02 / 94$ & Column 11 east sidewalk support south face & 45 & 248 & 20 \\
\hline$\overline{02 / 08 / 94}$ & Bay 9 beam 1 bottom & 45 & 148 & 22 \\
\hline $02 / 10 / 94$ & Bay 10 beam 1 east face & 45 & 211 & 18 \\
\hline $02 / 14 / 94$ & Bay 11 beam 1 east face & 45 & 229 & 22 \\
\hline $02 / 11 / 94$ & Column 11 west sidewalk support north face & 45 & 270 & 25 \\
\hline $02 / 08 / 94$ & Column 10 west sidewalk support north face & 45 & 222 & 20 \\
\hline $02 / 10 / 94$ & Bay 10 beam 1 west face & 45 & 295 & 20 \\
\hline $02 / 04 / 94$ & Bay 8 beam 5 east face & 45 & 192 & 25 \\
\hline$\overline{02 / 09 / 94}$ & Column 11 east sidewalk support north face & 45 & 369 & 20 \\
\hline$\overline{02 / 09 / 94}$ & Bay 9 deck between beams 4 and 5 & 45 & 177 & 20 \\
\hline $04 / 05 / 94$ & Col 4 west sidewalk support south face & 46 & 222 & 22 \\
\hline $04 / 05 / 94$ & Bay 4 beam 1 bottom & 46 & 240 & 23 \\
\hline $04 / 05 / 94$ & Bay 4 beam 2 west face & 46 & 211 & 20 \\
\hline $04 / 04 / 94$ & Bay 4 beam 5 bottom & 46 & 310 & 19 \\
\hline $04 / 04 / 94$ & Col 5 west sidewalk support north face & 46 & 181 & 23 \\
\hline$\overline{04 / 04 / 94}$ & Bay 5 beam 1 east face & 46 & 273 & 20 \\
\hline $04 / 01 / 94$ & Bay 5 beam 2 bottom & 46 & 288 & 19 \\
\hline $04 / 01 / 94$ & Bay 5 beam 5 west face & 46 & 203 & 21 \\
\hline $04 / 01 / 94$ & Bay 6 beam 3 east face & 46 & 240 & 18 \\
\hline $03 / 31 / 94$ & Bay 6 beam 5 bottom & 46 & 229 & 19 \\
\hline $04 / 01 / 94$ & Bottom face col 7 web beam & 46 & 185 & 20 \\
\hline $03 / 31 / 94$ & Bay 7 deck between beams 1 and 2 & 46 & 192 & 23 \\
\hline $03 / 31 / 94$ & bay 7 beam 2 west face & 46 & 185 & 23 \\
\hline $03 / 31 / 94$ & bay 7 beam 2 west face & 46 & 226 & 25 \\
\hline $03 / 31 / 94$ & Bay 7 beam 4 east face & 46 & 163 & 39 \\
\hline$\overline{04 / 01 / 94}$ & Bay 7 east sidewalk beam & 46 & 189 & 25 \\
\hline $03 / 31 / 94$ & Col 8 west sidewalk support north face & 46 & 163 & 23 \\
\hline $04 / 01 / 94$ & West col 7 stage floor-socket hinge joint west face & 46 & 214 & 18 \\
\hline$\overline{05 / 10 / 94}$ & Bay 1 beam 1 east face & 47 & 310 & 18 \\
\hline $05 / 10 / 94$ & Bay 1 beam 2 east face & 47 & 369 & 25 \\
\hline $05 / 09 / 94$ & Bay 2 deck between beam 2 and 3 & 47 & 244 & 25 \\
\hline $05 / 09 / 94$ & Bay 2 beam 5 bottom & 47 & 185 & 24 \\
\hline $05 / 06 / 94$ & Bay 3 beam 2 bottom & 47 & 163 & 20 \\
\hline$\overline{05 / 06 / 94}$ & Bay 3 beam 4 bottom & 47 & 159 & 25 \\
\hline $05 / 06 / 94$ & Bay 3 beam 5 west face & 47 & 211 & 23 \\
\hline$\overline{05 / 06 / 94}$ & Bay 3 beam 5 bottom & 47 & 199 & 25 \\
\hline $05 / 06 / 94$ & Bay 3 beam 5 east face & 47 & 261 & 25 \\
\hline$\overline{05 / 06 / 94}$ & bay 3 beam 5 east face & 47 & 199 & 20 \\
\hline
\end{tabular}




\section{Yaquina Bay Bridge}

\begin{tabular}{|c|c|c|c|c|}
\hline Date & Location & Zone & psi & Mils \\
\hline $06 / 29 / 94$ & Col.11 stage floor to $\mathrm{n} / \mathrm{s}$ col. flare north face & 48 & 189 & 23 \\
\hline$\overline{06 / 28 / 94}$ & Col. 11 col. flare to elev.95.55 east face (flare -8 ) & 48 & 103 & 29 \\
\hline $06 / 28 / 94$ & Col.11, elev.95.55 to 87.55 east face (previous -8 ) & 48 & 195 & 29 \\
\hline $06 / 28 / 94$ & Col.11 elev. 79.55 to 71.55 east face (previous $-8 \mathrm{ft}$ ) & 48 & 314 & 19 \\
\hline $06 / 28 / 94$ & Col.11 arch pedestal north face & 48 & 107 & 22 \\
\hline $06 / 28 / 94$ & Col.11 arch pedestal east face & 48 & 369 & 19 \\
\hline $06 / 27 / 94$ & Pier 5 to col.11 arch west face. & 48 & 177 & 21 \\
\hline $06 / 27 / 94$ & Pier 5 -col.11 arch bottom to pier 5 (south) & 48 & 233 & 22 \\
\hline $06 / 27 / 94$ & Col.11, inter rib strut south face. & 48 & 240 & 23 \\
\hline $07 / 06 / 94$ & Col.10, col. flare to elev.97.53(flare $-7 \mathrm{ft}$ ) west face. & 48 & 255 & 21 \\
\hline$\overline{06 / 30 / 94}$ & Col.10,elev. 83.53 to arch pedestal south face. & 48 & 133 & 33 \\
\hline $06 / 30 / 94$ & Col.10, arch pedestal south face. & 48 & 229 & 21 \\
\hline $06 / 30 / 94$ & Col.11-col.10, arch west face. & 48 & 167 & 20 \\
\hline$\overline{07 / 06 / 94}$ & Col.9,100.86 to arch pedestal east face. & 48 & 196 & 25 \\
\hline $07 / 05 / 94$ & Col.10- col 9 arch west face. & 48 & 295 & 22 \\
\hline 07/06/94 & Col.9, inter-rib strut bottom edge(1.8" thick) & 48 & 355 & 18 \\
\hline $07 / 06 / 94$ & Col.9,inter-rib strut bottom edge(1.8" thick) & 48 & 310 & 18 \\
\hline $07 / 08 / 94$ & Col.11 web beam section, east face (@ level-12) & 49 & 295 & 22 \\
\hline $06 / 29 / 94$ & Col.11 ,stage floor to $\mathrm{n} / \mathrm{s}$ col. Flare north face. & 49 & 196 & 22 \\
\hline $06 / 28 / 94$ & Col.11 stage floor to $\mathrm{n} / \mathrm{s}$ col, flare west face. & 49 & 163 & 24 \\
\hline $06 / 28 / 94$ & Col.11, elev. 79.55 to 71.55 west face (previous $-8 \mathrm{ft}$ ) & 49 & 159 & 18 \\
\hline $06 / 28 / 94$ & Col.11 elev. 71.55 to 63.55 south face (previous $-8 \mathrm{ft}$ ) & 49 & 226 & 22 \\
\hline $06 / 28 / 94$ & Col.11,arch pedestal south face. & 49 & 222 & 22 \\
\hline $06 / 27 / 94$ & Pier 5 -col.11, arch top. & 49 & 229 & 22 \\
\hline $07 / 06 / 94$ & Col.10 elev.83.53 to arch pedestal north face. & 49 & 288 & 22 \\
\hline $06 / 30 / 94$ & Col.10, elev. 83.53 to arch pedestal south face. & 49 & 233 & 25 \\
\hline $06 / 30 / 94$ & Col.10,elev.83.53 to arch pedestal west face. & 49 & 189 & 33 \\
\hline $07 / 07 / 94$ & Col.10, arch pedestal north face. & 49 & 295 & 25 \\
\hline $07 / 07 / 94$ & Col.10, arch pedestal north face. & 49 & 273 & 26 \\
\hline $07 / 06 / 94$ & Col.10-col.9 arch west face. & 49 & 222 & 26 \\
\hline $08 / 18 / 94$ & West column 8 , web beam section, west face. & 50 & 126 & 25 \\
\hline $08 / 17 / 94$ & North face column 8 web beam. & 50 & 244 & 20 \\
\hline $08 / 18 / 94$ & South face column 6 web beam & 50 & 192 & 22 \\
\hline$\overline{08 / 18 / 94}$ & East column 6 , web beam section, north face. & 50 & 292 & 18 \\
\hline $08 / 09 / 94$ & West rib, column 8 - col.7 arch east face. & 50 & 255 & 18 \\
\hline $08 / 10 / 94$ & West rib, column 7 - col. 6 arch top. & 50 & 152 & 20 \\
\hline $08 / 10 / 94$ & West column 6, stage floor to pedestal top west face. & 50 & 137 & 22 \\
\hline$\overline{08 / 10 / 94}$ & West column 6 , pedestal top to arch east face. & 50 & 133 & 22 \\
\hline
\end{tabular}




\section{Yaquina Bay Bridge}

\begin{tabular}{|c|c|c|c|c|}
\hline Date & Location & Zone & psi & Mils \\
\hline$\overline{08 / 09 / 94}$ & East rib, column 9 - col. 8 , arch top. & 50 & 270 & 21 \\
\hline$\overline{08 / 11 / 94}$ & East rib, column 8 - col. 7 , arch top. & 50 & 332 & 22 \\
\hline $08 / 10 / 94$ & East rib, column 8 - col. 7, arch bottom. & 50 & 170 & 23 \\
\hline $08 / 10 / 94$ & East column 6 , stage floor to pedestal top north face. & 50 & 126 & 19 \\
\hline$\overline{08 / 11 / 94}$ & East column 6 , pedestal top to arch south face. & 50 & 273 & 22 \\
\hline $08 / 10 / 94$ & East column 6 , pedestal top to arch west face. & 50 & 185 & 42 \\
\hline $08 / 09 / 94$ & East column 8, pedestal top to arch north face. & 50 & 222 & 20 \\
\hline $08 / 10 / 94$ & West column 7 ,stage floor to pedestal top south face. & 50 & 167 & 33 \\
\hline $08 / 10 / 94$ & West column 7 , state floor to pedestal top west face. & 50 & 155 & 26 \\
\hline$\overline{08 / 18 / 94}$ & East column 7, stage floor to pedestal top south face. & 50 & 192 & 25 \\
\hline $10 / 01 / 94$ & West column 3 web beam section, south face. & 51 & 233 & 21 \\
\hline $09 / 26 / 94$ & East column 3, elev. 90.34 to 83.34 (previous $-7 \mathrm{ft}$ ) north face. & 51 & 301 & 20 \\
\hline$\overline{09 / 26 / 94}$ & East column 3, elev. 90.34 to 83.34 (previous $-7 \mathrm{ft}$ ) east face. & 51 & 140 & 22 \\
\hline $09 / 26 / 94$ & East column 3, elev. 90.34 to 83.34 (previous $-7 \mathrm{ft}$ ) east face. & 51 & 152 & 21 \\
\hline $09 / 21 / 94$ & Column 4,inter-rib strut top edge (1`-8" thick)west half. & 51 & 211 & 20 \\
\hline $09 / 22 / 94$ & Column 4 , inter-rib strut north face west half. & 51 & 322 & 20 \\
\hline $09 / 22 / 94$ & West col.4, stage floor to 111.73 (stage floor -6 ) north face. & 51 & 207 & 21 \\
\hline$\overline{09 / 22 / 94}$ & West col.4, elev.93.55 to arch pedestal east face. & 51 & 163 & 21 \\
\hline $09 / 22 / 94$ & East col.4, 99.73 to elev.93.55 (previous -6) north face. & 51 & 207 & 19 \\
\hline $09 / 20 / 94$ & West rib, col. 5 south 2 ft. Arch bottom. & 51 & 199 & 18 \\
\hline $09 / 28 / 94$ & East col.5, web beam section north face. & 51 & 174 & 23 \\
\hline$\overline{09 / 20 / 94}$ & East col.5, arch pedestal north face. & 51 & 233 & 22 \\
\hline$\overline{09 / 20 / 94}$ & East col.5, arch pedestal west face. & 51 & 181 & 21 \\
\hline$\overline{01 / 05 / 95}$ & East col. 2 web beam section, north face & 52 & 236 & 25 \\
\hline$\overline{12 / 27 / 94}$ & West col.2 stage floor to $\mathrm{n} / \mathrm{s}$ flare, east face & 52 & 273 & 21 \\
\hline$\overline{12 / 27 / 94}$ & West col.2 flare to el.104.32(flare-8ft.),north face & 52 & 170 & 27 \\
\hline $12 / 21 / 94$ & West col.2 el.88.32 to 80.32 , south face & 52 & 259 & 28 \\
\hline $12 / 27 / 94$ & West col.2 el.80.32 to 72.32 ,north face & 52 & 181 & 21 \\
\hline$\overline{12 / 20 / 94}$ & West col.2 to west col.3 arch bottom, south half & 52 & 192 & 26 \\
\hline$\overline{12 / 27 / 94}$ & East col.2 stage floor to $\mathrm{n} / \mathrm{s}$ flare, west face & 52 & 295 & 24 \\
\hline $12 / 27 / 94$ & East col.2 flare to el.104.32(flare-8ft.), east face & 52 & 236 & 23 \\
\hline $12 / 27 / 94$ & East col.2 el.64.32 to arch pedestal.,east face & 52 & 174 & 28 \\
\hline $12 / 27 / 94$ & East col.2 el.64.32 to arch pedestal.,east face & 52 & 148 & 31 \\
\hline$\overline{12 / 21 / 94}$ & East col.2 el. 64.32 to arch pedestal., west face & 52 & 358 & 18 \\
\hline$\overline{01 / 17 / 95}$ & West face pier 4 col. El.39 to 47 & 53 & 322 & 21 \\
\hline $01 / 12 / 95$ & East face pier 4 col. El.47 to 55 & 53 & 207 & 21 \\
\hline $01 / 12 / 95$ & South face pier 4 col. El. 47 to 55 & 53 & 236 & 21 \\
\hline $01 / 23 / 95$ & North face pier 4 col. El. 55 to 63 & 53 & 359 & 21 \\
\hline
\end{tabular}




\section{Yaquina Bay Bridge}

\begin{tabular}{|c|c|c|c|c|}
\hline Date & Location & Zone & psi & Mils \\
\hline $01 / 12 / 95$ & South face pier 4 middle arch web wall el.63 to 72 west half & 53 & 214 & 18 \\
\hline $01 / 23 / 95$ & North face pier 4 col. El. 71 to 79 & 53 & 285 & 20 \\
\hline $01 / 23 / 95$ & East face pier 4 col. El. 87 to 95 & 53 & 277 & 20 \\
\hline $01 / 16 / 95$ & South face pier 4 col. El.95 to 103 & 53 & 204 & 23 \\
\hline $01 / 09 / 95$ & South face upper web beam deck soffit to stage floor & 53 & 355 & 22 \\
\hline $01 / 09 / 95$ & North face west col. web beam section & 53 & 366 & 19 \\
\hline $01 / 09 / 95$ & West face west col. web beam section & 53 & 310 & 24 \\
\hline$\overline{01 / 19 / 95}$ & South face web beam section, west col. & 53 & 369 & 21 \\
\hline $01 / 17 / 95$ & East face pier 4 east col. El. 39 to 47 & 54 & 259 & 32 \\
\hline $01 / 12 / 95$ & West face pier 4 col. El. 47 to 55 & 54 & 336 & 25 \\
\hline $01 / 19 / 95$ & North face pier 4 col. El. 55 to 63 & 54 & 281 & 19 \\
\hline $01 / 19 / 95$ & North face pier 4 col. El. 55 to 63 & 54 & 259 & 23 \\
\hline $01 / 25 / 95$ & North face pier 4 middle arch web beam wall el. 63 to 72 & 54 & 185 & 21 \\
\hline $01 / 19 / 95$ & East face pier 4 col. El. 79 to 87 & 54 & 281 & 23 \\
\hline $01 / 25 / 95$ & North face pier 4 col. El.87 to 95 & 54 & 163 & 27 \\
\hline $01 / 23 / 95$ & South face pier 4 col. El. 95 to 103 & 54 & 211 & 19 \\
\hline $01 / 10 / 95$ & East face pier 4 col. El. 103 to 111 & 54 & 318 & 18 \\
\hline $01 / 10 / 95$ & North face upper web beam deck soffit to stage floor & 54 & 270 & 18 \\
\hline $01 / 19 / 95$ & East face col. web beam section & 54 & 170 & 25 \\
\hline $07 / 13 / 94$ & Bay 9,middle beam, west face(@level 12) & 55 & 307 & 19 \\
\hline $07 / 13 / 94$ & Bay 9 east middle beam west face. & 55 & 247 & 23 \\
\hline $07 / 11 / 94$ & Bay 10 east middle beam east face. & 55 & 281 & 21 \\
\hline $07 / 12 / 94$ & Bay 11, west side walk soffit. & 55 & 214 & 20 \\
\hline $07 / 12 / 94$ & Bay 11, middle beam, bottom. & 55 & 295 & 22 \\
\hline $07 / 07 / 94$ & Bay 11, east beam, east face. & 55 & 170 & 19 \\
\hline $07 / 07 / 94$ & Bay 11, east soffit. & 55 & 318 & 19 \\
\hline $07 / 07 / 94$ & Bay 11, east sidewalk beam. & 55 & 229 & 19 \\
\hline $08 / 18 / 94$ & Bay 6, west sidewalk beam. & 56 & 170 & 22 \\
\hline $08 / 18 / 94$ & Bay 6, west sidewalk beam. & 56 & 148 & 26 \\
\hline $08 / 18 / 94$ & Bay 6,middle beam bottom. & 56 & 192 & 25 \\
\hline $08 / 18 / 94$ & Bay 6 east middle beam, west face. & 56 & 292 & 18 \\
\hline $08 / 17 / 94$ & South face column 7 web beam. & 56 & 214 & 22 \\
\hline $08 / 17 / 94$ & Bay 7, west sidewalk soffit. & 56 & 181 & 25 \\
\hline $08 / 18 / 94$ & Bay 7, west beam, east face. & 56 & 273 & 21 \\
\hline $08 / 17 / 94$ & Bay 7, east middle beam, bottom. & 56 & 211 & 22 \\
\hline $08 / 17 / 94$ & Bay 7, east middle beam, bottom. & 56 & 207 & 26 \\
\hline $08 / 17 / 94$ & Bay 7, east middle beam, bottom. & 56 & 266 & 23 \\
\hline $08 / 16 / 94$ & Bay 7, east soffit (galvanized drain) & 56 & 196 & 18 \\
\hline
\end{tabular}




\begin{tabular}{|c|c|c|c|c|}
\hline \multicolumn{5}{|c|}{ Yaquina Bay Bridge } \\
\hline Date & Location & Zone & psi & Mils \\
\hline$\overline{08 / 17 / 94}$ & Bay 8 , west sidewalk beam. & 56 & 307 & 22 \\
\hline$\overline{08 / 16 / 94}$ & Bay 8 , middle beam, east face. & 56 & 288 & 24 \\
\hline $08 / 16 / 94$ & Bay 8 , east middle beam, west face. & 56 & 174 & 24 \\
\hline $08 / 16 / 94$ & Bay 8, east beam ,east face. & 56 & 199 & 20 \\
\hline $08 / 16 / 94$ & Bay 8, east sidewalk soffit. & 56 & 130 & 22 \\
\hline $10 / 03 / 94$ & Bay 3, west sidewalk beam, south half & 57 & 177 & 23 \\
\hline $10 / 03 / 94$ & Bay 3, west sidewalk soffit-north face. & 57 & 174 & 22 \\
\hline $10 / 03 / 94$ & Bay 3, west beam, west face, south half & 57 & 199 & 22 \\
\hline $10 / 01 / 94$ & Bay 3, west beam, east face, south half & 57 & 303 & 20 \\
\hline $10 / 01 / 94$ & Bay 3, west deck north half. & 57 & 233 & 22 \\
\hline $10 / 01 / 94$ & Bay 3, west middle beam, east face, south half & 57 & 236 & 21 \\
\hline $10 / 01 / 94$ & Bay 3, west middle beam, east face, south half & 57 & 163 & 27 \\
\hline $10 / 01 / 94$ & Bay 3, west middle deck, south half & 57 & 122 & 22 \\
\hline $10 / 01 / 94$ & Bay 3, middle beam, east face, south half & 57 & 236 & 22 \\
\hline $10 / 03 / 94$ & Bay 3, east beam, bottom, south half & 57 & 107 & 22 \\
\hline $10 / 01 / 94$ & Bay 4,west beam , east face. & 57 & 192 & 20 \\
\hline $09 / 30 / 94$ & Bay 4, middle beam, bottom. & 57 & 177 & 19 \\
\hline $09 / 30 / 94$ & Bay 4, east beam, bottom (galvanized drain) & 57 & 189 & 19 \\
\hline $09 / 30 / 94$ & Bay 4, east beam, bottom (galvanized drain) & 57 & 89 & 23 \\
\hline $09 / 30 / 94$ & Bay 4, east beam, bottom (galvanized drain) & 57 & 152 & 24 \\
\hline $10 / 03 / 94$ & Col 5 web beam, bottom face & 57 & 148 & 20 \\
\hline $09 / 30 / 94$ & Bay 5, west sidewalk beam & 57 & 189 & 25 \\
\hline $09 / 30 / 94$ & Bay 5, west soffit & 57 & 181 & 22 \\
\hline $09 / 29 / 94$ & Bay 5 ,west beam, east face & 57 & 295 & 18 \\
\hline $09 / 29 / 94$ & Bay 5, west beam, east face & 57 & 244 & 18 \\
\hline $09 / 30 / 94$ & Bay 5, middle beam, west face & 57 & 281 & 18 \\
\hline $09 / 29 / 94$ & Bay 5, middle beam, east face & 57 & 207 & 24 \\
\hline $9 / 29 / 94$ & Bay 5, east beam, bottom & 57 & 214 & 25 \\
\hline $9 / 28 / 94$ & Bay 5, east sidewalk beam & 57 & 181 & 19 \\
\hline$\overline{9 / 30 / 94}$ & Col. 6, west sidewalk support, south half & 57 & 273 & 21 \\
\hline $01 / 06 / 95$ & Bay 1 west beam, west face & 58 & 244 & 20 \\
\hline $01 / 06 / 95$ & Bay 1 west middle deck & 58 & 303 & 23 \\
\hline $01 / 06 / 95$ & Bay 1 west middle deck & 58 & 277 & 22 \\
\hline $01 / 05 / 95$ & North face col. 2 web beam & 58 & 251 & 20 \\
\hline $01 / 04 / 95$ & Bay 2 west middle beam, east face & 58 & 226 & 18 \\
\hline $01 / 04 / 95$ & Col. 3 west sidewalk support, north face & 58 & 222 & 22 \\
\hline
\end{tabular}




\section{Depoe Bay Bridge}

\begin{tabular}{|c|c|c|c|c|}
\hline Date & Location & Zone & psi & Mils \\
\hline $1 / 11 / 95$ & West beam east face & 10 & 203 & 24 \\
\hline $1 / 11 / 95$ & Middle beam west face & 10 & 244 & 20 \\
\hline $1 / 12 / 95$ & Bent 2 south face of web wall west half & 10 & 170 & 22 \\
\hline$\overline{1 / 12 / 95}$ & Bent 2 west column south face & 10 & 236 & 23 \\
\hline $1 / 17 / 95$ & Column 2 west east face & 10 & 170 & 22 \\
\hline$\overline{1 / 17 / 95}$ & Column 2 west south face & 10 & 111 & 22 \\
\hline$\overline{1 / 19 / 95}$ & Bent 2 west column south face & 10 & 229 & 25 \\
\hline$\overline{1 / 19 / 95}$ & Bent 2 west column west face & 10 & 192 & 21 \\
\hline$\overline{1 / 19 / 95}$ & Old bridge west column bent 2 west face & 10 & 244 & 24 \\
\hline$\overline{1 / 19 / 95}$ & Old bridge west column bent 2 north face & 10 & 321.5 & 21 \\
\hline$\overline{1 / 23 / 95}$ & Deck between east beam and middle beam & 10 & 236 & 21 \\
\hline $1 / 3 / 95$ & West side walk support bracket south face & 11 & 369 & 27 \\
\hline$\overline{1 / 3 / 95}$ & East face of east beam near bent 3 & 11 & 340 & 22 \\
\hline $1 / 3 / 95$ & South face of west side sidewalk support & 11 & 273 & 24 \\
\hline $1 / 5 / 95$ & West sidewalk between bent 3 and bent 4 & 11 & 244 & 22 \\
\hline $1 / 6 / 95$ & Bottom of middle beam north of bent 3 & 11 & 259 & 24 \\
\hline$\overline{12 / 12 / 94}$ & East sidewalk soffit & 11 & 111 & 19 \\
\hline $12 / 14 / 94$ & Sidewalk support east side south face & 11 & 288 & 19 \\
\hline $12 / 14 / 94$ & Sidewalk support east side south face & 11 & 332 & 21 \\
\hline $12 / 15 / 94$ & East fascia 2nd sidewalk support north face & 11 & 277 & 20 \\
\hline$\overline{12 / 20 / 94}$ & East deck between bent 4 and bent 3 & 11 & 310 & 18 \\
\hline $12 / 21 / 94$ & Bent 3 web beam east panel south face & 11 & 148 & 21 \\
\hline$\overline{12 / 21 / 94}$ & Bent 3 west column east face & 11 & 107 & 20 \\
\hline $12 / 21 / 94$ & Bent 3 web beam west half north face & 11 & 170 & 18 \\
\hline $1 / 19 / 95$ & New bridge east col bent 2 west face & 12 & 236 & 19 \\
\hline $2 / 15 / 95$ & Beam $1 \mathrm{~b}$ east middle panel north face & 12 & 174 & 19 \\
\hline$\overline{2 / 17 / 95}$ & East middle transverse beam south face & 12 & 181 & 23 \\
\hline$\overline{2 / 24 / 95}$ & Beam 1a middle beam bottom & 12 & 199 & 18 \\
\hline$\overline{11 / 9 / 94}$ & Bent 3 web beam north face west panel & 13 & 199 & 22 \\
\hline$\overline{11 / 14 / 94}$ & East middle panel north face & 13 & 196 & 19 \\
\hline$\overline{11 / 14 / 94}$ & East middle panel north face & 13 & 185 & 21 \\
\hline$\overline{11 / 15 / 94}$ & Sec 2a west panel south face & 13 & 185 & 23 \\
\hline $11 / 15 / 94$ & Sec $2 \mathrm{a}$ west middle beam west face & 13 & 196 & 23 \\
\hline $11 / 15 / 94$ & Section 2a west middle beam east face & 13 & 218 & 21 \\
\hline $11 / 16 / 94$ & Section $2 \mathrm{~b}$ east middle beam east face & 13 & 255 & 23 \\
\hline $11 / 17 / 94$ & West middle beam west face section $2 b$ & 13 & 185 & 22 \\
\hline $11 / 22 / 94$ & Bent $\# 3$ west column east face & 13 & 266 & 23 \\
\hline$\overline{11 / 22 / 94}$ & Bent 3 west column south face & 13 & 251 & 22 \\
\hline$\overline{11 / 22 / 94}$ & Bent 3 west column south face & 13 & 244 & 22 \\
\hline $11 / 22 / 94$ & Bent 3 west column & 13 & 259 & 20 \\
\hline
\end{tabular}




\section{Depoe Bay Bridge}

\begin{tabular}{|c|c|c|c|c|}
\hline Date & Location & Zone & psi & Mils \\
\hline$\overline{11 / 22 / 94}$ & Bent 3 east column south face & 13 & 359 & 20 \\
\hline$\overline{4 / 19 / 95}$ & West col 9 floor beam sec south face & 5 & 163 & 19 \\
\hline$\overline{4 / 24 / 95}$ & By 9 west sidewalk soffit & 5 & 126 & 20 \\
\hline$\overline{4 / 24 / 95}$ & Bay 10 west beam east face & 5 & 174 & 20 \\
\hline $4 / 25 / 95$ & East col 10 centerline support bracket north face & 5 & 218 & 19 \\
\hline $4 / 27 / 95$ & Sidewalk support west col 10 south face & 5 & 177 & 25 \\
\hline$\overline{5 / 1 / 95}$ & Bottom of beam at east pier 2 to west col 11 & 5 & 130 & 20 \\
\hline$\overline{5 / 4 / 95}$ & Bay 7 deck & 5 & 144 & 21 \\
\hline$\overline{5 / 5 / 95}$ & Bay 7 deck & 5 & 163 & 20 \\
\hline$\overline{6 / 30 / 95}$ & East col 7 centerline support bracket north face & 5 & 240 & 19 \\
\hline$\overline{3 / 24 / 95}$ & Pier 2 east col east face elev 48 to 58 zone 8 & 8 & 122 & 23 \\
\hline $3 / 24 / 95$ & Col between floor level one and pier 2 east face & 8 & 130 & 21 \\
\hline$\overline{3 / 31 / 95}$ & East arch pier 2 to col 11 & 8 & 159 & 24 \\
\hline$\overline{4 / 3 / 95}$ & East arch col 10 to col 9 bottom & 8 & 170 & 21 \\
\hline $4 / 3 / 95$ & East arch col 10 to col 9 bottom & 8 & 148 & 22 \\
\hline $4 / 3 / 95$ & East arch col 11 to col 10 top & 8 & 255 & 21 \\
\hline$\overline{4 / 4 / 95}$ & Pier 2 west south face elev 40 tp 48 & 8 & 159 & 20 \\
\hline$\overline{4 / 4 / 95}$ & West arch col 8 to col 7 east face & 8 & 214 & 21 \\
\hline$\overline{4 / 5 / 95}$ & West arch col 8 to col 7 bottom & 8 & 74 & 24 \\
\hline $4 / 5 / 95$ & West col 11 arch pedestal north face & 8 & 263 & 18 \\
\hline $4 / 5 / 95$ & West col 11 top of arch pedestal to elev 40 south face & 8 & 273 & 18 \\
\hline $4 / 6 / 95$ & East face of west arch between col 11 and 10 & 8 & 152 & 24 \\
\hline $4 / 7 / 95$ & Pier 2 west col south face bush hammer to pedestal & 8 & & 21 \\
\hline $6 / 7 / 95$ & East col 11 previous to elev 52 east face & 8 & 192 & 24 \\
\hline $3 / 9 / 95$ & Bottom of pier 2 south face east column & 9 & 140 & 23 \\
\hline $3 / 9 / 95$ & Bottom of pier 2 south face east column & 9 & 100 & 25 \\
\hline$\overline{3 / 10 / 95}$ & Bay 7 col 8 to col 7 east face & 9 & 159 & 20 \\
\hline$\overline{3 / 13 / 95}$ & Sec 2a west panel south face & 9 & 133 & 20 \\
\hline$\overline{3 / 13 / 95}$ & Old bridge west col 9 arch pedestal & 9 & 118 & 28 \\
\hline $3 / 14 / 95$ & West arch col 10 to col 9 top & 9 & 152 & 18 \\
\hline $3 / 14 / 95$ & West col 10 top of arch pedestal to elev $48 \mathrm{n}$ face & 9 & 126 & 18 \\
\hline$\overline{3 / 23 / 95}$ & Pier 2 col west face elev 11 to 20 & 9 & 299 & 18 \\
\hline $3 / 24 / 95$ & Pier 2 east col east face elev 48 to 58 & 9 & 189 & 20 \\
\hline $3 / 27 / 95$ & South face of col 11 east between level 2 and 3 & 9 & 163 & 18 \\
\hline$\overline{3 / 28 / 95}$ & West col 11 arch pedestal north face & 9 & 218 & 25 \\
\hline $3 / 28 / 95$ & East col 11 arch pedestal south face & 9 & 15 & 23 \\
\hline $3 / 31 / 95$ & Pier 2 west face of west bottom of level 4 & 9 & 137 & 22 \\
\hline $6 / 7 / 95$ & East col 10 previous to elev 52 top of col cap north face & 9 & 207 & 21 \\
\hline $7 / 18 / 95$ & West sidewalk soffit bay 11 & 3 & 222 & 21 \\
\hline $8 / 2 / 95$ & Bay 3 east beam bottom & 3 & 137 & 21 \\
\hline $8 / 3 / 95$ & Bottom face col 3 floor beam & 3 & 177 & 24 \\
\hline
\end{tabular}




\section{Depoe Bay Bridge}

\begin{tabular}{|c|c|c|c|c|}
\hline Date & Location & Zone & psi & Mils \\
\hline $8 / 5 / 95$ & North face col 5 floor beam bottom & 3 & 236 & 25 \\
\hline$\overline{8 / 8 / 95}$ & Bay 1 east soffit & 3 & 236 & 19 \\
\hline$\overline{8 / 8 / 95}$ & West col 4 floor beam south face & 3 & 322 & 29 \\
\hline $8 / 9 / 95$ & Bay 2 west beam bottom & 3 & 163 & 18 \\
\hline$\overline{5 / 30 / 95}$ & Bottom face of col 10 floor beam & 3 & 167 & 23 \\
\hline$\overline{5 / 31 / 95}$ & Bay 9 east beam west face & 3 & 222 & 19 \\
\hline $6 / 5 / 95$ & East col 9 floor beam sec north face & 3 & 222 & 25 \\
\hline $6 / 6 / 95$ & Bottom face col 8 floor beam & 3 & 159 & 22 \\
\hline $6 / 8 / 95$ & Bay 6 east beam west face & 3 & 163 & 22 \\
\hline $7 / 17 / 95$ & West sidewalk soffit bay 11 & 3 & 222 & 21 \\
\hline $7 / 19 / 95$ & West face of west curtain wall at bay 8 & 3 & 281 & 21 \\
\hline$\overline{7 / 19 / 95}$ & West face of west curtain wall at bay 8 & 3 & 285 & 23 \\
\hline $9 / 1 / 95$ & East col $1 \mathrm{cl}$ support bar south face & 4 & 318 & 20 \\
\hline $5 / 10 / 95$ & West col 4 floor beam section south face & 4 & 148 & 24 \\
\hline$\overline{5 / 10 / 95}$ & Bay 4 west beam east face & 4 & 185 & 23 \\
\hline $5 / 10 / 95$ & West col 5 floor beam section north face & 4 & 222 & 18 \\
\hline $5 / 10 / 95$ & West col 5 floor beam section north face & 4 & 148 & 24 \\
\hline$\overline{5 / 12 / 95}$ & West col 4 floor beam section south face & 4 & 93 & 21 \\
\hline$\overline{5 / 17 / 95}$ & East col 4 floor beam section south face & 4 & 211 & 22 \\
\hline$\overline{5 / 17 / 95}$ & East col 4 centerline support bracket south face & 4 & 248 & 22 \\
\hline$\overline{5 / 18 / 95}$ & East col 3 floor beam section south face & 4 & 266 & 25 \\
\hline$\overline{5 / 19 / 95}$ & West pier 1 floor beam north face & 4 & 314 & 21 \\
\hline$\overline{5 / 23 / 95}$ & West pier one floor beam bottom & 4 & 229 & 21 \\
\hline$\overline{5 / 23 / 95}$ & East col 2 floor beam section north face & 4 & 314 & 21 \\
\hline$\overline{5 / 25 / 95}$ & West col 2 sidewalk support south face & 4 & 303 & 26 \\
\hline$\overline{5 / 25 / 95}$ & Bay 2 west soffit & 4 & 181 & 24 \\
\hline$\overline{5 / 30 / 95}$ & West pier one west sidewalk soffit & 4 & 218 & 23 \\
\hline$\overline{5 / 31 / 95}$ & West col 4 side walk support north face & 4 & 218 & 21 \\
\hline$\overline{6 / 13 / 95}$ & West arch col 5 to col 6 top & 6 & 118 & 20 \\
\hline $6 / 15 / 95$ & Pier 2 west col east face elev 25 and 33 & 6 & 152 & 23 \\
\hline $6 / 15 / 95$ & West col 2 top of arch pedestal elev 40 north face & 6 & 185 & 22 \\
\hline$\overline{6 / 15 / 95}$ & West arch col 2 to $\operatorname{col} 3$ top & 6 & 177 & 23 \\
\hline $6 / 16 / 95$ & West col 9 arch pedestal north face & 6 & 177 & 23 \\
\hline $6 / 29 / 95$ & West col 4 top arch pedestal to elev 52 north face & 6 & 244 & 21 \\
\hline $6 / 30 / 95$ & East arch col 6 to mid span east face & 6 & 179 & 25 \\
\hline $7 / 3 / 95$ & East arch col 5 to col 6 top & 6 & 240 & 18 \\
\hline$\overline{7 / 12 / 95}$ & Pier 1 east col south face elev 20 to 25 & 6 & 163 & 20 \\
\hline $7 / 13 / 95$ & Pier 1 east col south face elev 40 to 48 & 6 & 259 & 23 \\
\hline$\overline{7 / 13 / 95}$ & Pier 1 e col south face elev. 48 to 58 & 6 & 229 & 24 \\
\hline$\overline{10 / 6 / 95}$ & West landing north beam north face & 1 & 310 & 21 \\
\hline $10 / 24 / 95$ & West stairway west beam west face & 1 & 199 & 22 \\
\hline
\end{tabular}




\section{Depoe Bay Bridge}

\begin{tabular}{|c|c|c|c|c|}
\hline Date & Location & Zone & psi & Mils \\
\hline $10 / 25 / 95$ & West stairway soffit & 1 & 193 & 23 \\
\hline $10 / 26 / 95$ & West bent north column west face lower third & 1 & 244 & 21 \\
\hline $10 / 27 / 95$ & West span west mid dia west face & 1 & 233 & 22 \\
\hline $10 / 27 / 95$ & West Bent North Column West Face Lower Third & 1 & 281 & 22 \\
\hline $10 / 27 / 95$ & West Bent South, South Column West Face Lower Third & 1 & 295 & 25 \\
\hline $11 / 3 / 95$ & West Span East Middle Diaphragm East Face & 1 & 255 & 21 \\
\hline$\overline{11 / 7 / 95}$ & west span middle diaphragm bottom & 1 & 159 & 24 \\
\hline$\overline{11 / 13 / 95}$ & East stair head interm. Col. NF & 1 & 251 & 18 \\
\hline $11 / 18 / 95$ & East Bent East Diaphragm West Face & 1 & 159 & 22 \\
\hline$\overline{11 / 18 / 95}$ & East Span mid diaphragm WF & 1 & 233 & 20 \\
\hline $11 / 28 / 95$ & East Stairway Soffit & 1 & 152 & 22 \\
\hline$\overline{12 / 5 / 95}$ & East stair head Col EF lower & 1 & 266 & 22 \\
\hline$\overline{12 / 5 / 95}$ & east span, N Beam E stair head sec. bottom & 1 & 148 & 26 \\
\hline$\overline{12 / 19 / 95}$ & Middle bent north column North Face & 1 & 152 & 24 \\
\hline$\overline{10 / 6 / 96}$ & West Stair head West Beam WEST Face & 1 & 174 & 18 \\
\hline$\overline{8 / 30 / 95}$ & Pier 1 W Sidewalk Soffit & 2 & 255 & 21 \\
\hline $8 / 30 / 95$ & Bay OC W Soffit & 2 & 192 & 23 \\
\hline$\overline{9 / 1 / 95}$ & Bay OC W 3BM Bottom & 2 & 181 & 21 \\
\hline$\overline{9 / 2 / 95}$ & Bay OC W Sidewalk BM & 2 & 325 & 23 \\
\hline$\overline{9 / 7 / 95}$ & Bay OB W Sidewalk Soffit & 2 & 196 & 27 \\
\hline$\overline{9 / 15 / 95}$ & Deck E-2 E-1 S 1/2 & 2 & 285 & 24 \\
\hline$\overline{9 / 22 / 95}$ & E $1 \mathrm{BM} \mathrm{S1} / 2 \mathrm{WF}$ & 2 & 322 & 23 \\
\hline$\overline{9 / 23 / 95}$ & E 1 BM S $1 / 2$ Bottom & 2 & 292 & 21 \\
\hline $8 / 8 / 95$ & West Col.4 arch to Elev.52, North Face & 7 & 229 & 21 \\
\hline $8 / 8 / 95$ & West Arch, Column.6 to mid span, West Face & 7 & 285 & 24 \\
\hline $8 / 8 / 95$ & West Column 4 pedestal North Face. & 7 & 218 & 25 \\
\hline$\overline{8 / 9 / 95}$ & East Column 2 previous to Elev.52 East Face & 7 & 137 & 24 \\
\hline$\overline{8 / 9 / 95}$ & E Col 2 Elev. 52 West Face. & 7 & 155 & 25 \\
\hline$\overline{8 / 11 / 95}$ & West Col.3 Elev. 52 South Face. & 7 & 148 & 22 \\
\hline$\overline{8 / 12 / 95}$ & E Col 2 Elev. 52 West Face. & 7 & 236 & 20 \\
\hline$\overline{8 / 12 / 95}$ & E Col $2 \mathrm{~W}$ est Face. Elev.52 & 7 & 207 & 23 \\
\hline$\overline{8 / 12 / 95}$ & West Col 2 Elev. 52 East Face. & 7 & 236 & 22 \\
\hline$\overline{8 / 12 / 95}$ & Column 3 Inter-Arch strut, South Face. & 7 & 207 & 18 \\
\hline$\overline{8 / 15 / 95}$ & West Col 2 Prev. Elev. 48 South Face. & 7 & 244 & 21 \\
\hline$\overline{8 / 15 / 95}$ & W est Col 2, Elev.48 North Face. & 7 & 214 & 24 \\
\hline$\overline{8 / 15 / 95}$ & W est Col 2 Top Arch Pedestal to Elev.40 East Face & 7 & 229 & 20 \\
\hline$\overline{8 / 16 / 95}$ & East Arch Column 2 to Column 3, Bottom. & 7 & 236 & 23 \\
\hline
\end{tabular}




\section{Depoe Bay Bridge}

\begin{tabular}{l|l|c|c|c}
\hline Date & \multicolumn{1}{|c|}{ Location } & Zone & psi & Mils \\
\hline $8 / 18 / 95$ & Pier 1 West Col East Face. & 7 & 266 & 23 \\
\hline $8 / 23 / 95$ & Pier\#1, South strut, South Face. & 7 & 211 & 22 \\
\hline $8 / 23 / 95$ & Pier 1 North Struts South Face. & 7 & 214 & 18 \\
\hline $8 / 25 / 95$ & Pier 1 East Column West Face Elev. 25 to33. & 7 & 152 & 18 \\
\hline
\end{tabular}

\section{Big Creek Bridge}

\begin{tabular}{l|l|c|c|c}
\hline Date & \multicolumn{1}{|c|}{ Location } & Zone & psi & Mils \\
\hline $3 / 25 / 98$ & Bay 9,Deck slab "I" west side & 6 & 182 & 15 \\
\hline $3 / 26 / 98$ & Bent 4,West column, South side, Above capital & 6 & 262 & 9 \\
\hline $3 / 26 / 98$ & Bent 4,Cell 1B,Upper web wall, South side & 6 & 396 & 10 \\
\hline $3 / 26 / 98$ & Cell 1,N.W. sidewalk support, Bottom side & 6 & 174 & 12 \\
\hline $3 / 26 / 98$ & Cell 1C,East middle beam, Bottom side & 6 & 285 & 8 \\
\hline $3 / 26 / 98$ & Cell 2B,Middle beam, West side & 6 & 186 & 11 \\
\hline $3 / 26 / 98$ & Cell 2B,Middle beam, Bottom side & 6 & 155 & 8 \\
\hline $3 / 26 / 98$ & Cell 2D,East middle beam, East side & 6 & 218 & 12 \\
\hline $3 / 27 / 98$ & Cell 3D,East middle beam, East side & 6 & 357 & 8 \\
\hline $3 / 27 / 98$ & Cell 3D,East beam, West side & 6 & 357 & 7 \\
\hline $3 / 27 / 98$ & Bent 5,East column, North side & 6 & 147 & 8 \\
\hline $3 / 27 / 98$ & Cell 2,East sidewalk Bottom & 6 & 95 & 7 \\
\hline $3 / 27 / 98$ & Cell 2,East sidewalk Bottom & 6 & 48 & 13 \\
\hline $3 / 27 / 98$ & Cell 2,East sidewalk Bottom & 6 & 123 & 16
\end{tabular}


APPENDIX C: POWDER SAMPLING TECHNIQUES 



\section{APPENDIX C: POWDER SAMPLING TECHNIQUES}

Powder samples of the concrete were taken to determine chloride distribution in the slabs as a function of distance from the surface. The following equipment was used to collect powdered concrete samples :

The Vacuum Collection Apparatus is designed to collect powder from a rotary hammered hole in concrete. The powder is drawn though a $1.6 \mathrm{~cm}(5 / 8 \mathrm{in})$ diameter hollow bit by a vacuum and collected in a \#6 size cone coffee filter. The Rotary Hammer (large) was a Bosch 11232EVS, Model 0-611-232-739, 8.8 amp, 950 watt; 450 RPM at 3750 BPM (beats per minute). A drill that produces powder more rapidly than this one may plug the air hole in the drill bit. The Anchor Bore Air Bit, Part No. AA62518, was 5/8-inch diameter with $42 \mathrm{~cm}$ (16.5 in) usable length (47 $\mathrm{cm}$ (18.5 in) overall length) and a conical secondary cutting head with a vacuum hole. The Anchor Bore Air System Adapter was SDS Plus, Part No. AA71368. The Vacuum Cleaner Connector was Part No. AA82543 (All manufactured by Heller Anchor Bore, Fraser MI 48026 (313-294-6066)). The Wet/Dry Vacuum was a typical unit, 120 V, 7.4 A; It used the standard vacuum hose end (1 $1 / 4$ inch diameter).

The Powder Filter Apparatus connects the vacuum to the Plastic Air Vacuum Head (included on Anchor Bore Air System Adapter, but ordered separately as Part No. AA10256) on the rotary hammer and collects the powder sample in a \#6 standard cone type coffee filter (any brand works). The length of the $1.3 \mathrm{~cm}$ ( $0.5 \mathrm{in})$ dia. hose should be as short as practical; this will facilitate cleaning and improved the performance of the vacuum system. The powder filter requires the following items: 30.5 to $45.7 \mathrm{~cm}$ (12 to 18 in) of $1.3 \mathrm{~cm}(0.5 \mathrm{in})$ reinforced Tygon hose, one nylon $1.3 \mathrm{~cm}(0.5 \mathrm{in})$ hose to $1.3 \mathrm{~cm}$ (0.5 in) pipe adapter, one $1.3 \mathrm{~cm}(0.5 \mathrm{in}) \mathrm{SS}$ hose clamp, two $1.3 \mathrm{~cm}$ ( $0.5 \mathrm{in})$ O-ring ( $1 / 8$ inch thick), two $1.3 \mathrm{~cm}$ ( 0.5 in) conduit lock nuts, two 2.5 $\mathrm{cm}(1 \mathrm{in}) \times 1.3 \mathrm{~cm}(0.5 \mathrm{in})$ conduit reducing washers.

The Filter Container should have a top lip of 40.6 to $50.5 \mathrm{~cm}$ (16 to 20 in) in circumference. This is the vacuum seal for the \#6 coffee filter. A snap seal will facilitate removal of the filter containing the sample. A suitable container can be made from a 1 to 1.6 quart Rubbermaid Servin'Saver Canister. Make a 13/16 inch hole in the center of the snap top and a $4.1 \mathrm{~cm}$ (1.6 in) hole in the center of the container bottom for hose connectors. Connection from the filter container to the vacuum hose requires the following items: one $11 / 2 \times 1 / 4$ NFS-dwv adapter (plastic drain pipe), one sink overflow washer, one $5.1 \mathrm{~cm}$ (2 in) x $3.2 \mathrm{~cm}$ (1.25 in) conduit reducing washer. A standard Shop Vac vacuum cleaner hose will fit into the drain pipe adapter. Place the threaded adapter end with the compression nut inside the container and washers outside, and tighten the nut to form a vacuum seal.

The Spacers for drilling concrete to incremental depths are NOT made using PVC pipe. Instead, $1.9 \mathrm{~cm}$ (0.75 in) diameter polypropylene pipe (it contains no halogens which might influence the chloride analyses) is used. The pipe is made by Simtek PolyPro, SI 34PP150. Available from Familian Northwest, Industrial Plastics Div., Washougal WA, (360-835-2129). The Dust Removal Snoot is a $61 \mathrm{~cm}$ (24 in) long piece of $0.6 \mathrm{~mm}$ (0.25 in) diameter SS tube attached by duct tape (and possibly a Swagelok fitting to give a better fit to the vacuum line) to a vacuum cleaner. It is used to suck out debris from the drill hole between samples to prevent 
cross-contamination of samples. 


\section{APPENDIX D: CHLORIDE ANALYSIS OF CONCRETE POWDER}





\section{APPENDIX D: CHLORIDE ANALYSIS OF CONCRETE POWDER SAMPLES}

Powdered samples of the concrete were taken to determine the chloride distribution in bridges along the Oregon coast. Samples reported here were collected at $13 \mathrm{~mm}(0.5 \mathrm{inch})$ depth increments. Special care was taken not to contaminate a sample with leftover powder from the previous sample. To do this, the hole, the hollow drill, and the collection line were all cleaned with a vacuum cleaner between each sample collection.

The last samples at the bottom of a hole, as the hole breaks through the beam, can result in incomplete sample collection. This is typically also where the chloride concentration gradient is high. As the concrete breaks away only a small sample representing concrete one or two increments deep in the concrete is collected. Because of this, a series of samples were incrementally taken from the opposite (back) side of the original hole, overlapping the original hole by 1 1/2 inches (about 3 sample collections) so that good samples from the bottom side of the slab were collected. In this way, all of the samples were put together into a seamless chloride profile with good sampling practice throughout.

All powders were analyzed for both total and water-soluble chloride content. Analysis techniques given in AASHTO T260-94, "Sampling and Testing for Chloride Ion in Concrete and Concrete Raw Materials," (AASHTO 1995). Detection limits were $0.12 \mathrm{~kg} / \mathrm{m}^{3}\left(0.2 \mathrm{lb} / \mathrm{yd}^{3}\right)$ for the total chloride ion content and $0.06 \mathrm{~kg} / \mathrm{m}^{3}\left(0.1 \mathrm{lb} / \mathrm{yd}^{3}\right)$ for the water-soluble chloride ion content.

Powder samples of concrete contain varying amounts of pulverized aggregate that dilute the amount of cement paste in the sample. Chlorides in the concrete are contained only in the cement paste. Therefore, in converting the amount of chloride in a specific powder sample to its concentration in a cubic meter (or yard) of concrete, it is necessary to adjust the chloride value for the dilution resulting from the aggregate that was powdered during the sampling process. This is normally done using the value of soluble $\mathrm{Ca}$ (normally present only in the cement paste) in the concrete as the reference point.

Type 1 Portland contains approximately 46.5 weight $\%$ Ca. 

APPENDIX E: COST OF THERMAL SPRAYED ZN ANODE IMPRESSED CURRENT CATHODIC PROTECTION SYSTEMS FOR COASTAL OREGON BRIDGES 



\section{APPENDIX E: COST OF THERMAL SPRAYED ZN ANODE IMPRESSED CURRENT CATHODIC PROTECTION SYSTEMS FOR COASTAL OREGON BRIDGES}

\section{E.1 IMPRESSED CURRENT CATHODIC PROTECTION PROJECTS}

The experience in Oregon is that the cost of the cathodic protection system is only a fraction of the total project cost (Holcomb and Cryer 1998). The projects can be broken down into five broad categories: mobilization and traffic, bridge rehabilitation, concrete preparation and repair, enclosure, and cathodic protection. Mobilization is preparation to perform work such as moving personnel and equipment, and establishing an office. Traffic is usually disrupted during mobilization and for these jobs all traffic control costs are included in the mobilization and traffic category. Bridge rehabilitation is maintenance or upgrading bearings, joints, and overlays to current standards. Apart from bridge rehabilitation, concrete preparation and repair consists of restoring the structural concrete and steel to original or redesigned specifications. The enclosure is a structure that provides convenient, stable, and protected access to all surfaces for ICCP, and also minimizes contamination of the environment from the thermal spray process.

Cathodic protection can be broken down into its components: quality control training and certification, reference cells and null probes, continuity, terminal plates, anode surface preparation, anode installation, and electrical systems. The bridges were divided into ICCP zones, each 279 to $465 \mathrm{~m}^{2}$ (3000 to $5000 \mathrm{ft}^{2}$ ) in area. The zones were identified and selected based on architectural features and so as to have similar concrete cover over the rebar. Some zones group similar discontinuous areas such as columns.

The objective of quality control training and certification is to ensure that critical work elements are reliably performed to specification. Reference cells and null probes are embedded in the concrete of each ICCP zone to monitor the zone performance. Reference cells monitor corrosion potential (voltage) and null probes monitor corrosion current. Electrical continuity is required in the steel that is to be protected and any steel which is not electrically continuous is to be located and welded to adjacent steel. Since there are no epoxy coated rebar in these bridges, the majority of reinforcing bars in the bridge are expected to be sufficiently interconnected by direct contact. This component also includes establishing the ICCP system negative electrical connection to the steel. The attachment is accomplished by excavating the concrete around the rebar, performing a series of welds to attach the copper wire to the rebar (via a brass bolt and short rebar stub), applying epoxy to any exposed metal, and then installing a PVC junction box over the excavation.

Terminal plates are $6.4 \mathrm{~cm}$ ( $2.5 \mathrm{in})$ diameter brass plates where the ICCP system positive wire terminates and the electric current is distributed to the $\mathrm{Zn}$ anode. Figure E.1 shows one such terminal plate prior to thermal-spraying. It is attached with non-conductive epoxy and insulated bolts so that it is flush with the concrete surface. The terminal plates are then thermal sprayed with $\mathrm{Zn}$ along with the rest of the concrete. Two terminal plate connections are used for each ICCP zone or continuous area. 


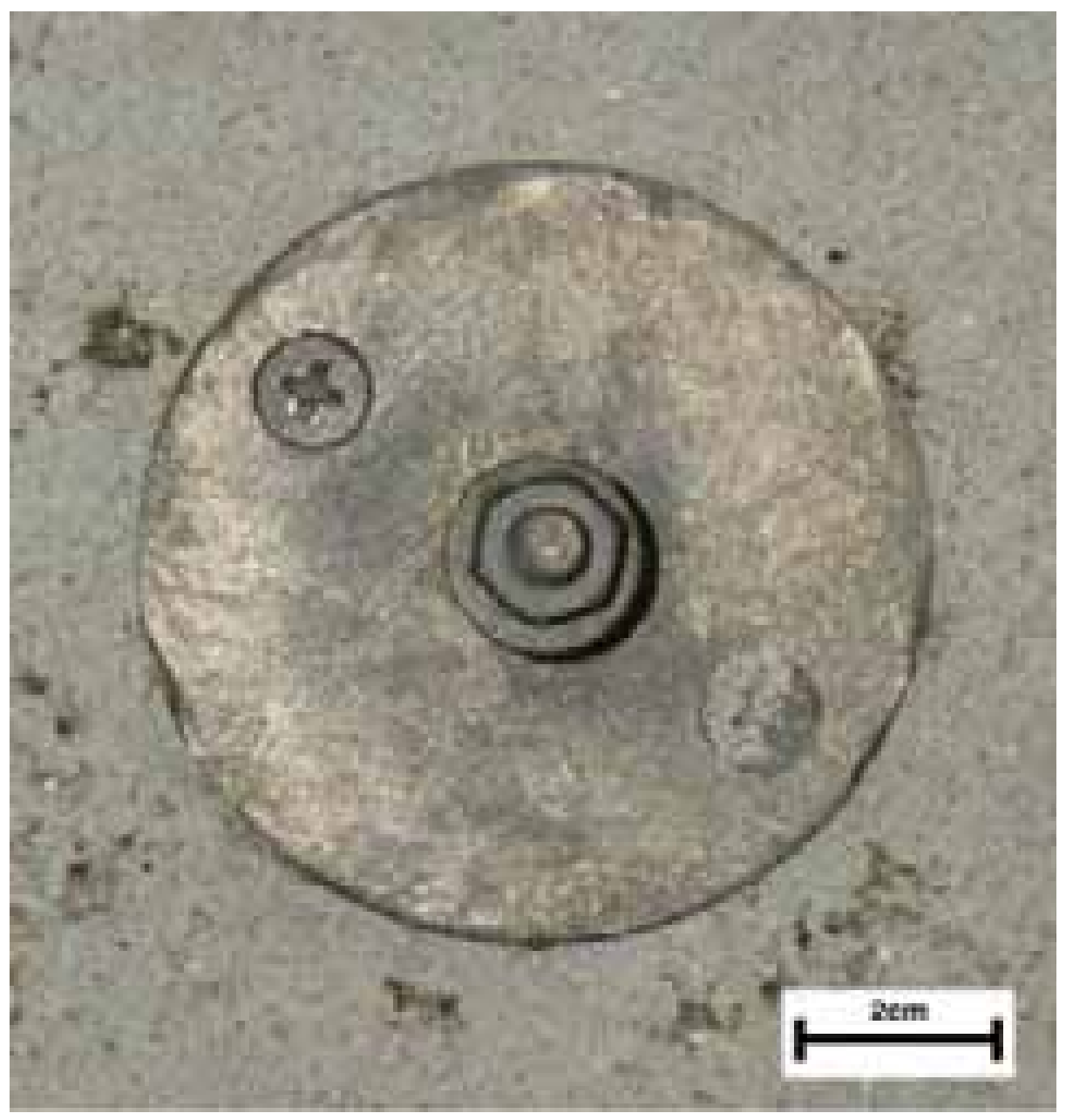

Figure E.1: Terminal plate connection prior to thermal spraying with $\mathrm{Zn}$

Anode surface preparation consists of roughening and cleaning the concrete surface in preparation for application of the $\mathrm{Zn}$ anode. Another surface preparation step was to preheat the concrete surface with a propane torch. However, recent research (Covino et al. 1996a, Covino et al. 1996b, Holcomb et al. 1996) showed that the initial bond strength benefits from preheating are lost after electrochemical aging. Thus, current Oregon ICCP projects use preheating only when the concrete surface is not dry. Anodes are an electrically conductive layer of thermallysprayed $\mathrm{Zn}$ applied to the concrete surface in areas where the embedded steel is to be protected. Approximately $0.5 \mathrm{~mm}$ (20 mils) of $\mathrm{Zn}$ were applied on these three bridges. Recent research (Covino et al. 1996a, Covino et al. 1996b, Holcomb et al. 1996) led to a reduction in the anode thickness to 10 mils $(0.25 \mathrm{~mm})$ in current Oregon ICCP projects.

Electrical systems include the cabinets, power supplies, controls, remote monitoring, and all electrical wiring. The ICCP systems are controlled and monitored by programmable logic controllers (PLC). One PLC controls the current supplied by six individual power supplies-one for each zone. Programmable, 0 to $40 \mathrm{~V}$, direct current power supplies are used. The current range of each power supply is a function of the ICCP zone requirements (and has allowances for 
additional protection current should it become necessary). A typical value for the applied current density is $0.0022 \mathrm{~A} / \mathrm{m}^{2}\left(0.2 \mathrm{~mA} / \mathrm{ft}^{2}\right)$. The PLC also records the cathodic protection zone current, zone voltage, reference cell voltages, temperature, and relative humidity. On demand, each PLC will perform a depolarization test. System engineers evaluate the effectiveness of each zone and adjust the zone current based on these data.

While each ICCP project can be described by the above categories, each project was also unique. For example, engineering and construction of the enclosure for the Yaquina Bay Bridge arches and the Depoe Bay Bridge were much more costly than the other two projects since much of each structure was above water. And concrete preparation and repair for the original Depoe Bay Bridge constructed in 1927 was much more costly than for the widened section constructed in 1939. The same analogy follows for other structures-costs may vary substantially for bridges of different design, age, and severity of damage.

The enclosure protects personnel and bridge surfaces from the adverse Pacific marine environment and protects the environment from contaminating wastes and noise generated during construction. The enclosure allowed work to proceed on schedule during inclement weather and maintained the work area atmosphere required for application of the anode (Brousseau, Arnott, and Baldock 1994a, Brousseau et al. 1994b)showed that low initial bond strengths result from high moisture levels on the concrete). Also, Oregon is very protective of her environment and even though a small amount of $\mathrm{Zn}$ is an essential nutrient (for example, $\mathrm{Zn}$ should be present in concentrations of $15-30 \mathrm{ppm}$ in the food for rainbow trout (Ogino and Yang 1978)), the introduction of abnormal amounts of $\mathrm{Zn}$ into the local ecosystem is unacceptable (for example, excess $\mathrm{Zn}$ may damage gill epithelial tissue, which increases the diffusion distance between water and blood leading to arterial and tissue hypoxia (i.e., suffocation) (Skidmore and Tovell 1972, Cairns 1980)). Containment was achieved by requiring the enclosure around the work platform be capable of filtering contaminated air of all particulate greater than 1.0 micrometer before the air is exhausted to the surrounding atmosphere. This goes beyond the environmental requirements established by the U.S. Environmental Protection Agency (EPA) and the Oregon Department of Environmental Quality (DEQ). The box-like structure straddling the Yaquina Bay Bridge arches in Fig. 1.3 is the enclosure.

\section{E.2 PROJECT COSTS}

In order to obtain an average project cost by each ICCP category, the two lowest bids for each of the four projects were averaged and converted to 1997 dollars using the Consumer Price Index (U.S. Bureau of Labor Statistics 1997) for all items, not seasonally adjusted, for 1/1997 and expressed in terms of price per unit area. The results are shown in Table E.1. Bids have the advantage of breaking the costs down into their component parts. But since the bottom line for awarding a bid was the total cost, experience has shown that some categories are understated while some are overstated. The causes of this difference in bid items varied from the underestimating the extent of concrete damage to a contractor overloading the mobilization to get operating capitol. To minimize such errors, the averages in the two lowest bids (and not just the lowest bid) are used, even though averaging in the second lowest bid raises the reported costs. 
Table E.1 Total cost and cost breakdown for CP projects on Oregon Coast Bridges

\begin{tabular}{|c|c|c|c|c|c|}
\hline Bridge Project & Cape Creek & $\begin{array}{c}\text { Yaquina Bay } \\
\text { Arches } \\
\end{array}$ & Depoe Bay & $\begin{array}{l}\text { Yaquina Bay } \\
\text { Approach }\end{array}$ & $\begin{array}{c}\text { Average } \\
\text { Cost }\end{array}$ \\
\hline Bridge Construction Date & 1931 & 1934 & $1927 / 1939$ & 1934 & \\
\hline Open Bid Date & $2 / 90$ & $10 / 91$ & $8 / 93$ & $8 / 95$ & \\
\hline Surface Area, $\mathrm{ft}^{2}\left(\mathrm{~m}^{2}\right)$ & $\begin{array}{l}102,500 \\
(9,526) \\
\end{array}$ & $\begin{array}{l}195,500 \\
(18,169) \\
\end{array}$ & $\begin{array}{l}65,000 \\
(6,041) \\
\end{array}$ & $\begin{array}{l}65,000 \\
(6,041) \\
\end{array}$ & \\
\hline Total Cost ${ }^{1}$ & $\$ 2.54 \mathrm{~m}$ & $\$ 10.76 \mathrm{~m}$ & $\$ 4.39 \mathrm{~m}$ & $\$ 2.36 \mathrm{~m}$ & \\
\hline Cost, ${ }^{1} \$ / \mathrm{ft}^{2}$ & $\$ 24.75$ & $\$ 55.02$ & $\$ 67.51$ & $\$ 36.38$ & $\$ 45.92$ \\
\hline $\mathrm{CPI}^{2}$ & 128.0 & 137.4 & 144.8 & 152.9 & \\
\hline $\begin{array}{l}\text { Conversion Factor to } \\
\text { Convert to } 1997 \text { Dollars }{ }^{3}\end{array}$ & 1.24 & 1.16 & 1.10 & 1.04 & \\
\hline Total Cost (1997 Dollars) $^{1}$ & $\$ 3.15 \mathrm{~m}$ & $\$ 12.46 \mathrm{~m}$ & $\$ 4.82 \mathrm{~m}$ & $\$ 2.46 \mathrm{~m}$ & \\
\hline Cost (1997 Dollars), ${ }^{1} \$ / \mathrm{ft}^{2}$ & $\$ 30.77$ & $\$ 63.72$ & $\$ 74.18$ & $\$ 37.85$ & $\$ 51.63$ \\
\hline \multicolumn{6}{|c|}{ Cost Breakdown (1997 Dollars), ${ }^{1} \$ / \mathrm{ft}^{2}$} \\
\hline Mobilization \& Traffic & $\$ 4.54$ & $\$ 8.06$ & $\$ 9.38$ & $\$ 5.49$ & $\$ 6.87$ \\
\hline Bridge Rehabilitation & $\$ 2.93$ & $\$ 7.95$ & $\$ 7.32$ & $\$ 7.31$ & $\$ 6.38$ \\
\hline $\begin{array}{l}\text { Concrete Preparation \& } \\
\text { Repair }\end{array}$ & $\$ 3.34$ & $\$ 6.36$ & $\$ 15.57$ & $\$ 3.59$ & $\$ 7.22$ \\
\hline Enclosure & $\$ 6.50$ & $\$ 24.18$ & $\$ 26.89$ & $\$ 10.79$ & $\$ 17.09$ \\
\hline Cathodic Protection & $\$ 13.46$ & $\$ 17.17$ & $\$ 15.02$ & $\$ 10.66$ & $\$ 14.08$ \\
\hline \multicolumn{6}{|c|}{ Cathodic Protection Cost Breakdown (1997 Dollars), ${ }^{1} \$ / \mathrm{ft}^{2}$} \\
\hline $\begin{array}{l}\text { QCE Training \& } \\
\text { Certification } \\
\end{array}$ & & & & $\$ 0.23$ & $\$ 0.06$ \\
\hline $\begin{array}{l}\text { Reference Cells and } \\
\text { Null Probes }\end{array}$ & $\$ 0.43$ & $\$ 0.97$ & $\$ 1.71$ & $\$ 1.46$ & $\$ 1.14$ \\
\hline Continuity & $\$ 1.93$ & $\$ 3.53$ & $\$ 1.35$ & $\$ 0.75$ & $\$ 1.89$ \\
\hline Terminal Plates & $\$ 0.47$ & $\$ 0.12$ & $\$ 0.10$ & $\$ 0.18$ & $\$ 0.22$ \\
\hline Anode Surface Preparation & $\$ 1.41$ & $\$ 1.90$ & $\$ 2.77$ & $\$ 1.06$ & $\$ 1.79$ \\
\hline Anode Installation & $\$ 7.09$ & $\$ 9.08$ & $\$ 7.41$ & $\$ 4.93$ & $\$ 7.13$ \\
\hline Electrical Systems & $\$ 2.13$ & $\$ 1.57$ & $\$ 1.68$ & $\$ 2.06$ & $\$ 1.86$ \\
\hline
\end{tabular}

From Table E.1, it can be seen that the overall average cost, in 1997 dollars, of Oregon DOT ICCP projects was $\$ 555.51 / \mathrm{m}^{2}\left(\$ 51.63 / \mathrm{ft}^{2}\right)$, with $\$ 151.47 / \mathrm{m}^{2}\left(\$ 14.08 / \mathrm{ft}^{2}\right)$ of that attributed to cathodic protection. The category with the largest cost was not cathodic protection; it was the enclosure at $\$ 183.91 / \mathrm{m}^{2}\left(\$ 17.09 / \mathrm{ft}^{2}\right)$. This cost is large because of the local geography, design of the bridges, and the level of protection chosen by Oregon. Concrete repair cost escalated from the Cape Creek Bridge to the Yaquina Bay Bridge arches and again at the Depoe Bay Bridge due to the depth of the damage to the concrete. On the Yaquina Bay Bridge arches, large areas of their surface were delaminated and the concrete repair costs were double. In the 1927 structure at Depoe Bay, the corrosion damage penetrated below the top layer of reinforcing steel and repair costs were a factor of four larger than those for the Cape Creek Bridge or the Yaquina Bay Bridge approach. 
Of the cathodic protection components, the largest cost was anode installation at $\$ 76.67 / \mathrm{m}^{2}$ $\left(\$ 7.13 / \mathrm{ft}^{2}\right)$. This represented $51 \%$ of the cathodic protection cost and $14 \%$ of the total cost.

\section{E.3 PROJECT ECONOMIC EVALUATION}

At least one major consequence of replacing the Alsea Bay Bridge that was not reducible to money was its historic value. The importance of historic value was not evident until the bridge replacement was proposed in 1984. After the proposal, a local committee was formed dedicated to saving the Alsea Bay Bridge. Though an independent study determined the bridge was not salvageable, this group of concerned citizens focused attention on the pride Oregon has in these arched coastal bridges. Consequently, a coastal bridge program was initiated to search for ways to extend the useful life of corrosion damaged bridges. Engineers designed the Zn ICCP system for the Cape Creek Bridge based on the California design (Concrete repair digest 1994). After completing the first project, the appearance and cost of the Zn ICCP system were satisfactory, so the Yaquina Bay and Depoe Bay projects were initiated. These four ICCP projects were completed for $35 \%$ of the estimated replacement costs.

Some rehabilitation decisions were troublesome and controversial. The cathodic protection projects were evaluated by comparing estimated life cycle costs of rehabilitation versus replacement and the ability of Oregon to fund the work. Because of the high traffic volume on the Yaquina Bay Bridge, a new earthquake resistant four lane bridge was desirable. Oregon's experience with replacing coastal bridges indicated extra cover and a more dense concrete would increase the life of a coastal bridge for about $30 \%$ added cost. Also, new bridges of standard designs do not look like the historic bridges. A design with a graceful arch structure compatible with the historic bridges would cost an additional 40\%. The replacement cost would have been over twice the cost of using ICCP. Since all projects were competing for limited funds, the ICCP option was selected.

Maintenance costs for the Cape Creek Bridge ICCP system have been $\$ 1200$ per year for site visits and data acquisition. The power requirements to operate the ICCP systems are small. For example, the ICCP system of the Cape Creek Bridge requires approximately 15,000 kWhr $(\sim 700)$ per year. These costs are small compared to overall bridge maintenance costs.

Laboratory studies (Covino et al. 1996a, Covino et al. 1996b, Holcomb et al. 1996) suggest that the $\mathrm{Zn}$ anodes may eventually need replacement. Since the ICCP system protects the steel rebar, which in turn should reduce concrete cracking and deterioration, reinstallation costs are expected to be significantly lower than the initial installation costs. The cost reduction should be most pronounced in the categories of bridge rehabilitation, concrete rehabilitation and repair, and continuity. 
